$2016-10-24$

\title{
Our evolving understanding of aeolian bedforms, based on observation of dunes on different worlds
}

\author{
Diniega, $\mathrm{S}$
}

http://hdl.handle.net/10026.1/6778

10.1016/j.aeolia.2016.10.001

Aeolian Research

Elsevier BV

All content in PEARL is protected by copyright law. Author manuscripts are made available in accordance with publisher policies. Please cite only the published version using the details provided on the item record or document. In the absence of an open licence (e.g. Creative Commons), permissions for further reuse of content should be sought from the publisher or author. 


\title{
Manuscript Details
}

Manuscript number

Title

Article type
AEOLIA_2016_55

Our evolving understanding of aeolian bedforms, based on observation of dunes on different worlds

Review Article

\begin{abstract}
Dunes, dune fields, and ripples are unique and useful records of the interaction between wind and granular materials - finding such features on a planetary surface immediately suggests certain information about climate and surface conditions (at least during the dunes' formation and evolution). Additionally, studies of dune characteristics under nonEarth conditions allow for "tests" of aeolian process models based primarily on observations of terrestrial features and dynamics, and refinement of the models to include consideration of a wider range of environmental and planetary conditions. To-date, the planetary aeolian community has found and studied dune fields on Mars, Venus, and the Saturnian moon Titan. Additionally, we have observed candidate "aeolian bedforms" on Comet 67P/ChuryumovGerasimenko, the Jovian moon lo, and - most recently -- Pluto. In this paper, we hypothesize that the progression of investigations of aeolian bedforms and processes on a particular planetary body follows a consistent sequence primarily set by the acquisition of data of particular types and resolutions, and by the maturation of knowledge about that planetary body. We define that sequence of generated knowledge and new questions (within seven investigation phases) and discuss examples from all of the studied bodies. The aim of such a sequence is to better define our past and current state of understanding about the aeolian bedforms of a particular body, to highlight the related assumptions that require re-analysis with data acquired during later investigations, and to use lessons learned from planetary and terrestrial aeolian studies to predict what types of investigations could be most fruitful in the future.
\end{abstract}

Keywords

Corresponding Author

Corresponding Author's

Institution

Order of Authors
Planetary; terrestrial; aeolian bedforms; aeolian science; dunes; ripples

Serina Diniega

Jet Propulsion Laboratory

Serina Diniega, Mikhail Kreslavsky, Jani Radebaugh, simone silvestro, Matt Telfer, Daniela Tirsch

\section{Submission Files Included in this PDF}

\section{File Name [File Type]}

Replytoreviewers.docx [Response to Reviewers]

Supplement_yearcounts_references.docx [Response to Reviewers]

AeolSciEvol_manuscript_revise_v3_formatted_noinfo_acc.docx [Manuscript (without Author Details)]

AeolSciEvol_manuscript_revise_v3_formatted_noinfo.pdf [Editor-Annotated Manuscript]

Titlepage_AeolianSciencef.pdf [Title Page (with Author Details)]

To view all the submission files, including those not included in the PDF, click on the manuscript title on your EVISE Homepage, then click 'Download zip file'. 
Manuscript number: AEOLIA_2016_55

Title: Our evolving understanding of aeolian bedforms, based on observation of dunes on different worlds

(Previous Title: Our evolving understanding of aeolian bedforms, based on studies of different Worlds)

Article type: Review Article

We thank the two reviewers and the editor for their insightful and helpful comments. In particular, the many reference suggestions and questions about the specific types of investigations we focused on in constructing our "Phase" framework helped point out areas of confusion or incompleteness. We believe this revision much more clearly lays out our inputs, resultant framework, and overall aims.

In the following pages, we have replied in detail to reviewer comments (our replies are in italics). Changes can also be found within the tracked-changes manuscript Word document. Additionally, below, we address a couple of large-scale revisions:

- As stated above, thank you all very much for the reference suggestions. We added most of them in (and explain below if we did not). These strengthen the paper and help fill gaps.

- We edited the title and added a paragraph to the Introduction to narrow our focus to dunes on planetary bodies, as studied through observational data. Dunes are usually the first aeolian bedform seen on a body (there's a slight exception for Venus, where surface observations by the Venera missions pre-dated Magellan radar images - we touch on this in the text) and are a highly useful record of atmosphere and surface conditions (and can provide quantitative constraints on both, via models of their formation processes). We have highlighted more strongly that there are parallel investigations that focus on model development/refinement, on laboratory work, and on field studies (sometimes the feature is studied within the context of model development or sometimes as terrestrial analogs) -that are touched on but which are not completely described within this paper.

- Although both reviewers asked about TARs (with good reason), as well as other aeolian bedforms -- we have not included discussion of those features. In the particular case of TARs, their formation mechanism is still debated and thus discussion of them is much less straight-forward than for aeolian dunes. However, as noted in our new Introduction paragraph, we would expect that a similar framework would work for them.

- One reviewer also expressed concern that the summaries at the end of each phase section may not work very well in their present format. The goal of these end-portions were to provide easy-to-find-and-read summaries of each Phase. We have added an alternative version which perhaps may be easier to read at the end of Phase 1 - what do you think of 
the Table version? If this is an improvement, we can easily turn all summaries into a Table.

Thank you again for your assistance in improving this manuscript!

Thank you,

Serina Diniega and co-authors 


\section{Editor's (Matt Chojnacki) comments}

- Ln 351-356 and related text: Consider the following reference which used multiple criteria to constrain dune sediment sources: Chojnacki, M., D. M. Burr, J. E. Moersch, and J. J. Wray (2014b), Valles Marineris dune sediment provenance and pathways, Icarus, 232(0), 187-219, doi:10.1016/j.icarus.2014.01.011.

Reference has been added.

- Fig. 9's caption needs a citation (Silvestro et al. 2013).

Added.

- Ln 632 and others: "Chojnacki"

Apologies! This has been fixed.

- Ln 640-643 (for sediment fluxes) and Ln 640-643 (for dune ages termed "turnover times") and related text: Consider the following reference: Chojnacki, M., J. R. Johnson, J. E. Moersch, L. K. Fenton, T. I. Michaels, and J. F. Bell III (2015), Persistent aeolian activity at Endeavour crater, Meridiani Planum, Mars; new observations from orbit and the surface, Icarus, 251(0), 275-290, doi:10.1016/j.icarus.2014.04.044.

Added.

- Please cite all instruments (HiRISE, THEMIS etc.) appropriately.

I assumed this comment was regarding the images used within the figures ... I have checked the captions and now have identified in each what instrument acquired the discussed data. 


\section{Reviewer 1's (Lori Fenton) comments:}

The author(s) propose that scientific investigations of planetary aeolian bedforms follow a predictable progression of inquiry, with the aim of understanding how specific data set types either contribute to knowledge gain or leave knowledge gaps. They identify a striking sequence of methods and perspectives used as understanding of planetary bedforms increases, which necessarily differs significantly from the progression of terrestrial aeolian science. The proposed sequence (Phases 1-7) is simpler than the whole available literature would contain (see general and specific comments below). Many studies, aeolian features, and ideas have not been included here, likely leading to the oversimplified nature of the sequence. However, the proposed sequence is essentially consistent with the published literature, and does provide insight for both planetary and terrestrial aeolian scientists. I suggest that, following the comments below, this manuscript should be published with major revisions.

I generally disapprove of not revealing myself to authors, in the hopes that open communication can help clarify concerns and more quickly answer the authors' questions (hopefully leading to the best science and quicker revisions). I encourage the authors to contact me to address any such questions regarding this review.

- Lori Fenton1fenton@seti.org

\section{General comments}

1. The work seems to be limited by not including the full available literature for Mars. For example, the first global maps (which define Phase 4) of martian dunes were produced by Thomas (1982) and Ward et al. (1985), which were not included here, and are not shown in Fig. 13 (see specific comments below for these and other references - there are many striking gaps, and I did not include all relevant references). The authors need to include a more thorough search of the rather extensive martian literature, which could be illuminating. Note also that many papers address more than one phase.

Based on this (thank you, Lori!) and other reviewers' comments, we have added in many more references, especially regarding Mars but also some additional studies for Titan, Venus, and the comet -- and these were valuable additions. However, we note that we cannot aim to include all papers while keeping this manuscript to a reasonable length and focus. We do not aim to present a fully comprehensive review of e.g., Mars aeolian research - although we do try to accurately represent the full scope of work when placing this work within the proposed Phase framework. We have aimed for a reasonable sampling, and hope this is enough to justify our proposal, and to provide a starting ground for any reader interested in learning more on that (or any) particular topic.

In general, we have edited the Title and Introduction text to clarify the focus of this paper - especially the new $3^{\text {rd }}$ paragraph of the Introduction. 
2. I suspect that the advent of new missions (on Mars that would include three "pulses" of activity: Mariner/Viking in the 1970s, MGS/MPF in the 1990s, and the more recent $\mathrm{MO} / \mathrm{MRO} / \mathrm{MEX} / \mathrm{MER} / \mathrm{MSL}$ missions in the past 10 years) or new methods (e.g., mesoscale models, use of gross bedform-normal transport, the recent introduction of "fingering" vs. "instability" modes, etc.) can cause renewed activity in lower phases that produces a more thorough understanding.

Absolutely - this is a point of the paper; by defining a framework, it should be easier to see when renewed activity occurs and thus to identify where updated understanding should flow, with improved constraints on assumptions, a need to re-do a study with increased or improved data, etc. A sentence emphasizing this has been added to the Introduction.

3. Figure 13 is very informative and clearly demonstrates progression through the phases. However, the horizontal bars do not adequately represent progression within a given phase. I suggest that, using the more thorough literature search from point 1 above, the horizontal bars can be broken into individual years, showing the number (or fraction) of publications that year that addressed each phase. This would nicely show that new methods and data sets produce new pulses of research activity, and reveal the complexity of progression through the phases, as it is not likely to be linear or even monotonic in time.

This was an intriguing idea. We considered several ways of collecting such information and then displaying it. Our chosen method: we focused first on the papers cited within this manuscript (so that readers have some idea of where the information comes from) and showed what years are included in this reference list with darker colors within Figure 13 (also are listed in the supplemental table). A more general "period" for studies within each Phase was then shown with the light \& dark colors. This was based on a looser categorization of the papers (e.g., these included smaller contributions to an additional Phase, versus just the Phase(s) under which the paper was cited) and supplemental checks via google scholar (e.g., we searched for references under keywords "Venus dune" and saw the few years that came up). This latter method was an attempt to mitigate the limitations of our reference list -- as many papers (cited and otherwise) contribute towards more than one Phase, there are many papers that we did not cite, and there were also many abstracts and papers presenting work that was eventually compiled into a more complete/seminal peer-reviewed publication.

From all of this, we updated Figure 13 (and its caption).

4. There is ambiguity over whether the manuscript seeks to address only dunes, or any bedforms. If considering only dunes, then the features on Io and 67P/C-G may not (yet) qualify for discussion, and it may not make sense to discuss the "large martian ripples" in 
great detail. The title suggests the authors are discussing any aeolian bedforms, but the main discussion in on dunes (e.g., there is no mention of TARs, the study of which may follow a similar progression of inquiry). Much knowledge on Mars has been gained from ripples (migration rates), TARs, wind tails, and sand drifts (El Dorado) that are not properly classified as "dunes". While including all aeolian features (e.g., wind streaks, loess deposits, yardangs) would be overly exhaustive (although worth study), I recommend that the manuscript expand to include all (aeolian) bedform types, and thus include, e.g., lee dunes, TARs, coarse-grained ripples, and wind shadows. As discussed under point (1) above, to keep this manuscript to a reasonable length, we have focused it onto dunes, so as to present one evolution sequence. Other aeolian features, such as wind shadows, could also be discussed within a similar framework. For TARs specifically: we had previously decided to not mention then as there is not yet a well-accepted description of their formation mechanism (they've been identified as transverse dunes forming within a reversing wind regime, granule ripples, and sub-aerial anti-dunes), and so the information these features provide about the environment isn't as clear or easy to trace as interpretation of dunes. However, as pointed out by both reviewers - this omission without explanation is confusing. So, we have added a note to the Introduction, explaining the focus of this paper and explicitly noting that other "aeolian features" (including TARs) are not included. With mention of the TARs, we have also included the point that there may be no good Earth analogue for these strange features, as this is an interesting idea.

In general, we have edited the Title and Introduction text to clarify the focus of this paper.

5. I suggest including a Phase 0: "Predictions", made prior to direct observation of bedforms. Some discoveries have been quite surprising (e.g., Io, 67P/C-G), whereas others were considered long before spacecraft data were obtained (e.g., Mars, Titan, Pluto). How correct have the predictions been, and what lessons can be learned to aid predictions for future missions (e.g., Venus)? Given the more surprising locations where putative bedforms have been observed, what other exotic locations can be considered (e.g., on the surfaces of Neptune and Uranus, if any such solid interface exists?). This is a very good idea. We have not added an actual Phase 0 to the discussion (for one thing, describing this in sequence did not seem feasible without having gone through the discussion at least within Phase 1 - and thus seemed to be giving away the punchline before telling the joke), but we have added this intriguing point to the conclusion. And within Phase 1, we discuss predictions that have been made (in either direction, and with different degrees of success). 
6. Finally, I wonder if any similar study has been done for other geologic/atmospheric processes/features found on several planetary worlds. Has nobody considered the sequence of study methods for volcanism or impact cratering throughout the Solar System? If not, then does this investigation of aeolian processes provide a platform for any such studies to work from?

The authors have not come across any such studies - those would be intriguing to read, and to see if the advancement of science understanding follows a similar progression. (I would imagine so for features that rely upon similar data sets, which would include impact cratering and volcanism as suggested.)

\section{Specific suggestions:}

- Line 72: typo: “... each Phase, s, we use...”

Fixed.

- Table 1: suggest changing "dune" to "bedform"

- Phase 2, "Unit": "Dune morphology" is not a unit or feature of interest. Suggest: "Dune, aeolian surface materials"

We disagree that "morphology" cannot be described as the "feature of interest," although perhaps "characteristic of interest" may be more correct. "Unit" has been removed.

- Phase 2: "composition" doesn't seem to fit here as this row is worded. Could also include thermal properties, relief, surface roughness.

"Characteristics of surface materials" has been added to include those options.

- Phase 3: Suggest "Morphological analysis of the dunes within a field"

Phase 3 we have used "Pattern analysis" as is suggested in a later comment (Line 394).

- Phase 4: Suggest also including regional studies here. Many informative studies focus on particular regions in greater detail. This could also be added as a subsequent phase. Note that both global and regional analyses of these features often include atmospheric modeling.

"Regional" has been added.

- Phase 5: could also include erosional features (e.g., gullies).

Phase 5 focuses on evidence of wind interaction with the dunes, and so gullies are left in Phase 6 (more general "activity" and dune evolution).

- Line 104, 143, etc.: Suggest using "saltatable grains" rather than "sand grains". It's possible that in some unusual planetary environments, the saltated grains could be larger or (less likely) smaller than sand (e.g., there are reports of saltating pebbles in katabatic flows in Antarctica, or the $>\mathrm{mm}$-sized grains on comet $67 \mathrm{P} / \mathrm{C}-\mathrm{G}$ ). As discussed within Phase 1, "sand" is commonly used to refer to a specific absolute grain size, but in fact can refer to a grain size defined by how the grains are moved by the 
wind (i.e., are saltatable). We retain use of "sand grains" or "grains" throughout the document as this was much cleaner/smoother in usage than "saltatable grains," but we have added text to make the meaning clearer.

- Line 117: See also Edgett, K. S., and N. Lancaster (1993), Volcaniclastic aeolian dunes: terrestrial examples and application to martian sands, J. Arid Environ., 25(3), 271-297, doi:10.1006/jare.1993.1061.

Reference has been added.

- Lines 129-130: "direction and velocity": Suggest "direction and speed", as velocity inherently incorporates both direction and speed.

- Line 150: "every deeply-studied body with an atmosphere..." Suggest including "and an observable surface". Jupiter and Saturn are also deeply-studied bodies with atmospheres...

- Lines 154-158: Excellent points, but a very long sentence. Suggest breaking it up.

- Line 195: Use if "either" implies two possibilities, but three are listed. Text changed as suggested.

- Line 202: On comparing venusian bedforms to underwater terrestrial bedforms, see also Neakrase (2015) http://www.hou.usra.edu/meetings/dunes2015/pdf/8023.pdf.

- Line 208: See also the description and measurements of ripples and "dune-like structures" in Thomas et al. (2015). They also argue for the airfall mechanism of initiating transport. Thomas, N. et al. (2015), Redistribution of particles across the nucleus of comet 67P/Churyumov-Gerasimenko, Astron. Astrophys., 583(A17), doi:10.1051/0004-6361/201526049.

References were added.

- Line 249: typo "imagery"

Fixed.

- Line 283: Another question: "If conditions are unusual (e.g., tenuous atmosphere), how does sustained saltation and/or reptation occur on this world?" (This comes from considering the unusually low air pressures on Io and 67P/C-G.)

Question added.

- Line 302: Suggest “ $350 \mathrm{~m} / \mathrm{px}$ ”

- Line 309: Remove "via"

Text changed as suggested. 
- Line 309-312: See Rubin and Hunter (1987) and Rubin and Ikeda (1990). Longitudinal dunes form when two winds of roughly equal transport strength (i.e., they move the same amount of sand) are $>\sim 90^{\circ}$ apart. Essentially the crestline is trying to be as normal to the incident wind as possible. When two winds are $<\sim 90^{\circ}$ apart they produce transverse dunes (i.e., they are "parallel enough" to work constructively to produce the same crestline alignment). Inbetween these extremes are oblique dunes, which have characteristics of both types - most dunes likely have some oblique component to them. Rubin, D. M., and R. E. Hunter (1987), Bedform alignment in directionally varying flows, Science, 237(4812), 276-8, doi:10.1126/science.237.4812.276. Rubin, D. M., and H. Ikeda (1990), Flume experiments on the alignment of transverse, oblique, and longitudinal dunes in directionally varying flows, Sedimentology, 37, 673-684. References added. (Thank you, I was looking for these!)

- See also Courrech du Pont et al. (2014) and other related publications, who found that dunes align either in a "bed instability mode", which can approximate the gross bedformnormal transport alignment found by Rubin and Hunter (1987) and Rubin and Ikeda (1990), or (in conditions of low sediment supply/availability), in a "fingering mode", which can approximate a longitudinal direction parallel to the resultant drift direction. Courrech du Pont, S., C. Narteau, and X. Gao (2014), Two modes for dune orientation, Geology, 42(9), doi:10.1130/G35657.1. The two modes identified in China by Rubin and Hesp (2009) and applied to Titan dunes (as described in Sec. 3.2) likely occur for reasons of changing sediment availability (i.e., the "sticky" sediment leads to lower sediment availability, so these dunes formed in "fingering mode").

- This is an example of my general comment \#2 above: that introduction of a new model for dune alignment has redefined aeolian science, and prompted reanalysis of previous data sets. In this case, the study of Titan dunes occurred as this recent understanding was being developed. A very good point. This reference and description has been added within Section 3.2.

- Lines 327-328: The text (outside the Fig. 6 caption) does not describe what processing has been done to this image. Suggest rewording and/or a brief description in the text (or removing this frame from the figure).

This image (6b) has not really been "processed", aside from the fact that it's a SAR image. Text has been added to the caption to better explain this - "The right image (b), a Synthetic Aperture RADAR (SAR) image, shows bedrock as bright, because it is rough, and unorganized dune sands as dark, because dunes are smooth at the SAR wavelength of $6 \mathrm{~cm}$ (black areas are regions devoid of data returned to the SAR antenna)."

- Line 336: Surely images from Viking 1 have been used for mapping as well? Also see Ward et al. (1985) and Thomas (1982). Ward, A. W., K. B. Doyle, P. J. Helm, M. K. 
Weisman, and N. E. Witbeck (1985), Global Map of Eolian Features on Mars, $J$. Geophys. Res., 90(B2), 2038-2056, doi:10.1029/JB090iB02p02038. Thomas, P. (1982), Present wind activity on Mars - Relation to large latitudinally zoned sediment deposits, $J$. Geophys. Res., 87(B12), 9999-10,008, doi:10.1029/JB087iB12p09999.

Very good point - references have been added and this start on Phases 3-4 has been added to Figure 13.

- Lines 344-347: The work by Fenton et al. (2005) was done using MOC NA images, worth mentioning so readers don't assume it was done with Mariner 9 and Viking images (as stated in the first sentence of the paragraph). Also, this work used a mesoscale model, not a GCM.

Text has been fixed.

- Note also that the first comparisons with atmospheric models were done before MGS: see Greeley, R., A. Skypeck, and J. B. Pollack (1993), Martian aeolian features and deposits: comparisons with general circulation model results, J. Geophys. Res., 98(E2), 31833196.

Thank you for the pointer. However, this reference has not been added as the aeolian features considered for this comparison did not include dunes. The study focused instead on bright wind streaks, dark wind streaks, and yardangs.

- Line 353: Suggest "proposed" instead of "identified", as these sources are not confirmed. See also Geissler, P. E., N. W. Stantzos, N. T. Bridges, M. C. Bourke, S. Silvestro, and L. K. Fenton (2013), Shifting sands on Mars: insights from tropical intra-crater dunes, Earth Surf. Process. Landforms, 38(4), 407-412, doi:10.1002/esp.3331.

Text has been fixed. And the reference has been added to that section (in addition to where it was already cited).

- Line 361: Suggest "proposed" instead of "identified"; the presence of microdunes are by no means verified.

- Line 369: typo "withing"

- Lines 375-381: Suggest that Phase 2 can continue concurrently with initiation of Phases $3-5$, with the introduction of new observations and the development of models, and analysis methods.

Text changed as suggested.

- Table 2:

- Suggest "low albedo" rather than "dark albedo". Fixed.

- If not including Io and Pluto here, then why include 67P/C-G? Analysis of the comet has passed peer review, while analysis of the Pluto and Io features have not yet. (This distinction is made within the title of Table 2: "as presented in the literature.") 
- Line 394: Suggest calling this phase "Pattern analysis", as simply "analysis" alone could mean anything, and is used to describe other phases.

Done (related: see Table 1 comment above).

- Line 403: Suggest "upwind margin" rather than "start" (which could imply time rather than space) and "lateral margins" rather than "boundaries". Note that not all dune fields have a single upwind and downwind margin (e.g., many intracrater dune fields on Mars), complicating this issue.

- Line 438: Suggest "uniformity" rather than "consistency".

- Line 446: The knowledge gain is considerably more than just the dune field pattern and shape. The pattern reveals the maturity state, and perhaps relative age, of the bedforms (defined by defect density, which is not directly discussed but hinted at in lines 436-440) and possible temporal changes in the sediment state (e.g., sediment supply, wind patterns).

Text changed/added to as suggested.

- Line 456: In this section, consider including discussion of the martian global (or nearly global) inventories of Thomas (1982), Ward et al. (1985), Hayward et al. (2007; 2014) and the included discussions of world-scale processes and factors (e.g., sediment sources, characteristic dune field sizes, location relative to topography and geology, relation to global-scale wind circulation, etc.). Hayward, R. K., L. K. Fenton, and T. N. Titus (2014), Mars Global Digital Dune Database (MGD3): Global dune distribution and wind pattern observations, Icarus, 230, 38-46, doi:10.1016/j.icarus.2013.04.011. References have been added, along with a bit of discussion about global studies of martian aeolian bedforms.

- Lines 464-465: Suggest “...terrestrial dunes can rely on, for example, detailed petrographic..." Other studies have done the same with different methods. Changed "can" to "may" to address this point.

- Line 470: Suggest "proposed" rather than "identified", as the source of the NPSS is still debated. Some mention should also be made of the extensive aeolian deposit underlying the current polar cap (which is the most recent major sand source), making the extent of the sand reservoir even more vast. See Byrne and Murray (2002). Byrne, S., and B. C. Murray (2002), North polar stratigraphy and the paleo-erg of Mars, J. Geophys. Res., 107(E6, 5044).

Text changed and references has been added.

- Line 493: Suggest "incorporated" rather than "absorbed".

- Line 505: Suggest "crater retention age of $<10000$ years", as the dunes may be much older. Text has been fixed.

- Lines 531-532: Note that some early global-scale studies (limited simply by the low resolution of earlier data sets) may produce the larger-scale sediment transport pathways 
or atmospheric circulation interpretations (Phase 4) sooner than the "field-specific results of Phase 2 and 3". (e.g., Ward et al., 1985). The progression through the phases is not necessarily directly in order.

This point has been added to the summary.

- Line 539: Crater-retention age, rather than actual age.

Text has been fixed.

- Line 543: "Details" as described here refers to "superposed bedforms", suggest being more specific.

Phase name is now "Analysis of superposed bedforms on the dune formed due to wind interaction with the dune."

- Line 548: Suggest "as fine as" in place of "up to" $(0.25 \mathrm{~m} / \mathrm{pixel} . .$.

Text changed as suggested.

- Lines 631-636: Actually there were a few publications indicating observations of bedform movement/change prior to the HiRISE overlap studies (Fenton, 2006; Bourke et al., 2008; Sullivan et al., 2008). Fenton, L. K. (2006), Dune migration and slip face advancement in the Rabe Crater dune field, Mars, Geophys. Res. Lett., 33(20), 1-5, doi:10.1029/2006GL027133. Bourke, M. C., K. S. Edgett, and B. A. Cantor (2008), Recent aeolian dune change on Mars, Geomorphology, 94(1-2), 247-255, doi:10.1016/j.geomorph.2007.05.012. Sullivan, R. et al. (2008), Wind-driven particle mobility on Mars: Insights from Mars Exploration Rover observations at "El Dorado" and surroundings at Gusev Crater, J. Geophys. Res., 113, E06S07, doi:10.1029/2008JE003101.

Thank you-references have been added.

- Line 630: Suggest also including features indicative of inactivity, which is also revealing about bedform migration rates (e.g., fissures on north polar dunes from Portyankina et al., 2012, pits and other features on southern midlatitude dunes from Fenton and Hayward, 2010). Portyankina, G., A. Pommerol, K.-M. Aye, C. J. Hansen, and N. Thomas (2012), Polygonal cracks in the seasonal semi-translucent $\mathrm{CO} 2$ ice layer in Martian polar areas, J. Geophys. Res., 117(E2006), doi:10.1029/2011JE003917.

This is a very good point -- it has been added to the end of Phase 6 (with the suggested reference).

- Lines 642-643: Note that the sand fluxes are comparable to those in the Antarctic Dry Valleys, which are low compared to those elsewhere on Earth.

Text has been fixed.

- Line 658: Suggest also Kereszturi, A., D. Möhlmann, S. Berczi, T. Ganti, A. Horvath, A. Kuti, A. Sik, and E. Szathmary (2010), Indications of brine related local seepage phenomena on the northern hemisphere of Mars, Icarus, 207(1), 149-164, doi:10.1016/j.icarus.2009.10.012. 
Within the paper, we discuss features that move significant movement of sand over the dune lee slopes. This paper discusses a different type of activity on the dunes, but over a scale that is much smaller and thus is not as relevant for analysis of present-day dune evolution. Thus, this reference has not been added.

- Line 685: typo "dunes slopes", "levels of aeolian activity"

- Line 692: "were" in place of "was"

- Line 719: Suggest adding "How can observations of sediment grain size and bedform morphology provide insight regarding transport processes and the nature/frequency of mobilization events?"

Text has been changed as suggested.

- Line 776-778: Sullivan et al. (2008) would be a good reference for this. They proposed that the meter-scale bedforms on the El Dorado deposit in Gusev crater were sand ripples. Reference has been added.

- Line 905: typo "transverse" Text has been fixed.

- Line 932-950: The case of the Amazonian paleo-dune fields seems to be more of a lesson that terrestrial dune researchers can learn from planetary dune researchers than the reverse. Suggest relocation to the following section.

The text has been moved, as suggested, to the end of the next section.

- Line 954-955: "no global catalogue of dunes for Earth" See Lancaster et al. (2015). However, it is telling that this database was assembled many years after the first planetary examples. Lancaster, N. et al. (2016), The INQUA Dunes Atlas chronologic database, in press at Quat. Int., doi:10.1016/j.quaint.2015.10.044.

This reference has been added, with some explanation of what it is -- despite the name, this paper is a database of dated dune samples, rather than a spatial atlas of dune extent, morphology, etc. (For instance, currently very-active regions such as the Sahara scarcely feature in this database.) It is telling that a comprehensive global database of the type to be expected within planetary science has not yet been created for Earth, and even partial catalogs have been put together only in the current decade!

- Line 955: typo "editions"

Text has been fixed. 


\section{Reviewer 2's comments:}

This is an interesting review of progress in planetary dune studies, with a valuable conceptual framework to organize the recent history of investigations and to refer to the often scattered literature on planetary dunes.

- The conceptual organization into 7 phases provides a good way to organize understanding of studies. It seems to me that phases 6 and 7 could be combined, as both emphasize the "details" - which I would prefer to call "'dynamics". There is a natural progression from inferring dynamics from morphology, to actual observations of processes and dynamics.

While we agree that there is a natural progression between and partial overlap of studies fitting into Phases 6 and 7, we want to highlight the different temporal/spatial scale, frequency, and mode of observation that is used in the two Phases, as these lead into different types of investigations. Phase 6 can rely solely on orbital images (even if that leads down the wrong path), although of course in situ observations can assist; and so the dynamics observed within Phase 6 can span a much longer time period than in situ observations may allow for, with coarser temporal resolution. Phase 7 may involve no observation of dynamics, or only evidence of sand transport and not bedform evolution; but instead can yield groundtruth information about grain characteristics and bedform scale. Thus we maintain them as separate phases.

- I am not sure that the summaries at the end of each phase section work very well in their present format. I suggest that they be re-written as continuous prose, so that each provides a lead into the next section.

The goal of these end-portions were to provide easy-to-find-and-read summaries of each Phase. Turning them into smooth prose would lengthen them significantly, and thus somewhat negate this intent. We have added an alternative version which perhaps may be easier to read, at the end of Phase 1 - what do you think of the Table version? If this is an improvement, we can easily turn all summaries into a Table.

- Inevitably, such a review is selective, and one can quibble about the selection of material and examples. On example is the use of spectral information to examine dune sediment composition. There is a lot more that could be said here (especially for Mars), because compositional information is key to understanding many aspects of planetary geologic and climatic evolution. Another example is a bed form that has proved difficult to understand is the transverse aeolian bedforms (TARs) of Mars - this is a good example of where Earth analogues have failed to help.

Based on other reviewers' comments, we have added in a few more references relevant to compositional studies on Mars. We agree we cannot include them all, while keeping this manuscript to a reasonable length! We have aimed for a reasonable sampling, and hope 
this is enough to provide a starting ground for any reader interested in learning more on that (or any) particular topic.

As for TARs, we had previously decided to not mention them as there is not yet a wellaccepted description of their formation mechanism (they've been identified as transverse dunes forming within a reversing wind regime, granule ripples, and sub-aerial antidunes), and so the information these features provide about the environment isn't as clear or easy to trace as interpretation of dunes. However, as pointed out by both reviewers - this omission without explanation is confusing. So, we have added a note to the Introduction, explaining the focus of this paper and explicitly noting that other "aeolian features" (including TARs) are not included. With mention of the TARs, we have also included the point that there may be no good Earth analogue for these strange features, as this is an interesting idea.

In general, we have edited the Title and Introduction text to clarify the focus of this paper - especially the new $3^{\text {rd }}$ paragraph of the Introduction.

- One aspect that could be emphasized more is the linkages between planetary and terrestrial aeolian studies. It is clear that in many cases questions raised by planetary studies have resulted in a re-examination of the basic physics of particle movement (e.g Greeley and Iverson work in the 1970's on thresholds for particle movement), in addition to prompting further study of terrestrial aeolian features.

More discussion and references around this point have been added to various parts of the manuscript (in particular, within the caption for Figure 1), to emphasize this point.

\section{Some specific comments}

- Some additional sub headings within each section would be very helpful - to emphasize the examples discussed - and to break up the lengthy text

This was tried (as we agree the text is lengthy). However, while a few sections had natural subsection break points, others did not; and so we decided to leave subsection headers out rather than create an inconsistent organizational framework.

We also note that part of the difficulty that we had with this is that we did not want to create subsections that divided discussion about different planets -- Part of the goal of this paper was to show that all planetary studies fall onto a common framework.

- In the introduction, the conceptual framework for dune field dynamics is perhaps best exemplified by Kocurek, G., Lancaster, N., 1999. Aeolian system sediment state: theory and Mojave Desert Kelso dune field example. Sedimentology 46, 505 - 515.

This is an intriguing summary of dune field dynamics, and a pointer towards it is now included within the Phase 1 discussions (as a more technical description of the fairly 
basic points discussed within this manuscript). We did not add it to the Introduction as there are no other citations within that portion of the manuscript.

- A good summary of the status of knowledge of Martian aeolian and dune studies at the end of the Viking era is provided by Greeley R., Lancaster, N., Lee, S., Thomas, P., 1992. Martian aeolian processes, sediments and features, in: Kieffer, H., Jakosky, B.M., Snyder, C.W., Matthews, M.S. (Eds.), Mars. University of Arizona Press, Tucson, pp. 730-767.

Reference has been added. 


\begin{tabular}{|c|c|c|c|c|}
\hline \multicolumn{2}{|r|}{ Phase of aeolian bedform study on a planetary body } & \multirow{2}{*}{$\begin{array}{l}\text { Mars } \\
71-1,72-2,73-1,76-1\end{array}$} & \multirow{2}{*}{$\begin{array}{l}\text { Venus } \\
92-1,94-1\end{array}$} & \multirow{2}{*}{$\begin{array}{l}\text { Titan } \\
06-1\end{array}$} \\
\hline 1 & Recognition of dune(s) & & & \\
\hline 2 & $\begin{array}{l}\text { Analysis of gross individual dune characteristics: } \\
\text { e.g., morphology and composition }\end{array}$ & $\begin{array}{l}79-2,81-1,82-1 \\
92-1 \\
05-1 \\
10-1,11-1,13-1,16-2\end{array}$ & $\begin{array}{l}92-1,95-1,97-1,99- \\
1 \\
15-1\end{array}$ & $\begin{array}{l}08-2,09-1,10-1,13- \\
1,14-1,15-1\end{array}$ \\
\hline 3 & $\begin{array}{l}\text { Pattern analysis of the dunes within a field, } \\
\text { including variations due to e.g., sediment supply } \\
\text { and wind variations }\end{array}$ & $\begin{array}{l}79-1,81-1 \\
05-2,06-1 \\
10-3,11-1,12-2,14-1 \\
15-1,16-3\end{array}$ & $\begin{array}{l}94-1 \\
06-1\end{array}$ & $11-1,14-1$ \\
\hline 4 & $\begin{array}{l}\text { Regional and global surveys and aggregate- } \\
\text { analysis of dune characteristics, with a re- } \\
\text { aggregation of data for e.g., estimates of age or } \\
\text { sand volumes, identification of large-scale } \\
\text { sediment transport pathways, or identification/ } \\
\text { estimation of the effect of location-related non- } \\
\text { aeolian processes }\end{array}$ & $\begin{array}{l}82-1,83-1,85-1 \\
92-1 \\
00-1 \\
03-1 \\
07-2,09-1,10-1,11-2 \\
12-1,14-1\end{array}$ & $94-1$ & $\begin{array}{l}09-1,11-1,12-1,13- \\
1,14-1,15-3,16-2\end{array}$ \\
\hline 5 & $\begin{array}{l}\text { Analysis of dune superposed bedforms on the } \\
\text { (such as ripples) formed due to wind interaction } \\
\text { with the dune }\end{array}$ & $\begin{array}{l}06-1 \\
10-1,11-1,12-3,13-1 \\
14-1,15-1,16-6\end{array}$ & & \\
\hline 6 & $\begin{array}{l}\text { Observation of activity on the dune, including } \\
\text { non-aeolian activity }\end{array}$ & $\begin{array}{l}\text { (non-activity) } 00-1 \\
06-1 \text {, (dome dunes } \\
\text { disappearing) } 08-1 \\
10-1,11-2,12-4,14-1 \text {, } \\
15-3,16-3\end{array}$ & & \\
\hline 7 & Groundtruth data & $16-5$ & & \\
\hline
\end{tabular}



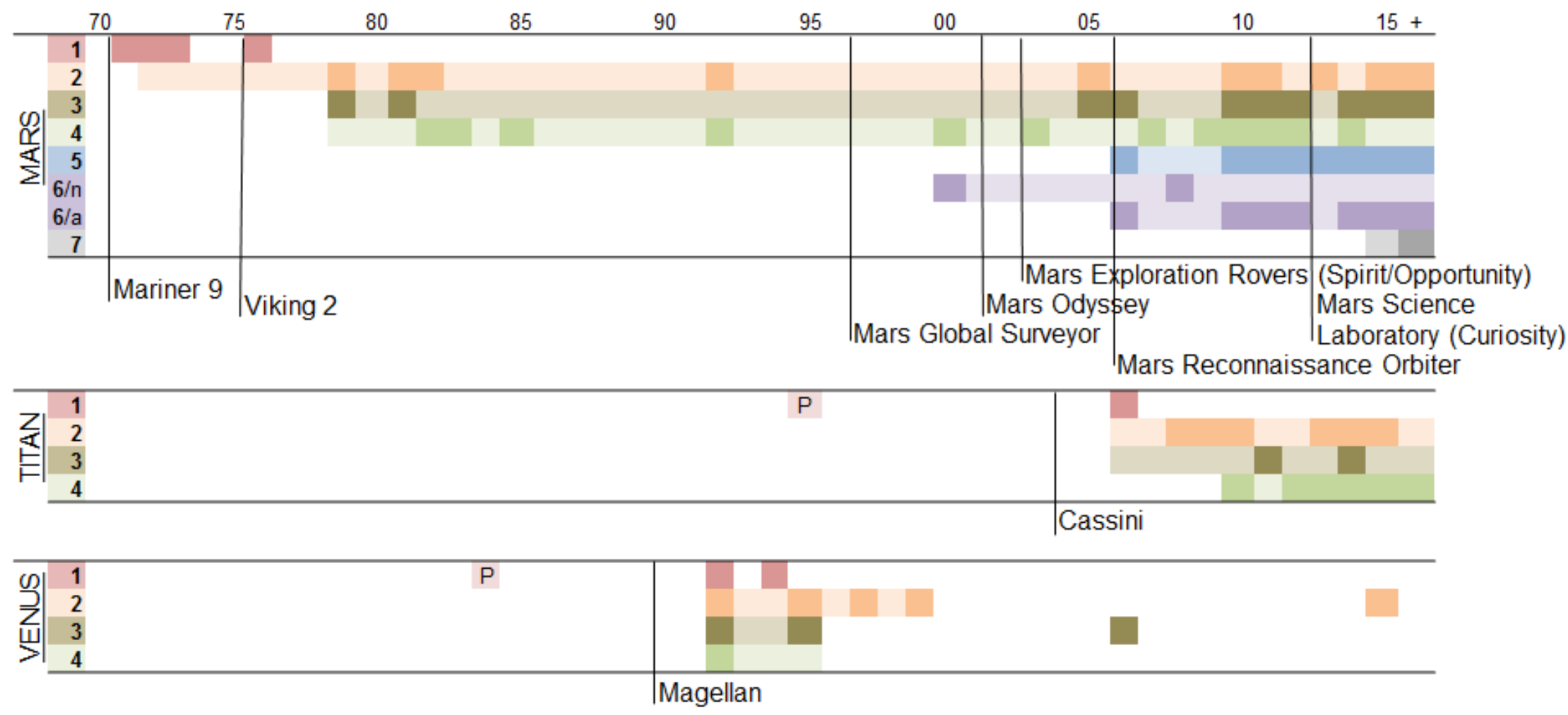
1 Title: Our evolving understanding of aeolian bedforms, based on observation of dunes on different

2 worlds

3 (c) 2016. All rights reserved

4

Abstract (253 words)

Dunes, dune fields, and ripples are unique and useful records of the interaction between wind and granular materials - finding such features on a planetary surface immediately suggests certain information about climate and surface conditions (at least during the dunes' formation and evolution).

9 Additionally, studies of dune characteristics under non-Earth conditions allow for "tests" of aeolian process models based primarily on observations of terrestrial features and dynamics, and refinement of

11 the models to include consideration of a wider range of environmental and planetary conditions. To-

12 date, the planetary aeolian community has found and studied dune fields on Mars, Venus, and the

13 Saturnian moon Titan. Additionally, we have observed candidate "aeolian bedforms" on Comet

14 67P/Churyumov-Gerasimenko, the Jovian moon lo, and - most recently -- Pluto. In this paper, we

15 hypothesize that the progression of investigations of aeolian bedforms and processes on a particular

16 planetary body follows a consistent sequence - primarily set by the acquisition of data of particular

17 types and resolutions, and by the maturation of knowledge about that planetary body. We define that sequence of generated knowledge and new questions (within seven investigation phases) and discuss examples from all of the studied bodies. The aim of such a sequence is to better define our past and current state of understanding about the aeolian bedforms of a particular body, to highlight the related assumptions that require re-analysis with data acquired during later investigations, and to use lessons learned from planetary and terrestrial aeolian studies to predict what types of investigations could be most fruitful in the future. 
Highlights (max 85 characters, including spaces)

- Planetary dunes yield useful/unique information about climate $\&$ surface conditions.

- Aeolian bedform studies progress logically in questions/assumptions/new knowledge.

- Considering this progression exposes gaps/assumptions to be reviewed with new data.

- Comparing planetary progression with Earth aeolian studies yields lessons for each.

\section{Introduction}

Over the past couple of centuries, explorers and scientists of terrestrial dune fields have shown that the interaction between wind and granular material results in regular geometries and rates of evolution. Field observations and studies have inspired modeling and experimental works that have

37 aided in the interpretation of measurable ripples and dunes as proxy indicators of wind speed and direction(s), grain sizes and sources, and underlying topography. The study of such landforms has been greatly extended and advanced by observation of analogous features on other planetary bodies. The comparison of these extraterrestrial features with aeolian process models has increased our understanding of aeolian bedform evolution in both directions - observations of (potential) aeolian bedforms generate investigations into the wind regime and granulometrics of surface materials on a planetary body, and also enable refinement of bedform evolution models as hypotheses about dominant effects are "tested" outside of Earth-conditions. and/or ripples on a planetary body, and the information those aeolian bedforms yield about planetary

47 conditions and processes, has progressed on different bodies. We hypothesize that the progression of 48 investigations of these types of aeolian bedforms on a particular planetary body follows a consistent 49 sequence - primarily set by the acquisition of data of particular types and resolutions, and by the maturation of knowledge about that planetary body. Our aim is to define that progression so we can 
51 better constrain our level of knowledge about the aeolian bedforms of a particular body, highlight the

52 gaps in our knowledge (i.e., our assumptions), and predict what type of future investigations could be most useful in addressing new questions and/or enabling improvement over an assumption.

In the interests of space and focus, most discussion (and cited literature) will focus on dunes and dune fields - i.e., the larger aeolian bedforms and thus usually the first seen on a planetary body. We do delve into ripples (and martian mega-ripples) in portions of the discussion, but primarily as features seen on dunes and that complement dune analysis; and we acknowledge that far more could be said about these smaller-scale bedforms and that studies of these bedforms on Mars has contributed much more towards our understanding of the aeolian environment and processes than is presented here. We also do not generally discuss other types of aeolian bedforms within this paper. In particular, we do not include discussion of Transverse Aeolian Ridges (TARs) on Mars as there is still much debate about their formation mechanism (perhaps as they are an example of a feature that does not have a good terrestrial analog?). It is likely, however, that one could trace advancements in our understanding of TARs or other aeolian features along a similar progression of ideas as is presented here for dunes, as all of these features are studied via similar observation types and their dynamics and morphologies tie into similar questions about atmospheric and surface conditions. We also consider only the observation and analysis of bedforms on the surface of a planet, not e.g., evidence of past bedforms recorded within sandstone stratigraphy (and thus, while dunes and ripples can also form due to the flow of other fluids, such as water, in this paper we focus on aeolian dunes). Thirdly, in discussing our evolution in thinking about aeolian bedforms and processes on other planets, we focus on observation-driven science advancements; we touch on but do not delve as deeply into the parallel lines of investigation focused on model development and validation, empirical studies, and (analog) terrestrial field work - investigations that feed into advancements within (and between) the Phases that we outline here. Finally, we recognize that we present only a sampling of relevant studies - we aimed for enough to map out 
advances in understanding, to justify our proposed framework, and to provide a starting ground for any

reader interested in learning more on a more specific topic.

In defining the "progression" of understanding (Section 2), we focus on Mars, Venus, and the Saturnian moon Titan - all planetary bodies where aeolian bedforms have primarily been explored with remotely acquired data. We also will comment on recently discovered candidate "aeolian bedforms" on Comet 67P/Churyumov-Gerasimenko and possible dune-like landforms on lo and Pluto. Within each phase of investigation (Subsections 2.1-7), we aim to identify the type of observations generally needed and connect these to the primary knowledge, assumptions, and questions that result, and then lead into future investigations (summarized at the end of each section). Furthermore, we identify the typical investigations (outside of direct studies of the aeolian bedforms) that follow each gain in knowledge, to show how aeolian bedform studies contribute to the larger study of that planetary body.

Our proposed framework of phases, regarding investigation of aeolian bedforms on a planetary body, is summarized in Table 1. We again note that this framework is not meant to be fully comprehensive for aeolian dune studiesWe also note that progression in investigations and understanding is not necessarily linear/sequential - for example, planetary missions are generally focused on objectives other than aeolian bedform investigations, so observation types can be acquired in a "mixed" order. Additionally, the advent of new missions, methods, or models can lead to renewed activity within "lower" phases along with advances into higher phases. Science questions also often end up circling back as an assumption becomes superseded by new information and derived products and assumptions must be re-thought. Thus, in addition to identifying typical assumptions associated with each Phase, we use that framework to identify some example areas of knowledge gaps or the types of typical assumptions and results that need re-evaluation when new data becomes available (Section 3.1). We also discuss how modeling (Section 3.2) and terrestrial studies (Section 3.3) relate to planetary aeolian studies. In particular, we highlight lessons learned regarding our understanding of 
99 aeolian processes and their drivers, as well as in methodologies employed. These lessons translate (or 100 could translate) to improved results within other areas of aeolian science. 
Table 1. Summary of the investigation phases

\begin{tabular}{|c|c|c|c|c|c|}
\hline \multicolumn{2}{|r|}{$\begin{array}{l}\text { Phase of aeolian bedform study on } \\
\text { a planetary body }\end{array}$} & \multirow{2}{*}{\begin{tabular}{l|}
$\begin{array}{l}\text { Area of } \\
\text { interest }\end{array}$ \\
Dune \\
(possibl \\
y a dune \\
field)
\end{tabular}} & \multirow{2}{*}{$\begin{array}{l}\text { Characteristic(s)/Fea } \\
\text { ture(s) of interest } \\
\text { Dune morphology } \\
\text { (i.e., recognizable, } \\
\text { distinctive gross dune } \\
\text { shape or crestline } \\
\text { patterns within a } \\
\text { field) }\end{array}$} & \multirow{2}{*}{$\begin{array}{l}\text { Data needed to move to this phase } \\
\text { (from an earlier phase) } \\
\text { Images (visible, radar, spectral, etc.) } \\
\text { with sufficient resolution to } \\
\text { distinguish dune from non-dune } \\
\text { surroundings, e.g., linear/arcuate and } \\
\text { isolated/repeated morphology }\end{array}$} & \multirow{2}{*}{$\begin{array}{l}\text { Complementary science } \\
\text { investigations } \\
\text { Knowledge of and about } \\
\text { analog features (terrestrial } \\
\text { or planetary) }\end{array}$} \\
\hline 1 & Recognition of dune(s) & & & & \\
\hline 2 & $\begin{array}{l}\text { Analysis of gross individual } \\
\text { dune characteristics: e.g., } \\
\text { morphology and composition }\end{array}$ & Dune & $\begin{array}{l}\text { Dune morphology, } \\
\text { characteristics of } \\
\text { surface materials }\end{array}$ & $\begin{array}{l}\text { Images (visible, radar, spectral, etc.) } \\
\text { with sufficient resolution to } \\
\text { identify/correlate with dune margin } \\
\text { and/or crestline patterns (possibly } \\
\text { same data as Phase 1) }\end{array}$ & $\begin{array}{l}\text { Global/regional-scale } \\
\text { climate models (specifically: } \\
\text { wind velocity, direction, and } \\
\text { variation); Dune formation } \\
\text { models }\end{array}$ \\
\hline 3 & $\begin{array}{l}\text { Pattern analysis of the dunes } \\
\text { within a field, including } \\
\text { variations due to e.g., sediment } \\
\text { supply and wind variations }\end{array}$ & $\begin{array}{l}\text { Dune } \\
\text { field }\end{array}$ & $\begin{array}{l}\text { Dune shapes } \\
\text { throughout the field }\end{array}$ & $\begin{array}{l}\text { Coverage (of images, see above) } \\
\text { throughout dune field }\end{array}$ & $\begin{array}{l}\text { Regional/local-scale climate } \\
\text { models (specifically: wind); } \\
\text { Regional/local-scale } \\
\text { topography; Studies of non- } \\
\text { aeolian dune-modifying } \\
\text { processes (e.g., polar or } \\
\text { surface crust forming } \\
\text { processes); Maps of other } \\
\text { aeolian features around the } \\
\text { dune field }\end{array}$ \\
\hline 4 & $\begin{array}{l}\text { Regional and global surveys } \\
\text { and aggregate-analysis of dune } \\
\text { characteristics; e.g., estimates } \\
\text { of age or sand volumes, } \\
\text { identification of large-scale } \\
\text { sediment transport pathways, } \\
\text { or identification/ estimation of } \\
\text { the effect of location-related } \\
\text { non-aeolian processes }\end{array}$ & $\begin{array}{l}\text { Regional } \\
\text { or } \\
\text { Global } \\
\text { (i.e., } \\
\text { multiple } \\
\text { dune } \\
\text { fields) }\end{array}$ & $\begin{array}{l}\text { Dune field } \\
\text { characteristics } \\
\text { (including } \\
\text { morphology of field } \\
\text { and dunes within } \\
\text { each field) and } \\
\text { spatial distribution }\end{array}$ & $\begin{array}{l}\text { At least regional coverage of images } \\
\text { or (often coarser and/or less } \\
\text { definitive) proxy data (e.g., thermal } \\
\text { inertia) }\end{array}$ & $\begin{array}{l}\text { Expansive composition } \\
\text { maps for identification of } \\
\text { potential sand sources; } \\
\text { Maps of other aeolian } \\
\text { features; Global or regional- } \\
\text { scale climate models }\end{array}$ \\
\hline 5 & Analysis of superposed & Dune & Within/on-dune & (Very) high-resolution images & Ripple formation models; \\
\hline
\end{tabular}




\begin{tabular}{|l|l|l|l|l|l|}
\hline & $\begin{array}{l}\text { bedforms on the dune (such as } \\
\text { ripples) formed due to wind } \\
\text { interaction with the dune }\end{array}$ & $\begin{array}{l}\text { features (e.g., } \\
\text { ripples) }\end{array}$ & $\begin{array}{l}\text { High-resolution topography } \\
\text { (dune); Very high resolution } \\
\text { climate model (CFD) } \\
\text { (specifically: wind) }\end{array}$ \\
\hline $\mathbf{6}$ & $\begin{array}{l}\text { Observation of activity on the } \\
\text { dune, including non-aeolian } \\
\text { activity }\end{array}$ & Dune & $\begin{array}{l}\text { Smaller-scale } \\
\text { evidence of change } \\
\text { (e.g., ripple } \\
\text { crestlines, dune } \\
\text { margins) }\end{array}$ & $\begin{array}{l}\text { Repeat images for seeing planform } \\
\text { changes (e.g., movement of } \\
\text { material); these images need } \\
\text { sufficient resolution and temporal } \\
\text { baseline for changes to be observable }\end{array}$ & $\begin{array}{l}\text { Ripple and dune migration } \\
\text { models }\end{array}$ \\
\hline $\mathbf{7}$ & Groundtruth data & Dune & $\begin{array}{l}\text { All features and } \\
\text { components of the } \\
\text { dune, especially sand } \\
\text { size/composition }\end{array}$ & $\begin{array}{l}\text { In situ observations of the dune, } \\
\text { sampling and analysis }\end{array}$ & $\begin{array}{l}\text { In situ observations of } \\
\text { potential sediment sources } \\
\text { for fluvio-sedimentary } \\
\text { landforms }\end{array}$ \\
\hline
\end{tabular}




\section{The Phases of Investigation}

\subsection{Phase 1: Recognition of dune(s)}

In this first phase of aeolian studies, we focus on the occurrence of the first observation of a dune (or, more likely, a dune field). This has geologic significance as aeolian bedforms - dunes and ripples - directly record an interaction between the atmosphere and surface: specifically, the movement of granular material due to wind. Furthermore, a dune or ripple is more than a pile of sand - it is a distinctive landform that requires certain conditions to organize, and that appears to evolve and move "as a unit" through the aggregation of the actual movement of individual grains of sand, onto and off of the dune. Specifically, the existence of an aeolian bedform implies:

- A sufficient supply of saltatable (sand) grains,

- A wind of sufficient velocity and consistency to move those grains, and

- A period of consistent wind blowing, long enough for the bedform to form and evolve.

(We now examine what each of those underlined terms imply about the planetary body's environment, focusing on the larger-scale dunes that are typically observed first. A more technical summary of the conceptual framework for dune field dynamics and how this is affected by the sediment state of a dune field -- related to sediment supply, sediment availability, and transport capacity of the wind - is described within Kocurek and Lancaster (1999).)

A sufficient supply means much more than the volume of the dune - for most dunes to form and evolve, sand must be able to move onto and off of the dune (possible exceptions would be climbing dunes or other such features where the sand accumulates due to blockage). Barchans in particular are an inefficient dune shape due to sand leakage from the horns (Hersen, 2004). Thus, an important implication with the first recognition of a dune feature on a planetary body is that a process must exist that will yield a significant amount of sand (discussed in within an example in Phase 4). Depending on the body, that process may involve erosion of larger rocks (e.g., as is common on the Earth) or a process 
that directly forms grains of that size. For instance, martian volcanic activity has been proposed to create sand-sized particles (Edgett and Lancaster, 1993; Wilson and Head, 1994) and photochemical processes in the Titan atmosphere may eventually lead to saltatable grains, perhaps via an intermediate evaporite or sedimentary location (Soderblom et al. 2007; Radebaugh, 2013; Barnes et al. 2015).

On the Earth, nearly all dunes and ripples are comprised of sand grains - and this refers to a specific size. (e.g., the Canada Dept. Agriculture (1976) lists sand as grains 0.05-2 mm in diameter). However, "sand grains" can also be defined based on dynamics. "Sand" is the size of grains most easily moved by a fluid (Bagnold, 1941) - smaller grains are held together by interparticle, cohesive forces and larger grains have more mass and so are held down more by gravity. Under the Earth's atmosphere and gravity, grains $\sim 1 \mathrm{~mm}$ in diameter are able to saltate, and thus are the most easily moved by the wind. However, under the influence of a different atmospheric (or fluid) density and gravity, the grain size most easily moved by the wind could be a different size (Figure 1; Edgett and Christensen, 1991; Greeley et al., 1974; 1980; 1992a; Moore et al., 2015). Throughout this discussion, when discussing "sand grains," we mean "the grain most easily moved by the wind (or fluid)" and not a fixed size range. Thus, the existence of a dune (i.e., a landform composed of sand grains) on a planetary surface yields a coupled constraint on the grains and the wind velocity.

Even if the wind reaches sufficient strength to transport sand, if it is not consistent (in direction and speed) over a sufficient period of time, the wind would just move small amounts of sand back-andforth until that sand became trapped into depressions, sheltered areas, and other sand-traps; that sand would not be able to organize into a bedform. Models have shown that sand dunes have a minimum size (e.g., Claudin and Andreotti, 2006; Parteli et al., 2007); below this size the slipface is unable to develop. A slipface is necessary to stabilize the dune (as sand then can be captured on the sheltered, lee slope) to allow it to continue growing and migrating. 


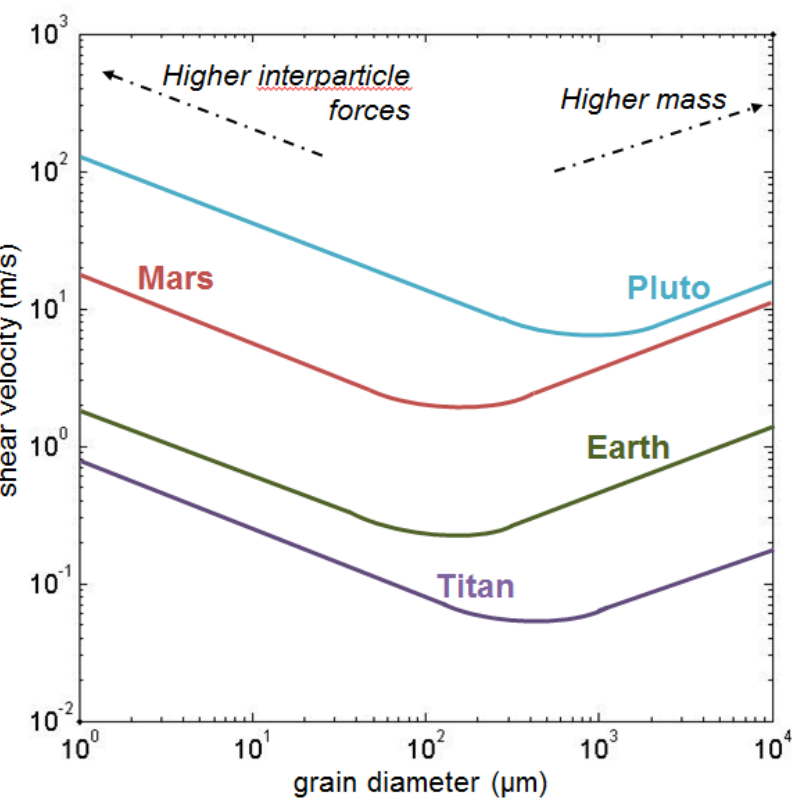

Figure 1: Wind shear velocity needed to move grains of different sizes, on different planets. Plot

151 showing the estimated threshold shear velocity for wind-driven transport of a grain of a specific diameter

152 for (from top) Pluto, Mars, Earth, and Titan; curves are taken from Moore et al. (2015; Fig. 17). The

153 general shape of the curve is reflective of smaller particles experiencing stronger interparticle forces

154 (such as electrostatic forces), while larger particles have more mass - either effect thus requiring more 155 shear velocity to initiate and sustain grain movement. The curve's minimum indicates the expected size 156 of "sand grains" (i.e., the grains most easily lifted and moved by a shearing fluid - by saltation) on that 157 planetary body, that would be involved in the formation of aeolian bedforms. On Earth, sand grains are 158 commonly $0.1 \mathrm{~mm}$ in diameter. On Mars observations of saltatable grains ("sand grains") in aeolian deposits such as dunes (e.g., Figure 11) yield comparable diameters, which is consistent with the curves

160 shown. The differences in shear velocity needed to initiate motion are due primarily to differences in the 161 estimated air (fluid) and grain densities on each planetary body. The first investigations into these curves 162 and how they shift under different planetary conditions (Greeley et al., 1974) were initiated based on 163 observation of dunes on Mars (as described in the text: Belcher et al., 1971; McCauley et al., 1972; Cutts 164 and Smith, 1973). 
To date, we have seen potential dunes on every deeply-studied body with an atmosphere and

167 observable surface (including Titan, where dunes were considered unlikely: Lorenz et al., 1995), as well

168 as a few bodies with no known atmosphere (Table 2). Based on the connections outlined above, this first

169 "sighting" suggests the accumulation of a lot of sand (leading to questions about where the sand is

170 coming from and why it is accumulating) and implications about wind strength, direction, and

171 consistency. This yields a "groundtruth" observation for comparison with atmospheric models in both

172 wind strength and direction (although it may be unclear when the bedform was created and thus what

173 input conditions should be used for the model, or how the bedforms may have since been modified by

174 non-aeolian processes).

Two classic examples of this are Mars and Titan. On Mars, signs of aeolian processes had been

176 seen in cyclic, large-scale albedo changes and Mariner 6 imaged crescent-shaped features that were

177 hypothesized to be very large barchan or parabolic dunes (Belcher et al., 1971). The first clear example

178 of martian dunes was observed by Mariner 9 (McCauley et al., 1972; Cutts and Smith, 1973). Those

179 observations suggested a wind regime that would allow for transport and collection of, as well as the 180 presence of, a large amount of granular materials ${ }^{1}$, leading into laboratory studies of aeolian granular 181 transport (Greeley et al., 1974; 1980). When Viking 2 imaged the north polar erg (Figure 2), this led to 182 investigations of martian erosional processes (acting on polar layered deposits or soils of lower 183 latitudes?) and climate models (Cutts et al., 1976). (A summary of results from Viking and Mariner-based 184 aeolian studies can be found in Greeley et al., 1992a.) On Titan, "cat-scratch" features had been 185 observed circumnavigating its equator, but were not immediately recognized as dunes until Vic Baker

\footnotetext{
${ }^{1}$ As Cutts and Smith [1973, p4151] put it: "The principal implication of dunes is a supply of noncohesive particles in the Martian surface environment and wind velocities sufficient for saltation transport. ... Dunes are not amenable to an alternative explanation of this sort. Thus we feel that we can now confidently assert the existence of a saltation regime on Mars", which leads to "many implications of a saltation regime such as wind abrasion, wind scour, and dust production."
} 
brought the large draa of Saharan/Arabian/Namib deserts to the attention of the Cassini RADAR Team.

187 The presence of dunes was a surprise as it had been hypothesized that while Titan's atmosphere may be capable of moving sand grains, it seemed unlikely that grains of the right size would exist (Lorenz et al., 1995). Observation of the dunes (Lorenz et al., 2006) led immediately to detailed investigations of what grains could be made of and how they would form (furthering studies of the chemistry on this Saturnian moon: Lorenz et al. 2006; Soderblom et al. 2007; Barnes et al. 2015) as well as leading to attempts to reconcile the observed dune morphologies with the model-predicted wind regime around the equator

193 (Lorenz and Radebaugh 2009).

194
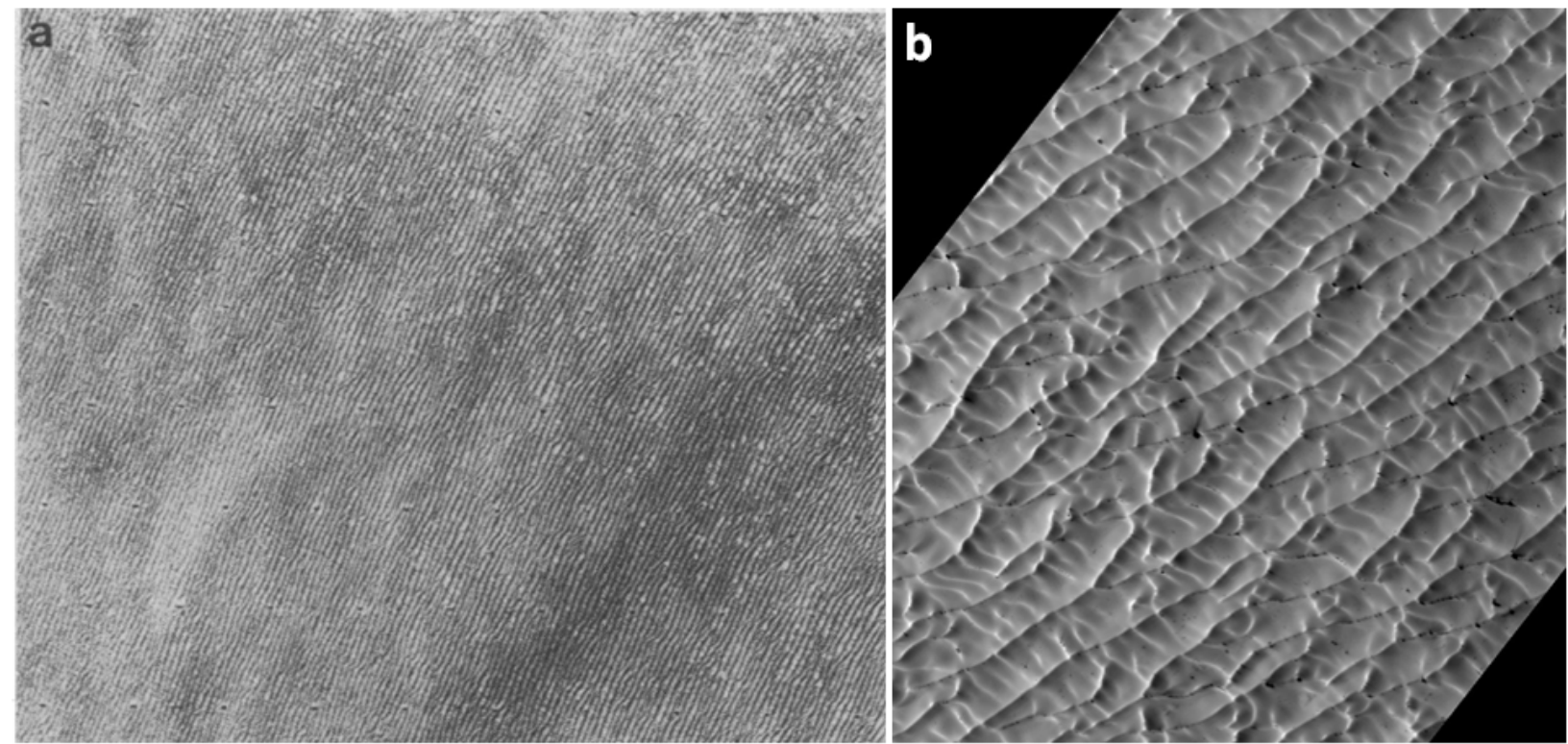

Figure 2. An early image of the martian north polar erg. (a) These linear features, imaged near the martian north polar cap by Viking 2 (frame 59B32: $62 \mathrm{~km} \times 104 \mathrm{~km}$ ), were hypothesized to be dune fields based on their consistent orientation and wavelength, and low sinuosity, branching and merging. Image and description are taken from Cutts et al. (1976; Fig. 7). (b) Higher-resolution images have proven that these are dune fields, with a wavelength (between primary crestlines) of approximately $0.4 \mathrm{~km}$. A few 


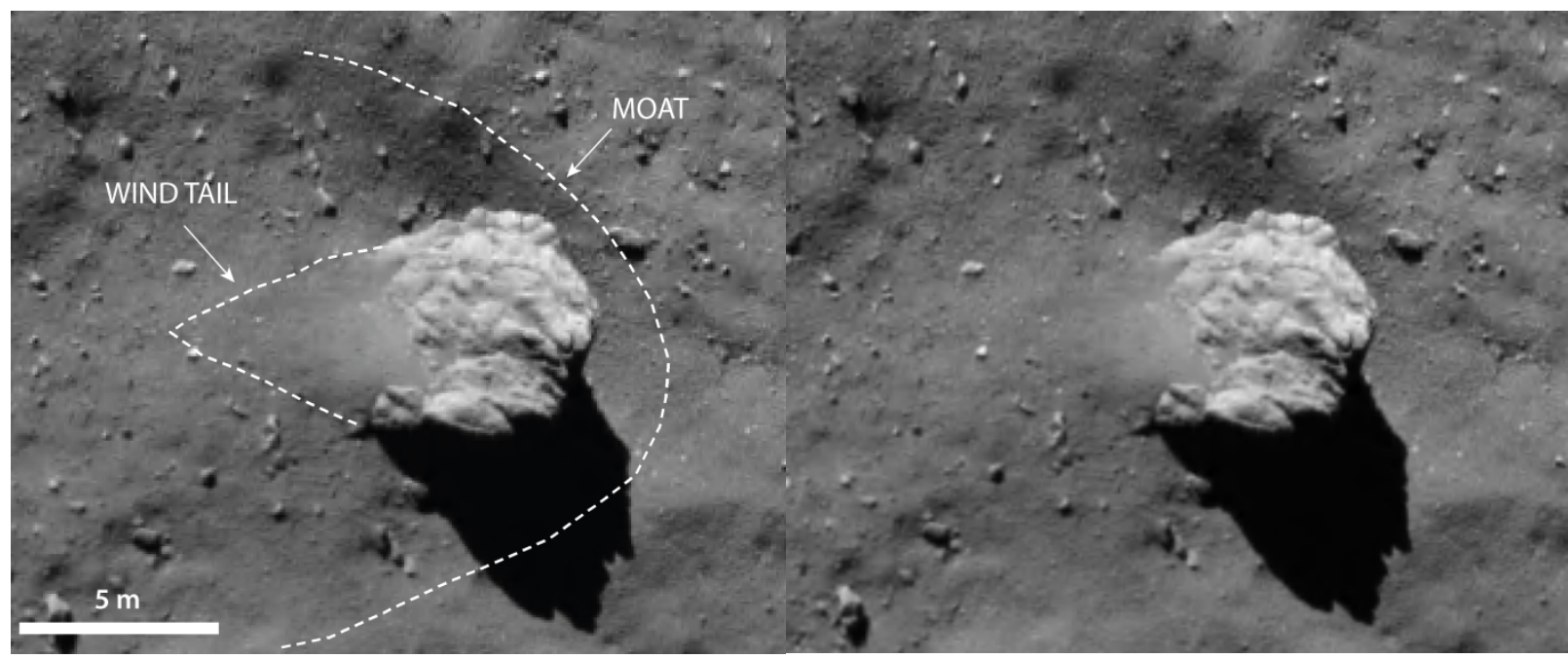

Figure 3. A 5 $m$ boulder and potential aeolian features at Philae lander's touch-down-1 site. This

apron on the opposite side have been interpreted as a moat and a windtail, indicating transport of granular material across the comet's surface (Mottola et al., 2015). Initial studies evaluated possible aeolian mechanisms for this transport. (C) ESA/Rosetta/Philae/ROLIS/DLR coverage in other aeolian features such as windstreaks and potential yardangs (Greeley et al., 1995). This confirmed the hypothesis that aeolian bedform development on Venus must be limited, based on Venera 13 and 14 observations of the venusian surface that showed a dearth of aeolian ripples within

217 loose material (Basilevsky et al., 1985; Florensky et al., 1983). (Note that for Venus, surface observations were first, before the mapping of surface topography from orbit.) The implication was that venusian 
conditions and processes commonly obliterate features, the conditions for dune formation are not

220 common on Venus (e.g., that there are few sands available on Venus or wind is not sustained at the 221 surface), or that dunes are not generally visible via the radar images (Greeley and Arvidson, 1990; Weitz

222 et al., 1994). Wind tunnel (Greeley et al., 1984a; 1984b; Marshall and Greeley, 1992; Williams and

223 Greeley, 1994) and sand flux modeling (Kok et al., 2012) has shown that saltation under venusian

224 conditions may occur in a very thin near-surface layer with very low velocity, which does not favor

225 formation of large dunes. Thus, venusian sand transport appears more comparable to terrestrial

226 bedform formation under water (Marshall and Greeley, 1992; Kok et al. 2012; Neakrase, 2015).

227 Unfortunately, no new data about Venus has been acquired since Magellan, so Venus dune

228 investigations remain stuck just past Phase 1 (with a small start within Phases 2-4, see discussion of

229 Phase 2; Figure 13).

Potential aeolian bedforms have also been seen on planetary bodies lacking an atmosphere. For example, planetary scientists were recently very surprised to see features that looked like aeolian bedforms (i.e. moats, wind tails, and dune-like ridges) on comet 67P/Churyumov-Gerasimenko (Figure 3; Mottola et al. 2015; Thomas et al. 2015a; 2015b). A comet seemed clearly to be a planetary body that would lack an atmosphere, and thus any wind -- yet the features were observed. This immediately led to studies trying to determine how a "wind" could exist on this comet, if even transiently. One mechanism proposed to explain particle mobilization on comets was gas outflow from reservoirs of subsurface 237 sublimating ice that emerges and erodes particles from channel walls (Cheng et al., 2013). However, 238 since this process would only affect localized regions and the dune-like features on 67P have been 239 observed in a much wider area, "splashing" initiated by airfall, i.e. ejection of particles by incoming 240 projectiles, has been suggested as the most significant mechanism to explain particle mobility (Mottola 241 et al, 2015; Thomas et al., 2015b). A three-dimensional cellular automaton model has proven that moats 242 can result from abrasion of the surface by impinging particles, whereas wind tails develop where 
243 granular surface materials were shielded by obstacles from particle transport (Mottola et al., 2015). The

244 results of this study put forward the explanation that the aeolian bedform-like features on comet 67P

245 are of erosional nature, rather than depositional - but the questions and investigations that arose in

246 response to the recognition of features that resembled aeolian bedforms were consistent with typical

247 Phase 1 discussions.

248 The surface of lo is covered in a ubiquitous frost of $\mathrm{SO}_{2}$ as seen by the Galileo Near Infrared

249 Mapping Spectrometer (NIMS), likely mixed with dust and fine-grained materials, all ejected from the

250 continuously erupting volcanic plumes and explosive volcanic eruptions (Kieffer et al. 2000, Milazzo et

251 al. 2001). The surface as seen by the Imaging Science Subsystem (ISS) instrument on Galileo is mostly

252 uniformly light-colored from this frost and generally smooth, with some fractures, slumps and pits

253 (McEwen et al. 2000). In a few regions, there are landforms with dune-like characteristics: regular

254 spacing, a slightly meandering form, "crestline" defects, and apparent topography visible through the

255 uneven collection of frosts (not possible to confirm with Galileo's instruments). In one location, the

256 dune-like landforms are found near a particularly active volcanic plume source, the Prometheus plume,

257 which is sourced by advancing lava flows over vaporizing frosts (Figure 4; Kieffer et al. 2000; Milazzo et

258 al. 2001). It is possible this plume forms a localized atmosphere dense enough to loft particles from the

259 surface and deposit them nearby in dunes, much like one of the processes hypothesized for forming the

260 features on comet 67P.

261 


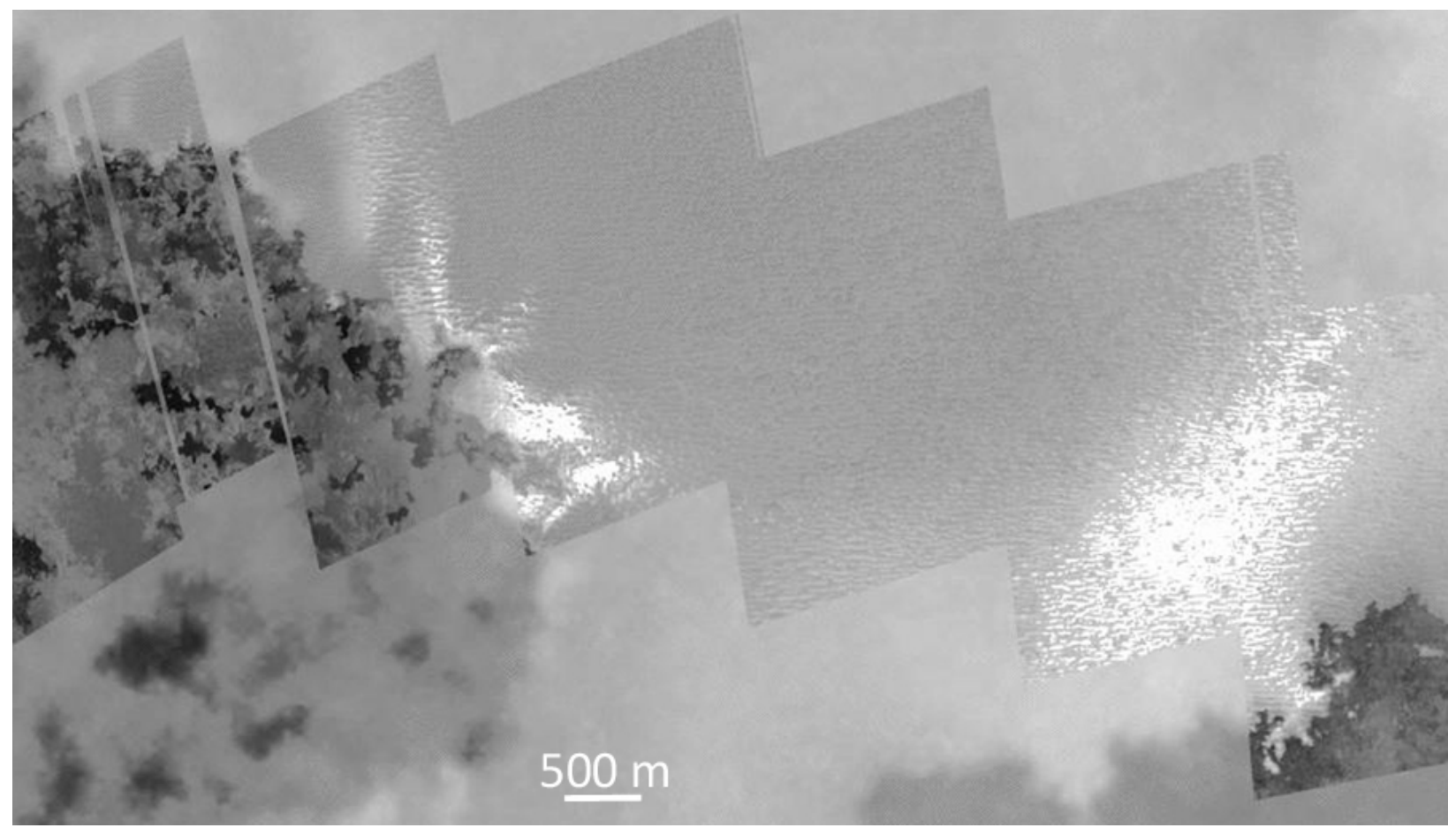

Figure 4. Potential aeolian bedforms on lo. This ridged terrain has been postulated as potential aeolian bedforms, formed from volcanic plume deposits. Lava is erupting from a fissure about $40 \mathrm{~km}$ east (right) of the edge of this mosaic, and the $100 \mathrm{~km}$ tall Prometheus plume is erupting from somewhere near the western (left) end of this mosaic. The bright streaks radiating from the area where the lava flows (the dark features) overrun the field are where the hot lava recently vaporized the sulfur dioxide, which then coated the lava-facing sides of the ridges. These images were taken by Galileo during a flyby of lo on February 22, 2000, with a resolution of $12 \mathrm{~m} /$ pixel. Image and description are taken from NASA Photojournal PIA02568. The flyby of Pluto by New Horizons in July 2015 produced one of the most striking increases in 273 image quality of a planetary surface in the history of planetary exploration (Moore et al., 2016; New 274 Horizons, 2015; Stern et al., 2016). The landscape imaged during the flyby revealed a surprising diversity 275 of landforms, which suggest varied geological and geomorphological processes active within recent 276 geological history surface (Moore et al., 2016; Stern et al. 2015; Trilling et al., 2016). Mountains, glaciers, 
277 plains, possible cryovolcanism and a surprisingly low density of craters covered much of the surface.

278 Initial science results from the flyby noted the possible existence of 'windstreaks' (Stern et al. 2015) on

279 Sputnik Planum, apparently extending in the lee of dark hills protruding through the nitrogen ice of

280 which the plains are composed. Aeolian bedforms were speculated on before New Horizons arrived

281 (Moore et al., 2015), and dunes have since been posited in the Baré Montes and enigmatic features in

282 the Tartarus Dorsa have been interpreted variously as dunes or erosional aeolian features (Fenton,

283 2016; New Horizons, 2016). However, recent imagery from Sputnik Planum (Figure 5) provides perhaps

284 some of the most convincing examples of potential aeolian bedforms, with continuous linear features

285 with a spacing of $\sim 400-600 \mathrm{~m}$. These features extend across the polygonal dark features, which have

286 been interpreted as convectional cells within the ice, suggesting that they are the result of surface

287 processes not related to the convective movement within the ice. Pluto is thus tentatively within Phase

2881 of the progression, and if an aeolian origin can be shown to be feasible, then available data may be

289 sufficient for progression into Phases 2-3.The dune-like landforms on comet 67P, lo and Pluto are well in

290 Phase 1 discussions and primary work remains to be done for these features to determine their ultimate

291 origin.

292 


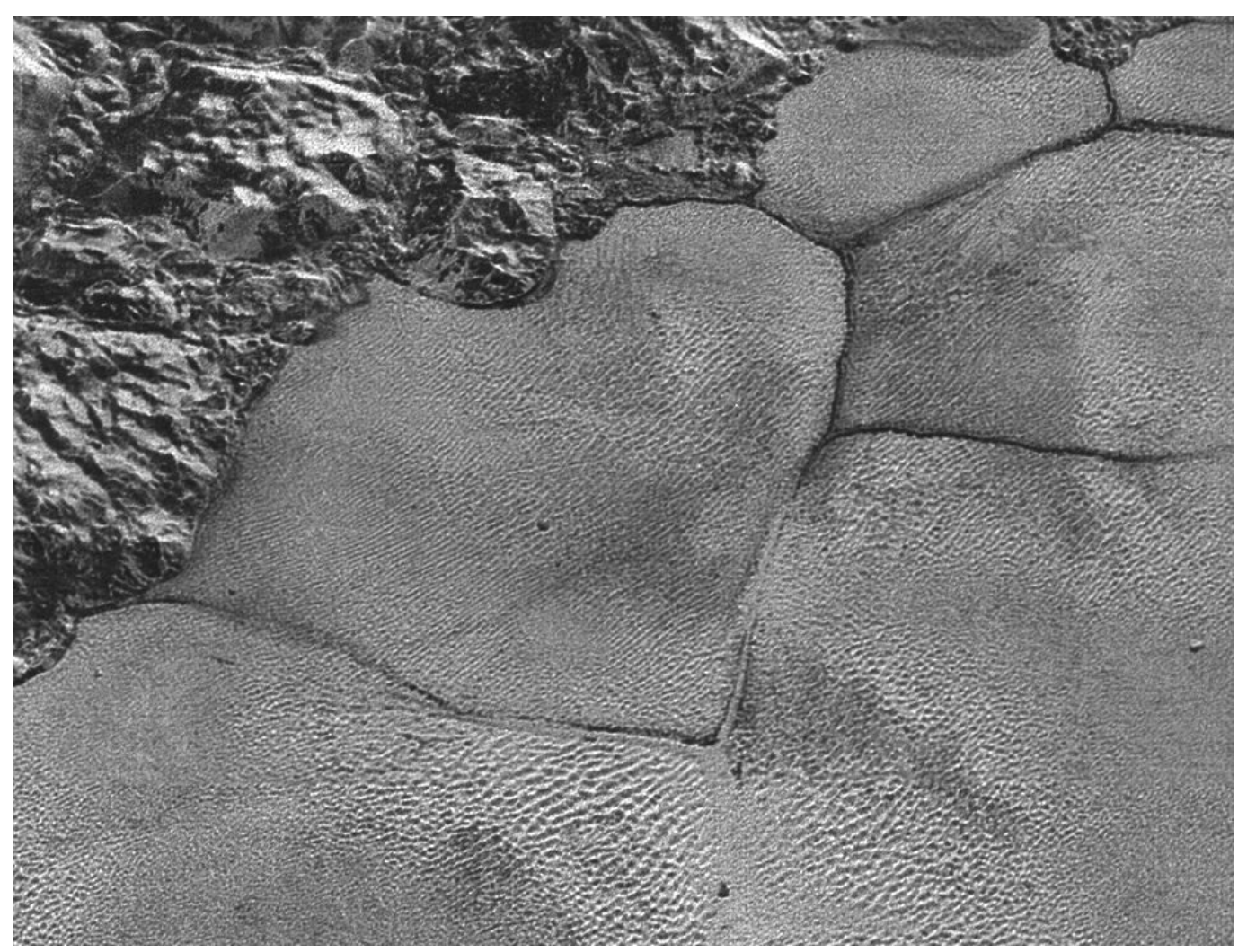

294 Figure 5. Possible Pluto aeolian bedforms at the margins of the nitrogen ice of Sputnik Planum. These

295 features are oriented approximately parallel to the 'shore' where the ice abuts mountains. Image width

296 is approximately $75 \mathrm{~km}$. Image credit: NASA/JHUAPL/SWRI.

\section{Summary of Phase 1}

299 Data needed: Images of the surface topography, of sufficient resolution to identify the distinctive

300 shapes of dunes -- images could be visible or spectral imagery or radar scans of the planetary body's

301 surface; identified analog (usually terrestrial) aeolian bedforms.

302 Knowledge gain (from that data): Existence of a potential aeolian bedform.

303 Assumptions generated: Conditions (wind conditions and grain size/supply) conducive to dune

304 formation and evolution exist or have existed - note that this is a coupled constraint, and further

305 information is needed to estimate each individual measurement. 
Questions: What is the composition of the grains? How were sand-sized grains formed? Why do the

grains accumulation in that particular location (related to winds, topography, sand source)? Are the

dunes active? If conditions are unusual (e.g., tenuous atmosphere), how does sustained saltation and/or

reptation occur on this world?

Lead to investigations of: Models of surface processes and rates (chemical, erosional, etc.) that could

create "sand" grains; comparison to (global) atmospheric models; independent measurements of

speeds and/or grain sizes (e.g., thermal inertia) to decouple saltation conditions.

(Alternatively: ) Table N. Summary of Phase 1

\begin{tabular}{|c|c|}
\hline $\begin{array}{l}\text { Data needed } \\
\text { within Phase } 1\end{array}$ & $\begin{array}{l}\text { Images of the surface topography, of sufficient resolution to identify the distinctive } \\
\text { shapes of dunes -- images could be visible or spectral imagery or radar scans of } \\
\text { the planetary body's surface; } \\
\text { Identified analog (usually terrestrial) aeolian bedforms. }\end{array}$ \\
\hline $\begin{array}{l}\text { Knowledge gain } \\
\text { (from that data) }\end{array}$ & Existence of a potential aeolian bedform. \\
\hline $\begin{array}{l}\text { Assumptions } \\
\text { generated }\end{array}$ & $\begin{array}{l}\text { Conditions (wind conditions and grain size/supply) conducive to dune formation and } \\
\text { evolution exist or have existed - note that this is a coupled constraint, and further } \\
\text { information is needed to estimate each individual measurement. }\end{array}$ \\
\hline $\begin{array}{l}\text { Questions } \\
\text { generated }\end{array}$ & $\begin{array}{l}\text { What is the composition of the grains? } \\
\text { How were sand-sized grains formed? } \\
\text { Why do the grains accumulation in that particular location (related to winds, } \\
\text { topography, sand source)? } \\
\text { Are the dunes active? } \\
\text { If conditions are unusual (e.g., tenuous atmosphere), how does sustained saltation } \\
\text { and/or reptation occur on this world? }\end{array}$ \\
\hline $\begin{array}{l}\text { Leads to } \\
\text { investigations of }\end{array}$ & $\begin{array}{l}\text { Models of surface processes and rates (chemical, erosional, etc.) that could create } \\
\text { "sand" grains; } \\
\text { Comparison to (global) atmospheric models; } \\
\text { Independent measurements of surface conditions/composition for comparison to } \\
\text { grain-formation models; } \\
\text { Independent studies of wind speeds and/or grain sizes (e.g., thermal inertia) to } \\
\text { decouple saltation conditions. }\end{array}$ \\
\hline
\end{tabular}

\subsection{Phase 2: Analysis of gross individual dune characteristics}


1995) and laboratory studies (e.g., Andreotti et al., 2006; Parteli et al., 2009) have established, a dune's

overall shape and orientation yields additional information about wind conditions when the dunes were forming and evolving ${ }^{2}$. Thus, this investigation stage generally involves detailed mapping of dune shape (outline and crestline) and comparison to analog terrestrial dunes. Numerical models of sand transport and dune evolution are also used for comparison between dune-generated predicted wind directions and atmospheric models (possibly down to a mesoscale or regional scale and including the effects of large-scale topography). were dunes (Lorenz et al. 2006), researchers began investigating what type of dunes were observed and what wind conditions were required for their formation and persistence (in addition to questions about what the sand may be made of). From the morphology of the dunes, visible in $350 \mathrm{~m} / \mathrm{px}$ Synthetic Aperture RADAR (SAR) data from the Cassini spacecraft (slightly hyper-resolution in nature in some locations because of the high contrast between SAR-absorbing sands and fractured, signal-scattering bedrock), it was determined they are longitudinal in type (also called linear; Lorenz et al. 2006; Radebaugh et al. 2008). Cassini Visual and Infrared Mapping Spectrometer (VIMS) data in select, highresolution regions confirmed the general morphology of Titan's longitudinal dunes as well as their spectral contrast between sand and substrate (Barnes et al. 2008). On the Earth, longitudinal dunes are typically formed when several alternating winds of roughly equal transport strength (i.e., they move the same amount of sand) are $>90^{\circ}$ apart, yielding a single sand transport direction that is along the dune crestline (Fryberger and Dean 1979; Parteli et al., 2009; Rubin and Hunter, 1987; Rubin and Ikeda, 1990; Tsoar, 1983). (An alternate hypothesis that had been put forth connecting longitudinal dune morphology and wind directionality for Titan and some Earth dunes is discussed in Subsection 3.2.)

\footnotetext{
${ }^{2}$ However, establishing a connection between wind directions and dune slipface orientations sometimes is not a straightforward process - such studies often rely on many assumptions about timing of the winds and their consistency, and results are usually non-unique. Thus additional information is usually needed to evaluate a proposed interpretation. See Phase 3 for more discussion of the complexity that can be found in many dune fields.
} 
342 directions, for comparison with climate models (discussed here, but merging into Phase 3

343 investigations). Titan's dunes are found strictly between $30^{\circ} \mathrm{N}$ and S, ringing the equator, and are

344 oriented roughly parallel to the equator (Lorenz et al. 2006; Radebaugh et al. 2008). Their morphology,

345 and especially behavior around topographic obstacles (wherein grains are piled up at the upwind margin

346 and are more sparse at the downwind margin), indicated a general sand transport direction from west

347 to east (Figure 6; Courrech du Pont et al., 2014; Lorenz and Radebaugh 2009; Lucas et al., 2014;

348 Radebaugh et al. 2010;). However, this was found to be at odds with the global atmospheric transport

349 direction of east-to-west predicted in the equatorial zone by global climate models. Subsequent

350 modeling studies revealed that seasonal or storm-driven winds could produce fast westerlies near the

351 equator (Tokano 2010; Charnay et al., 2015), possibly resolving this inconsistency. 

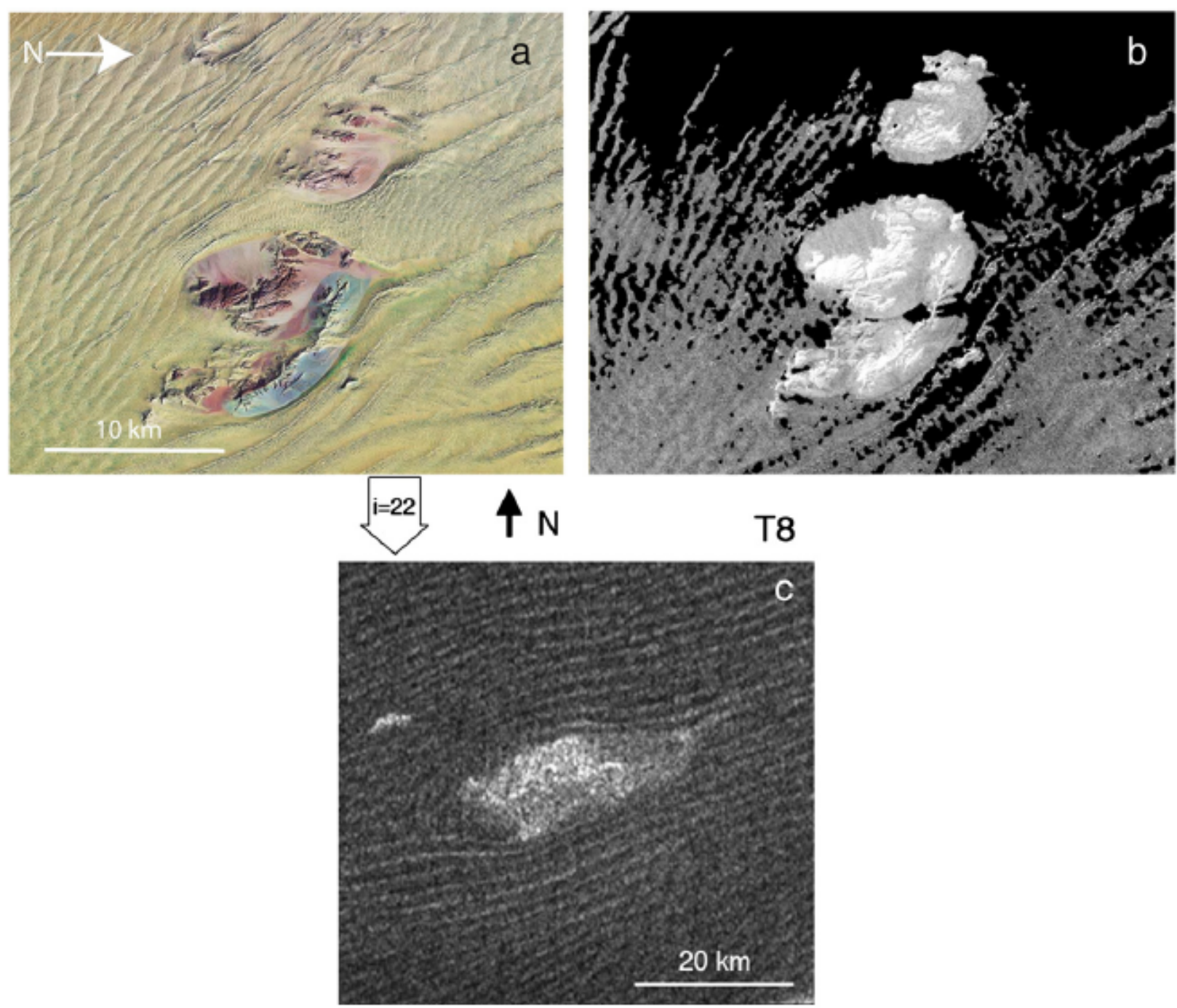

354 Figure 6: Earth and Titan dunes, diverging around topographic obstacles. (a-b) Landsat 7 ETM+ and

355 SRTM C-band images of dunes in Namibia (centered on $25^{\circ} 23^{\prime} \mathrm{S} 15^{\circ} 16^{\prime} \mathrm{E}$ ). The right image (b), a

356 Synthetic Aperture RADAR (SAR) image of the same dunes, shows bedrock as bright, because it is rough,

357 and unorganized dune sands as dark, because dunes are smooth at the SAR wavelength of $6 \mathrm{~cm}$ (black

358 areas are regions devoid of data returned to the SAR antenna). The winds blow SE to NW (bottom L to

upper R), as evidenced by the dune-free regions in the lee of the bedrock topography and the diversion of dunes around the upwind sides of the topography. In the lower image (c), dunes similarly divert around

361 topographic obstacles and resume on the downwind side, within this region of the Belet sand sea, Titan. 
This is a Cassini Radar image ( $300 \mathrm{~m}$ resolution) centered on $6.5^{\circ} \mathrm{S}, 251^{\circ} \mathrm{W}$, with winds interpreted to

363 blow SW-NE (L-R). Images and description are from Radebaugh et al. (2009).

On Mars, mapping of the duneforms observed by Mariner 9 and Viking orbiters, combined with

366 information about the surrounding surface topography and composition (including other potential

367 aeolian features), was used to determine the wind direction(s) that would yield the dune crestline

368 orientation(s), the wind and topography that would yield sand accumulation within that area and its

369 likely stability (i.e., was this a stable sink for sand, or a temporary repository), and possible sand sources

370 (Cutts and Smith, 1973; Greeley et al., 1992a; Thomas, 1981; 1982; Tsoar, 1979). For example, the large

371 number of transverse dunes observed within southern mid-latitudes and north polar region on Mars (vs.

372 longitudinal dunes), in Viking and Mariner images, implied that dune fields were forming within regions

373 of near unidirectional winds, and the asymmetry in dune field complexity between the north and south

374 hemisphere was seen as evidence of a more complex southern wind regime (Greeley et al., 1992a;

375 Thomas, 1981). After higher resolution images became available and atmospheric modeling became

376 more refined in technique and topography/boundary inputs, a more detailed comparison was done to

377 see if atmospheric models could reproduce the observed dune shapes and orientations. For example,

378 mesoscale modeling of dunes within Proctor Crater on Mars based on MOC NA images matched two

379 sets of dune slipface orientations (the primary and tertiary) to seasonal winds that were impacted by

380 daily and seasonal insolation patterns and the crater topography, as predicted by a mesoscale model

381 (Fenton et al., 2005; however, the secondary dune slipface orientation remained unexplained). This

382 study validated the mesoscale atmospheric model by providing a reasonable explanation for the range

383 of slipface orientations seen within that dune field, and thus advanced the use of these models within

384 model-observation comparison studies for understanding aeolian processes on Mars. 
386 be studied to identify sediment sources and sand transport pathways. In some areas, distinct sand 387 transport pathways leading from the sediment layer to the dune bodies have been revealed by the 388 detection of congruent material composition. For example, on Mars, local sediment sources for intra389 crater dunes have been proposed at impact crater walls by comparative analyses of high resolution 390 image and spectral data of dune bodies and the sediment layers exposed (e.g., Fenton, 2005; Geissler et 391 al., 2013; Silvestro et al., 2010a; Tirsch et al., 2011). Within the Valles Marineris rift system, spectral 392 analysis, morphological evidence of erosion and sand transport, and topographic information was used 393 to show that diverse and distinct sediment sources serve as local and regional sources (Chojnacki et al., 394 2014).

On Venus, analysis of dune morphology is almost impossible due to lack of data. Dunes in both 396 recognized dune fields are at the resolution limit of radar images obtained by Magellan mission (Figure 397 7), the only adequate data source. Therefore, results of attempted of detailed analysis are not reliable 398 and are controversial (Greeley et al., 1997; Lorenz, 2015). Modeling of anisotropic radar scattering 399 (Kreslavsky and Vdovichenko, 1999) indicated that the microdune fields proposed by Weitz et al. (1994) 400 possess abundant unresolved steep slipfaces.

401 


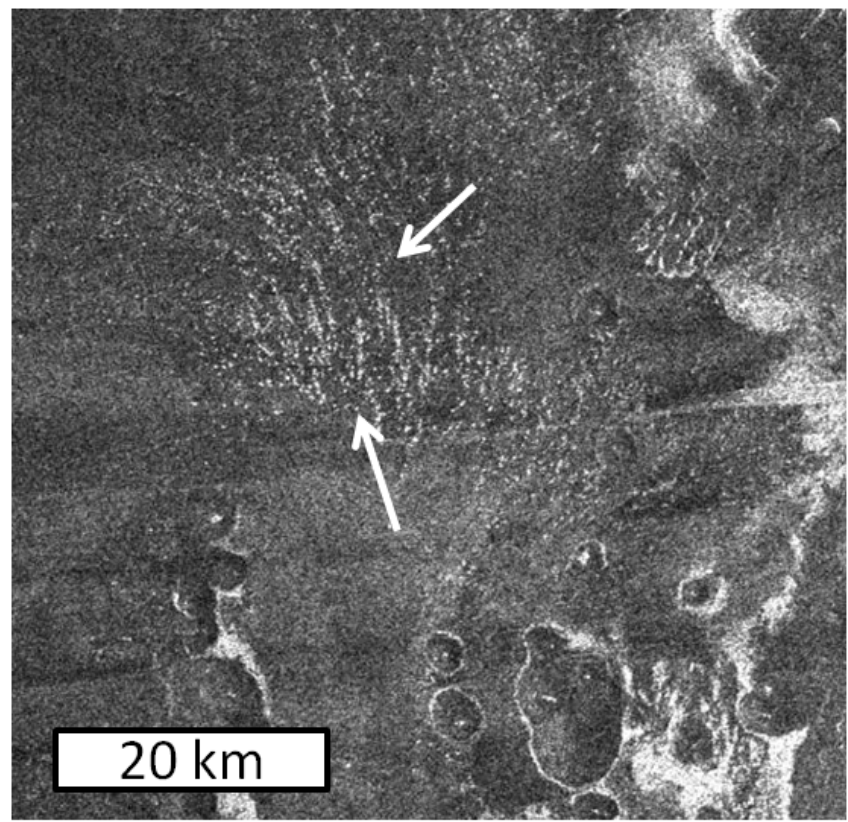

Figure 7: Venusian dune field. This Magellan SAR image of the Aglaonice dune field $\left(25^{\circ} \mathrm{S}, 340^{\circ} \mathrm{E}\right)$ shows

404 a field of white dots that are interpreted as specular reflections from the slopes of transverse dunes

405 (between the arrows). This type of reflection occurs if the slope is mostly smooth, and is oriented nearnormal to the incidence angle of the radar (which is $35^{\circ}$ or near the angle of repose); similar features are

407 observed within Seasat and space shuttle radar images of terrestrial sand dunes. The implied wind

408 direction of these features, based on their orientation, is also consistent with nearby bright and dark 409 wind streaks extending from behind cones (not included in this cropped image). Radar illumination is

410 from the left, and north is at the top. Image is from NASA Photojournal PIA00483, and description is from

411 Photojournal and Weitz et al. (1994).

In general, Phase 2-type investigations can continue for a long period with refinement of the

414 investigations as higher-resolution images of the dunes are acquired, more information becomes

415 available about the local topography and other evidence of aeolian processes and conditions, and/or

416 atmospheric or bedform formation models are improved. This investigation phase may eventually grade

417 into (and occur concurrently with) Phases 3 and 5 which involve, respectively, higher-resolution analysis 
418 of features within the dune field and features on the dunes formed by the dune-wind interaction (such

419 as ripple patterns on the dune slopes). Additionally, as new observations, models, and analysis methods

420 are developed, Phase 2 investigations can be renewed and revisited (as with all Phases beyond Phase 1).

421

422 Summary of Phase 2

423 Data needed: same as Phase 1.

424 Knowledge gain: Morphology of the potential crestlines and general dune shape; composition of the

425 dunes and surroundings; possibly identification of local sand sources.

426 Assumptions generated: Wind direction and consistency hypothesized to generate the observed shapes;

427 variations in wind speed implied by changes in sinuosity and shape through the dune field.

428 Questions: What sets the wind direction and causes its variations (e.g., daily or seasonal cycles)? Are

429 these representative of present-day wind conditions, conditions during a past period, or a convolution

430 of conditions during different past periods?

431 Lead to investigations of: Comparison over one to several dune fields with (global/mesoscale)

432 atmosphere models; reliably identify wind direction(s) consistent with the dunes' forms. 
Table 2: Recognition and first analysis of dunes and dune fields on planetary bodies (Phases 1-2), as presented in the literature

\begin{tabular}{|c|c|c|c|c|c|}
\hline $\begin{array}{l}\text { Planet. } \\
\text { body }\end{array}$ & $\begin{array}{l}\text { "Aeolian" } \\
\text { bedforms } \\
\text { first sighted }\end{array}$ & Data used & Immediate Implications & Immediate Questions & $\begin{array}{l}\text { Referenc } \\
\text { e }\end{array}$ \\
\hline \multirow[t]{4}{*}{ Mars } & \multirow[t]{2}{*}{$\begin{array}{l}\text { Mariner } 9, \\
\text { Hellespontu } \\
\text { s region of } \\
\text { Mars, dense } \\
\text { and large } \\
\text { transverse } \\
\text { dune field }\end{array}$} & $\begin{array}{l}\text { Visual image of } \\
\text { surface, }<1 \mathrm{~km} / \text { pixel }\end{array}$ & $\begin{array}{l}\text { Dune material is dark (so some low } \\
\text { albedo areas are regions of } \\
\text { deposition, not erosion; and some } \\
\text { dark material will saltate); Due to } \\
\text { the lower atmospheric density on } \\
\text { Mars, wind velocities may need to } \\
\text { be much higher to move sand. }\end{array}$ & $\begin{array}{l}\text { Which "dark splotch[s] or } \\
\text { streak[s]" are due to deposition of } \\
\text { material (vs. deflation of overlying bright } \\
\text { material)? What is the source of the dark } \\
\text { material? Does the wind reach transonic } \\
\text { velocities? Is high-velocity sand-blasting } \\
\text { resulting in highly-efficient wind erosion? }\end{array}$ & $\begin{array}{l}\text { Sagan et } \\
\text { al., } 1972\end{array}$ \\
\hline & & $\begin{array}{l}\text { above; comparisons } \\
\text { to other albedo } \\
\text { markings indicative } \\
\text { of wind direction }\end{array}$ & $\begin{array}{l}\text { Presence of lots of sand and } \\
\text { saltation processes; Dune material } \\
\text { accretion directions and influence } \\
\text { of topography (craters) on field } \\
\text { location and dune morphologies; } \\
\text { comparable scale and shapes as } \\
\text { terrestrial dunes }\end{array}$ & $\begin{array}{l}\text { What is the composition of the sand? Why } \\
\text { is it so dark? }\end{array}$ & $\begin{array}{l}\text { Cutts } \\
\text { and } \\
\text { Smith, } \\
1973\end{array}$ \\
\hline & \multirow{2}{*}{$\begin{array}{l}\text { Viking 2, } \\
\text { north polar } \\
\text { erg, } \\
\text { transverse } \\
\text { and barchan } \\
\text { dune fields }\end{array}$} & \multirow[t]{2}{*}{$\begin{array}{l}\text { Visual image of } \\
\text { surface, } 30-60 \\
\mathrm{~m} / \text { pixel }\end{array}$} & $\begin{array}{l}\text { Lots of sand } \rightarrow \text { some erosional } \\
\text { process; Variability in wind regime; } \\
\text { two wind directions in portions }\end{array}$ & $\begin{array}{l}\text { What is the composition and source of } \\
\text { sand? Why is it accumulated around north } \\
\text { polar cap? }\end{array}$ & $\begin{array}{l}\text { Cutts et } \\
\text { al., } 1976\end{array}$ \\
\hline & & & $\begin{array}{l}\text { Strong winds; Two wind directions, } \\
\text { thought to be seasonal; grains may } \\
\text { be eroded from the northern plains }\end{array}$ & $\begin{array}{l}\text { Are the dunes active, and how mature is } \\
\text { the dune field? Are the dunes modified } \\
\text { during the winter/early spring, when the } \\
\text { entire region is covered by } \mathrm{CO}_{2} \text { ice? }\end{array}$ & $\begin{array}{l}\text { Tsoar et } \\
\text { al., } 1979\end{array}$ \\
\hline Venus & $\begin{array}{l}\text { Magellan, } \\
\text { transverse } \\
\text { dunes, two } \\
\text { fields }\end{array}$ & $\begin{array}{l}\text { Radar images, } 75 \\
\mathrm{~m} / \text { pixel; compared } \\
\text { with orientation of } \\
\text { other aeolian } \\
\text { features in same } \\
\text { dataset }\end{array}$ & $\begin{array}{l}\text { Lots of sand in specific areas } \rightarrow \\
\text { some erosional process (perhaps } \\
\text { impacts?) }\end{array}$ & $\begin{array}{l}\text { What is the composition and source of the } \\
\text { sand? What are the saltation dynamics } \\
\text { under a much denser atmosphere? }\end{array}$ & $\begin{array}{l}\text { Greeley } \\
\text { et al., } \\
1992 b\end{array}$ \\
\hline Titan & $\begin{array}{l}\text { Cassini, } \\
\text { longitudinal } \\
\text { dunes, large }\end{array}$ & $\begin{array}{l}\text { Synthetic Aperture } \\
\text { Radar images, } 175 \\
\text { m/pixel }\end{array}$ & $\begin{array}{l}\text { Lots of sand } \rightarrow \text { some "grain" } \\
\text { formation process; one dominant } \\
\text { or at least two converging wind }\end{array}$ & $\begin{array}{l}\text { What is the composition and source of the } \\
\text { sand? What is the underlying topography, } \\
\text { causing accumulation in equatorial region }\end{array}$ & $\begin{array}{l}\text { Lorenz et } \\
\text { al., } 2006\end{array}$ \\
\hline
\end{tabular}




\begin{tabular}{|c|c|c|c|c|c|}
\hline & \multirow[t]{2}{*}{$\begin{array}{l}\text { field around } \\
\text { equator }\end{array}$} & & $\begin{array}{l}\text { directions throughout equatorial } \\
\text { region; pristine appearance and } \\
\text { superposition over geologic } \\
\text { features } \rightarrow \text { young and possibly } \\
\text { currently active }\end{array}$ & $\begin{array}{l}\text { and divertion of dunes? Is there any } \\
\text { connection with the potential fluvial } \\
\text { channels? Has the sand circumnavigated } \\
\text { the globe several times (implying a lack of } \\
\text { sand-sinks in the area)? }\end{array}$ & \\
\hline & & $\begin{array}{l}\text { Visual and Infrared } \\
\text { Mapping } \\
\text { Spectrometer } \\
\text { (VIMS) } \\
\text { observations, } 500 \\
\text { m/pixel }\end{array}$ & $\begin{array}{l}\text { Observations of interdunes } \rightarrow \\
\text { recent activity and overall dune } \\
\text { field maturity; spectral information } \\
\rightarrow \text { constraints on the composition } \\
\text { of the dunes and interdune } \\
\text { regions; photoclinometry yielded } \\
\text { height and wavelength estimates }\end{array}$ & $\begin{array}{l}\text { What information does the variability in } \\
\text { dune coverage and height, and in the } \\
\text { terrain that they cover, yield for the } \\
\text { evolution history and conditions for these } \\
\text { mature and recently active dunes? What } \\
\text { are the dune grains made of, given their } \\
\text { lower relative waterice content than } \\
\text { Titan's average? }\end{array}$ & $\begin{array}{l}\text { Barnes et } \\
\text { al., } 2008\end{array}$ \\
\hline $\begin{array}{l}\text { Comet } \\
67 \mathrm{P} / \mathrm{Chu} \\
\text { ryumov- } \\
\text { Gerasim } \\
\text { enko }\end{array}$ & $\begin{array}{l}\text { Rosetta, } \\
\text { moats, wind } \\
\text { tails, and } \\
\text { aeolian-like } \\
\text { ridges/rippl } \\
\text { es }\end{array}$ & $\begin{array}{l}\text { optical imagery: } \\
\text { OSIRIS orbiter } \\
\text { camera images } \\
(\geq 0.29 \mathrm{~m} / \mathrm{px}), \text { ROLIS } \\
\text { decent camera } \\
\text { images ( } \geq 1 \mathrm{~cm} / \mathrm{px} \text { ) }\end{array}$ & $\begin{array}{l}\text { "Sustained" granular transport } \\
\text { along the surface (so as to form } \\
\text { aeolian bedform-like features) } \\
\text { exists on a comet }\end{array}$ & $\begin{array}{l}\text { How does granular transport work on a } \\
\text { body without atmosphere? What is the } \\
\text { moving agens? Are these bedforms } \\
\text { accumulative or erosive? What is the } \\
\text { grainsize of the bedform materials? What } \\
\text { are the material sources? How long does it } \\
\text { take to form bedforms? }\end{array}$ & $\begin{array}{l}\text { Mottola } \\
\text { et al., } \\
2015 ; \\
\text { Thomas } \\
\text { et al., } \\
2015 a \text {; } \\
2015 b\end{array}$ \\
\hline
\end{tabular}




\subsection{Phase 3: Pattern analysis of the dunes within a field}

Dune field evolution is related to the evolution of its constituent dunes, but occurs on a larger spatial and temporal scale and involves areas of investigation that are different from (and can be largerthan) the sum of its parts. For example, as dunes evolve within a field they exchange sand between each other through both sand flux and collisions, and environmental boundary conditions such as the sand influx geometry can affect dune field pattern development (Diniega et al., 2010a; Ewing and Kocurek, 2010). As such, it is necessary to model dune field evolution as more than just a collection of individually evolving dunes, and to recognize that the large-scale dune field pattern can reflect conditions (and changes in those conditions) around and throughout the field. For example, sand and dune influx conditions will be different near the upwind margin of the dune field than near the terminus or lateral margins (Ewing and Kocurek, 2010) due to proximity to sand sources or other dunes, or changes in topography or "cementing" influences (e.g., chemical duricrust or, on the Earth, vegetation) within the field (Kocurek and Ewing, 2005) (Figure 6: examples of dune interactions with topography on Titan and Earth). Such changes can result in different dune sizes, spacing, or defect frequency (Diniega et al., 2010a; Ewing and Kocurek, 2010).

The effect of underlying topography is also a key parameter affecting dune characteristics at the dune field scale (Ewing and Kocurek, 2010). On Earth, bedrock topography has been linked to the effect of roughness variations induced by the dune field itself producing an internal boundary layer decreasing the shear stress downwind (Jerolmack et al., 2012) and/or to the feedback mechanism between longwavelength topography and the dunes (Pelletier, 2015). The role of topography in enhancing and deflecting regional winds has also been invoked to explain complex dune field pattern on Mars in Olympia Undae (Ewing et al., 2010) and complex dune arrangements in Moreux (Cardinale et al., 2012) and Matara crater (Diniega et al., 2010b; Silvestro et al., 2012). However, it was only thanks to the availability of high resolution DTMs from the HiRISE instrument that the effect of underlying topography 
could be more precisely linked to different dune characteristics such as migration rates, dune heights

458 and density (Cardinale et al., 2016, Vaz et al., submitted). In particular, in Herschel crater dune density, 459 slip face advancements and migration rates are all controlled by two major topographic highs on the 460 crater floor (Vaz et al., submitted).

The dune field may also record changes in conditions over a longer-timescale than that recorded 462 within any individual dune. Multiple patterns (e.g., different types of dunes) can be superimposed 463 (creating a complex, versus a simple, dune field) as smaller dunes migrate and change in response to the 464 new environment faster than larger dunes (Ewing and Kocurek, 2010; Hugenholtz and Barchyn, 2010; 465 Kocurek and Ewing, 2005). We note that this possible complexity within dune fields can complicate 466 analysis of the dune morphology (Phase 2). For example, even identification of the dominant (or most 467 recent?) slipface orientations can be non-trivial. This is especially true within planetary dune fields 468 where datasets may be limited to remote images, so dune slope angles and potential activity have to be 469 interpreted from images of the dunes' planform appearance, possibly under suboptimal illumination 470 conditions for this type of image analysis. For example, within the north polar erg on Mars, many dunes 471 contain slipfaces pointing in opposite directions (sometimes on the same dune). One interpretation is 472 that some of these fields may contain both active and fossil dunes (Gardin et al., 2012). Within the Mars 473 southern mid-latitudes, at least two periods of dune-building (or dune-building occurring over 2 474 different timescales) are apparent as within the same field one can often find a dense collection of 475 transverse dunes (with slipface towards the east) and then barchans clearly climbing up and over the 476 transverse dunes on the east side (with slipfaces towards the west) (Figure 8; Diniega et al., 2010b). 


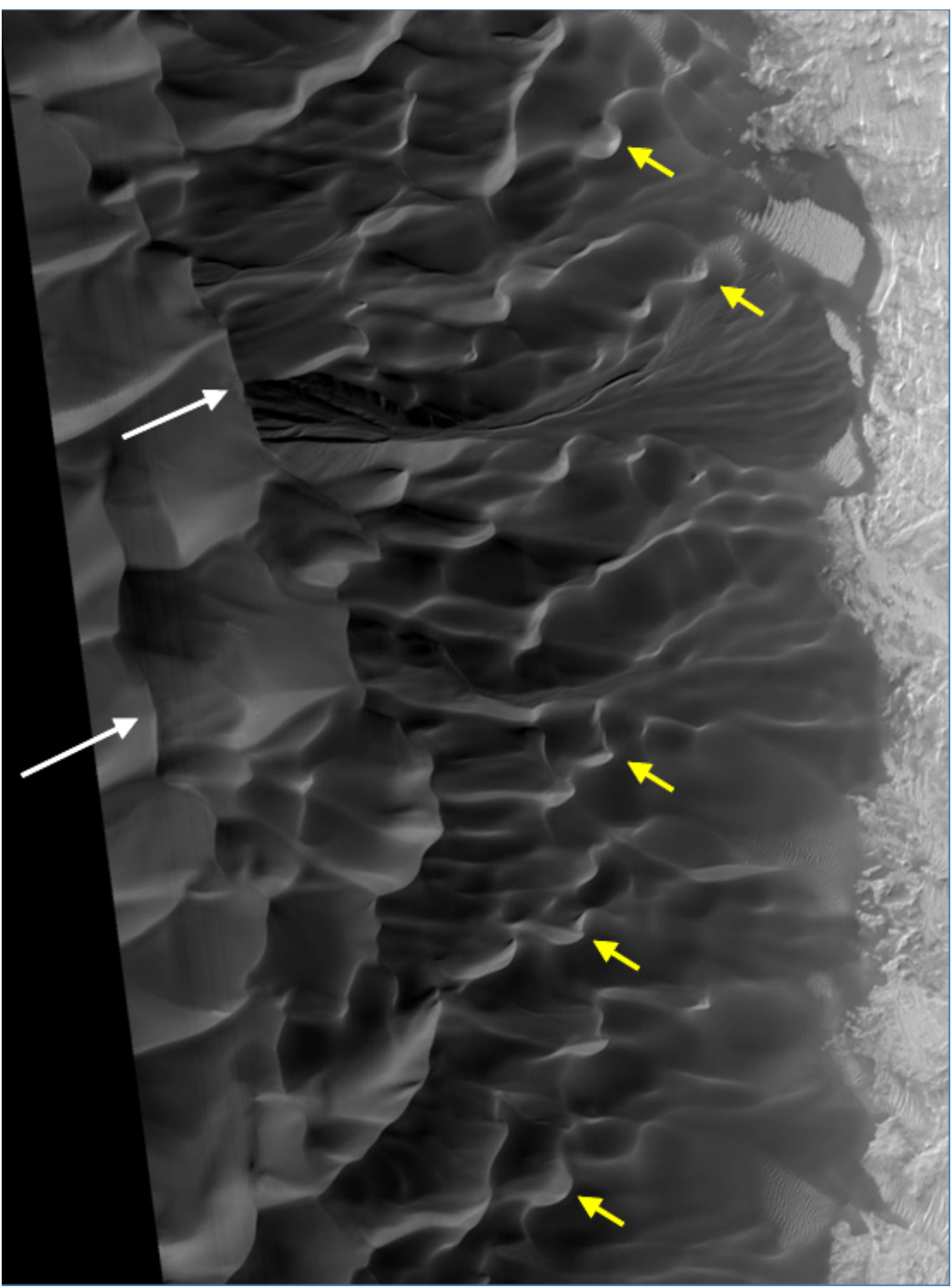

Figure 8: The complex dune patterns found in along the eastern edge of Matara dune field, Mars

$480\left(49.5^{\circ} \mathrm{S}, 34.8^{\circ} \mathrm{E}\right)$. This dune field, like many others in the Mars southern mid-latitudes, is a dense

481 transverse dune field, captured within a crater. The transverse dune crestlines are oriented north-south

482 with the clearest slipfaces towards the east (white arrows extend up the possible stoss slope, towards the

483 dune brink). However, along the eastern side of this field, many smaller dunes (mostly barchans - yellow

484 arrows, some possible transverse crestlines near the bottom of the image) are oriented with towards the

485 northwest. This potentially reflects two periods (or just two timescales?) of dune evolution, with a 
change in the dominant wind direction. North is up and illumination is from the left. Image is a portion of

A lack of variations can also yield information about the field's and planetary body's history. On

Titan, dune width and spacing measurements over more than 7000 linear dunes showed a high level of

491 uniformity around the moon, with no signs of compound or complex dunes (Savage et al., 2014). This,

492 coupled with the dunes' large sizes, indicates that Titan's dunes are mature features that have evolved

493 within consistent and stable environmental conditions for a long period of time.

\section{Summary of (3)}

496 Data needed: Observations of dunes fields, of sufficient spatial coverage and resolution to note changes

497 in dune patterns throughout the field, especially in tracing crestlines; possibly need knowledge of

498 topography.

499 Knowledge gain: The dune field pattern and shape; maturity state (and possibly relative age) of the

500 bedforms; possible temporal changes in e.g., sediment supply and wind patterns

501 Assumptions generated: Changes in the environmental conditions, in space or time.

502 Questions: For a given dune field, is sand sourced from one or several locations? Is the dune evolving

503 through one dominant wind pattern, or several? Have the dominant effects (sand source or wind

504 pattern) changed over the lifetime of the dune field?

505 Lead to investigations of: Explore influences on dune shapes beyond current dominant winds (Phase 2)

506 - such as the location of sand source(s) or of sand-starved regions of the field, a transition between

507 wind regimes, interactions between dunes (such as dune collisions), or other environmental

508 influences/processes.

509 


\subsection{Phase 4: Regional and global surveys and aggregate-analysis of dune characteristics}

As we gather information about dunes in more and more different dune fields around a planetary body, it becomes possible to aggregate data to deal with high-level, large timescale questions about aeolian processes and sediment supply, such as "How much sand is available in total?" and "Are there primary types/locations of sediment sources that can yield information about how that sand has been created, how it is transported, and whether it has been recycled?" Addressing such big-picture questions can provide important information for investigations of grain-producing processes (e.g., surface erosion) and planetary surface history over the lifetime of the involved sand grains. Note that while studies of grain history and sediment transport pathways involving terrestrial dunes may rely on detailed petrographic and heavy-mineral techniques, with geochronology (e.g., Garzanti et al., 2013), studies of planetary bodies often are based only on surface topography and, possibly, coarse compositional information.

For example, on Mars, a near-global map of sediment deposits (including dunes) and wind streaks to generate early estimates of sediment transport pathways/source regions (Thomas, 1982). An early global map of aeolian features showed variations in time and space in the large-scale wind directions recorded by the orientation of dunes, wind streaks, yardangs, wind grooves, and deflation pits (Ward et al., 1985). Such studies have since been updated with increased coverage and image resolution (e.g., Hayward et al., 2007; 2014), and still provide important information about direction and variability in the wind patterns (down to intra-field scales), the influence of topography and local geology on windflow and bedform development, and likely sediment sources for the observed deposits. At a regional scale, the martian north polar erg volume has been estimated as $\sim 1130-3250 \mathrm{~km}^{3}$ of dark sand (Greeley et al., 1992a; Hayward, 2011), which is significant as the icy layers of the north polar cap has been proposed as the source of the circumpolar dune fields (Byrne and Murray, 2002; Tanaka et al, 2008).

These deposits appear composed of recycled aeolian sediments, which were likely transported poleward 
and deposited (Breed et al., 1979; Byrne and Murray, 2002). This suggests that a huge volume of sand

535 may have formed on Mars during an earlier epoch and that these sand grains have survived at least a couple of sustained dune-forming periods.

The Titan dune fields provide an example of how analysis of the distribution of dune field

538 locations (on the planetary body, or relative position within regional topography) and morphologies (i.e., 539 field outline or crestline patterns) can yield additional information about larger-scale atmospheric and 540 topographic/surface conditions. Mapping of 16,000 Titan dune segments (covering $8 \%$ of Titan's surface 541 which suggested that dunes cover a total of $20 \%$ of the global surface: Lorenz and Radebaugh, 2009) 542 showed general dune field orientation and spacing patterns and confirmed that these features are 543 within a global field with few longitudinal trends, but with latitudinal trends in orientation and limited to 544 within $30^{\circ}$ of Titan's equator. Although dunes on Titan are organized into several separate sand seas 545 across the equator, all have some level of broad interconnectedness (Le Gall et al. 2012; Radebaugh 546 2013; Savage et al. 2014). As such, studies of the Titan sand sources, sediment transport pathways, and 547 deposition patterns are best analyzed from a "global" perspective.

548 Titan sands may be derived directly from the atmosphere, perhaps through clumping on the 549 surface, though it is perhaps more likely the sand has been processed through erosion of organic 550 sedimentary layers (Radebaugh 2013), possibly close to the equator where fluvial channels have been 551 imaged (Burr et al., 2013; Lorenz et al., 2008; Radebaugh et al., 2016). Other possible sources include erosion of the SAR-uniform mid-latitudes, a possible sedimentary deposit (Malaska et al., 2016), and the 553 northern dry lakebed evaporite deposits, which have similar spectral characteristics to the VIMS 554 instrument (Barnes et al., 2015). Once the materials are transported into the Titan sand seas, they are 555 incoporated into the giant linear dunes, and either stay confined to one sand seaor contribute to a 556 global system of west-to-east sediment transport that persists over time (Savage et al., 2014).

557 Topography appears to play an important role, as it does for sand seas on Earth, in that it can help 
confine the sands to certain regions or preclude them from others, like from the rugged Xanadu region

559 (Lorenz et al., 2006; Radebaugh et al., 2011). Decreases in dune density within radar-bright and elevated regions may provide regional-scale constraints on Titan's winds for atmospheric models (Lucas et al.,

561 2014). Furthermore, topographic obstacles can cause diversion of dunes and dune/topography

562 relationships and perhaps reveal longer-term climatic changes (Ewing et al. 2015).

564 area or more numerous measurements to reflect larger-scale temporal or spatial trends. For example,

565 dune fields on Mars appear very young as they lack craters, but constraints on their age had large

566 uncertainties due to their low individual areal coverage. Adding the dune fields together allowed for a

567 more robust estimated crater-retention age of $<10000$ years (Fenton and Hayward, 2010). These dune

568 fields also exhibit latitude-dependent morphological trends in crestline sharpness/pattern, dune slopes,

569 and field shapes, so considering the dunes over the hemisphere enables studies of influence from polar

570 as well as aeolian processes (Fenton and Hayward, 2010). Another study of southern intracrater dune

571 fields on Mars compared dune field centroid locations, relative to the crater center, with mesoscale

572 atmospheric modeling to look at broad-scale atmospheric trends (over a much longer time period than

573 that recorded in dune slipface orientations within an individual dune field) (Hayward et al., 2009).

Although only two dune fields and a few microdune fields were identified with some certainty in

575 the whole set of Magellan radar images of Venus, a few lines of indirect evidence suggest that

576 unresolved small-scale anisotropic topographic features are ubiquitous; such features have been

577 interpreted as unresolved gently sloping aeolian bedforms (Kreslavsky and Vdovichenko, 1999;

578 Bondarenko et al., 2006). A comprehensive global inventory of aeolian bedforms on Venus will require

579 global imaging data set(s) of a higher resolution than presently exists. 
582 to identify large deposits of unconsolidated, granular material. On Mars, further evidence that these

583 dark patches with high-thermal inertia were aeolian deposits were that these were found downwind of

584 topographic depressions (Christensen, 1983; Mellon et al., 2000). Thus global maps of thermal inertia

585 with resolution $\sim 100 \mathrm{~m} /$ pixel have been used to map dune fields around Mars and estimate the number

586 of dune fields and their surface areal extent (Christensen et al., 2003; Hayward et al., 2007; Hayward,

587 2011).

588

\section{Summary of (4)}

590 Data needed: Identification of dunes around globe (from the data used in Phases 1-3, and possibly from

591 proxy data such as thermal inertia).

592 Knowledge gain: Dune field location and (possibly) morphology/type distributions; variations in location

593 and morphology related to sediment supply, climate history, and/or and other active processes (e.g.,

594 related to latitude, regional topography); identification of large-scale sediment transport pathways

595 (larger-scale than field-specific results of Phase 2 and 3; and possibly first produced earlier based on

596 low-resolution, but high-coverage datasets) based on (global/mesoscale) atmospheric models and

597 observation of sediment sources.

598 Assumptions generated: Correlations between dunes and proxy data; feasibility of extrapolation from

599 studies of individual dune fields/sand sources to a global model.

600 Questions: How much sand is there, where is it from/stored, and how did it get there? Over what spatial

601 and temporal scale is the sand being transported (i.e., what is the lifetime of a sand grain and is

602 sand/bedforms being recycled)?

603 Lead to investigations of: Age estimation of dune fields (as can aggregate together land-areas to

604 statistical significance; likely to be a relative or crater-retention age); identification/investigation of 


\subsection{Phase 5: Analysis of superposed bedforms on the dune formed due to wind interaction with the}

609 dune

Ripples, like dunes, form spontaneously within sand beds due to wind (or fluid) flow and record

611 wind and sediment conditions through their period of formation and evolution. However, as these are

612 much smaller features, they record conditions over smaller temporal and spatial scales and thus can be

613 reflective of a different set of environmental conditions than dunes. To-date, ripple-like features have

614 been only observed on Mars, where HiRISE images of the martian surface have resolution as fine as 0.25

$615 \mathrm{~m} /$ pixel (McEwen et al., 2007). These features have wavelengths of 1-to-a-few meters, have been found

616 within sandy regions including on the slopes of dunes, and have been individually mapped and

617 monitored for movement (Phase 6) (Figure 9; Bridges et al., 2012; Silvestro et al., 2011). The study of

618 ripple morphologies and dynamics on Mars yields information about the wind flow over the dunes,

619 under the influence of the local wind patterns as well as the dune topography. This yields information

620 about the recent, local wind regime within several areas on Mars (Bridges et al., 2012b). Such

621 information about the temporally and spatially small-scale surface wind dynamics can be compared with

622 meso and microscale climatic models and in-situ wind measurements (e.g., Jackson et al., 2015; Silvestro

623 et al., 2013). In addition, because ripple morphology and migration rates are controlled by the

624 topographic and wind flow boundary conditions imposed by the dune morphology (Kocurek and Ewing,

625 2012), studies of the ripples' form and variation provide insights to the underlying dune's evolution

626 (Ewing et al., 2010; Vaz et al., submitted).

Ripple mapping and monitoring have been an important tool within recent martian studies,

628 where the crestline orientations and migration rates and directions of the large martian ripples are 
629

630

631

632

633

634

635

636

637

638

639

640

641

642

643

644

645

646

647

648

649

650

651

commonly used to reconstruct the wind regime over the dunes and to estimate sand fluxes (Ayoub et al., 2014; Bridges et al., 2012a; 2012b; Cardinale et al., 2016; Silvestro et al., 2010b, 2011, 2013).

Automatic approaches have been developed to derive ripple trend and migration rates, enabling highresolution wind regime estimations and sand flux measurements to be computed over large areas

(Ayoub et al., 2014; Bridges et al., 2012a; 2012b; Silvestro et al., 2011; Vaz and Silvestro, 2014).

However, all of these studies have assumed that that the observed "smaller" bedforms on the dunes are analogous to terrestrial sand ripples, and that ripple trends and migrations are normal to the last wind of sufficient strength to move sand, as is typically the case for aeolian ripples on Earth. Recent work has drawn those assumptions into question:

- Most ripple patterns on Mars are dominated by sinuous crestlines (Vaz et al., submitted), while on Earth ripple crestlines are typically straight (Rubin, 2012) (Figure 9). In some areas, ripple patterns observed on Mars show complex arrangements with two crestlines intersecting at right angles (Figure 10; Silvestro et al., 2011, 2013). This suggests that some of the ripples on Mars might not be in equilibrium with the last sand-moving winds or that the two sets of crestlines are contemporaneous, but oblique to the formative winds (Silvestro et al., 2016).

- Additionally, unusual longitudinal displacement of crest-line defect terminations and oblique crest migrations have been observed within orbital data in Gale and Herschel crater, suggesting that the large ripples of Mars are different from terrestrial impact ripples (Silvestro et al., in press; Vaz et al., submitted). This hypothesis is in agreement with recent in situ observations from the NASA MSL Curiosity rover, which shows that large ripples have sinuous and sharp crests and slip faces with evident grainfall and grainflow structures (Bridges et al., 2016; Lapotre et al., 2016a) (Figure 10) that are not common within terrestrial impact ripples. Superposing these large bedforms are smaller "terrestrial-like" impact ripples of $\sim 10 \mathrm{~cm}$ in wavelength (Bridges et al., 2016; Lapotre et al., 2016a). 
These observations suggest that terrestrial aeolian impact ripples might not be good analogs for

653 the Martian large ripples (Lapotre et al., 2016a; Silvestro et al., 2016; Vaz et al., submitted). As this gets

654 worked out, previous studies will need to be carefully reviewed, such as where the interpretation has

655 been that a multidirectional wind regime exists, perhaps triggered by the local dune topography or by

656 larger topographic features (e.g., Jackson et al., 2015; Silvestro et al., 2011). Also, the presence of such

657 large ripples on the dune's stoss side and their migration across the slipface (Figures 9-10) may alter the

658 wind profile above the dune and the slipface dynamics, beyond the way that these processes are

659 typically captured in dune evolution models applied to terrestrial dunes and their ripples (e.g., Ewing et

660 al., 2016). Increased coverage of high-resolution images coupled with in-situ observations by rovers are

661 necessary to progress understanding of the nature and dynamic of the martian large ripples. This is

662 fundamental for understanding how these ripples can be used to constrain local wind directions and to 663 tune sand flux estimations over the dunes.

664

\section{Summary of (5)}

666 Data needed: Higher-resolution images of dune field, reflecting variation over the dune, including in

667 composition or granulometrics; mapping and analysis of second-order and higher-order bedforms (e.g.,

668 ripples) and how these reflect the wind pattern around the dune.

669 Knowledge gain: Measurements of ripple movement and characteristics over the dune.

670 Assumptions generated: Use of the right analog features/models for interpretation of the smaller-scale

671 features.

672 Questions: What is the local sand flux and wind patterns over the dunes (as reflected in ripple

673 movement)? Are grains sorted within the ripples, and if so, why? Is ripple movement coupled

674 with/connected with current dune evolution, or e.g. does ripple movement reflect a surficial mobile

675 layer of sand over a relict dune core? 
677 of local source regions.

678
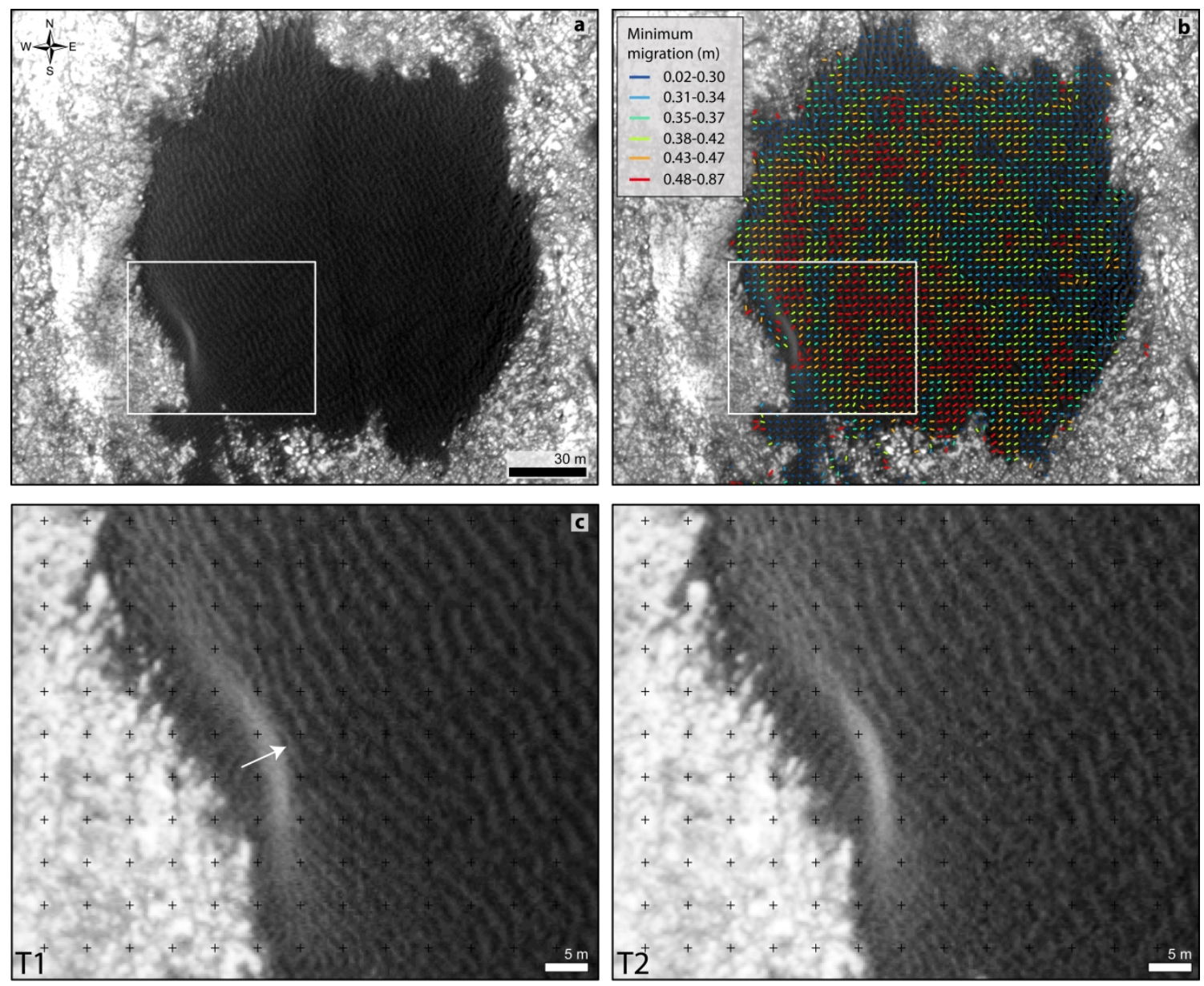

680 Figure 9. Observed ripple movement on Mars. Images show (a) a rippled dome dune in the Bagnold

dune field, Gale Crater, with (b) ripple migration over the dune stoss side between Mars years 28 (2006)

and 29 (2008) (Silvestro et al., 2013). (c: T1-T2) The zoom-in shows one ripple (white arrow) moving over

683 the dune brink, reflecting grain transport onto the slipface and suggesting that dune migration may also

684 be occurring. HiRISE images shown: (a,c/T1) PSP_001488_1750 (taken 20 November 2006), (c/T2) 

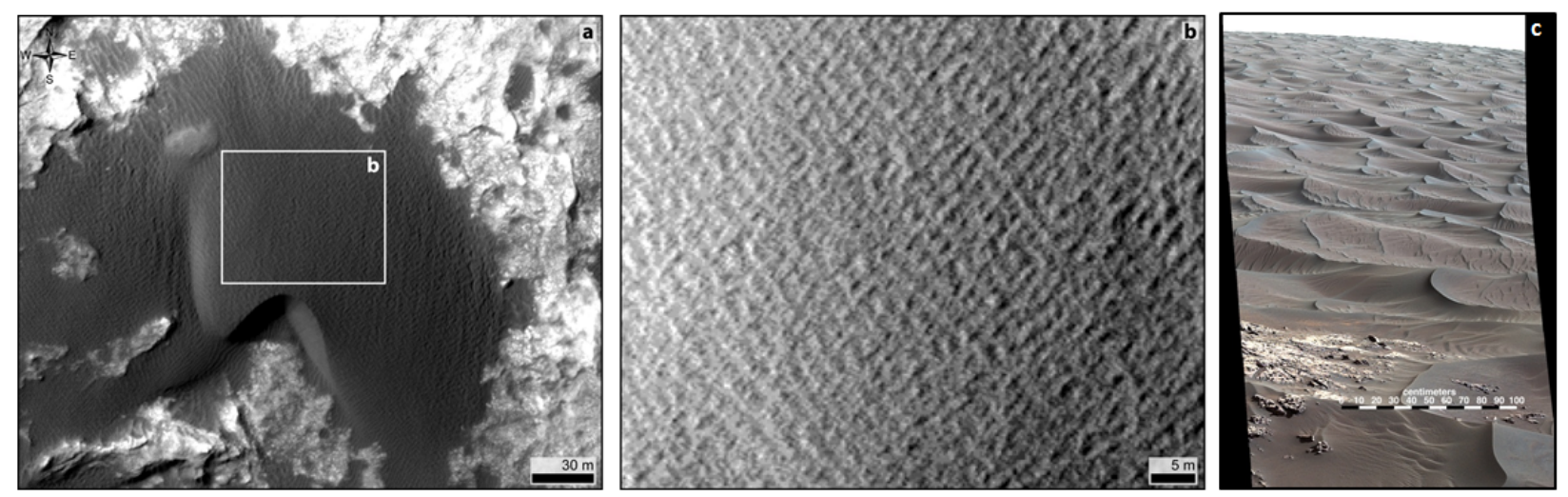

Figure 10. Ripple morphology on Mars. (a-b) HiRISE images of High Dune, an active dune within the

Bagnold dune field, Gale Crater, that has also been investigated by MSL Curiosity (Bridges et al., 2016;

Lapotre et al., 2016a). Visible in these orbital images is a complex ripple pattern on High dune's stoss

slope, with what appears to be two sets of large ripples intersecting at right angles (Silvestro et al.,

2016). This ripple configuration is typical of the Bagnold dunes and seems to be common on Mars. HiRISE images are: (a) ESP_042682_1755, (b) PSP_009294_1750. (MRO/NASA/UA) (c) This image of the High

Dune stoss slope was taken by the Mast Camera on Curiosity, showing the complex morphology of these large ripples, which in this closer-inspection perhaps do not appear analogous to terrestrial sand ripples.

The scalebar (one meter length) is for the lower portion of this cropped image. Image is from NASA Photojournal PIA20168.

\subsection{Phase 6: Observation of dune activity (aeolian or otherwise)}


suggested that some aeolian bedforms should be active. However climate models did not produce the wind velocities predicted for saltation processes to occur under present conditions and no bedform motion was observed within higher-resolution images (although some dome dunes were seen to disappear (Bourke et al., 2008)). This was taken to imply that martian dunes may be stabilized (e.g., Zimbelman, 2000) and possibly relict features of a past climate with a denser atmosphere (e.g., Breed et al., 1979), and that surface degradation processes must be slow. However, acquisition of a sufficient temporal baseline and careful comparison of overlapping high-resolution images now yield measurable and consistent changes in dune margin and ripple crestline locations through several fields (e.g., Endeavor Crater: Chojnacki et al., 2015), and show that sand fluxes on Mars are comparable to sand fluxes in the Antarctic Dry Valleys (Bridges et al., 2012b). Within Endeavor Crater, these martian sand fluxes are sufficient for dune turnover times to be much less than the time since known large climatic shifts (e.g., an obliquity shift or increased atmosphere density), implying that these dunes are not records of paleo-climate conditions (Chojnacki et al., 2015).

These new observations, proving that sand is currently moving on Mars in large volumes and that at least some aeolian bedforms are presently active, were helpful in the advance of sediment flux models and understanding how sediment flux dynamics may vary on different planetary bodies. For example, an update to the model of steady state saltation (Kok and Renno, 2009) and application to Earth and Mars conditions (Kok, 2010) showed that saltation can be maintained on Mars by wind speeds an order of magnitude less than that required to initiate it, while nearly the same wind speed is needed to both initiate and maintain saltation on Earth. This provides a viable explanation for why aeolian bedforms appear to evolve at lower-than-predicted wind velocities (as well as an explanation for the smaller-than-expected minimum dune size on Mars: Kok, 2010). Estimates of aeolian sand flux (in the present or past) are important as they feed into models of surface erosion rates (e.g., Golombek et al., 2006; 2014). 
Sand dunes on Mars are also subject to other processes in the present-day. For example, alcove-

731 apron and alcove-channel-apron (i.e., gully) formation has been observed in southern mid-latitude dune

732 fields (Figure 8; Diniega et al., 2010b; Dundas et al., 2012; 2015) and similar activity has been observed

733 in the north polar dune fields (Hansen et al., 2011; 2015; Horgan and Bell, 2012), moving large volumes

734 of sand downslope and possibly contributing to the overall migration of the dunes. Some have proposed

735 that this activity may have aeolian drivers (Horgan and Bell, 2012; Treiman, 2003), but most studies have

736 shown a seasonal control on the timing of feature formation and evolution, possibly related to $\mathrm{CO}_{2}$ frost

737 processes (Diniega et al., 2010b; Dundas et al., 2012; 2015; Hansen et al., 2011). It is also possible that

738 both aeolian and seasonal frost processes have an influence on these types of dune modification

739 activities (Hansen et al., 2015). Regardless of underlying process, these changes are actively modifying

740 the dune slopes (Allen et al., 2016; Diniega et al., 2016; Hansen et al., 2011) and thus need to be

741 investigated and explained to form a complete story for the martian dune evolution and accurate

742 interpretation of observed dune morphology.

It is also important to note that some dunes have features indicative of a lack of activity, such as

744 fissures on north polar dunes (Portyankina et al., 2012) and pits and softened topography on southern

745 mid-latitude dunes (Fenton and Hayward, 2010). Such evidence for stability can provide constraints on

746 the current availability of mobile material and the near-surface wind environment, as well as a contrast

747 with the conditions when the (now inactive) bedform had evolved.

748

749 Summary of (6)

750 Data needed: Repeat images of sufficient spatial and temporal resolution to detect (and measure)

751 changes in surface morphology (or lack thereof).

752 Knowledge gain: Observation and constraints on the estimated (average/net) amount of of sediment

753 transport. 

and conditions.

Questions: What other processes are contributing to dune evolution? How much sediment is moving

climate?

Lead to investigations of: How the estimated sediment transport may affect surface erosion rates

(including formation of sand) and formation of other aeolian features such as yardangs; How the climate

has shifted, if changes in sediment transport are apparent.

\subsection{Phase 7: Groundtruth measurements}

To-date, we have only visited - at ground-level and up-close - dunes on one planet other than the Earth. While various Mars rovers have in situ imaged sand deposits and ripples (e.g., Greeley et al., 2006; JPL, 2012; 2014; Sullivan et al., 2005), Curiosity's visit to Bagnold Dune Field is the first in situ observation of dunes and dune sand (JPL, 2015; Bridges et al., 2016). This rover has examined dune sand on several different slopes on and around dune thought to be undergoing different levels of aeolian activity (based on orbital observations of ripple migration and the strength of spectral signatures of dust

771 slope and imaged on the lee slope; Figure 11), grain size differences have been noted that are perhaps

772 correlated with differences in grain composition (as grains of different sizes appear to correspond to

773 different materials) (Achilles et al., 2016; Cousin et al., 2016; Ehlmann et al., 2016). Images of the lee

774 slope of the more active "High dune" have yielded many grainflow features and potentially evidence of

775 some level of induration (Figure 12; Ewing et al., 2016) - none of which were visible in the orbital

776 images. The first results of this work are currently being put together, and we look forward to learning

777 more about the first in situ investigated extraterrestrial dunes. 


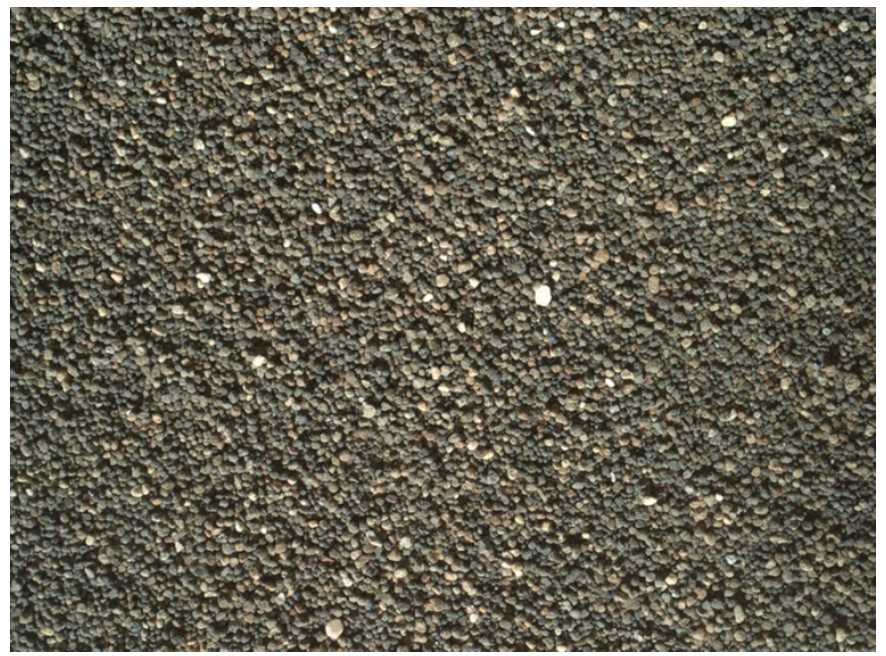

780 Figure 11. Image of the undisturbed surface within the base a Martian sand dune called "High Dune"

781 visited by NASA's Curiosity rover. The image covers an area 3.6 by 2.7 centimeters. Grain sizes show

782 some range, but a fairly consistent size - comparable to dune sand on Earth. It was taken by the Mars

783 Hand Lens Imager (MAHLI) camera on the Curiosity rover's arm on Dec. 5, 2015. Image and description

784 are from JPL (2015). 


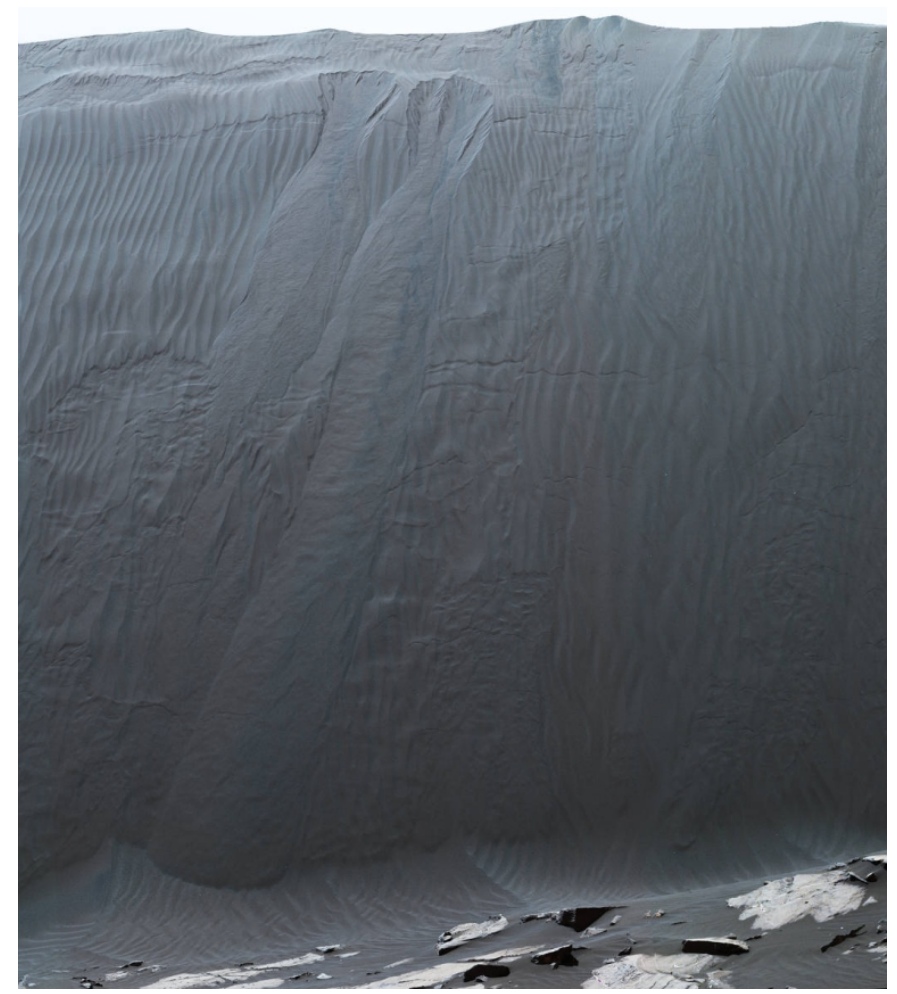

787 Figure 12: An active dune slipface on Mars, imaged by NASA's Curiosity Mars rover. Multiple grain 788 flows, slumps, and ripples are visible on the slipface of "Namib Dune," a dune within the "Bagnold 789 Dunes" field along the northwestern flank of Mount Sharp, Gale Crater. None of these fine details are 790 visible from orbital (HiRISE) images. The overall slope is $26-28^{\circ}$, and $4-5 \mathrm{~m}$ in height. This view combines 791 multiple images from the telephoto-lens camera of the Mast Camera (Mastcam), taken on Dec. $21,2015$.

792 The scene is presented with a color adjustment that approximates white balancing, to resemble how the 793 sand would appear under daytime lighting conditions on Earth. Image and description are from NASA 794 Photojournal PIA20283.

796 Summary of (7)

797 Data needed: In situ observations of the dune and dune sand (possibly from different portions of the 798 dune); possibly observations of saltation on the dune or grainflow on the slipface. 799 Knowledge gain: Size, composition, and other characteristics of grains involved in saltation. 
Assumptions generated: That the observed characteristics and activity are not anomalous, in time and space (i.e., the observation didn't catch a rare circumstance/event).

Questions: Why do the grains look as they do, and what causes the variation/distribution in grain size?

How representative is this observed dune's characteristics and activity? What causes the dune's

804 features? How can observations of sediment grain size and bedform morphology provide insight

regarding transport processes and the nature/frequency of mobilization events?

Lead to investigations of: Models of dune activity and evolution, and generation of the observed sand

grains (extending or perhaps redirecting previous work); Based on in situ observation of features that

808

may not be visible from orbit, what is implied about dune activity and characteristics and how does

information that feed back into models of dune evolution (and what assumptions and related results

810 should be re-evaluated).

\section{Discussion}

There are some differences between the aeolian science investigations undertaken on each

814 planetary body - in particular as study methods of more recently studied bodies can build from lessons

815 learned in aeolian bedform studies of a previously observed body, and as overall our understanding of

816 aeolian processes becomes more refined as models are forced to reconcile with a wider range of

817 environmental and planetary conditions. But, as has been described, studies of aeolian bedforms on

818 planets (other than Earth) broadly tend to follow a similar pattern of gained knowledge, generated

819 assumptions, and follow-up investigations (that rely on the new knowledge and assumptions). The

820 similarities in the history of aeolian science over different planetary bodies (Figure 13) are due partially

821 to the knowledge-advancement at each body being based on the same types of data. Such data is

822 usually acquired in the same order, which is based on the way in which higher-resolution and increased 
coverage are acquired during extended or subsequent missions, and as concepts and investigations mature and become more specific within all areas of planetary exploration.

826 body. We then move beyond planetary aeolian studies, to look at the interplay of planetary aeolian

827 bedform studies with investigative fields that follow their own sequences of discovery and refinement: aeolian process modeling and terrestrial aeolian studies.
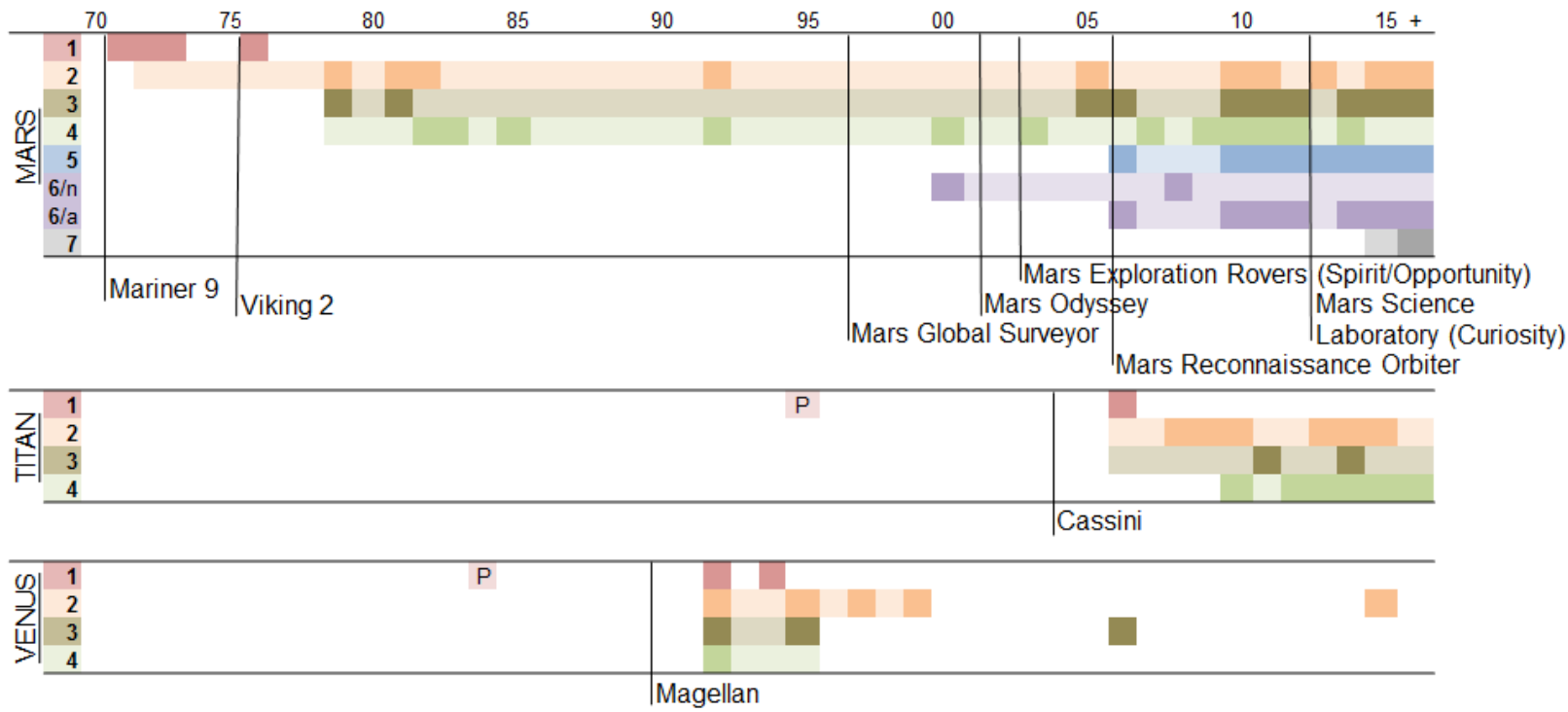

Figure 13. Timelines showing movement into and through different investigation phases, for Mars,

832 Titan, and Venus. Darker colors indicate publication dates for relevant studies (as referenced within this 833 paper), and lighter colors indicate the general period of activity (again, based references within this 834 paper and checked against google.scholar search results with keywords e.g., "Venus dunes"). Under 835 Mars, Phase 6 is divided into observations of "no dune activity due to aeolian bedform processes" (6/n) and of such activity (6/a). Within Phase 1 for Titan and Venus, publications predicting a limit on aeolian

837 bedform formation on those bodies are highlighted with a $P$ - and the first observation of a bedform 838 occurs later. Arrival dates of relevant spacecraft, to the planetary body, are included - for obvious reasons, these often initiate or re-invigorate investigations begun during a previous mission. 


\subsection{Gaps that can form within the planetary aeolian science sequence of investigations}

Over time and as more data is acquired, our understanding of aeolian processes and

843 interpretation of the aeolian landforms builds. However, as that understanding builds, it is important to

844 keep track of which building blocks are assumptions and not actual observations. It is necessary for

845 assumptions to be made to keep the science investigations moving forward and to guide development

846 of the next set of investigations, but an assumption that is treated like an "observation" can lead to

847 models with unrecognized limitations, which in turn can lead to incorrect interpretations of new

848 observations or even a lack of attention paid to "contradictory" observations. Thus, assumptions should

849 be recognized as such (and not treated as data) and be re-evaluated for consistency with new and

850 different data, until direct measurement of the assumed variable or process is possible - doing this can

851 make it easier to identify and investigate intriguing new understandings about processes and conditions.

852 Several examples of areas where new information has supplanted previous assumptions have

853 been mentioned within the discussion of the investigation phases (Subsections 2.1-7). Some additional

854 examples:

855 - As higher-resolution and more detailed studies are completed about specific dune fields, results of

856 these studies (Phases 5-7) should be inserted into field (Phases $2 \&$ 3) and global studies (Phase 4)

857 that previously relied on lower-resolution or less complete data and assumptions about form and

858 process uniformity (in time and space) through the field. As was discussed under Phase 7, the

859 martian large ripples are a new example of this -- where in situ observations are drawing into

860 question previous work done regarding the scaling of aeolian bedform size between Earth and Mars

861 and interpretations of ripple crestline complexity, that had been based on interpretation of orbital

862 images. In general, as more detailed studies are conducted over specific martian dune fields, it is

863 important to regularly consider how those results fit within the results of larger-scale studies. 
- These observations have also led into a model of a potential new mode of subaerial bedform migration and evolution (Lapotre et al., 2016a). As discussed in Phase 5, on the stoss slope of Namib dune, two types of ripples have been imaged: The large ripples (few m-wavelength) were previously observed in orbital images, and were through to be analogous to the wind ripples that we see on the slopes of terrestrial dunes (e.g., Sullivan et al. 2008). However these large ripples have very different morphology and dynamics (Silvestro et al., 2016) and in fact are superimposed by small ripples ( 10s cm wavelength) that have morphology more similar to terrestrial impact ripples (but were not visible within orbital images; Figure 10). The large ripples are now hypothesized to be fluiddrag ripples (Bagnold, 1951; Wilson, 1973), which on Earth form under water, but on Mars are able

873 to develop sub-aerially because of the higher kinematic viscosity of the low density atmosphere

874 (Lapotre et al., 2016a). This example shows the limitations of analysis from only orbital imagery,

875 even when we think that we understand what we are looking at. Additionally, the limits of

876 comparative planetology can mean we misinterpret observations where we lack a terrestrial analog.

877 - Dune sand grain sizes on Mars have been estimated since dunes were first seen, based on

878 assumptions about conditions for dune formation (Phases $1 \& 2$ ). Efforts to "measure" grain sizes

879 from proxy thermal inertia estimates have also been undertaken (mentioned within Phase 4), and

880 compared to and debated against the assumptions about the ability of the wind to move grains of

881 different sizes. Studies based on these estimations, and their results, now should be re-evaluated as

882 Curiosity has recently completed the first in situ investigation of a dune located on a planet other

883 than Earth (Phase 7), yielding the first direct measurements of martian dune grain sizes (Figure 11).

$884 \quad$ While on Titan sand grain sizes have not yet been measured in situ (and won't be in the near-

885 future), studies have explored what grain sizes can be reached via feasible physical processes which

886 puts constraints on models of dune formation conditions, and visa-versa. 
Additionally, it is important to recognize the gaps and limitations that can occur in aeolian

888 studies if only the "standard" aeolian science inputs are considered (e.g., the "complementary sciences"

889 listed in Table 1 also need to be considered). As in all areas of planetary science and geology, it is

890 important to consider many pieces of information (and observations, as possible), and all need to be

891 consistent with the model for the model to be validated. For example, while potential sediment sources

892 can possibly be tracked from visible imagery, climate models, and/or topography models, compositional

893 information about the dune grains and the potential sand sources is needed to check that the model is

894 consistent with the full environment. This may extend beyond compositional information in the local

895 environment (which was included in Phase 2), as grains may have been transported over large distances

896 or have been recycled a few times - and this history may not be apparent without a broad-swath of

897 environmental information. Additionally, processes outside of standard, dune-forming aeolian processes

898 may be playing a role in dune evolution and observed morphology. For example, the dunes in the

899 martian polar regions have morphologies and features different from those in the equatorial region,

900 making it clear that polar processes are altering the aeolian bedforms and thus must be considered in

901 their interpretation (e.g., in the north: Hansen et al., 2011; 2015; in the south: Fenton et al., 2010).

902

903

\subsection{Connections to modeling of the physical processes}

As discussed above, looking at aeolian bedforms on other planets allows models to be tested

905 against a range of environmental and planetary conditions. From that, we refine our understanding of

906 aeolian processes without assumption of Earth-conditions. This can especially have a large impact on

907 models of the small-scale and complicated dynamics of sand-wind and sand-sand interactions. For

908 example, as discussed under Phases 2 and 6, our understanding of the way in which sand is picked up by

909 the wind, causing or continuing saltation, has now been "tested" under terrestrial, martian, and 
venusian conditions (Kok, 2010; 2012), resulting in an updated model of how saltation and reptation are initiated and interact.

On Titan, questions about how "sticky" organic sand particles would interact with the wind were part of an investigation to explain how the dunes had formed, and from that to connect the crestline orientation to the forming-wind direction(s). The Titan dune sand color appears consistent with a composition of organics, and such long-chain molecules (of as-yet undetermined exact composition) could be derived from the atmospheric photodissociation of methane, which creates small particles (Carl Sagan's "tholins") that snow down from the atmosphere (and then perhaps get incorporated into surface sedimentary layers or clump together into larger granules, that are eroded and transported to the dune-forming regions) (Radebaugh, 2013; Barnes et al., 2015). Studies of clay-rich dunes in China had revealed that "sticky" particles could form dunes, but would anchor themselves to the downwind edge of a longitudinal dune and thus grow and migrate the dune along the dune crestline; this was proposed as a potential analog to the Titan dunes (Rubin and Hesp, 2009). Although the Titan dune morphologies were overall found to be more consistent with freely-moving particles (i.e., the saltation more usually observed on Earth) and thus this longitudinal dune formation model is less favored than the model discussed in Subsection 2.2. This type of questioning highlighted a different type of terrestrial dune-formation mechanism and "tested" behavior of the traditional dune formation model if one does not assume a non-cohesive sand grain. This led to further development of a dune-wind alignment model that brought these two hypotheses together as well as explained how bedforms with different alignments can exist within the same multidirectional wind regime (Courrech du Pont et al., 2014). Within this single model, dune alignment reflects growth via either a "bed instability mode" (which approximates the longitudinal dune growth process proposed by Rubin and Hunter (1987) and Rubin and Ikeda (1990)) or a "fingering mode" (the growth process proposed by Rubin and Hesp (2009)), depending on sediment availability. 
Models that examine larger-scale dynamics can also be tested through application to different

935 planetary surfaces. For example, it was in studying martian dunes that a discrepancy was noticed

936 between the minimum dune size expected on that planet ( 100x the minimum Earth dune size) and that

937 observed $(\sim 10 x)$, thus driving new models of dune formation to explain the scaling factor. Model studies

938 aiming to replicate the observed minimum barchan dune size on Earth and Mars addressed this

939 question, and tested assumptions about how saltation, reptation, and wind drag interact in setting

940 characteristic sand trajectory distances, and from this the generation of instability within a sand bed

941 under a moving fluid (Claudin and Andreotti, 2006).

942

943

\subsection{Connections to terrestrial studies and knowledge gain}

The trajectory of terrestrial dune studies has differed markedly from the framework proposed

945 here for planetary dune studies. In essence, the difference is one of top-down vs. bottom-up approaches

946 as in situ observations of terrestrial landforms, conditions, and activity are significantly easier to carry

947 out. However, this has not resulted in the history of terrestrial dune fields being an opposite to the

948 sequence suggested as being characteristic of planetary dune research. The earliest published studies of

949 terrestrial dune fields were linked with exploration by non-indigenous people, and many of the founding

950 points of contemporary dune science can be traced to these expeditions. The exploration of the

951 southern African and Australian interior (mid-19th century), the Sahara (around the beginning of the

952 20th century, mostly by the French in the west and the English in the east) and the Arabian Rub al'Khali

953 (most notably by Wilfred Thesiger in the late 1940s) all had exploration as their primary goals. As with

954 contemporary rover exploration of the martian dune fields, many dune fields were approached with

955 trepidation due to the hazards they posed. Despite science being incidental rather than implicit to most

956 of the explorations, there was, nonetheless, early recognition of the great spatial extent of many dune 
957 fields, the remarkably organized nature of dunes and the fact that dunes could exist at differing activity 958 levels.

Although Bagnold's work in the 1930s and 1940s is most commonly cited as being the

960 foundation of modern understanding of aeolian processes and landforms, there were significant

961 precursors. George Perkins Marsh (1864) considered geoengineering problems associated with drifting

962 sand, and the role of vegetation in stabilizing dunes, and Russian geologist Nikolay Sokolów had

963 discussed dune sedimentology and theories of dune formation in a 300 page book devoted to the

964 subject (1894). Georges Rolland, a French mining engineer, set out a series of propositions in 1890

965 based on fieldwork in the Algerian Sahara which addressed such issues as sediment source, the

966 distribution of dune fields, varying levels of dune activity and the relationship between wind regime and

967 different dune shapes (Burt et al., 2008). At this point, the role of the wind in dune formation was still

968 contested by many, and it was widely held that dunes would prove to have rocky cores (Goudie, 2002).

969 Many other aspects of contemporary aeolian science date from surprisingly early studies. Aerial imagery

970 was used to examine dune planform morphology in the 1930s (Aufrère 1932, Madigan 1936), and the

971 recognition of dunes as a particulate waveform in a fluid medium can be traced to the work of Cornish

972 (1914). Bagnold's work, utilizing field and wind tunnel experimentation, is an early example of the

973 'quantitative revolution' widely recognized in geosciences in the middle of the 20th century. This directly

974 influenced the next half-century of research, via fieldwork and laboratory experimentation, in a phase

975 perhaps best summarized by Lancaster's (1995) state-of-the-art textbook. Coincidentally, the same year

976 saw the publication of Werner's (1995) application of cellular automata models to aeolian bedforms,

977 which accepted that dunes formed as an emergent property of a complex system, one of the first

978 indications of the failure of reductionist approaches to fully explain aeolian landscapes (Livingstone et

979 al., 2007). The same period saw the rise of the use of luminescence dating to provide ages for dune 
emplacement, since described as having has a transformative effect on studies of dryland science

981 (Singhvi and Porat, 2008).

Planetary studies of aeolian dunes therefore have the advantage of decades of terrestrial work

to draw upon, and this is reflected in the very rapid progress made on newly-discovered dunes (e.g.

984 Titan, Comet 67P). Terrestrial science, conversely, has had the advantage of a relatively steady

progression in the quality of the available data -- although the related understanding of aeolian systems

986

987

988

989

990

991

992

993

994

995

996

997

998

999

1000

1001

1002

1003

has not progressed as steadily. The progress made in understanding terrestrial dunes has not been

without challenges, and it is instructive to reflect on whether there are lessons for the planetary

community can be drawn from progress on terrestrial dune fields, and conversely whether the evolution of extraterrestrial dune research can inform the research strategies of Earth's dune studies.

\section{What can planetary science learn from the history of terrestrial dune studies?}

Much of planetary dune science is already directly influenced by the methods, theory and process understanding derived from terrestrial studies, manifest in the numerous analog studies. However, there are some less well-discussed points that are worthy of consideration.

As was noted in section 3.1, close attention must be paid to the difference between assumed and observed knowledge. Cautionary tales can be drawn from terrestrial dune studies, and this is perhaps best illustrated by the roll vortex hypothesis for longitudinal (linear) dune formation. First proposed by Bagnold (1953), and promoted subsequently (e.g. Hanna, 1969) this suggested that thermally induced vortices in regional wind-flow would lead to the development of helical horizontal flow cells that might lead to sand accumulation in linear bedforms extending downwind. The theory is strikingly devoid of empirical supporting evidence, and yet still persists in the literature. Quite simply, vortices of sizes that might explain dune spacing have never been observed despite numerous experimental attempts, and the transverse component of roll vortices does not appear to have sufficient 
velocity to move sand (Lancaster 1995). Planetary studies should be careful to question existing 1005 paradigms and theories, and be willing to point out when data do not support these hypotheses. Bagnold's great advances in aeolian science can be largely attributed to willingness and fearlessness towards innovation, in terms of methods and physical exploration. The novel application of 1008 wind tunnels to aeolian transport and sedimentation and the methods developed to enable remote 1009 desert travel directly enabled the advances in understanding that Bagnold brought. Planetary 1010 perspectives support this, with the radical advances in data brought from missions such as MSL, 1011 Cassini/Huygens, Rosetta/Philae and New Horizons. Such evidence supports the potential knowledge 1012 gains from similarly ambitious mission concepts of other planetary surface exploration missions, such as 1013 AVIATR (Barnes et al. 2012) and VISE (NRC, 2013) which have been considered for Titan and Venus 1014 exploration, respectively. The evidence from both terrestrial and planetary dune studies suggests that 1015 high-risk, innovative research has led to some of the greatest advances. The discrepancy between the timescales of aeolian process and the timescales evident in 1017 aeolian landscapes is also very evident - possibly even more so - on some planetary bodies. Despite 1018 processes operating within dune landscape on timescales of seconds to hours, the resultant landscape 1019 development frequently operates on timescales of $>10^{3}$ years. Dating of aeolian sediment, primarily via 1020 the suite of luminescence dating methods, has been adopted very widely on terrestrial dune studies, 1021 and has played a crucial role in linking the short-term process understanding with the long-term 1022 geomorphological record. It has enabled calculation of rates of landform evolution beyond that possible 1023 using observational records (e.g. Kocurek et al., 2007; Telfer, 2011), revealed complex spatial variability 1024 in aeolian accumulation (Telfer and Thomas, 2007) and frequently been used to infer external drivers of 1025 dune activity (e.g. climatic changes). Experimentation with luminescence readers suitable for Mars 1026 missions has been explored (e.g. McKeever et al., 2003; Jain et al. 2006), and if the substantial technical 1027 challenges can be overcome (Doran et al. 2004), martian luminescence dating offers the potential to 
1028

1029

1030

1031

1032

1033

1034

1035

1036

1037

1038

1039

1040

1041

1042

1043

1044

1045

1046

1047

1048

1049

1050

extend understanding of accumulation beyond the period of direct observation. Recent progress suggests that solutions may exist to these challenges (e.g. Sohbati et al., 2012).

\section{What can terrestrial dune studies learn from the history of planetary science?}

Although at least parts of Phases 1-3 and 5-7 have been investigated on Earth for 70 years or more, a striking difference between planetary and terrestrial dune studies is that currently there is no global catalogue of dunes for Earth (Phase 4). The first edition of the Mars Global Digital Dune Database (Hayward et al., 2007) was published within six years of the start of THEMIS data collection (which are used to identify the thermal inertia proxy identifiers for dune fields), and global mapping of Titan's dunes within the constraints of the available data (Lorenz and Radebaugh, 2009) was published within a similar timeframe since the arrival of Cassini at Titan. Although some terrestrial regions have been mapped and duneforms catalogud (e.g., Namib; Livingstone et al., 2010), and a global database of dunes with dating constraints has recently been complied (Lancaster et al., in press), global-scale consideration of terrestrial dune fields is currently lagging behind planetary science. Efforts in this direction are currently in progress (Hesse et al., 2015) -- but it has been over 40 years since the advent of global terrestrial satellite coverage. The focus of planetary global catalogues of dunes has been on understanding global circulation patterns (e.g. Charnay et al. 2015, Ewing et al. 2015), sediment sources (e.g. Tirsch et al., 2011), identification of large-scale variations in dune form due to different evolution processes or rates (e.g., Hayward and Fenton, 2010; Savage et al., 2014), and targeting areas for detailed study (e.g., Hayward, 2011). Whilst it is not necessary to use dune morphology to understand modern circulation patterns on Earth, applications of such a database would include quantification of aeolian sediment volumes and flux, improved understanding of regions where dunes are currently stabilized, and potential for monitoring change in environmentally-sensitive, dynamic landscapes. 

geomorphology, concluded that decades of largely inductive, and increasingly reductionist, study had not brought the completeness of understanding that had been hoped, and that integration of methodologies (field, modeling and remote sensing) offered the best prospects for knowledge. Perhaps due to the difficulties in conducting 'field study' of extraterrestrial dunes (i.e., Phase 7), which are only very recently being overcome on Mars, such combined strategies are often exemplified by planetary aeolian studies, where studies employing a wide range of methodologies including numerical modeling,

1058 laboratory experimentation, field study (presently via analog environments), and remote sensing are commonplace (e.g., Lucas et al. 2014). Although some terrestrial studies do synthesize such diverse methodologies, the example set by many planetary studies is a good one for terrestrial dune studies. of new remotely sensed data. The same has been true for Earth, and here lessons learned in planetary studies help guide interpretation of terrestrial images at the margins of the spectral and/or spatial resolution of the imagery. This is perhaps best illustrated with the example of the highly contested issue 1065 of extensive palaeo-dune fields in the Amazon Basin, presently covered with extensive tropical forest. 1066 Tricart (1974), working with recently-released first-generation Landsat imagery, identified widespread 1067 stabilized aeolian landforms in the tropical Amazon Basin. This interpretation was repeated numerous 1068 times (e.g. Klammer, 1982) and lead to a widespread belief in arid phases accompanied by vegetation 1069 loss during the late Quaternary evolution of the region, with huge implications for understanding of 1070 regional biogeography in one of the world's most biodiverse regions. However, whilst subsequent 1071 reanalysis of high-resolution data has revealed aeolian dune fields around the margins of the Amazon 1072 basin (e.g. Teeuw and Rhodes, 2004; May, 2013) and/or immediately adjacent to large rivers where the 1073 sediment supply has at times been the dominant control (e.g. Carneiro, 2002), the existence of wide 1074 swathes of paleodunes across the Amazon basin has not withstood closer scrutiny (Colinvaux et al., 
1075 2001). Tripaldi and Zarate (in press) reviewed the evidence, and demonstrated the importance of 1076 groundtruthing when image interpretation is challenging. Planetary geomorphologists are usually

1077 admirably conservative in terms of implying process from (apparent) landform, especially when imagery

1078 is at the limit of its spatial or spectral resolution, and terrestrial incidents such as the question of an arid 1079 Amazon suggest that such conservatism is wise.

1080

1081 4. Conclusion/Summary

1082 Studies of aeolian bedforms over a wide range of planetary bodies have resulted in significant 1083 progress in our understanding of past and present climate and surface conditions, physical processes, 1084 and the interconnectivity of dynamics over a range of spatial and temporal scales. These studies 1085 contribute, in meaningful and often unique ways, towards a range of planetary science investigations.

1086 For example, as discussed, interpretation of dune morphology often provides unique, if proxy, 1087 groundtruth data about past or present wind conditions, and the proven presence of a large amount of 1088 sand grains can drive investigations about processes responsible for creating such grains. Beyond studies 1089 that involve this type of direct interpretation of the aeolian bedforms, aeolian science studies also yield 1090 information about many tangentially-related areas of investigation. In particular, aeolian-driven sand 1091 flux appears to be an important force in erosional modification of a planetary surface. Quantitative 1092 estimations of wind speeds and sand flux and identification of sediment transport pathways yield 1093 quantitative estimates of erosional process rates. This can, for example, lead to improved interpretation 1094 of observed landforms - such as yardangs (e.g., Ward 1979), or the rate of crater degradation by aeolian 1095 processes which is important for accurately estimating the age of a planetary surface (e.g., Golombek et 1096 al., 2014; Grant et al., 2006; 2008; 2016). This can also provide bounds on surface-ages of exposed rock 1097 surfaces, which is can be of importance to rover missions - such as Mars missions searching for 
1098

1099

1100

1101

1102

1103

1104

1105

1106

1107

1108

1109

1110

1111

1112

1113

1114

1115

1116

1117

1118

1119

1120

reachable-environments near the surface that may have been habitable and that may include preserved biosignatures (e.g., Arvidson et al., 2015).

As discussed, planetary aeolian studies have also made key contributions towards improving the methodologies employed in aeolian science, and in challenging assumptions built (perhaps inadvertently) into aeolian process models based on terrestrial observations. To-date, this has resulted in the refinement of several models of dune-field forming processes, from interactions between sand grains and the wind or with each other, up through interactions between dunes and topography and climate shifts.

Given all of the ways in which our aeolian study results impact our understanding of planetary surface conditions and histories (as well as the Earth's), it is thus very important to critically look at how we progress in planetary aeolian science, and in particular to consider carefully which results (and resultant models) are based on assumptions versus observations - and then to revisit those results when new information becomes available. Here, we have proposed one framework for identifying progress within planetary aeolian studies, and have used that framework to chart the progression of data, assumptions, and generated knowledge. We hope this framework, and our identification of gaps, will help future planetary aeolian researchers strategically fill knowledge gaps or at least carefully recognize where assumptions are being used to progress a study.

Additionally, this framework may help identify the types of data that would be most useful for future planetary missions. Pluto, lo, and Comet 67P were all discussed as having reached Phase 1, where at least a potential aeolian bedform has been observed. On Titan, global datasets exist and have contributed to large shifts in our understanding of the Titan climate and organic cycles. Venus also has a global topography dataset, but the low resolution and apparent lack of dune fields stalled progress in its aeolian science investigations (and thus related advancements in planetary surface studies). 
1121 Unfortunately for Venus and Titan, further progression within Phases 2-4 (and movement into Phases 5

1122 and beyond) will likely need to wait for new and higher-resolution surface datasets.

Mars' aeolian bedforms are the best studied within planetary aeolian science (outside of

1124 Earth's), with both widespread coverage in certain data-types and many regions with high-resolution

1125 data regarding the dunes' and dune field environment's morphology and composition, collected over

1126 the past 43 years. However, with the progress that has been made, we cannot lose sight of the fact that

1127 much of it has been built on interpretations of remote data. (As discussed under Phase 7, in situ dune

1128 field observations have not been possible until just recently.) Furthermore, much of the work involves a

1129 meshing of coarse global data with a few more-deeply monitored and studied dune fields, and thus

1130 much extrapolation is done that assumes certain types of consistency between fields. This is an odd

1131 contrast with Earth dune field studies, where the global dataset (Phase 4) is what is missing.

For all planetary bodies (including Earth), we look forward to further advancements in the

1133 interpretation of aeolian bedforms and what interpretations about those bedforms will imply about the

1134 environmental conditions and processes. If history is to be any guide, with each advance into a new

1135 phase (due to acquisition of a new type of data and/or enablement of a new type of analysis), we find

1136 exciting new understandings about that planetary body and the general understanding of aeolian

1137 processes. One area of intriguing advancement is the prediction of where dunes and/or ripples could be

1138 found (which could be thought of as a "Phase 0" within our framework). As we explore more bodies and

1139 learn more about the conditions under which bedforms resembling aeolian dunes are found, we can

1140 wonder about the next place where we may expect to find potential dunes, as well as identify lessons to

1141 aid in such predictions (e.g., when we return to Venus). In addition, perhaps in the near future, we will

1142 move into a yet-undefined Phase 8 (e.g., through comparison between in situ measurements of some

1143 very different types of aeolian bedforms? Hints of that are starting with sand grain comparisons (e.g.,

1144 O'Connell-Cooper, 2016)), yielding a new type of data that can supersede assumptions made in Phases 
1-7, further expanding our broad understanding of aeolian processes and bedforms, and increasing the

1146 overall information gained from planetary aeolian studies.

\section{Acknowledgements}

1149

[Mostly removed for review.] We thank the two reviewers for their very helpful comments, and in particular for the suggestions of additional references.

\section{References}

1153

Achilles, C.N., D.T. Vaniman, D.F. Blake, T.F. Bristow, E.B. Rampe, D.W. Ming, S.J. Chipera, R.V. Morris, S.M. Morrison, R.T. Downs, K.V. Fendrich, B.L. EhImann, A.S. Yen, P.C. Sarrazin, A.H. Treiman, P.I. Craig, M.G.A. Lapotre, K.S. Edgett, R. Gellert, J.A. Crisp, J.M. Morookian, J.P. Grotzinger, D.J. Des Marais, J.D. Farmer, 2016. Mineralogy of eolian sands at Gale crater. 47th LPSC, Ab. 2532.

Allen, A., S. Diniega, C. Hansen, 2016. Gully and aeolian activity within the "Tleilax" dune field in the Olympia Undae, Mars. 47 th LPSC, Ab. 1759.

Andreotti, B., P. Claudin, O. Pouliquen, 2006. Aeolian Sand Ripples: Experimental Study of Fully Developed States. Physical Review Letters, v. 96, 028001, doi:10.1103/PhysRevLett.96.028001.

Arvidson, R. E., J.F. Bell III, J.G. Catalano, B.C. Clark, V.K. Fox, R. Gellert, J.P. Grotzinger, E. A. Guinness, K.E. Herkenhoff, A.H. Knoll, M. G. A. Lapotre, S.M. McLennan, D.W. Ming, R.V. Morris, S.L. Murchie, K.E. Powell, M.D. Smith, S.W. Squyres, M.J. Wolff, J.J. Wray, 2015. Mars Reconnaissance Orbiter and Opportunity Observations of Burns Formation and Underlying Strata: Crater-Hopping at Meridiani Planum. J. Geophys. Res. - Planets, v. 120, issue 3, 429-451, doi:10.1002/2014JE004686.

Aufrère, L., 1932. Morphologie dunaire et météorologie saharienne. Association de Géographes Français Bulletin 56, 34-47.

Ayoub, F., J-P. Avouac, C.E. Newman, M.I. Richardson, A. Lucas, S. Leprince, N.T Bridges, 2014. Threshold for sand mobility on Mars calibrated from seasonal variations of sand flux. Nature Communications 5, doi:10.1038/ncomms6096.

Bagnold, R.A., 1941. The Physics of Blown Sand and Desert Dunes (New York: Methuen).

Bagnold, R.A, 1953. The surface movement of blown sand in relation to meteorology. Research Council of Israel, Special Publication, 2, 89-93.

Barnes, J.W., R.H. Brown, L. Soderblom, C. Sotin, S. Le Mouelic, S. Rodriguez, R. Jaumann, R.A. Beyer, R. Clark, P. Nicholson, 2008. Spectroscopy, morphometry, and photoclinometry of Titan's dune fields from Cassini/VIMS. Icarus 195, 400-414.

Barnes, J.W., L. Lemke, R. Foch, C.P. McKay, R.A. Beyer, J.Radebaugh, D.H. Atkinson, R.D. Lorenz, S. Le Mouélic, S. Rodriguez, J. Gundlach, 2012. AVIATR-Aerial Vehicle for In-situ and Airborne Titan Reconnaissance. Experimental Astronomy, 33(1), pp.55-127.

Barnes, J.W., R.D. Lorenz, J. Radebaugh, A.G. Hayes, K. Arnold, C. Chandler, 2015. Production and global transport of Titan's sand particles. Planetary Science 4, 1-19. 
Basilevsky, A.T., R.O. Kuzmin, O.V. Nikolaeva, A.A. Pronin, L.B. Ronca, V.S. Avduevsky, G.R. Uspensky, Z.P. Cheremukhina, V.V. Semenchenko, V.M. Ladygin, 1985. The surface of Venus as revealed by the Venera landings: Part II. Geological Society of America Bulletin, 96, 137-144.

Belcher, D., J. Veverka, C. Sagan, 1971. Mariner photography of Mars and aerial photography of Earth: Some analogies, Icarus, vol. 15, 241252.

Bondarenko, N. V., M. A. Kreslavsky, J. W. Head, 2006. North-south roughness anisotropy on Venus from the Magellan Radar Altimeter: Correlation with geology, Journal of Geophysical Research (Planets) 111, E06S12.

Bourke, M.C., K.S. Edgett, B.A. Cantor, 2008. Recent aeolian dune change on Mars. Geomorphology, 94(1-2), 247-255, doi:10.1016/j.geomorph.2007.05.012.

Breed, C., M. J. Grolier, J.F. McCauley, 1979. Morphology and Distribution of Common 'Sand' Dunes on Mars: Comparison With the Earth, J. Geophys. Res., vol. 84, no. B14, 8183-8204.

Bridges, N.T., M.C. Bourke, P.E. Geissler, M.E. Banks, C. Colon, S. Diniega, M.P. Golombek, C.J. Hansen, S. Mattson, A.S. McEwen, M.T. Mellon, N. Stantzos, B.J. Thomson (2012a), Planet-wide sand motion on Mars. Geology 40(1), 31-34, doi:10.1130/G32373.1.

Bridges, N.T., F. Ayoub, J-P. Avouac, S. Leprince, A. Lucas, S. Mattson (2012b), Earth-like sand fluxes on Mars. Nature 485, 339-342, doi:10.1038/nature11022.

Bridges,N.T, B.L. Ehlmann, R.C. Ewing, C.E. Newman, R. Sullivan, P.G. Conrad, A. Cousin, K.S. Edgett, M.R. Fisk, A.A. Fraeman, J.R. Johnson, M. Lamb, M. Lapotre, S. Le Mouélic, G.M. Martinez, P-Y. Meslin, P. Pinet, L.M. Thompson, J. van Beek, A.R. Vasavada, R.C. Wiens, 2016. Investigation of the Bagnold Dunes by the Curiosity rover: Overview of initial results from the first study of an active dune field on another planet, 47th LPSC, Ab. 2298.

Burt et al. 2008 (eds). The history of the study of landforms, Volume 4: A history of geomorphology between the 1890s and the 1960s. London, The Geological Society.

Burr, D. M., S.A. Drummond, R. Cartwright, B.A. Black, J.T. Perron (2013). Morphology of fluvial networks on Titan: Evidence for structural control, Icarus, vol. 226(1), 742-759, doi:10.1016/j.icarus.2013.06.016.

Canada Dept. Agriculture (1976), Glossary of terms in soil science, (c) Minister of Supply and Services, Canada, ISBN 0-662-01533-9. http://sis.agr.gc.ca/cansis/publications/manuals/1976glossary/pub1459_report.pdf

Cardinale, M., G. Komatzu, S. silvestro, D. Tirsch, 2012. The influence of local topography for wind direction on Mars: two examples of dune fields in crater basins. Earth Surface Processes and Landforms, 37, 13, 1437-1443, DOI: 10.1002/esp.3289.

Cardinale, M., S. Silvestro, D.A. Vaz, T. Michaels, M.C. Bourke, G. Komatsu, L. Marinangeli, 2016. Presentday aeolian activity in Herschel Crater, Mars. Icarus 265, 139-148, doi:10.1038/ncomms6096.

Carneiro Filho, A., D. Schwartz, S.H. Tatumi, T. Rosique, 2002. Amazonian paleodunes provide evidence for drier climate phases during the Late Pleistocene-Holocene. Quaternary Research, 58(2), pp.205209.

Charnay, B., E. Barth, S. Rafkin, C. Narteau, S. Lebonnois, S. Rodriguez, S.C. Du Pont, A. Lucas, 2015. Methane storms as a driver of Titan's dune orientation. Nature Geoscience, 8(5), pp.362-366.

Cheng, A.F., C.M. Lisse, M. A'Hearn, 2013. Surface geomorphology of Jupiter Family Comets: A geologic process perspective. Icarus 222, 808-817, doi:10.1016/j.icarus.2012.10.004. 
1224

1225

1226

1227

1228

1229

1230

1231

1232

1233

1234

1235

1236

1237

1238

1239

1240

1241

1242

1243

1244

1245

1246

1247

1248

1249

1250

1251

1252

1253

1254

1255

1256

1257

1258

1259

1260

1261

1262

1263

1264

1265

Christensen, P.R., 1983. Eolian intracrater deposits on Mars: Physical properties and global distribution. Icarus 56(3), 496-518.

Christensen, P.R., J.L. Bandfield, J.F. Bell III, N. Gorelick, V.E. Hamilton, A. Ivanov, B.M. Jakosky, H.H. Kieffer, M.D. Lane, M.C. Malin, T. McConnochie, 2003. Morphology and composition of the surface of Mars: Mars Odyssey THEMIS results. Science 300(5628), pp.2056-2061.

Chojnacki, M., D.M. Burr, J.E. Moersch, T.I. Michaels, 2011. Orbital observations of contemporary dune activity in Endeavour Crater, Meridiani Planum, Mars. J. Geophys. Res. 116, E00F19. Chojnacki, M., D. M. Burr, J. E. Moersch, J. J. Wray, 2014. Valles Marineris dune sediment provenance and pathways. Icarus, 232(0), 187-219, doi:10.1016/j.icarus.2014.01.011.

Chojnacki, M., J.R. Johnson, J.E. Moersch, L.K. Fenton, T.I. Michaels, J.F. Bell III, 2015. Persistent aeolian activity at Endeavour crater, Meridiani Planum, Mars; new observations from orbit and the surface. Icarus, 251(0), 275-290, doi:10.1016/j.icarus.2014.04.044.

Claudin, P., B. Andreotti, 2006. A scaling law for aeolian dunes on Mars, Venus, Earth, and for subaqueous ripples. Earth and Planetary Science Letters, vol. 252, 30-44, doi:10.1016/j.epsl.2006.09.004.

Colinvaux, P.A., G. Irion, M.E. Räsänen, M.B. Bush, J.N. De Mello, 2001. A paradigm to be discarded: geological and paleoecological data falsify the Haffer \& Prance refuge hypothesis of Amazonian speciation. Amazoniana, 16(3), pp.609-646.

Courrech du Pont, S., C. Narteau, X. Gao, 2014. Two modes for dune orientation. Geology, 42(9), doi:10.1130/G35657.1.

Cousin, A., O. Forni, P.-Y. Meslin, S. Schröder, O. Gasnault, N. Bridges, B. Elhmann, S. Maurice, R. Wiens, 2016. Chemical diversity among fine-grained soils at Gale (Mars): a chemical transition as the rover is approaching the Bagnold Dunes? 47 th LPSC, Ab. 2044.

Cutts, J.A., R.S.U. Smith, 1973. Eolian deposit and Dunes on Mars. J. Geophys. Res. 78(20), 4139-4154.

Cutts, J.A., K.R. Blasius, G.A. Briggs, M.H. Carr, R. Greeley, H. Masursky, 1976. North Polar Region of Mars: Imaging Results from Viking 2. Science, vol. 194(4271), 1329-37.

Diniega, S., K. Glasner, S. Byrne, 2010a. Long scale evolution of aeolian sand dune fields: influences of initial conditions and dune collisions. Geomorphology (special edition: Planetary Dunes) 121, 55-68, doi:10.1016/j.geomorph.2009.02.010.

Diniega, S., S. Byrne, N.T. Bridges, C.M. Dundas, A.S. McEwen, 2010b. Seasonality of present-day Martian dune-gully activity. Geology 38, no. 11, 1047-1050, doi:10.1130/G31287.1.

Diniega, S., A. Allen, T. Perez, C.J. Hansen, 2016. Tracking gully activity within the north polar erg, Mars. $47^{\text {th }}$ LPSC, Ab. 1740.

Doran, P.T., S.M. Clifford, S.L. Forman, L. Nyquist, D.A. Papanastassiou, B.W. Stewart, N.C. Sturchio, T.D. Swindle, T. Cerling, J. Kargel, G. McDonald, 2004. Mars chronology: assessing techniques for quantifying surficial processes. Earth-Science Reviews, 67(3), pp.313-337.

Dundas C.M., S. Diniega, C.J. Hansen, S. Byrne, A.S. McEwen, 2012. HiRISE observations of seasonal activity and morphological changes in Martian gullies. Icarus 220(1), 124-143, doi:10.1016/j.icarus.2012.04.005.

Dundas, C.M., S. Diniega, A.S. McEwen, 2015. Long-Term Monitoring of Martian Gully Formation on Mars and Evolution with HiRISE. Icarus (special issue: Dynamic Mars) 251, 244-263, doi:10.1016/j.icarus.2014.05.013. 
Edgett, K.S., P.R. Christensen, 1991. The particle size of Martian aeolian dunes. JGR 96(E5), 22765-22776. Edgett, K. S., N. Lancaster (1993), Volcaniclastic aeolian dunes: terrestrial examples and application to martian sands, J. Arid Environ., 25(3), 271-297, doi:10.1006/jare.1993.1061.

Ehlmann, B.L., N. Bridges, A.A. Fraeman, M.G.A. Lapotre, K. Edgett, J.R. Johnson, A. Cousin, A. Yen, P. Conrad, L. Thompson, J. Van Beek, D. Vaniman, S. Schröder, A. Vasavada, 2016. Chemistry and mineralogy in situ at the Bagnold sand dunes: Evidence for aeolian sorting and size-dependence in sand composition. $47^{\text {th }}$ LPSC, Ab. 1536.

Ewing, R.C., G. Kocurek, 2010. Aeolian dune-field pattern boundary conditions. Geomorphology 114, 175-187, doi:10.1016/j.geomorph.2009.06.015.

Ewing, R.C. A. Peyret, G. Kocurek and M.C. Bourke, 2010. Dune-field pattern formation and recent transporting winds in the Olympia Undae dune field, north polar region of Mars. Journal of Geophysical Research, 115, E08005.

Ewing, R.C., A.G. Hayes, A. Lucas, 2015. Sand dune patterns on Titan controlled by long-term climate cycles. Nature 10.1038/ngeo2323.

Ewing, R.C., N.T. Bridges, R. Sullivan, M.G.A. Lapotre, W.W. Fisher, M.P. Lamb, D. Rubin, K. Lewis, S. Gupta, 2016. Aeolian Sedimentary Processes at the Bagnold Dunes, Mars: Implications for Modern Dune Dynamics and Sedimentary Structures in the Aeolian Stratigraphic Record of Mars. $47^{\text {th }}$ LPSC, Ab. 2783.

Fenton, L.K., 2005. Potential sand sources for the dune fields in Noachis Terra, Mars. J. Geophys. Res., vol. 110, E11, doi:10.1029/2005JE002436.

Fenton, L. K., 2006. Dune migration and slip face advancement in the Rabe Crater dune field, Mars. Geophys. Res. Lett., 33(20), 1-5, doi:10.1029/2006GL027133.

Fenton, L., 2016. Dunes on Pluto? Blog on SETI website: http://www.seti.org/seti-institute/dunes-onpluto.

Fenton, L.K., R.K. Hayward, 2010. Southern high latitude dune fields on Mars: Morphology, aeolian inactivity, and climate change, Geomorphology 121, Issues 1-2, 98-121, doi:10.1016/j.geomorph.2009.11.006.

Fenton, L.K., A.D. Toigo, M.I. Richardson, 2005. Aeolian processes in Proctor Crater on Mars: Mesoscale modeling of dune-forming winds. J. Geophys. Res. 110, E06005, doi:10.1029/2004JE002309.

Florensky, C.P., A.T. Basilevsky, V.P. Krychkov, R.O. Kusmin, O.V. Nikolaeva, A.A. Pronin, I.M. Chernaya, Yu.S. Tyuflin, A.S. Selivanov, M.K. Naraeva, L.B. Ronca, 1983. Venera 13 and Venera 14: Sedimentary rocks on Venus? Science 221, 57-589.

Fryberger, S.G., G. Dean, 1979. Dune forms and wind regime, in, E. D. McKee, ed., A study of global sand seas. U.S. Geol. Surv. Prof. Pap. 1052, 137-169.

Gardin, E., P. Allemand, C. Quantin, S. Silvestro, C. Delacourt, 2012. Dune fields on Mars: Recorders of a climate change? Planet. Space Sci. 60, 314-321, doi:10.1016/j.pss.2011.10.004.

Garzanti, E., P. Vermeesch, S. Andò, G. Vezzoli, M. Valagussa, K. Allen, K.A. Kadi, A.I.A. Al-Juboury, 2013. Provenance and recycling of Arabian desert sand. Earth-Sci. Rev. 120, 1-19, doi:10.1016/j.earscirev.2013.01.005.

Geissler, P.E., N.W. Stantzos, N.T. Bridges, M.C. Bourke, S. Silvestro, L.K. Fenton, 2013. Shifting sands on Mars: Insights from tropical intra-crater dunes. ESP\&L, vol. 38, no. 4, 407-412, doi:10.1002/esp.3331. 
1308

1309

1310

1311

1312

1313

1314

1315

1316

1317

1318

1319

1320

1321

1322

1323

1324

1325

1326

1327

1328

1329

1330

1331

1332

1333

1334

1335

1336

1337

1338

1339

1340

1341

1342

1343

1344

1345

1346

1347

1348

Golombek, M. P., J.A. Grant, L.S. Crumpler, R. Greeley, R.E. Arvidson, J.F. Bell III, C.M. Weitz, R. Sullivan, P.R. Christensen, L.A. Soderblom, S.W. Squyres, 2006. Erosion rates at the Mars Exploration Rover landing sites and long-term climate change on Mars. J. Geophys. Res., 111, E12S10, doi:10.1029/2006JE002754.

Golombek, M.P., N.H. Warner, V. Ganti, M.P. Lamb, T.J. Parker, R.L. Fergason, R. Sullivan, 2014. Small crater modification on Meridiani Planum and implications for erosion rates and climate change on Mars. J. Geophys. Res. Planets, 119, doi:10.1002/2014JE004658.

Goudie, A., 2002. Great warm deserts of the world: landscapes and evolution (Vol. 1). Oxford University Press on Demand.

Grant, J. A., R.E. Arvidson, L.S. Crumpler, M.P. Golombek, B. Hahn, A.F.C. Haldemann, R. Li, L.A. Soderblom, S. W. Squyres, S.P. Wright, W.A. Watters, 2006. Crater gradation in Gusev crater and Meridiani Planum, Mars. J. Geophys. Res., 111, E02S08, doi:10.1029/2005JE002465.

Grant, J. A., S. A. Wilson, B. A. Cohen, M. P. Golombek, P. E. Geissler, R. J. Sullivan, R. L. Kirk, and T. J. Parker (2008), Degradation of Victoria crater, Mars, J. Geophys. Res., 113, E11010, doi:10.1029/2008JE003155.

Grant, J. A., T. J. Parker, L. S. Crumpler, S. A. Wilson, M. P. Golombek, and D. W. Mittlefehldt, (2016), The degradational history of Endeavour crater, Mars: Icarus, doi:10.1016/j.icarus.2015.08.019, in press.

Greeley, R., R.E. Arvidson, 1990. Aeolian processes on Venus. Earth, Moon, and Planets, 50/51, 127-157.

Greeley, R., J.D. Iversen, J.B. Pollack, N. Udovich, B. White, 1974. Wind tunnel studies of martian aeolian processes. Proc. Royal Soc. London, 341, 331-360, doi: 10.1098/rspa.1974.0191.

Greeley, R., R. Leach, B. White, J. Iversen, J. Pollack, 1980. Threshold windspeeds for sand on Mars: Wind tunnel simulations. Geophysical Research Letters, vol. 7, no. 2, 121-124.

Greeley, R., J. Iversen, R. Leach, J. Marshall, B. White, S. Williams, 1984a. Windblown sand on Venus: Preliminary results of laboratory simulations. Icarus 57(1), 112-124.

Greeley, R., J.R. Marshall, R.N. Leach, 1984b. Microdunes and other aeolian bedforms on Venus: Wind tunnel experiments. Icarus 60, 152-160.Greeley R., N. Lancaster, S. Lee, P. Thomas, 1992a. Martian aeolian processes, sediments and features, in: Kieffer, H., Jakosky, B.M., Snyder, C.W., Matthews, M.S. (Eds.), Mars. University of Arizona Press, Tucson, pp. 730-767.

Greeley, R., R.E. Arvidson, C. Elachi, M.A. Geringer, J.J. Plaut, R.S. Saunders, G. Schubert, E.R. Stofan, E.J.P. Thouvenot, S.D. Wall, C.M Weitz, 1992b. Aeolian features on Venus: Preliminary Magellan results. J. Geophys. Res. 97(E8), 13319-13345.

Greeley, R. K. Bender, P.E. Thomas, G. Schubert, D. Limonadi, C.M. Weitz, 1995. Wind-related features and processes on Venus: Summary of Magellan results. Icarus, 115, 399-420.

Greeley, R., K.C. Bender, R.S. Saunders, G. Schubert, C. M. Weitz, 1997. Aeolian processes and features on Venus, in Venus II: Geology, Geophysics, Atmosphere, and Solar Wind Environment, edited by S. W. Bougher, D. M. Hunten, and R. J. Philips, pp. 547- 590, Univ. of Ariz. Press, Tucson.

Greeley, R., R.E. Arvidson, P.W. Barlett, D. Blaney, N.A. Cabrol, P.R. Christensen, R.L. Fergason, M.P. Golombek, G.A. Landis, M.T. Lemmon, S.M. McLennan, J.N. Maki, T. Michaels, J.E. Moersch, L.D.V. Neakrase, S.C.R. Rafkin, L. Richter, S.W. Squyres, P.A. de Souza Jr., R.J. Sullivan, S.D. Thompson, P.L. Whelley, 2006. Gusev crater: Wind-related features and processes observed by the Mars Exploration Rover Spirit. J. Geophys. Res. 111, E02S09, doi:10.1029/2005JE002491. 
Hanna, S.R., 1969. The formation of longitudinal sand dunes by large helical eddies in the atmosphere. Journal of Applied Meteorology, 8(6), pp.874-883.

Hansen, C. J., M. Bourke, N.T. Bridges, S. Byrne, C. Colon, S. Diniega, C. Dundas, K. Herkenhoff, A. McEwen, M. Mellon, G. Portyankina, N. Thomas, 2011. Seasonal erosion and restoration of Mars' northern polar dunes. Science 331(6017), 575-578, doi:10.1126/science.1197636.

Hansen, C.J., S. Diniega, N. Bridges, S. Byrne, C. Dundas, A. McEwen, G. Portyankina, 2015. Agents of change on Mars' northern dunes: CO2 ice and wind, Icarus (special issue: Dynamic Mars) 251, 264274. doi:10.1016/j.icarus.2014.11.015.

Hayward, R.K., 2011. Mars Global Digital Dune Database (MGD3): north polar region (MC-1) distribution, applications, and volume estimates. Earth Surface Processes and Landforms, doi:10.1002/esp.2219.

Hayward, R.K., K.F. Mullins, L.K. Fenton, T.M. Hare, T.N. Titus, M.C. Bourke, A. Colaprete, P.R. Christensen, 2007. Mars global digital dune database and initial science results. J. Geophys. Res. Planets 112, E11007, doi:10.1029/2007JE002943.

Hayward, R.K., T.N. Titus, T.I. Michaels, L.K. Fenton, A. Colaprete, P.R. Christensen, 2009. Aeolian dunes as ground truth for atmospheric modeling on Mars. J. Geophys. Res., 114, E11012, doi:10.1029/2009JE003428.

Hayward, R.K., L.K. Fenton, T.N. Titus, 2014. Mars Global Digital Dune Database (MGD3): Global dune distribution and wind pattern observations. Icarus, 230, 38-46, doi:10.1016/j.icarus.2013.04.011.

Hersen, P., 2004. On the crescentic shape of barchan dunes. Eur. Phys. J. B., vol. 37, 507-514, doi:10.1140/epjb/e2004-00087-y.

Hesse, P., N. Lancaster, M.W. Telfer, 2015. Digital mapping of the extent of global dune systems. Geophysical Research Abstracts, vol. 17, EGU2015-3638.

Horgan, B.H.N., J.F. Bell, 2012. Seasonally active slipface avalanches in the north polar sand sea of Mars: Evidence for a wind-related origin. Geophys. Res. Lett. 39, L09201, doi:10.1029/2012GL051329.

Hugenholtz, C.H., T.E. Barchyn, 2010. Spatial analysis of sand dunes with a new global topographic dataset: new approaches and opportunities. Earth Surf. Process. Landforms 35, 986-992, doi:10.1002/esp.2013.

Jackson, D.W.T., M.C. Bourke, T.A.G. Smyth, 2015. The dune effect on sand-transporting winds on Mars. Nature Communications, DOI: 10.1038/ncomms9796.

Jain, M., C.E. Andersen, L. Bøtter-Jensen, A.S. Murray, H. Haack, J.C. Bridges, 2006. Luminescence dating on Mars: OSL characteristics of Martian analogue materials and GCR dosimetry. Radiation Measurements, 41(7), pp.755-761.

Jerolmack, D.J., R.C. Ewing, F. Falcini, R.L. Martin, C. Masteller, C. Phillips, M.D. Reitz, I. Buynevich, 2012. Internal boundary layer model for the evolution of desert dune fields. Nature Geoscience, 5, 3, 1-4, DOI: 10.1038/ngeo1381.

JPL, Oct. 4, 2012. NASA Mars Curiosity Rover Prepares to Study Martian Soil, Press Release http://www.jpl.nasa.gov/news/news.php?feature $=3540$.

JPL, Feb. 3, 2014. Through the Gap: Curiosity Mars Rover Crosses Dune, Press Release http://www.jpl.nasa.gov/news/news.php?release=2014-035.

JPL, Dec. 10, 2015. NASA Mars Rover Curiosity Reaches Sand Dunes, Press Release http://www.jpl.nasa.gov/news/news.php?feature=4787. 
Klammer, G., 1982. Die Paleoste des Pantanal von Mato Grosso und die pleistozene Klimageschichte der brasilianischen Randtropen. Zeitschrift. der Geomorphologie N.F., vol. 26, 393-416

Kieffer, S.W., R. Lopes-Gautier, A. McEwen, W. Smythe, L. Keszthelyi, R. Carlson, 2000. Prometheus: Io's wandering plume. Science 288, 1204-1208.

Kocurek, G., R.C. Ewing, 2005. Aeolian dune field self-organization - implications for the formation of simple versus complex dune-field patterns. Geomorphology 72, 94-105, doi:10.1016/j.geomorph.2005.05.005.

Kocurek, G., N. Lancaster, 1999. Aeolian system sediment state: theory and Mojave Desert Kelso dune field example. Sedimentology 46, 505 - 515.

Kocurek, G., R.C. Ewing, 2012. Source-to-sink: An Earth/Mars comparison of boundary conditions for eolian dune systems. Sedimentary Geology of Mars, SEPM Special Publication No. 102, Print ISBN 978-1-56576-312-8, CD/DVD ISBN 978-1-56576-313-5, p. 151-168.

Kocurek, G., M. Carr, R. Ewing, K.G. Havholm, Y.C. Nagar, A.K. Singhvi, 2007. White Sands Dune Field, New Mexico: age, dune dynamics and recent accumulations. Sedimentary Geology, vol. 197, no. 3, 313-331.

Kok, J. F., N.O. Renno, 2009. A comprehensive numerical model of steady state saltation (COMSALT). J. Geophys. Res., 114, D17204, doi:10.1029/2009JD011702.

Kok, J.F., 2010. Difference in the wind speeds required for initiation versus continuation of sand transport on Mars: Implications for dunes and dust Storms. Phys. Rev. Lett. 104, 074502, doi:10.1103/PhysRevLett.104.074502.

Kok J.F., E.J.R. Parteli, T.I. Michaels, D. Bou Karam, 2012. The physics of windblown sand and dust. Rep. Prog. Phys. 75, 106901, doi:10.1088/0034-4885/75/10/106901.

Kreslavsky, M.A., R.V. Vdovichenko, 1999. Anisotropy of Venus Surface Properties Inferred from Magellan Side-Looking-Radar Data. Solar System Research 33, 110.

Lancaster, N., 1995. Geomorphology of Desert Dunes (Routledge Physical Environment Series). Routledge. ISBN-13: 978-0415060943.

Lancaster, N., S. Wolfe, D. Thomas, C. Bristow, O. Bubenzer, S. Burrough, G. Duller, A. Halfen, P. Hesse, J. Roskin, A. Singhvi, H. Tsoar, A. Tripaldi, X. Yang, M. Zárate, M., in press. The INQUA Dunes Atlas chronologic database. Quaternary International, doi:10.1016/j.quaint.2015.10.044.

Lapotre, M.G.A., R.C. Ewing, M.P. Lamb, W.W. Fischer, J.P. Grotzinger, D.M. Rubin, K.W. Lewis, M. Ballard, M. Day, S. Gupta, S.G. Banham, N.T. Bridges, D.J. Des Marais, A.A. Fraeman, J.A. Grant, K.E. Herkenhoff, D.W. Ming, M.A. Mischna, M.S. Rice, D.A. Summer, A.R. Vasavada, R.A. Yingst, $2016 a$. Large wind ripples on Mars: A record of atmospheric evolution. Science, 353, 6294, 55-58, DOI: 10.1126/science.aaf3206.

Lapotre, M.G.A., B.L. Ehlmann, A.A. Fraeman, S.E. Minson, F. Ayoub, R.C. Ewing, R.E. Arvidson, N.T. Bridges, MSL Science Team, 2016b. A quantitative assessment of aeolian fractionation at the Bagnold dunes of Gale crater, Mars, from orbit to the ground. 47 th LPSC, Ab. 1513.

Le Gall, A., A.G. Hayes, R. Ewing, M.A. Janssen, J. Radebaugh, C. Savage, P. Encrenaz, 2012. Latitudinal and altitudinal controls of Titan's dune field morphometry. Icarus, vol. 217, issue 1, 231-242.

Livingstone, I., G.F. Wiggs, C.M. Weaver, 2007. Geomorphology of desert sand dunes: a review of recent progress. Earth-Science Reviews, 80(3), 239-257. 
Livingstone, I., C. Bristow, R.G. Bryant, J. Bullard, K. White, G.F. Wiggs, A.C. Baas, M.D. Bateman, D.S. Thomas, 2010. The Namib Sand Sea digital database of aeolian dunes and key forcing variables. Aeolian Research, 2(2), 93-104.

Lorenz, R.D., 2015. Heights of Fortuna-Meshknet Dunes (Al-Uzza Undae), Venus, from Magellan Radarclinometry. Fourth Annual International Planetary Dunes Workshop, abstract \# 8004.

Lorenz, R.D., J. Radebaugh, 2009. Global pattern of Titan's dunes: Radar survey from the Cassini prime mission. Geophys. Res. Lett. 36, L03202, doi:10.1029/2008/GL036850.

Lorenz, R.D., J.I. Lunine, J.A. Grier, M.A. Fisher, 1995. Prediction of aeolian features on planets: Application to Titan paleoclimatology. JGR 100(E12), 26377-26386.

Lorenz, R.D., S. Wall, J. Radebaugh, G. Boubin, E. Reffet, M. Janssen, E. Stofan, R. Lopes, R. Kirk, C. Elachi, J. Lunine, K. Mitchell, F. Paganelli, L. Soderblom, C. Wood, L. Wye, H. Zebker, Y. Anderson, S. Ostro, M. Allison, R. Boehmer, P. Callahan, P. Encrenaz, G.G. Ori, G. Francescetti, Y. Gim, G. Hamilton, S. Hensley, W. Johnson, K. Kelleher, D. Muhleman, G. Picardi, F. Posa, L. Roth, R. Seu, S. Shaffer, B. Stiles, S. Vetrella, E. Flamini, R. West, 2006. The sand seas of Titan: Cassini RADAR observations of longitudinal dunes. Science 312, 724-727, doi: 10.1126/science.1123257.

Lorenz, R. D., R.M. Lopes, F. Paganelli, J.I. Lunine, R.L. Kirk, K.L. Mitchell, L.A. Soderblom, E.R. Stofan, G. Ori, M. Myers, H. Miyamoto, J. Radebaugh, B. Stiles, S.D. Wall, C.A. Wood and the Cassini RADAR Team, 2008. Fluvial channels on Titan: Initial Cassini RADAR observations. Planet. Space Sci. 56, $1132-1144$.

Lucas, A., S. Rodriguez, C. Narteau, B. Charnay, S.C. Pont, T. Tokano, A. Garcia, M. Thiriet, A.G. Hayes, R.D. Lorenz, O. Aharonson, 2014. Growth mechanisms and dune orientation on Titan. Geophysical Research Letters, 41(17), 6093-6100.

Madigan, C.T., 1936. The Australian sand-ridge deserts. Geographical Review, 26(2), 205-227.

Malaska, M.J., R.M. Lopes, A.G. Hayes, J. Radebaugh, R.D. Lorenz and E.P. Turtle, 2016. Material transport map of Titan: The fate of dunes. Icarus, 270, 183-196, doi:10.1016/j.icarus.2015.09.029.

Marsh, G.P., 1864. Man and Nature. (Reprint, 1965) Cambridge, MA: Harvard University Press.

Marshall, J.R., R. Greeley, 1992. An experimental study of aeolian structures on Venus. J. Geophys. Res. 97(E1), 1007-1016.

May, J.H., 2013. Dunes and dune fields in the Bolivian Chaco as potential records of environmental change. Aeolian Research, vol. 10, 89-102.

McCauley, J.F., M.H. Carr, J.A. Cutts, W.K. Hartmann, H. Masursky, D.J. Milton, R.P. Sharp, D.E. Wilhelms, 1972. Preliminary Mariner 9 Report on the Geology of Mars, Icarus 17(2), 289-327, doi:10.1016/0019-1035(72)90003-6.

McEwen, A.S., M.J.S. Belton, H.H. Breneman, S.A. Fagents, P. Geissler, R. Greeley, J.W. Head, G. Hoppa, W.L. Jaeger, T.V. Johnson, L. Keszthelyi, 2000. Galileo at lo: Results from high-resolution imaging. Science, vol. 288, no. 5469, 1193-1198.

McEwen, A.S., E.M. Eliason, J.W. Bergstrom, N.T. Bridges, C.J. Hansen, W.A. Delamere, J.A. Grant, V.C. Gulick, K.E. Herkenhoff, L. Keszthelyi, R.L. Kirk, 2007. Mars Reconnaissance Orbiter's High Resolution Imaging Science Experiment (HiRISE). J. Geophys. Res., 112, issue E5, doi:10.1029/2005JE002605. 
McKeever, S.W.S., D. Banerjee, M. Blair, S.M. Clifford, M.S. Clowdsley, S.S. Kim, M. Lamothe, K. Lepper, M. Leuschen, K.J. McKeever, M. Prather, 2003. Concepts and approaches to in situ luminescence dating of martian sediments. Radiation Measurements, 37(4), pp.527-534.

Mellon, M.T., B.M. Jakovsky, H.H. Kieffer, P.R. Christensen, 2000. High-resolution thermal inertia mapping from the Mars Global Surveyor Thermal Emissino Spectrometer. Icarus, 148, 437-455, doi:10.1006/icar.2000.6503.

Milazzo, M.P., L.P. Keszthelyi, A.S. McEwen, 2001. Observations and initial modeling of lava-SO ${ }_{2}$ interactions at Prometheus, lo. J. Geophys. Res. 106, 33,121-33,127.

Moore, J.M., A.D. Howard, P.M. Schenk, W.B. McKinnon, R.T. Pappalardo, R.C. Ewing, E.B. Bierhaus, V.J. Bray, J.R. Spencer, R.P. Binzel, B. Buratti, 2015. Geology before Pluto: Pre-encounter considerations. Icarus, 246, 65-81, doi:10.1016/j.icarus.2014.04.028.

Moore, J.M., W.B. McKinnon, J.R. Spencer, A.D. Howard, P.M. Schenk, R.A. Beyer, F. Nimmo, K.N. Singer, O.M. Umurhan, O.L. White, S.A. Stern, K. Ennico, C.B. Olkin, H.A. Weaver, L.A. Young, R.P. Binzel, M.W. Buie, B.J. Buratti, A.F. Cheng, D.P. Cruikshank, W.M. Grundy, I.R. Linscott, H.J. Reitsema, D.C. Reuter, M.R. Showalter, V.J. Bray, C.L. Chavez, C.J.A. Howett, T.R. Lauer, C.M. Lisse, A.H. Parker, S.B. Porter, S.J. Robbins, K. Runyon, T. Stryk, H.B. Throop, C.C.C. Tsang, A.J. Verbiscer, A.M. Zangari, A.L. Chaikin, D.E. Wilhelms, New Horizons Science Team, 2016. The geology of Pluto and Charon through the eyes of New Horizons. Science v. 351, Is. 6279, 1284-93. doi:10.1126/science.aad7055.

Mottola, S., Arnold, G., Grothues, H.-G., Jaumann, R., Michaelis, H., Neukum, G., Bibring, J.-P., Schröder, S.E., Hamm, M., Otto, K.A., Pelivan, I., Proffe, G., Scholten, F., Tirsch, D., Kreslavsky, M., Remetean, E., Souvannavong, F., Dolives, B., 2015. The structure of the regolith on 67P/ChuryumovGerasimenko from ROLIS descent imaging. Science 349, 10.1126/science.aab0232.

Neakrase, L.D.V. (2015), Terrestrial Analogues for Venusian dunes: Sub-aqueous, seafloor dune fields. Fourth International Planetary Dunes Workshop. Ab. 8023.

New Horizons, 2015. http://www.nasa.gov/mission_pages/newhorizons/images/index.html.

New Horizons, 2016. The Tartarus Dorsa Mountains Rise Up Along Pluto, http://www.nasa.gov/imagefeature/the-tartarus-dorsa-mountains-rise-up-along-pluto.

NRC, 2013. Vision and Voyages for Planetary Science in the Decade 2013-2022. Steering Group Chair: Squyres, National Academies Press, Washington, D.C., ISBN: 0-309-20955-2.

O'Connell-Cooper, C.D., L.M. Thompson, J.G. Spray, J.A. Berger, E.D. Desouza, M. Schmidt, A. Yen, N.I. Boyd, R. Gellert, G. Perrett, S.J. VanBommel, the MSL-APXS Team, 2016. Preliminary comparison of soils within Gale crater to those from Gusev Crater and Meridiani Planum. 47 ${ }^{\text {th }}$ LPSC, Ab. 2477.

Parteli, E.J.R., O. Durán, H.J. Herrmann, 2007. Minimal size of a barchan dune. Phys. Rev. E 75, 011301, doi:10.1103/PhysRevE.75.011301.

Parteli, E.J.R., O. Durán, H. Tsoar, V. Schwämmle, H.J. Herrmann, 2009. Dune formation under bimodal winds. PNAS 106(52), 22085-22089, doi:10.1073/pnas.0808646106.

Pelletier, J.D., 2009. Controls on the height and spacing of eolian ripples and transverse dunes: A numerical modeling investigation. Geomorphology, v. 105, 322-333, doi:10.1016/j.geomorph.2008.10.010.

Pelletier, J.D., 2015. Controls on the large-scale spatial variations of dune field properties in the barchanoid portion of White Sands dune field, New Mexico. J. Geophys. Res. Earth Surf., 120, 453473, doi:10.1002/2014JF003314. 
1513

1514

1515

1516

1517

1518

1519

1520

1521

1522

1523

1524

1525

1526

1527

1528

1529

1530

1531

1532

1533

1534

1535

1536

1537

1538

1539

1540

1541

1542

1543

1544

1545

1546

1547

1548

1549

1550

1551

1552

Portyankina, G., A. Pommerol, K.-M. Aye, C. J. Hansen, N. Thomas, 2012. Polygonal cracks in the seasonal semi-translucent $\mathrm{CO}_{2}$ ice layer in Martian polar areas. J. Geophys. Res., 117(E2006), doi:10.1029/2011JE003917.

Radebaugh, J., 2013. Dunes on Saturn's moon Titan at the end of the Cassini Equinox Mission. Aeolian Research 11, 23-41.

Radebaugh, J., R. Lorenz, J. Lunine, S. Wall, G. Boubin, E. Reffet, R. Kirk, R. Lopes, E. Stofan, L. Soderblom, M. Allison, M. Janssen, P. Paillou, P. Callahan and the Cassini Radar Team, 2008. Dunes on Titan observed by Cassini Radar. Icarus 194, 690-703, doi:10.1016/j.icarus.2007.10.015.

Radebaugh, J., R. Lorenz, T. Farr, P. Paillou, C. Savage, C. Spencer, 2010. Linear dunes on Titan and earth: Initial remote sensing comparisons. Geomorphology 121, 122-132, doi:10.1016/j.geomorph.2009.02.022.

Radebaugh, J., R.D. Lorenz, S.D. Wall, R.L. Kirk, C.A. Wood, J.I. Lunine, E.R. Stofan, R.M.C. Lopes, P. Valora, T.G. Farr, A.G. Hayes, B. Stiles, G. Mitri, H. Zebker, M. Janssen, L. Wye, A. Le Gall, K.L. Mitchell, F. Paganelli, R.D. West, E.L. Schaller and the Cassini RADAR Team, 2011. Regional geomorphology and history of Titan's Xanadu province. Icarus 211, 672-685.

Radebaugh, J., D. Ventra, R.D. Lorenz, T. Farr, R. Kirk, A. Hayes, M.J. Malaska, S. Birch, Z. Y-C. Liu, J. Lunine, J. Barnes, A. Le Gall, R. Lopes, E. Stofan, S. Wall, P. Paillou, 2016. Alluvial and fluvial fans on Saturn's moon Titan reveal processes, materials and regional geology, in, Ventra, D. \& Clarke, L. E. (eds) Geology and Geomorphology of Alluvial and Fluvial Fans: Terrestrial and Planetary Perspectives. Geological Society, London, Special Publications, 440, doi: 10.1144/SP440.6.

Rubin, D.M., 2012. A unifying model for planform straightness of ripples and dunes in air and water. Earth-Science Reviews, 113(3), 176-185, doi:10.1016/j.earscirev.2012.03.010.

Rubin, D.M., P.A. Hesp, 2009. Multiple origins of linear dunes on Earth and Titan. Nature Geoscience, vol. 2, 653-658, doi:10.1038/ngeo610.

Rubin, D.M., R.E. Hunter, 1987. Bedform alignment in directionally varying flows. Science, 237(4812), 276-8, doi:10.1126/science.237.4812.276.

Rubin, D. M., H. Ikeda, 1990. Flume experiments on the alignment of transverse, oblique, and longitudinal dunes in directionally varying flows. Sedimentology, 37, 673-684.

Sagan, C., J. Veverka, P. Fox, R. Dubisch, J. Lederberg, E. Levinthal, L. Quam, R. Tucker, J.B. Pollack, B.A. Smith, 1972. Variable features on Mars: Preliminary Mariner 9 television results. Icarus 17(2), 346372, doi:10.1016/0019-1035(72)90005-X.

Sauermann, G., K. Kroy, H.J. Herrmann, 2001. Continuum saltation model for sand dunes, Physical Review E, v. 64, 031305, doi:10.1103/PhysRevE.64.031305.

Savage, C.J., J. Radebaugh, E.H. Christiansen, R.D. Lorenz, 2014. Implications of dune pattern analysis for Titan's surface history. Icarus 230, 180-190.

Silvestro, S., G. Di Achille, G.G. Oria, 2010a. Dune morphology, sand transport pathways and possible source areas in east Thaumasia Region (Mars), Geomorphology, vol. 121, 84-97, doi:10.1016/j.geomorph.2009.07.019.

Silvestro, S., L.K. Fenton, D.A. Vaz, N.T. Bridges, G.G. Ori, 2010b. Ripple migration and dune activity on Mars: Evidence for dynamic processes. Geophys. Res. Lett. 37, L20203 (2010). 
Silvestro, S., D.A. Vaz, L.K. Fenton and P.E. Geissler, 2011. Active Aeolian processes on Mars: a regional study in Arabia and Meridiani Terrae, Geophysical Research Letters, 38, L20201, doi:10.1029/2011GL048955.

Silvestro S., L.K. Fenton, T.I. Michaels, A. Valdez, G.G. Ori, 2012. Interpretation of the complex dune morphology on Mars: dune activity, modeling and a terrestrial analogue. Earth Surface Processes and Landforms, 37, 13, 1424-1436, DOI: 10.1002/esp.3286.

Silvestro, S., D.A. Vaz, R.C. Ewing, A.P. Rossi, L.K. Fenton, T.I. Michaels, J. Flahaut and P.E. Geissler, 2013. Pervasive aeolian activity along Curiosity's traverse in Gale Crater, Mars. Geology, 41 (4), 483-486, doi:10.1130/G34162.1.

Silvestro S., D.A. Vaz, H. Yizhaq, F. Esposito, 2016. Dune-like dynamic of martian aeolian large ripples. Geophysical Research Letters, doi:10.1002/2016GL070014.

Singhvi, A.K., N. Porat, 2008. Impact of luminescence dating on geomorphological and palaeoclimate research in drylands. Boreas, 37(4), 536-558.

Soderblom, L., J. Anderson, K. Baines, J. Barnes, J. Barrett, R. Brown, B. Buratti, R. Clark, D. Cruikshank, C. Elachi, M. Janssen, R. Jaumann, R. Kirk, E. Karkoschka, S. Lemouelic, R. Lopes, R. Lorenz, J. Lunine, T. McCord, P. Nicholson, J. Radebaugh, B. Rizk, C. Sotin, E. Stofan, T. Sucharski, M. Tomasko, S. Wall, 2007. Correlations between Cassini VIMS spectra and RADAR SAR images: Implications for Titan's surface composition and the character of the Huygens Probe landing site. Planetary and Space Science, 55, 2025-2036.

Sohbati, R., A.S. Murray, J.P. Buylaert, M. Ortuño, P.P. Cunha, E. Masana, 2012. Luminescence dating of Pleistocene alluvial sediments affected by the Alhama de Murcia fault (eastern Betics, Spain)-a comparison between OSL, IRSL and post-IR IRSL ages. Boreas, 41(2), 250-262, doi:10.1111/j.15023885.2011.00230.x

Sokolów, N. A., 1894. Die Dunen; Bildung, Entwicklung, and innerer Bau (German transl. from Russian 4th ed., 1884, assisted by A. Arzruni). Berlin, Springer.

Sullivan, R., R. Arvidson, J.F. Bell III, R. Gellert, M. Golombek, R. Greeley, K. Herkenhoff, J. Johnson, S. Thompson, P. Whelley, J. Wray, 2008. Wind-driven particle mobility on Mars: Insights from Mars Exploration Rover observations at "El Dorado" and surroundings at Gusev Crater. J. Geophys. Res., 113, E06S07, doi:10.1029/2008JE003101.

Stern and the New Horizons team, 2016. New Horizons: The Exploration of the Pluto System and the Kuiper Belt beyond. 47th LPSC, Ab. 1317.

Sullivan, R., D. Banfield, J. F. Bell III, W. Calvin, D. Fike, M. Golombek, R. Greeley, J. Grotzinger, K. Herkenhoff, D. Jerolmack, M. Malin, D. Ming, L. A. Soderblom, S. W. Squyres, S. Thompson, W.A. Watters, C.M. Weitz, A. Yen, 2005. Aeolian processes at the Mars Exploration Rover Meridiani Planum landing site. Nature 436, 58-61, doi:10.1038/nature03641.

Tanaka, K.L., Rodriguezb, J.A.P., Skinner Jr., J.A., Bourke, M.C., Fortezzo, C.M., Herkenhoff, K.E., Kolb, E.J., Okubo, C.H., 2008. North polar region of Mars: Advances in stratigraphy, structure, and erosional modification. Icarus 192, 318-358, 10.1016/j.icarus.2008.01.021.

Teeuw, R.M., E.J. Rhodes, 2004. Aeolian activity in northern Amazonia: optical dating of Late Pleistocene and Holocene palaeodunes. Journal of Quaternary Science, 19(1), pp.49-54.

Telfer, M.W., 2011. Growth by extension, and reworking, of a south-western Kalahari linear dune. Earth Surface Processes and Landforms, 36(8), pp.1125-1135. 
Telfer, M.W. and Thomas, D.S.G., 2007. Late Quaternary linear dune accumulation and chronostratigraphy of the southwestern Kalahari: implications for aeolian palaeoclimatic reconstructions and predictions of future dynamics. Quaternary Science Reviews, 26(19), pp.26172630.

Tirsch, D., R. Jaumann, A. Pacifici, F. Poulet, 2011. Dark aeolian sediments in Martian craters: Composition and sources. J Geophys Res-Planet 116, doi: 10.1029/2009je003562.

Thomas, P., 1981. North-south asymmetry of eolian features in martian polar regions: Analysis based on crater-related wind markers. Icarus, 48, 76-90.

Thomas, P., 1982. Present wind activity on Mars - Relation to large latitudinally zoned sediment deposits. J. Geophys. Res., 87(B12), 9999-10,008, doi:10.1029/JB087iB12p09999.

Thomas, N., H. Sierks, C. Barbieri, P.L. Lamy, R. Rodrigo, H. Rickman, D. Koschny, H.U. Keller, J. Agarwal, M.F. A'Hearn, F. Angrilli, A.-T. Auger, M.A. Barucci, J.-L. Bertaux, I. Bertini, S. Besse, D. Bodewits, G. Cremonese, V. Da Deppo, B. Davidsson, M. De Cecco, S. Debei, S., M.R. El-Maarry, F. Ferri, S. Fornasier, M. Fulle, L. Giacomini, O. Groussin, P.J. Gutierrez, C. Güttler, S.F. Hviid, W.-H. Ip, L. Jorda, J. Knollenberg, J.-R. Kramm, E. Kührt, M. Küppers, F. La Forgia, L.M. Lara, M. Lazzarin, J.J.L. Moreno, S. Magrin, S. Marchi, F. Marzari, M. Massironi, H. Michalik, R. Moissl, S. Mottola, G. Naletto, N. Oklay, M. Pajola, A. Pommerol, F. Preusker, L. Sabau, F. Scholten, C. Snodgrass, C. Tubiana, J.-B. Vincent, K.-P. Wenzel, 2015a. The morphological diversity of comet 67P/Churyumov-Gerasimenko. Science 347, doi:10.1126/science.aaa0440.

Thomas, N., B. Davidsson, M.R. El-Maarry, S. Fornasier, L. Giacomini, A.G. Gracia-Berná, S.F. Hviid, W.-H. Ip, L. Jorda, H.U. Keller, J. Knollenberg, E. Kührt, F. La Forgia, I.L. Lai, Y. Liao, R. Marschall, M. Massironi, S. Mottola, M. Pajola, O. Poch, A. Pommerol, F. Preusker, F. Scholten, C.C. Su, J.S. Wu, J.B. Vincent, H. Sierks, C. Barbieri, P.L. Lamy, R. Rodrigo, D. Koschny, H. Rickman, M.F. A'Hearn, M.A. Barucci, J.-L. Bertaux, I. Bertini, G. Cremonese, V. Da Deppo, S. Debei, M. de Cecco, M. Fulle, O. Groussin, P.J. Gutierrez, J.-R. Kramm, M. Küppers, L.M. Lara, M. Lazzarin, J.J. Lopez Moreno, F. Marzari, H. Michalik, G. Naletto, J. Agarwal, C. Güttler, N. Oklay, C. Tubiana, 2015b. Redistribution of particles across the nucleus of comet 67P/Churyumov-Gerasimenko. Astronomy and Astrophysics, 583, A17, doi:10.1051/0004-6361/201526049.

Treiman, A.H., 2003. Geologic settings of Martian gullies: Implications for their origins. J. Geophys. Res. 108 (E4), 8031, doi:10.1029/2002JE001900.

Tricart, J., 1974. Existence de periodes seches au Quaternaire en Amazonie et dans les regions voisines. Révue de Géomorphologie Dynamique 23, 145-158

Trilling, D.E., 2016. The surface age of Sputnik Planum, Pluto, must be less than 10 million years. PLOS ONE, doi:10.1371/journal.pone.0147386.

Tripaldi, A., M.A. Zárate, in press. A review of Late Quaternary inland dune systems of South America east of the Andes. Quaternary International, available online 24 July 2014, doi:10.1016/j.quaint.2014.06.069.

Tokano, T., 2008. Dune-forming winds on Titan and the influence of topography. Icarus 194, 243-262, doi:10.1016/j.icarus.2007.10.007.

Tsoar, H., R. Greeley, A.R. Peterfreund, 1979. Mars: The north polar sand seas and related wind patterns. J. Geophys. Res., vol. 84, no. B14, 8167-8180.

Tsoar, H., 1983. Dynamic processes acting on a longitudinal (seif) dune. Sedimentology 30, 567-578. 
Vaz, D.A., S. Silvestro, 2014. Mapping and characterization of small-scale aeolian structures on Mars: An example from the MSL landing site in Gale Crater. Icarus, vol. 230, 151-161.

Vaz, D.A., S. Silvestro, P.T.K. Sarmento, M. Cardinale, submitted. Migrating meter-scale bedforms on Martian dark dunes: are terrestrial aeolian ripples good analogs? To Aeolian Research (this issue). Ward, A.W., 1979. Yardangs on Mars: Evidence of recent wind erosion. J. Geophys. Res 84, 8147-8165. Ward, A.W., K.B. Doyle, P.J. Helm, M.K. Weisman, N.E. Witbeck, 1985. Global map of eolian features on Mars. J. Geophys. Res., 90(B2), 2038-2056.

Weitz, C.M., J.J. Plaut, R. Greeley, R.S. Saunders, 1994. Dunes and microdunes on Venus: Why were so few found in the Magellan data? Icarus 112, 282-295.

Werner, B.T., 1995. Eolian dunes: Computer simulations and attractor interpretation. Geology 23(12), 1107-1110.

Williams, S.H., R. Greeley, 1994. Windblown sand on Venus: The effect of high atmospheric density. Geophys. Res. Lett. 21(25), 2825-2828.

Wilson, L., J.W. Head, 1994. Mars: Review and analysis of volcanic eruption theory and relationships to observed landforms. Reviews of Geophysics, vol. 32, no. 3, 221-263.

Zimbelman, J.R., 2000. Non-active dunes in the Acheron Fossae Region of Mars between the Viking and Mars Global Surveyor eras. Geophys. Res. Lett. 27, 1069-1072, doi:10.1029/1999GL008399. 
1 Title: Our evolving understanding of aeolian bedforms, based on observation of dunesstudies onf 2 different worlds

3 (C) 2016. All rights reserved

4

$5 \quad$ Abstract (253 words)

6 Dunes, dune fields, and smaller aeolian bedformstipples are unique and useful records of the interaction between wind and granular materials - finding a dune fieldsuch features on a planetary surface immediately suggests certain information about climate and surface conditions (at least during the

9 dunes' formation and evolution). Additionally, studies of dune characteristics under non-Earth

10 conditions allow for "tests" of aeolian process models based primarily on observations of terrestrial

11 features and dynamics, and refinement of the models to include consideration of a wider range of

12 environmental and planetary conditions. To-date, the planetary aeolian community has found and

13 studied dune fields on Mars, Venus, and the Saturnian moon Titan. Additionally, we have observed

14 candidate "aeolian bedforms" on Comet 67P/Churyumov-Gerasimenko, the Jovian moon lo, and - most

15 recently -- Pluto. In this paper, we hypothesize that the progression of investigations of aeolian bedforms and processes on a particular planetary body follows a consistent sequence - primarily set by

17 the acquisition of data of particular types and resolutions, and by the maturation of knowledge about

18 that planetary body. We define that sequence of generated knowledge and new questions (within seven

19 | investigation phases) and discuss examples from all of the studied bodies. The - with an aim of such a

20 sequence is to better define our past and current state of understanding about the aeolian bedforms of

21 a particular body, to highlight the related assumptions that require re-analysis with data acquired during

22 later investigations, and to use lessons learned from planetary and terrestrial aeolian studies to predict

23 what types of investigations could be most fruitful in the future.

25 Keywords (at least 6): Planetary; terrestrial; aeolian bedforms; aeolian science; dunes; ripples 
$27 \quad$ Highlights (max 85 characters, including spaces)

- Planetary dunes yield useful/unique information about climate $\&$ surface conditions.

- Aeolian bedform studies progress logically in questions/assumptions/new knowledge.

- Considering this progression exposes gaps/assumptions to be reviewed with new data.

- Comparinge planetary progression with Earth aeolian studiesto yields lessons for each.

\section{Introduction}

Over the past couple of centuries, explorers and scientists of terrestrial dune fields have shown

that the interaction between wind and granular material results in regular geometries and rates of evolution. Field observations and studies have inspired modeling and experimental works that have

37 aided in the interpretation of measurable ripples and dunes as proxy indicators of wind speed and direction(s), grain sizes and sources, and underlying topography. The study of such landforms has been greatly extended and advanced by observation of analogous features on other planetary bodies. The comparison of these extraterrestrial features with aeolian process models has increased our understanding of aeolian bedform evolution in both directions - observations of (potential) aeolian

42 bedforms generate investigations into the wind regime and granulometrics of surface materials on a

43 planetary body, and also enable refinement of bedform evolution models as hypotheses about 44 dominant effects are "tested" outside of Earth-conditions. bedformssand dunes and/or ripples on a planetary body, and the information those aeolian bedforms yield about planetary conditions and processes, has progressed on different bodies. We hypothesize follows a consistent sequence - primarily set by the acquisition of data of particular types and 50 resolutions, and by the maturation of knowledge about that planetary body. Our aim is to define that 
51

52

53

54

55

56

57

58

59

60

61

62

63

64

65

66

67

68

69

70

71

72

73

74

progression so we can better constrain our understanding level of knowledge aboutef the aeolian bedforms of a particular body, highlight the gaps in our knowledge (i.e., our assumptions), and predict what type of future investigations could be most useful in addressing new questions and/or enabling improvement over an assumption.

In the interests of space and focus, most discussion (and cited literature) will focus on dunes and $\underline{\text { dune fields - i.e., the larger aeolian bedforms and thus usually the first seen on a planetary body. We do }}$ delve into ripples (and martian mega-ripples) in portions of the discussion, but primarily as features seen on dunes and that complement dune analysis; and we acknowledge that far more could be said about these smaller-scale bedforms and that studies of these bedforms on Mars has contributed much more towards our understanding of the aeolian environment and processes than is presented here. We also do not generally discuss other types of aeolian bedforms within this paper. In particular, we do not include discussion of Transverse Aeolian Ridges (TARs) on Mars as there is still much debate about their formation mechanism (perhaps as they are an example of a feature that does not have a good terrestrial analog?). It is likely, however, that one could trace advancements in our understanding of TARs or other aeolian features along a similar progression of ideas as is presented here for dunes, as all of these $\underline{\text { features are studied via similar observation types and their dynamics and morphologies tie into similar }}$ questions about atmospheric and surface conditions. We also consider only the observation and analysis of aeolian-bedforms on the surface of a planet, not e.g., evidence of past bedforms recorded within sandstone stratigraphy (and thus, while dunes and ripples can also form due to the flow of other fluids, such as water, in this paper we focus on aeolian dunes). Thirdly, in discussing our evolution in thinking $\underline{\text { about aeolian bedforms and processes on other planets, we focus on observation-driven science }}$ advancements; we touch on but do not delve as deeply into the parallel lines of investigation focused on model development and validation, empirical studies, and (analog) terrestrial field work - investigations that feed into advancements within (and between) the Phases that we outline here. Finally, we 
recognize that we present only a sampling of relevant studies - we aimed for enough to map out advances in understanding, to justify our proposed framework, and to provide a starting ground for any reader interested in learning more on a more specific topic.

In defining the "progression" of understanding (Section 2), we focus on Mars, Venus, and the Saturnian moon Titan - all planetary bodies where aeolian bedforms have primarily been explored with remotely acquired data. We also will comment on recently discovered candidate "aeolian bedforms" on Comet 67P/Churyumov-Gerasimenko and possible dune-like landforms on lo and Pluto. Within each phase of investigation (Subsections 2.1-7), we aim to identify the type of observations generally needed and connect these to the primary knowledge, assumptions, and questions that result, and then lead into future investigations (summarized at the end of each section). Furthermore, we identify the typical investigations (outside of direct studies of the aeolian bedforms) that follow each gain in knowledge, to show how aeolian bedform studies contribute to the larger study of that planetary body.

Our proposed framework of phases, regarding investigation of aeolian bedforms on a planetary body, is summarized in Table 1. We again note that this framework is not meant to be fully comprehensive for aeolian bedform-dune studies-we focus here on investigations relying on remote observations (exception: Phase 7) and on planetary studies, not the (parallel) development and validation of the models and terrestrial in situ studies that often feed information into those studies. We also note that progression in investigations and understanding is not necessarily linear/sequential - for example, planetary missions are generally focused on objectives other than aeolian bedform investigations, so observation types can be acquired in a "mixed" order. Additionally, the advent of new $\underline{\text { missions, methods, or models can lead to renewed activity within "lower" phases along with advances }}$ into higher phases. Science questions also often end up circling back as an assumption becomes superseded by new information and derived products and assumptions must be re-thought. Thus, in addition to identifying typical assumptions associated with each Phase, $s$, we use that framework to 
99 identify some example areas of knowledge gaps or the types of typical assumptions and results that 100 need re-evaluation when new data becomes available (Section 3.1).

101 We also then-discuss how modeling (Section 3.2) and terrestrial studies (Section 3.3) relate to 102 planetary aeolian studies. In particular, we highlight lessons learned regarding our understanding of

103 aeolian processes and their drivers, as well as in methodologies employed. These lessons translate (or 104 could translate) to improved results within other areas of aeolian science. 
Table 1. Summary of the investigation phases

\begin{tabular}{|c|c|c|c|c|c|}
\hline \multicolumn{2}{|r|}{$\begin{array}{l}\text { Phase of aeolian bedform study on } \\
\text { a planetary body }\end{array}$} & \multirow{2}{*}{$\begin{array}{l}\begin{array}{l}\text { Area of } \\
\text { interest }\end{array} \\
\text { Dune } \\
\text { (possibl } \\
\text { y a dune } \\
\text { field) }\end{array}$} & \multirow{2}{*}{$\begin{array}{l}\text { "Unit" }+ \text { Characteristic } \\
\text { (s)/Feature }(\mathrm{s}) \text { of } \\
\text { interest } \\
\text { Dune morphology } \\
\text { (and-i.e., } \\
\text { recognizable, } \\
\text { distinctive gross dune } \\
\text { shape or crestline } \\
\text { patterns within a } \\
\text { field) }\end{array}$} & \multirow{2}{*}{$\begin{array}{l}\text { Data needed to move to this phase } \\
\text { (from an earlier phase) }\end{array}$} & \multirow{2}{*}{$\begin{array}{l}\text { Complementary science } \\
\text { investigations } \\
\text { Knowledge of and about } \\
\text { analog features (terrestrial } \\
\text { or planetary) }\end{array}$} \\
\hline 1 & Recognition of dune(s) & & & & \\
\hline 2 & $\begin{array}{l}\text { Analysis of gross individual } \\
\text { dune characteristics: e.g., } \\
\text { morphology and composition }\end{array}$ & Dune & $\begin{array}{l}\text { Dune morphology } \\
\text { characteristics of } \\
\underline{\underline{\text { surface materials }}}\end{array}$ & $\begin{array}{l}\text { Images (visible, radar, spectral, etc.) } \\
\text { with sufficient resolution to } \\
\text { identify/correlate with dune margin } \\
\text { and/or crestline patterns (possibly } \\
\text { same data as Phase 1) }\end{array}$ & $\begin{array}{l}\text { Global/regional-scale } \\
\text { climate models (specifically: } \\
\text { wind velocity, direction, and } \\
\text { variation); Dune formation } \\
\text { models }\end{array}$ \\
\hline 3 & $\begin{array}{l}\text { Pattern Aanalysis of the dunes } \\
\text { within a field, including } \\
\text { variations due to e.g., sediment } \\
\text { supply and wind variations }\end{array}$ & $\begin{array}{l}\text { Dune } \\
\text { field }\end{array}$ & $\begin{array}{l}\text { Dune shapes } \\
\text { throughout the field }\end{array}$ & $\begin{array}{l}\text { Coverage (of images, see above) } \\
\text { throughout dune field }\end{array}$ & $\begin{array}{l}\text { Regional/local-scale climate } \\
\text { models (specifically: wind); } \\
\text { Regional/local-scale } \\
\text { topography; Studies of non- } \\
\text { aeolian dune-modifying } \\
\text { processes (e.g., polar or } \\
\text { surface crust forming } \\
\text { processes); Maps of other } \\
\text { aeolian features around the } \\
\text { dune field }\end{array}$ \\
\hline 4 & $\begin{array}{l}\text { Regional and gGlobal surveys } \\
\text { and aggregate-analysis of dune } \\
\text { characteristicss: } \\
\text { aggregation of data fore-g., } \\
\text { estimates of age or sand } \\
\text { volumes, identification of large- } \\
\text { scale sediment transport } \\
\text { pathways, or identification/ }\end{array}$ & $\begin{array}{l}\text { Regional } \\
\text { or } \\
\text { Global } \\
\text { (i.e.., } \\
\frac{\text { multiple }}{\text { dune }} \\
\text { fields) }\end{array}$ & $\begin{array}{l}\text { Dune field } \\
\text { characteristics } \\
\text { (including } \\
\text { morphology of field } \\
\text { and dunes within } \\
\text { each field) and } \\
\text { spatial distribution }\end{array}$ & $\begin{array}{l}\text { At least regional Global-coverage of } \\
\text { images or (often coarser and/or less } \\
\text { definitive) proxy data (e.g., thermal } \\
\text { inertia) }\end{array}$ & $\begin{array}{l}\text { Expansive composition } \\
\text { maps for identification of } \\
\text { potential sand sources } \\
\text { Maps of other aeolian } \\
\text { features; Global or regional- } \\
\text { scale climate models }\end{array}$ \\
\hline
\end{tabular}




\begin{tabular}{|l|l|l|l|l|l|}
\hline & $\begin{array}{l}\text { estimation of the effect of } \\
\text { location-related non-aeolian } \\
\text { processes }\end{array}$ & & & \\
\hline $\mathbf{5}$ & $\begin{array}{l}\text { Analysis of superposed } \\
\text { bedforms on the dune "details" } \\
\text { (such as ripples) formed due to } \\
\text { wind interaction with the dune }\end{array}$ & Dune & $\begin{array}{l}\text { Within/on-dune } \\
\text { features (e.g., } \\
\text { ripples) }\end{array}$ & (Very) high-resolution images & $\begin{array}{l}\text { Ripple formation models; } \\
\text { High-resolution topography } \\
\text { (dune); } \\
\text { climate } \\
\text { (specify high resolution }\end{array}$ \\
\hline $\mathbf{6}$ & $\begin{array}{l}\text { Observation of activity on the } \\
\text { dune, including non-aeolian } \\
\text { activity }\end{array}$ & Dune & $\begin{array}{l}\text { Smaller-scale } \\
\text { evidence of change } \\
\text { (e.g., ripple } \\
\text { crestlines, dune } \\
\text { margins) }\end{array}$ & $\begin{array}{l}\text { Repeat images for seeing planform } \\
\text { changes (e.g., movement of } \\
\text { material); these images need } \\
\text { sufficient resolution and temporal } \\
\text { baseline for changes to be observable }\end{array}$ & $\begin{array}{l}\text { Ripple and dune migration } \\
\text { models }\end{array}$ \\
\hline $\mathbf{7}$ & Groundtruth data & Dune & $\begin{array}{l}\text { All features and } \\
\text { components of the } \\
\text { dune, especially sand } \\
\text { size/composition }\end{array}$ & $\begin{array}{l}\text { In situ observations of the dune, } \\
\text { sampling and analysis }\end{array}$ & $\begin{array}{l}\text { In situ observations of } \\
\text { potential sediment sources } \\
\text { for fluvio-sedimentary } \\
\text { landforms }\end{array}$ \\
\hline
\end{tabular}




\section{The Phases of Investigation}

\subsection{Phase 1: Recognition of dune(s)}

In this first phase of aeolian studies, we focus on the occurrence of the first observation of a dune (or, more likely, a dune field). This has geologic significance as aeolian bedforms - dunes and ripples - directly record an interaction between the atmosphere and surface: specifically, the movement of granular material due to wind ${ }^{1}$. Furthermore, a dune or ripple is more than a pile of sand - it is a distinctive landform that requires certain conditions to organize, and that appears to evolve and move "as a unit" through the aggregation of the actual movement of individual grains of sand, onto and off of the dune. Specifically, the existence of an aeolian bedform implies:

- A sufficient supply of sand saltatable (sand) grains,

- A wind of sufficient velocity and consistency to move those grains, and

- A period of consistent wind blowing, long enough for the bedform to form and evolve.

107 (We now examine what each of those underlined terms imply about the planetary body's environment,

focusing on the larger-scale dunes that are typically observed first. A more technical summary of the conceptual framework for dune field dynamics and how this is affected by the sediment state of a dune

field -- related to sediment supply, sediment availability, and transport capacity of the wind - is

described within Kocurek and Lancaster (1999).)

113 and evolve, sand must be able to move onto and off of the dune (possible exceptions would be climbing

114 dunes or other such features where the sand accumulates due to blockage). Barchans in particular are

115 an inefficient dune shape due to sand leakage from the horns (Hersen, 2004). Thus, an important

116 implication with the first recognition of a dune feature on a planetary body is that a process must exist

117 that will yield a significant amount of sand (discussed in within an example-more detail in Phase $\underline{43}$ ).

\footnotetext{
${ }^{1}$ Dunes and ripples can also form due to the flow of other fluids, such as water. In this paper, we focus on aeolian dunes.
} 
Depending on the body, that process may involve erosion of larger rocks (e.g., as is common on the

119 Earth) or a process that directly forms grains of that size. For instance, martian volcanic activity has been 120 proposed to create sand-sized particles (Edgett and Lancaster, 1993; Wilson and Head, 1994) and

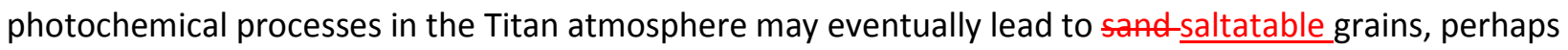
via an intermediate evaporite or sedimentary location (Soderblom et al. 2007; Radebaugh, 2013; Barnes 123 et al. 2015). On the Earth, nearly all dunes and ripples are comprised of sand grains - and this refers to a specific size.Although sand is commonly defined based on size (e.g., the Canada Dept. Agriculture (1976) lists sand as grains 0.05-2 mm in diameter). However, "sand grains"; itcan also be defined as a size class defined-based on dynamics. "Sand" is the size of grains most easily moved by a fluid (Bagnold, 1941) smaller grains are held together by interparticle, cohesive forces and larger grains have more mass and so are held down more by gravity. Under the Earth's atmosphere and gravity, grains $1 \mathrm{~mm}$ in diameter are able to saltate, and thus are the most easily moved by the wind. On Earth, this correlates with the size range generally considered as sand; but on other bodies (with different atmospheric (or fluid) density and gravitył, the grain size most easily moved by the wind could be a different size (Figure 1; Edgett and Christensen, 1991; Greeley et al., 1974; 1980; 1992a; Moore et

al., 2015). Thus, hroughout this discussion, when discussing "sand grains," we mean "the grain most easily moved by the wind (or fluid)" and not a fixed size range. Thus, the existence of a dune_(i.e., a

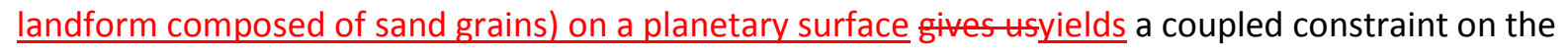
grains and the wind velocity. back-and-forth until that sand became trapped into depressions, sheltered areas, and other sand-traps; 
142 minimum size (e.g., Claudin and Andreotti, 2006; Parteli et al., 2007); below this size the slipface is 143 unable to develop. A slipface is necessary to stabilize the dune (as sand then can be captured on the 144 sheltered, lee slope) to allow it to continue growing and migrating.

145

146

147

148

149

150

151

152

153

154

155

156

157

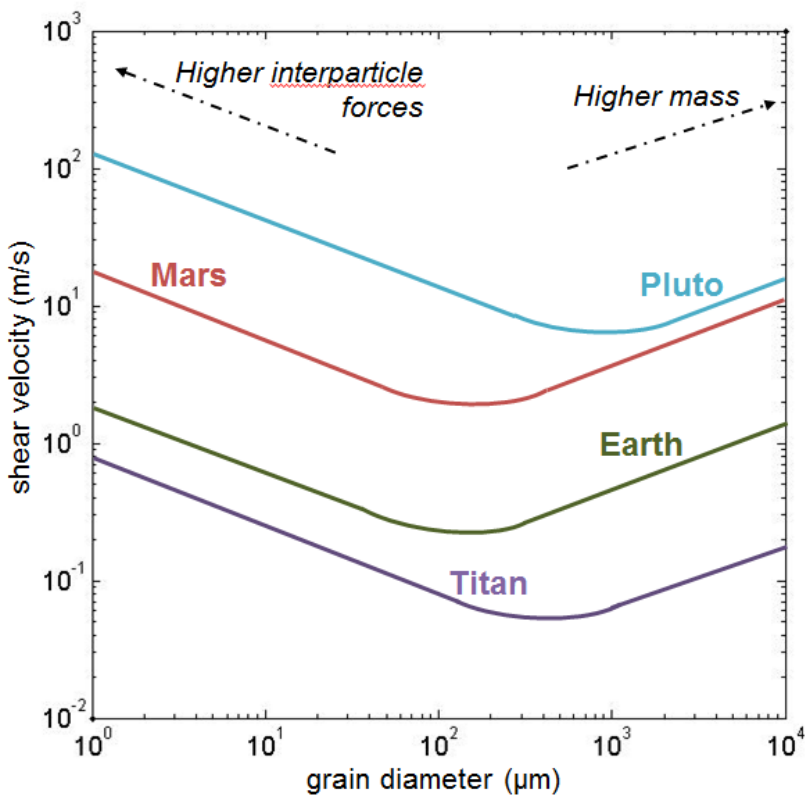

Figure 1: Wind shear velocity needed to move grains of different sizes, on different planets. Plot showing the estimated threshold shear velocity for moving wind-driven transport of a grain of a specific diameter for (from top) Pluto, Mars, Earth, and Titan; curves are taken from Moore et al. (2015; Fig. 17). The general shape of the curve is reflective of smaller particles experiencing stronger interparticle forces (such as electrostatic forces), while larger particles have more mass - either effect thus requiring more shear velocity to initiate and sustain grain movement. The curve's minimum indicates the expected size of "sand grains" (i.e., the grains most easily lifted and moved by a shearing fluid - by saltation) on that planetary body, that would be involved in the formation of aeolian bedforms. On Earth, sand grains are commonly $\sim 0.1 \mathrm{~mm}$ in diameter. On Mars observations of saltatable grains ("sand grains") in sand aeolian deposits and-such as dunes (e.g., Figure 11) yield comparable diameters, which is consistent with the curves shown. The differences in shear velocity needed to initiate motion are due primarily to 
differences in the estimated air (fluid) and grain densities on each planetary body. The first investigations into these curves and how they shift under different planetary conditions (Greeley et al., 1974) were initiated based on observation of dunes on Mars (as described in the text: Belcher et al., 1971; McCauley et al., 1972; Cutts and Smith, 1973).

To date, we have seen potential dunes on every deeply-studied body with an atmosphere and observable surface (including one-Titan, where dunes were considered unlikely: Lorenz et al., 1995), as well as a few bodies with no known atmosphere (Table 2). Based on the connections outlined above, this first "sighting" suggests the accumulation of a lot of sand (leading to questions about where the sand is coming from and why it is accumulating) and implications about wind strength, direction, and consistency. This yields (yielding a "groundtruth" observation for comparison with atmospheric models in both wind strength and direction $(-$-although it may be unclear when the bedform was created and thus what input conditions should be used for the model, or how the bedforms may have since been modified by non-aeolian processes).

Two classic examples of this are Mars and Titan. On Mars, signs of aeolian processes had been seen in cyclic, large-scale albedo changes and Mariner 6 imaged crescent-shaped features that were hypothesized to be very large barchan or parabolic dunes (Belcher et al., 1971). The first clear example of martian dunes was observed by Mariner 9 (McCauley et al., 1972; Cutts and Smith, 1973). Those observations suggested a wind regime that would allow for transport and collection of, as well as the presence of, a large amount of granular materials ${ }^{2}$, leading into laboratory studies of aeolian granular transport (Greeley et al., 1974; 1980). When Viking 2 imaged the north polar erg (Figure 2), this led to

\footnotetext{
${ }^{2}$ As Cutts and Smith [1973, p4151] put it: "The principal implication of dunes is a supply of noncohesive particles in the Martian surface environment and wind velocities sufficient for saltation transport. ... Dunes are not amenable to an alternative explanation of this sort. Thus we feel that we can now confidently assert the existence of a saltation regime on Mars", which leads to "many implications of a saltation regime such as wind abrasion, wind scour, and dust production."
} 

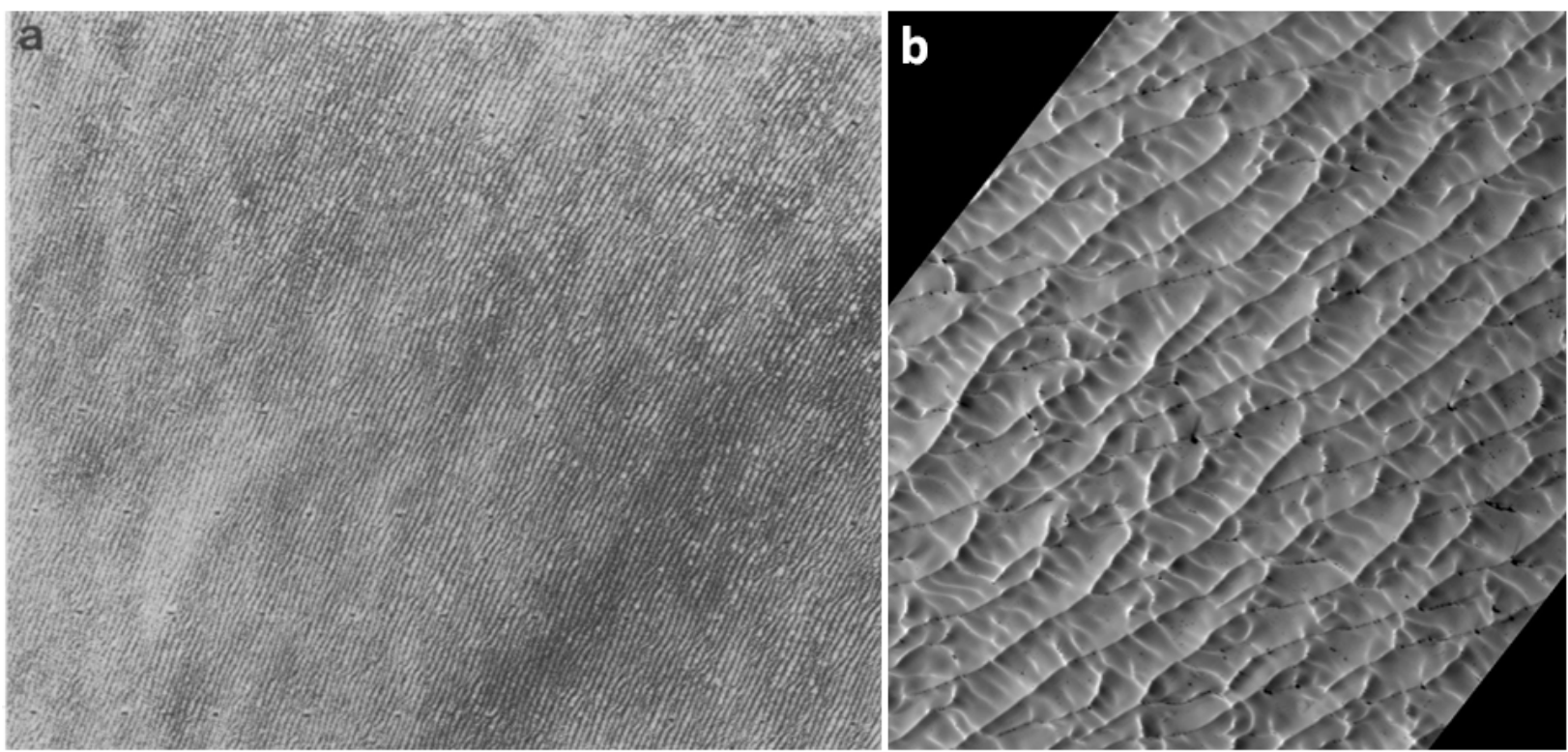

Figure 2. An early image of the martian north polar erg. (a) These linear features, imaged near the

investigations of martian erosional processes (acting on polar layered deposits or soils of lower latitudes?) and climate models (Cutts et al., 1976). (A summary of results from Viking and Mariner-based aeolian studies can be found in Greeley et al., 1992a.) On Titan, "cat-scratch" features had been observed circumnavigating its equator, but were not immediately recognized as dunes until Vic Baker brought the large draa of Saharan/Arabian/Namib deserts to the attention of the Cassini RADAR Team. The presence of dunes was a surprise as it had been hypothesized that while Titan's atmosphere may be capable of moving sand grains, it seemed unlikely that grains of the right size would exist (Lorenz et al., 1995). Observation of the dunes (Lorenz et al., 2006) led immediately to detailed investigations of what grains could be made of and how they would form (furthering studies of the chemistry on this Saturnian moon: Lorenz et al. 2006; Soderblom et al. 2007; Barnes et al. 2015) as well as leading to attempts to reconcile the observed dune morphologies with the model_-predicted wind regime around the equator (Lorenz and Radebaugh 2009).

martian north polar cap by Viking 2 (frame 59B32: $62 \mathrm{~km} \times 104 \mathrm{~km}$ ), were hypothesized to be dune fields 
based on their consistent orientation and wavelength, and low sinuosity, branching and merging. Image and description are taken from Cutts et al. (1976; Fig. 7). (b) Higher-resolution images have proven that these are dune fields, with a wavelength (between primary crestlines) of approximately $0.4 \mathrm{~km}$. A few more orders of aeolian bedforms (e.g., the smaller crestlines, transverse to the primary crestlines) are also visible. Image is a portion of HiRISE PSP_007115_2600 (MRO/NASA/UA).

200

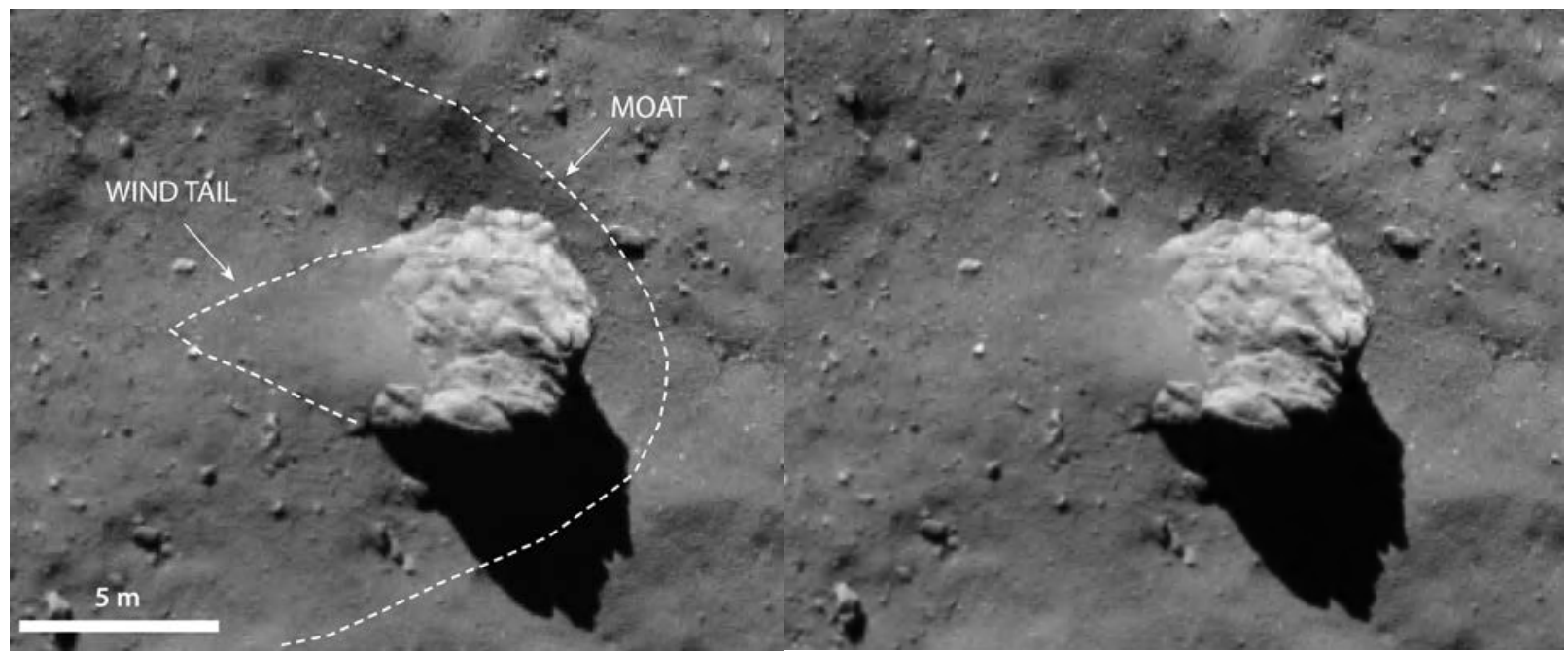

Figure 3. A $\sim 5 m$ boulder and potential aeolian features at Philae lander's touch-down-1 site. This

ROLIS descent camera image shows a depression partly surrounding the boulder and a triangular-shaped apron on the opposite side have been interpreted as a moat and a windtail, indicating transport of granular material across the comet's surface (Mottola et al., 2015). Initial studies evaluated possible aeolian mechanisms for this transport. (C) ESA/Rosetta/Philae/ROLIS/DLR

Contrarily, while Venus has a dense atmosphere, only two potential dune fields and a few possible microdune fields have been identified within Magellan radar data (Greeley et al., 1992b; 1995; Weitz et al., 1994),, which covers $98 \%$ of the surface with 100 - 200 m resolution(Greeleyet al., 1992;

Weitz et al., 1994) and shows wide coverage in other aeolian features such as windstreaks and potential yardangs (Greeley et al., 1995). This confirmed the hypothesis that aeolian bedform development on 
$\underline{\text { Venus must be limited, based on Venera } 13 \text { and } 14 \text { observations of the venusian surface that showed a }}$ dearth of aeolian ripples within loose material (Basilevsky et al., 1985; Florensky et al., 1983). (Note that for Venus, surface observations were first, before the mapping of surface topography from orbit.) The implication was implies that-either_venusian conditions and processes commonly obliterate features, the conditions for dune formation are not common on Venus (e.g., that there are few sands available on Venus or wind is not sustained at the surface), or that dunes are not generally visible via the radar images (Greeley and Arvidson, 1990; Weitz et al., 1994). Wind tunnel (Greeley et al., 1984a; 1984b; Marshall and Greeley, 1992; Williams and Greeley, 1994) and sand flux modeling (Kok et al., 2012) has shown that saltation under venusian conditions may occur in a very thin near-surface layer with very low velocity, which does not favor formation of large dunes. Thus, venusian sand transport appears more comparable to terrestrial bedform formation under water (Marshall and Greeley, 1992; Kok et al. 2012; Neakrase, 2015). Unfortunately, no new data about Venus has been acquired since Magellan, so Venus dune investigations remain stuck just past Phase 1 (with a small start withinat Phases 2-4, see discussion of Phase 2; Figure 13).

Potential aeolian bedforms have also been seen on planetary bodies lacking an atmosphere. For example, planetary scientists were recently very surprised to see features that looked like aeolian bedforms (i.e. moats, wind tails, and zeoliandune-like ridges) on comet 67P/Churyumov-Gerasimenko (Figure 3; Mottola et al. 2015; Thomas et al. 2015a; 2015b). A comet seemed clearly to be a planetary body that would lack an atmosphere, and thus any wind -- yet the features were observed. This immediately led to studies trying to determine how a "wind" could exist on this comet, if even transiently. One mechanism proposed to explain particle mobilization on comets was gas outflow from reservoirs of subsurface sublimating ice that emerges and erodes particles from channel walls (Cheng et al., 2013). However, since this process would only affect localized regions and the aeoliandune-like features on 67P have been observed in a much wider area, Mottola et al. (2015) suggested "splashing" 
initiated by airfall, i.e. ejection of particles by incoming projectiles, has been suggested asto be the most significant mechanism to explain particle mobility (Mottola et al, 2015; Thomas et al., 2015b). A threedimensional cellular automaton model has proven that moats can result from abrasion of the surface by impinging particles, whereas wind tails develop where granular surface materials were shielded by obstacles from particle transport (Mottola et al., 2015). The results of this study put forward the explanation that the aeolian bedform-like features on comet 67P are of erosional nature, rather than depositional - but the questions and investigations that arose in response to the recognition of features that resembled aeolian bedforms were consistent with typical Phase 1 discussions.

The surface of lo is covered in a ubiquitous frost of $\mathrm{SO}_{2}$ as seen by the Galileo Near Infrared Mapping Spectrometer (NIMS), likely mixed with dust and fine-grained materials, all ejected from the continuously erupting volcanic plumes and explosive volcanic eruptions (Kieffer et al. 2000, Milazzo et al. 2001). The surface as seen by the Imaging Science Subsystem (ISS) instrument on Galileo is mostly uniformly light-colored from this frost and generally smooth, with some fractures, slumps and pits (McEwen et al. 2000). In a few regions, there are landforms with dune-like characteristics: regular spacing, a slightly meandering form, "crestline" defects, and apparent topography visible through the uneven collection of frosts (not possible to confirm with Galileo's instruments). In one location, the dune-like landforms are found near a particularly active volcanic plume source, the Prometheus plume, which is sourced by advancing lava flows over vaporizing frosts (Figure 4; Kieffer et al. 2000; Milazzo et al. 2001). It is possible this plume forms a localized atmosphere dense enough to loft particles from the surface and deposit them nearby in dunes, much like one of the processes hypothesized for forming the features on comet 67P. 


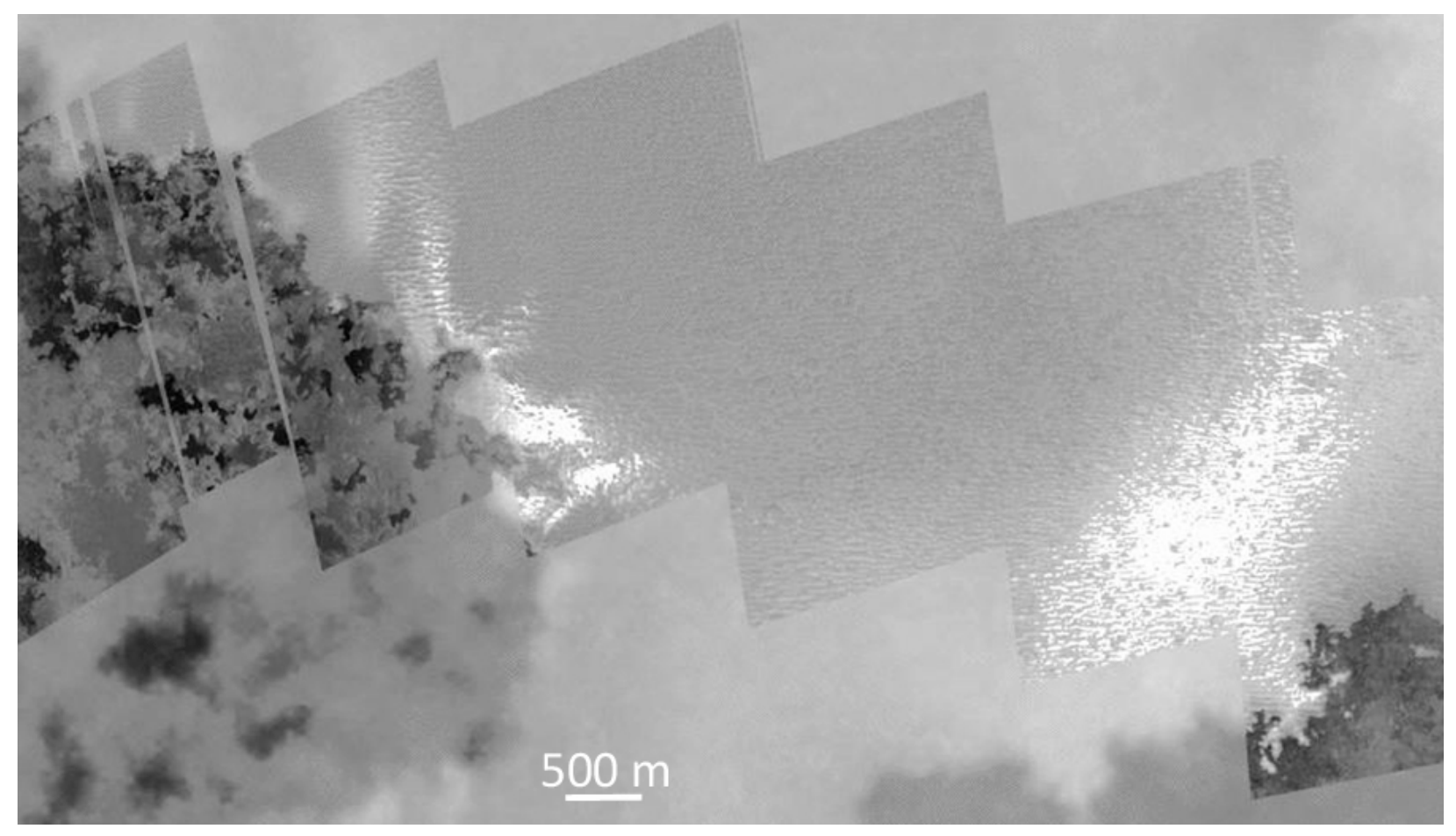

Figure 4. Potential aeolian bedforms on lo. This ridged terrain has been postulated as potential aeolian of the edge of this mosaic, and the $100 \mathrm{~km}$ tall Prometheus plume is erupting from somewhere near the western (left) end of this mosaic. The bright streaks radiating from the area where the lava flows (the dark features) overrun the field are where the hot lava recently vaporized the sulfur dioxide, which then coated the lava-facing sides of the ridges. These images were taken by Galileo during a flyby of lo on February 22, 2000, with a resolution of $12 \mathrm{~m} /$ pixel. Image and description are taken from NASA Photojournal PIA02568.

The flyby of Pluto by New Horizons in July 2015 produced one of the most striking increases in imagery quality of a planetary surface in the history of planetary exploration (Moore et al., 2016; New Horizons, 2015; Stern et al., 2016). The landscape revealed-imaged byduring the flyby revealed a surprising diversity of landforms, which suggest varied geological and geomorphological processes active 273 within recent geological history surface (Moore et al., 2016; Stern et al. 2015; Trilling et al., 2016). 
274 Mountains, glaciers, plains, possible cryovolcanism and a surprisingly low density of craters covered

275 much of the surface. Initial science results from the flyby noted the possible existence of 'windstreaks'

276 (Stern et al. 2015) on Sputnik Planum, apparently extending in the lee of dark hills protruding through

277 the nitrogen ice of which the plains are composed. Aeolian bedforms were speculated on before New

278 Horizons arrived (Moore et al., 2015), and dunes have since been posited in the Baré Montes and

279 enigmatic features in the Tartarus Dorsa have been interpreted variously as dunes or erosional aeolian

280 features (Fenton, 2016; New Horizons, 2016). However, recent imagery from Sputnik Planum (Figure 5)

281 provides perhaps some of the most convincing examples of potential aeolian bedforms, with continuous

282 linear features with a spacing of $\sim 400-600 \mathrm{~m}$. These features extend across the polygonal dark features,

283 which have been interpreted as convectional cells within the ice, suggesting that they are the result of

284 surface processes not related to the convective movement within the ice. Pluto is thus tentatively within

285 Phase 1 of the progression, and if an aeolian origin can be shown to be feasible, then available data may

286 be sufficient for progression into Phases 2-3.The dune-like landforms on comet 67P, lo and Pluto are

287 well in Phase 1 discussions and primary work remains to be done for these features to determine their

288 ultimate origin.

289 


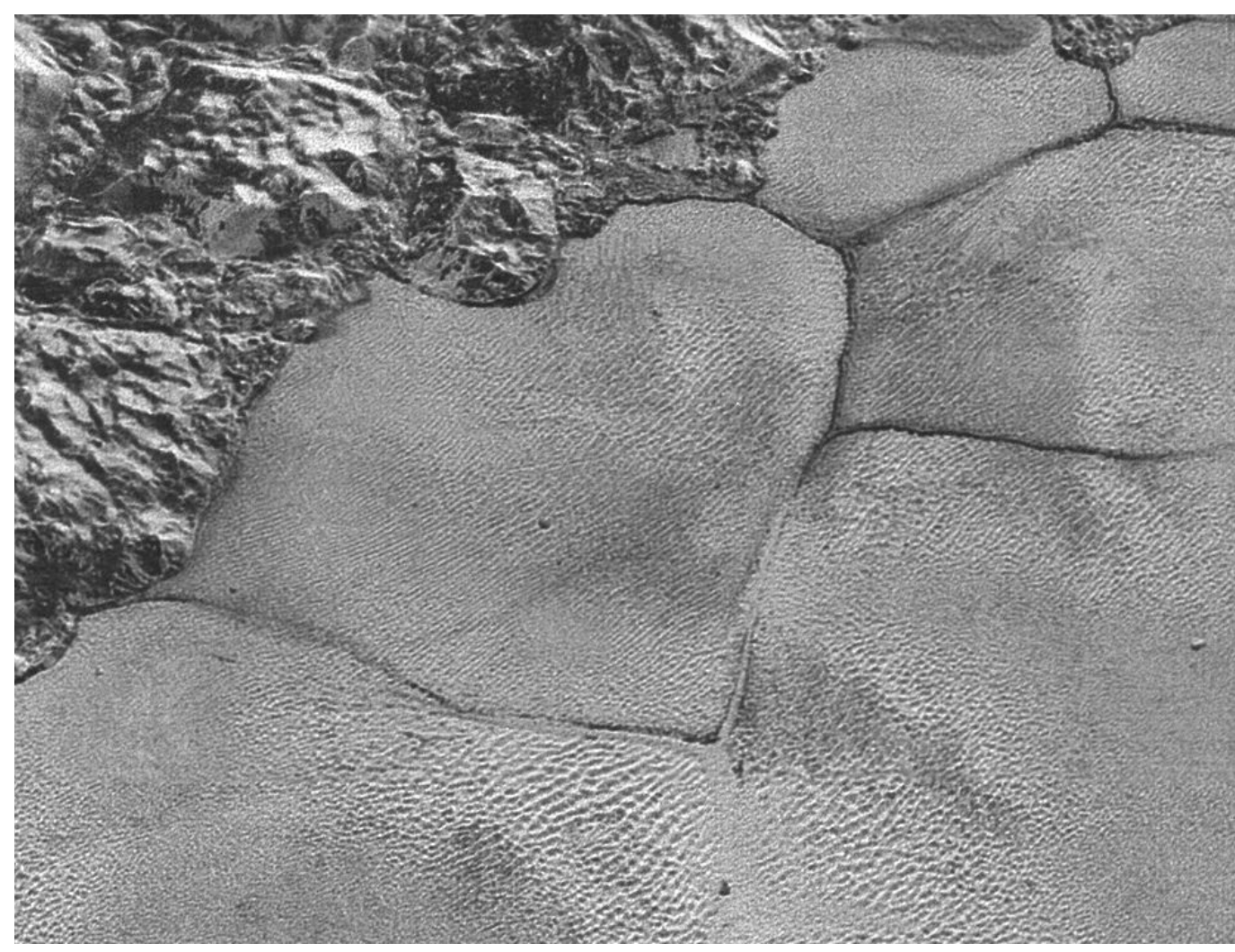

291 Figure 5. Possible Pluto aeolian bedforms at the margins of the nitrogen ice of Sputnik Planum. These

292 features are oriented approximately parallel to the 'shore' where the ice abuts mountains. Image width

293 is approximately $75 \mathrm{~km}$. Image credit: NASA/JHUAPL/SWRI.

295 Summary of Phase 1

296 Data needed: Images of the surface topography, of sufficient resolution to identify the distinctive

297 shapes of dunes -- images could be visible or spectral imagery or radar scans of the planetary body's

298 surface; identified analog (usually terrestrial) aeolian bedforms.

299 Knowledge gain (from that data): Existence of a potential aeolian bedform.

300 Assumptions generated: Conditions (wind conditions and grain size/supply) conducive to dune

301 formation and evolution exist or have existed - note that this is a coupled constraint, and further

302 information is needed to estimate each individual measurement. 
Questions: What is the composition of the grains? How were sand-sized grains formed? Why do the

grains accumulation in that particular location (related to winds, topography, sand source)? Are the

dunes active? If conditions are unusual (e.g., tenuous atmosphere), how does sustained saltation and/or

\section{reptation occur on this world?}

Lead to investigations of: Models of surface processes and rates (chemical, erosional, etc.) that could

create "sand" grains; comparison to (global) atmospheric models; independent measurements of

speeds and/or grain sizes (e.g., thermal inertia) to decouple saltation conditions.

\section{(Alternatively: ) Table N. Summary of Phase 1}

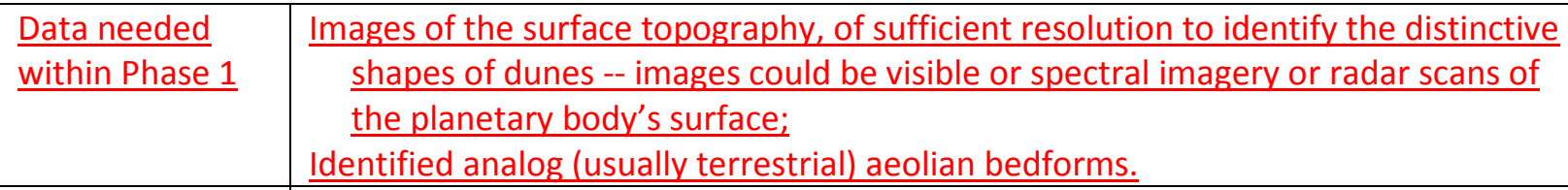

\subsection{Phase 2: Analysis of gross individual dune characteristics}


1995) and laboratory studies (e.g., Andreotti et al., 2006; Parteli et al., 2009) have established, a dune's

317 overall shape and orientation yields additional information about wind conditions when the dunes were

318 forming and evolving ${ }^{3}$. Thus, this investigation stage generally involves detailed mapping of dune shape

319 (outline and crestline) and comparison to analog terrestrial dunes. Numerical models of sand transport

320 and dune evolution are also used for comparison between dune-generated predicted wind directions

321 and atmospheric models (possibly down to a mesoscale or regional scale and including the effects of

322 large-scale topography).

For example, once it was recognized that the long, generally linear cat-scratch features on Titan

were dunes (Lorenz et al. 2006), researchers began investigating what type of dunes were observed and

what wind conditions were required for their formation and persistence (in addition to questions about

what the sand may be made of). From the morphology of the dunes, visible in $350 \mathrm{~m} / \mathrm{px}$ Synthetic

Aperture RADAR (SAR) data from the Cassini spacecraft (slightly hyper-resolution in nature in some

Radebaugh et al. 2008). Cassini Visual and Infrared Mapping Spectrometer (VIMS) data in select, high-

\footnotetext{
${ }^{3}$ However, establishing a connection between wind directions and dune slipface orientations sometimes is not a straightforward process - such studies often rely on many assumptions about timing of the winds and their consistency, and results are usually non-unique. Thus additional information is usually needed to evaluate a proposed interpretation. See Phase 3 for more discussion of the complexity that can be found in many dune fields.
} 
337 hypothesis that had been put forth connecting longitudinal dune morphology and wind directionality for

338 Titan and some Earth dunes is discussed in Subsection 3.2.)

339 Further information about these dune fields was then used to also predict the dominant wind

340 directions, for comparison with climate models (discussed here, but merging into Phase 3-type

341 investigations). Titan's dunes are found strictly between $30^{\circ} \mathrm{N}$ and S, ringing the equator, and are

342 oriented roughly parallel to the equator (Lorenz et al. 2006; Radebaugh et al. 2008). Their morphology,

343 and especially behavior around topographic obstacles (wherein sands-grains are piled up at the upwind

344 margin and are more sparse at the downwind margin), indicated a general sand transport direction from

345 west to east (Figure 6; Courrech du Pont et al., 2014; Lorenz and Radebaugh 2009; Lucas et al., 2014;

346 Radebaugh et al. 2010;). However, this was found to be at odds with the global atmospheric transport

347 direction of east-to-west predicted in the equatorial zone by global climate models. Subsequent

348 modeling studies revealed that seasonal or storm-driven winds could produce fast westerlies near the

349 equator (Tokano 2010; Charnay et al., 2015), possibly resolving this inconsistency.

350 


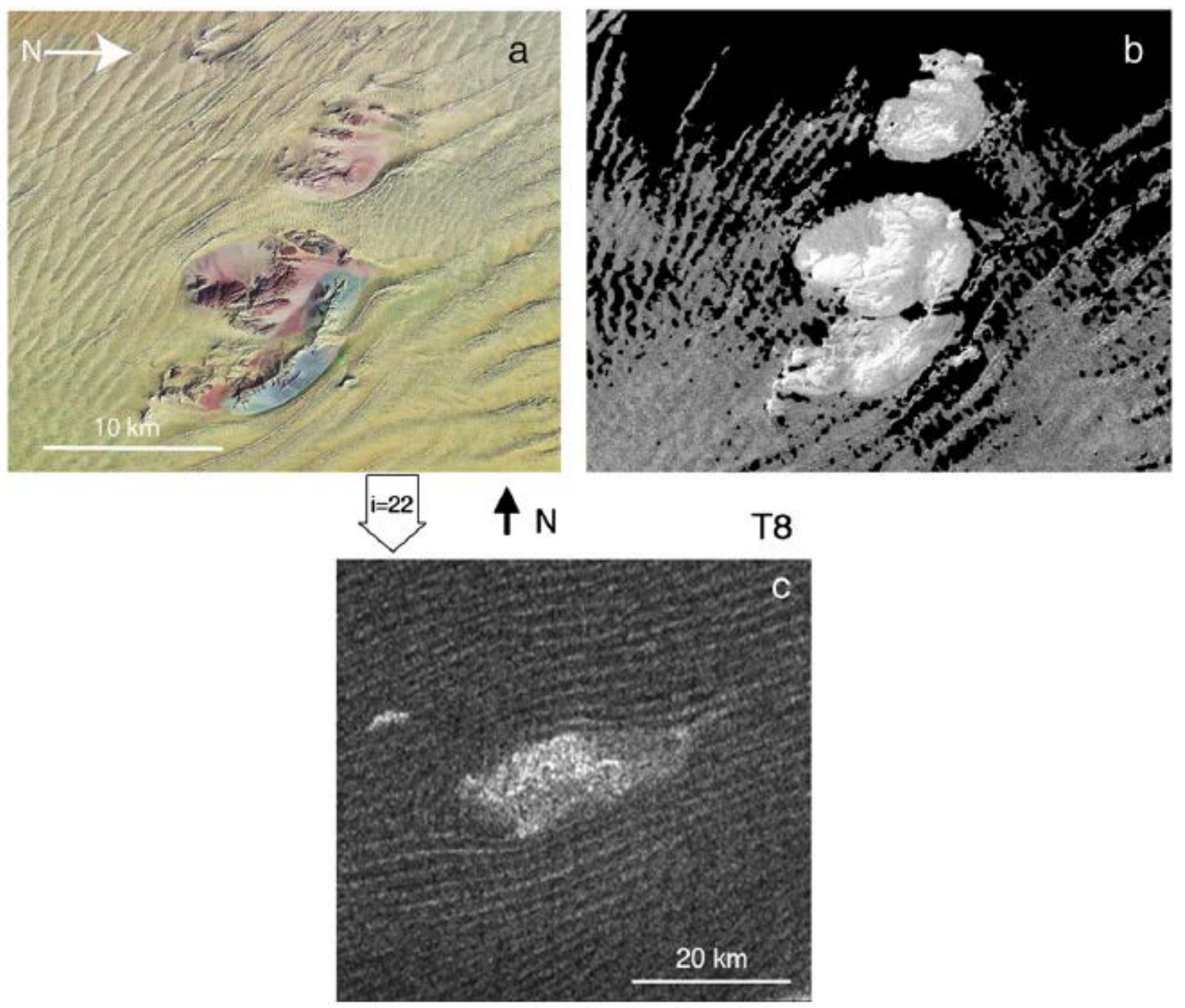

352 Figure 6: Earth and Titan dunes, diverging around topographic obstacles. (a-b) Landsat 7 ETM+ and

SRTM C-band images of dunes in Namibia (centered on $25^{\circ} 23^{\prime} S 15^{\circ} 16^{\prime} E$ ). The right image (b), a

Synthetic Aperture RADAR (SAR) image of the same dunes, shows bedrock as bright, because it is rough,

and unorganized dune sands as dark, because dunes are smooth at the SAR wavelength of $6 \mathrm{~cm}$ (black

areas are regions devoid of data returned to the SAR antenna). The right image (b) shows bedrock as

bright and unorganized dune sands as dark (black areas are unprocessed voids). The winds blow SE to

NW (bottom L to upper R), as evidenced by the dune-free regions in the lee of the bedrock topography

and the diversion of dunes around the upwind sides of the topography. In the lower image (c), dunes

similarly divert around topographic obstacles and resume on the downwind side, within this region of the 
On Mars, mapping of the duneforms observed by Mariner 9 and Viking orbiters $z$, combined with information about the surrounding surface topography and composition (including other potential aeolian features), was used to determine the wind direction(s) that would yield the dune crestline orientation(s), the wind and topography that would yield sand accumulation within that area and its

368 likely stability (i.e., was this a stable sink for sand, or a temporary repository), and possible sand sources 369 (Cutts and Smith, 1973; Greeley et al., 1992a; Thomas, 1981; 1982; Tsoar, 1979). For example, the large number of transverse dunes observed within southern mid-latitudes and north polar region on Mars (vs. longitudinal dunes), in Viking and Mariner images, implied that dune fields were forming within regions of near unidirectional winds, and the asymmetry in dune field complexity between the north and south hemisphere was seen as evidence of a more complex southern wind regime (Greeley et al., 1992a; Thomas, 1981). Afters higher resolution images became available and atmospheric modeling became more refined in technique and topography/boundary inputs, a more detailed comparison was thendone to see if atmospheric models could reproduce the observed dune shapes and orientations. For example, mesoscale modeling of dunes within Proctor Crater on Mars based on MOC NA images matched two sets of dune slipface orientations (the primary and tertiary) to seasonal winds that were impacted by

379 daily and seasonal insolation patterns and the crater topography, as predicted by a Global Circulation Model-mesoscale model (Fenton et al., 2005; however, the secondary dune slipface orientation remained unexplained). This study validated the mesoscale atmospheric model by providing a reasonable explanation for the range of slipface orientations seen within that dune field, and thus advanced the use of these models within model-observation comparison studies for understanding aeolian processes on Mars. 
Coupled with analysis of wind direction, observations of the dune's local surroundings can also recognized dune fields are at the resolution limit of radar images obtained by Magellan mission (Figure be studied to identify sediment sources and sand transport pathways. In some areas, $\underline{\underline{Q}} \underline{\underline{\text {distinct}}}$ sand transport pathways leading from the sediment layer to the dune bodies have been revealed by the detection of congruent material composition. For example, on Mars, local sediment sources for intracrater dunes have been identified-proposed at impact crater walls by comparative analyses of high resolution image and spectral data of dune bodies and the sediment layers exposed (e.g., Fenton, 2005;

Geissler et al., 2013; Silvestro et al., 2010a; Tirsch et al., 2011). Within the Valles Marineris rift system, spectral analysis, morphological evidence of erosion and sand transport, and topographic information was used to show that diverse and distinct sediment sources serve as local and regional sources

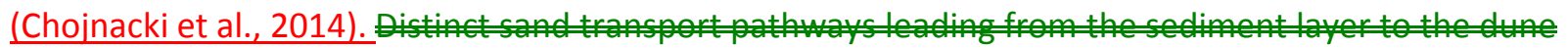
of o On Venus, analysis of dune morphology is almost impossible due to lack of data. Dunes in both 398 7), the only adequate data source. Therefore, results of attempted of detailed analysis are not reliable 399 and are controversial (Greeley et al., 1997; Lorenz, 2015). Modeling of anisotropic radar scattering 400 (Kreslavsky and Vdovichenko, 1999) indicated that the microdune fields identified-proposed by Weitz et 401 al. (1994) possess abundant unresolved steep slipfaces. 


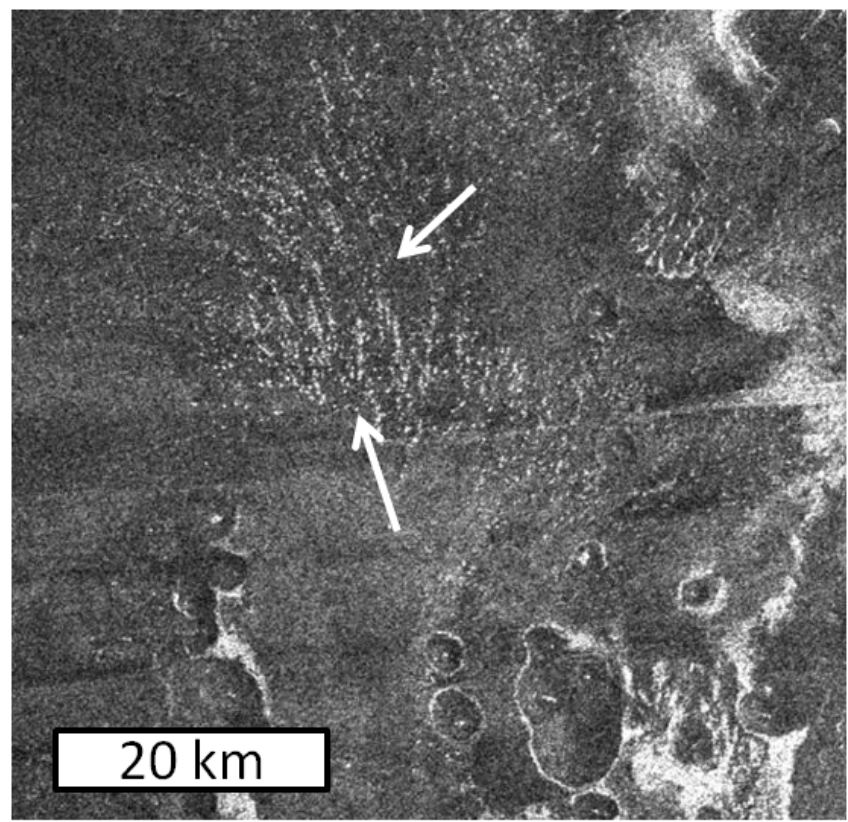

404 Figure 7: Venusian dune field. This Magellan SAR image of the Aglaonice dune field $\left(25^{\circ} \mathrm{S}, 340^{\circ} \mathrm{E}\right)$ shows

405 a field of white dots that are interpreted as specular reflections from the slopes of transverse dunes

406 (between the arrows). This type of reflection occurs if the slope is mostly smooth, and is oriented near-

407 normal to the incidence angle of the radar (which is $35^{\circ}$ or near the angle of repose); similar features are observed withing Seasat and space shuttle radar images of terrestrial sand dunes. The implied wind direction of these features, based on their orientation, is also consistent with nearby bright and dark wind streaks extending from behind cones (not included in this cropped image). Radar illumination is

411 from the left, and north is at the top. Image is from NASA Photojournal PIA00483, and description is from 412 Photojournal and Weitz et al. (1994). In general, Phase 2-type investigations can continue for a long period with refinement of the

415 investigations as higher-resolution images of the dunes are acquired, more information becomes 416 available about the local topography and other evidence of aeolian processes and conditions, and/or 417 atmospheric or bedform formation models are improved. This investigation phase may eventually grade into (and occur concurrently with) Phases 3 and 5 which involve, respectively, higher-resolution analysis 
419 of features within the dune field and features on the dunes formed by the dune-wind interaction (such

420 as ripple patterns on the stoss or lee-dune slopes-of dunes). Additionally, as new observations, models,

421 and analysis methods are developed, Phase 2 investigations can be renewed and revisited (as with all

422 Phases beyond Phase 1).

423

424 Summary of Phase 2

425 Data needed: same as Phase 1.

426 Knowledge gain: Morphology of the potential crestlines and general dune shape; composition of the

427 dunes and surroundings; possibly identification of local sand sources.

428 Assumptions generated: Wind direction and consistency hypothesized to generate the observed shapes;

429 variations in wind speed implied by changes in sinuosity and shape through the dune field.

430 Questions: What sets the wind direction and causes its variations (e.g., daily or seasonal cycles)? Are

431 these representative of present-day wind conditions, conditions during a past period, or a convolution

432 of conditions during different past periods?

433 Lead to investigations of: Comparison over one to several dune fields with (global/mesoscale)

434 atmosphere models; reliably identify wind direction(s) consistent with the dunes' forms. 
Table 2: Recognition and first analysis of dunes and dune fields on planetary bodies (Phases 1-2), as presented in the literature

\begin{tabular}{|c|c|c|c|c|c|}
\hline $\begin{array}{l}\text { Planet. } \\
\text { body }\end{array}$ & $\begin{array}{l}\text { "Aeolian" } \\
\text { bedforms } \\
\text { first sighted }\end{array}$ & Data used & Immediate Implications & Immediate Questions & $\begin{array}{l}\text { Referenc } \\
\text { e }\end{array}$ \\
\hline \multirow[t]{4}{*}{ Mars } & \multirow[t]{2}{*}{$\begin{array}{l}\text { Mariner 9, } \\
\text { Hellespontu } \\
\text { s region of } \\
\text { Mars, dense } \\
\text { and large } \\
\text { transverse } \\
\text { dune field }\end{array}$} & $\begin{array}{l}\text { Visual image of } \\
\text { surface, }<1 \mathrm{~km} / \text { pixel }\end{array}$ & $\begin{array}{l}\text { Dune material is dark (so some } \\
\text { dark-low albedo areas are regions } \\
\text { of deposition, not erosion; and } \\
\text { some dark material will saltate); } \\
\text { Due to the lower atmospheric } \\
\text { density on Mars, wind velocities } \\
\text { may need to be much higher to } \\
\text { move sand. }\end{array}$ & $\begin{array}{l}\text { Which "dark splotch[s] or } \\
\text { streak[s]" are due to deposition of } \\
\text { material (vs. deflation of overlying bright } \\
\text { material)? What is the source of the dark } \\
\text { material? Does the wind reach transonic } \\
\text { velocities? Is high-velocity sand-blasting } \\
\text { resulting in highly-efficient wind erosion? }\end{array}$ & $\begin{array}{l}\text { Sagan et } \\
\text { al., } 1972\end{array}$ \\
\hline & & $\begin{array}{l}\text { above; comparisons } \\
\text { to other albedo } \\
\text { markings indicative } \\
\text { of wind direction }\end{array}$ & $\begin{array}{l}\text { Presence of lots of sand and } \\
\text { saltation processes; Dune material } \\
\text { accretion directions and influence } \\
\text { of topography (craters) on field } \\
\text { location and dune morphologies; } \\
\text { comparable scale and shapes as } \\
\text { terrestrial dunes }\end{array}$ & $\begin{array}{l}\text { What is the composition of the sand? Why } \\
\text { is it so dark? }\end{array}$ & $\begin{array}{l}\text { Cutts } \\
\text { and } \\
\text { Smith, } \\
1973\end{array}$ \\
\hline & \multirow{2}{*}{$\begin{array}{l}\text { Viking 2, } \\
\text { north polar } \\
\text { erg, } \\
\text { transverse } \\
\text { and barchan } \\
\text { dune fields }\end{array}$} & \multirow[t]{2}{*}{$\begin{array}{l}\text { Visual image of } \\
\text { surface, } 30-60 \\
\mathrm{~m} / \text { pixel }\end{array}$} & $\begin{array}{l}\text { Lots of sand } \rightarrow \text { some erosional } \\
\text { process; Variability in wind regime; } \\
\text { two wind directions in portions }\end{array}$ & $\begin{array}{l}\text { What is the composition and source of } \\
\text { sand? Why is it accumulated around north } \\
\text { polar cap? }\end{array}$ & $\begin{array}{l}\text { Cutts et } \\
\text { al., } 1976\end{array}$ \\
\hline & & & $\begin{array}{l}\text { Strong winds; Two wind directions, } \\
\text { thought to be seasonal; grains may } \\
\text { be eroded from the northern plains }\end{array}$ & $\begin{array}{l}\text { Are the dunes active, and how mature is } \\
\text { the dune field? Are the dunes modified } \\
\text { during the winter/early spring, when the } \\
\text { entire region is covered by } \mathrm{CO}_{2} \text { ice? }\end{array}$ & $\begin{array}{l}\text { Tsoar et } \\
\text { al., } 1979\end{array}$ \\
\hline Venus & $\begin{array}{l}\text { Magellan, } \\
\text { transverse } \\
\text { dunes, two } \\
\text { fields }\end{array}$ & $\begin{array}{l}\text { Radar images, } 75 \\
\mathrm{~m} / \text { pixel; compared } \\
\text { with orientation of } \\
\text { other aeolian } \\
\text { features in same } \\
\text { dataset }\end{array}$ & $\begin{array}{l}\text { Lots of sand in specific areas } \rightarrow \\
\text { some erosional process (perhaps } \\
\text { impacts?) }\end{array}$ & $\begin{array}{l}\text { What is the composition and source of the } \\
\text { sand? What are the saltation dynamics } \\
\text { under a much denser atmosphere? }\end{array}$ & $\begin{array}{l}\text { Greeley } \\
\text { et al., } \\
1992 \underline{b}\end{array}$ \\
\hline Titan & $\begin{array}{l}\text { Cassini, } \\
\text { longitudinal }\end{array}$ & $\begin{array}{l}\text { Synthetic Aperture } \\
\text { Radar images, } 175\end{array}$ & $\begin{array}{l}\text { Lots of sand } \rightarrow \text { some "grain" } \\
\text { formation process; one dominant }\end{array}$ & $\begin{array}{l}\text { What is the composition and source of the } \\
\text { sand? What is the underlying topography, }\end{array}$ & $\begin{array}{l}\text { Lorenz et } \\
\text { al., } 2006\end{array}$ \\
\hline
\end{tabular}




\begin{tabular}{|c|c|c|c|c|c|}
\hline & \multirow[t]{2}{*}{$\begin{array}{l}\text { dunes, large } \\
\text { field around } \\
\text { equator }\end{array}$} & m/pixel & $\begin{array}{l}\text { or at least two converging wind } \\
\text { directions throughout equatorial } \\
\text { region; pristine appearance and } \\
\text { superposition over geologic } \\
\text { features } \rightarrow \text { young and possibly } \\
\text { currently active }\end{array}$ & $\begin{array}{l}\text { causing accumulation in equatorial region } \\
\text { and divertion of dunes? Is there any } \\
\text { connection with the potential fluvial } \\
\text { channels? Has the sand circumnavigated } \\
\text { the globe several times (implying a lack of } \\
\text { sand-sinks in the area)? }\end{array}$ & \\
\hline & & $\begin{array}{l}\text { Visual and Infrared } \\
\text { Mapping } \\
\text { Spectrometer } \\
\text { (VIMS) } \\
\text { observations, } 500 \\
\text { m/pixel }\end{array}$ & $\begin{array}{l}\text { Observations of interdunes } \rightarrow \\
\text { recent activity and overall dune } \\
\text { field maturity; spectral information } \\
\rightarrow \text { constraints on the composition } \\
\text { of the dunes and interdune } \\
\text { regions; photoclinometry yielded } \\
\text { height and wavelength estimates }\end{array}$ & $\begin{array}{l}\text { What information does the variability in } \\
\text { dune coverage and height, and in the } \\
\text { terrain that they cover, yield for the } \\
\text { evolution history and conditions for these } \\
\text { mature and recently active dunes? What } \\
\text { are the dune grains made of, given their } \\
\text { lower relative waterice content than } \\
\text { Titan's average? }\end{array}$ & $\begin{array}{l}\text { Barnes et } \\
\text { al., } 2008\end{array}$ \\
\hline $\begin{array}{l}\text { Comet } \\
67 \mathrm{P} / \mathrm{Chu} \\
\text { ryumov- } \\
\text { Gerasim } \\
\text { enko }\end{array}$ & $\begin{array}{l}\text { Rosetta, } \\
\text { moats, wind } \\
\text { tails, and } \\
\text { aeolian-like } \\
\text { ridges/rippl } \\
\text { es }\end{array}$ & $\begin{array}{l}\text { optical imagery: } \\
\text { OSIRIS orbiter } \\
\text { camera images } \\
(\geq 0.29 \mathrm{~m} / \mathrm{px}), \text { ROLIS } \\
\text { decent camera } \\
\text { images }(\geq 1 \mathrm{~cm} / \mathrm{px})\end{array}$ & $\begin{array}{l}\text { "Sustained" granular transport } \\
\text { along the surface (so as to form } \\
\text { aeolian bedform-like features) } \\
\text { exists on a comet }\end{array}$ & $\begin{array}{l}\text { How does granular transport work on a } \\
\text { body without atmosphere? What is the } \\
\text { moving agens? Are these bedforms } \\
\text { accumulative or erosive? What is the } \\
\text { grainsize of the bedform materials? What } \\
\text { are the material sources? How long does it } \\
\text { take to form bedforms? }\end{array}$ & $\begin{array}{l}\text { Mottola } \\
\text { et al., } \\
\text { 2015; } \\
\text { Thomas } \\
\text { et al., } \\
\text { 2015 } \text {; } \\
\text { 2015b }\end{array}$ \\
\hline
\end{tabular}




\subsection{Phase 3: Pattern $A$ analysis of the dunes within a field}

Dune field evolution is related to the evolution of its constituent dunes, but occurs on a larger spatial and temporal scale and involves areas of investigation that are different from (and can be largerthan) the sum of its parts. For example, as dunes evolve within a field they exchange sand between each other through both sand flux and collisions, and environmental boundary conditions such as the sand influx geometry can affect dune field pattern development (Diniega et al., 2010a; Ewing and Kocurek, 2010). As such, it is necessary to model dune field evolution as more than just a collection of individually evolving dunes, and to recognize that the large-scale dune field pattern can reflect conditions (and changes in those conditions) around and throughout the field. For example, sand and dune influx conditions will be different near the start upwind margin of the dune field than near the terminus or boundaries-lateral margins (Ewing and Kocurek, 2010) due to proximity to sand sources or other dunes, or changes in topography or "cementing" influences (e.g., chemical duricrust or, on the Earth, vegetation) within the field (Kocurek and Ewing, 2005) (Figure 6: examples of dune interactions with topography on Titan and Earth). Such changes can result in different dune sizes, spacing, or defect frequency (Diniega et al., 2010a; Ewing and Kocurek, 2010). The effect of underlying topography is also a key parameter affecting dune characteristics at the dune field scale (Ewing and Kocurek, 2010). On Earth, bedrock topography has been linked to the effect of roughness variations induced by the dune field itself producing an internal boundary layer decreasing the shear stress downwind (Jerolmack et al., 2012) and/or to the feedback mechanism between longwavelength topography and the dunes (Pelletier, 2015). The role of topography in enhancing and deflecting regional winds has also been invoked to explain complex dune field pattern on Mars in Olympia Undae (Ewing et al., 2010) and complex dune arrangements in Moreux (Cardinale et al., 2012) and Matara crater (Diniega et al., 2010b; Silvestro et al., 2012). However, it was only thanks to the availability of high resolution DTMs from the HiRISE instrument that the effect of underlying topography 
could be more precisely linked to different dune characteristics such as migration rates, dune heights

and density (Cardinale et al., 2016, Vaz et al., submitted). In particular, in Herschel crater dune density,

slip face advancements and migration rates are all controlled by two major topographic highs on the crater floor (Vaz et al., submitted).

The dune field may also record changes in conditions over a longer-timescale than that recorded within any individual dune. Multiple patterns (e.g., different types of dunes) can be superimposed (creating a complex, versus a simple, dune field) as smaller dunes migrate and change in response to the new environment faster than larger dunes (Ewing and Kocurek, 2010; Hugenholtz and Barchyn, 2010; Kocurek and Ewing, 2005). We note that this possible complexity within dune fields can complicate analysis of the dune morphology (Phase 2). For example, even identification of the dominant (or most recent?) slipface orientations can be non-trivial. This is especially true within planetary dune fields where datasets may be limited to remote images, so dune slope angles and potential activity have to be interpreted from images of the dunes' planform appearance, possibly under suboptimal illumination conditions for this type of image analysis. For example, within the north polar erg on Mars, many dunes contain slipfaces pointing in opposite directions (sometimes on the same dune). One interpretation is that some of these fields may contain both active and fossil dunes (Gardin et al., 2012). Within the Mars southern mid-latitudes, at least two periods of dune-building (or dune-building occurring over 2 different timescales) are apparent as within the same field one can often find a dense collection of transverse dunes (with slipface towards the east) and then barchans clearly climbing up and over the transverse dunes on the east side (with slipfaces towards the west) (Figure 8; Diniega et al., 2010b). 


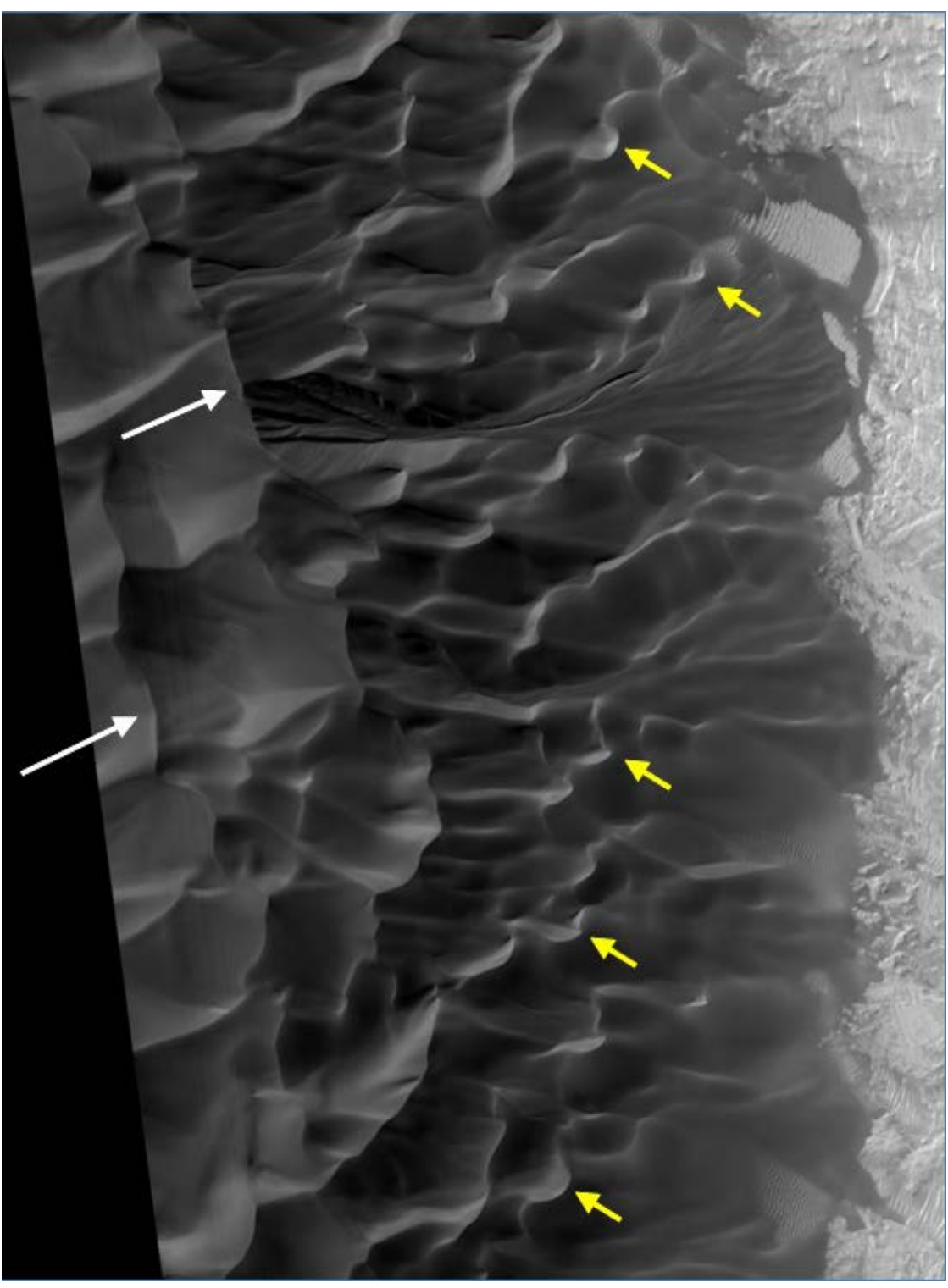

Figure 8: The complex dune patterns found in along the eastern edge of Matara dune field, Mars

$441\left(49.5^{\circ} \mathrm{S}, 34.8^{\circ} \mathrm{E}\right)$. This dune field, like many others in the Mars southern mid-latitudes, is a dense

442 transverse dune field, captured within a crater. The transverse dune crestlines are oriented north-south

443 with the clearest slipfaces towards the east (white arrows extend up the possible stoss slope, towards the

444 dune brink). However, along the eastern side of this field, many smaller dunes (mostly barchans - yellow

445 arrows, some possible transverse crestlines near the bottom of the image) are oriented with towards the

446 northwest. This potentially reflects two periods (or just two timescales?) of dune evolution, with a 
447 change in the dominant wind direction. North is up and illumination is from the left. Image is a portion of

448 HiRISE PSP_006648_1300 (MRO/NASA/UA).

449

A lack of variations can also yield information about the field's and planetary body's history. On

451 Titan, dune width and spacing measurements over more than 7000 linear dunes showed a high level of

452 consistency uniformity around the moon, with no signs of compound or complex dunes (Savage et al.,

453 2014). This, coupled with the dunes' large sizes, indicates that Titan's dunes are mature features that

454 have evolved within consistent and stable environmental conditions for a long period of time.

455

456 Summary of (3)

457 Data needed: Observations of dunes fields, of sufficient spatial coverage and resolution to note changes

458 in dune patterns throughout the field, especially in tracing crestlines; possibly need knowledge of

459 topography.

460 Knowledge gain: The dune field pattern and shape; maturity state (and possibly relative age) of the

461 bedforms; possible temporal changes in e.g., sediment supply and wind patterns:-

462 Assumptions generated: Changes in the environmental conditions, in space or time.

463 Questions: For a given dune field, is sand sourced from one or several locations? Is the dune evolving

464 through one dominant wind pattern, or several? Have the dominant effects (sand source or wind

465 pattern) changed over the lifetime of the dune field?

466 Lead to investigations of: Explore influences on dune shapes beyond current dominant winds (Phase 2)

467 - such as the location of sand source(s) or of sand-starved regions of the field, a transition between

468 wind regimes, interactions between dunes (such as dune collisions), or other environmental

469 influences/processes.

470 


\subsection{Phase 4: Regional and Globatglobal surveys and aggregate-analysis of dune characteristicss}

As we gather information about dunes in more and more different dune fields around a planetary body, it becomes possible to aggregate data to deal with high-level, large timescale questions about aeolian processes and sediment supply, such as "How much sand is available in total?" and "Are there primary types/locations of sediment sources that can yield information about how that sand has been created, how it is transported, and whether it has been recycled?" Addressing such big-picture questions can provide important information for investigations of grain-producing processes (e.g., surface erosion) and planetary surface history over the lifetime of the involved sand grains. Note that while studies of grain history and sediment transport pathways involving terrestrial dunes ean-may rely on detailed petrographic and heavy-mineral techniques, with geochronology (e.g., Garzanti et al., 2013), studies of planetary bodies often are based only on surface topography and, possibly, coarse compositional information.

For example, on Mars, a near-global map of sediment deposits (including dunes) and wind streaks to generate early estimates of sediment transport pathways/source regions (Thomas, 1982). the An early global map of aeolian features showed variations in time and space in the large-scale wind directions recorded by the orientation of dunes, wind streaks, yardangs, wind grooves, and deflation pits (Ward et al., 1985). Such studies have since been updated with increased coverage and image resolution (e.g., Hayward et al., 2007; 2014), and still provide important information about direction and variability in the wind patterns (down to intra-field scales), the influence of topography and local geology on windflow and bedform development, and likely sediment sources for the observed deposits. At a regional $\underline{\text { scale, the martian north polar erg volume has been estimated as } \sim 1130-3250 \mathrm{~km}^{3} \text { of dark sand (Greeley }}$ et al., 1992a; Hayward, 2011), which is significant as the Planum Boreum Cavy unit, which is part of the icy layers of the north polar cap, has been identified-proposed as the source of the circumpolar dune fields (Byrne and Murray, 2002; Tanaka et al, 2008). These deposits are-appear composed of recycled 
aeolian sediments, which were likely transported poleward and deposited there-(Breed et al., 1979;

Byrne and Murray, 2002). This suggests that a huge volume of sand may have formed on Mars during an earlier epoch and that these sand grains have survived at least a couple of sustained dune-forming periods.

The Titan dune fields provide an example of how an-analysis of the distribution of dune field locations (on the planetary body, or relative position within regional topography) and morphologies (i.e., field outline or crestline patterns) can yield additional information about larger-scale atmospheric and topographic/surface conditions. Mapping of 16,000 Titan dune segments (covering $8 \%$ of Titan's surface which suggested that dunes cover a total of $20 \%$ of the global surface: Lorenz and Radebaugh, 2009) showed general dune field orientation and spacing patterns and confirmed that these features are within a global field with few longitudinal trends, but with latitudinal trends in orientation and limited to within $30^{\circ}$ of Titan's equator. Although dunes on Titan are organized into several separate sand seas across the equator, all have some level of broad interconnectedness (Le Gall et al. 2012; Radebaugh 2013; Savage et al. 2014). As such, studies of the Titan sand sources, sediment transport pathways, and deposition patterns are best analyzed from a "global" perspective.

Titan sands may be derived directly from the atmosphere, perhaps through clumping on the surface, though it is perhaps more likely the sand has been processed through erosion of organic sedimentary layers (Radebaugh 2013), possibly close to the equator; where fluvial channels have been imaged (Burr et al., 2013; Lorenz et al., 2008; Radebaugh et al., 2016). Other possible sources include erosion of the SAR-uniform mid-latitudes, a possible sedimentary deposit (Malaska et al., 2016), and the northern dry lakebed evaporite deposits, which have similar spectral characteristics to the VIMS instrument (Barnes et al., 2015). Once the materials are incorporated-transported into the Titan sand seas, they are absorbed-incoporated into the giant linear dunes, and either stay confined to one sand sea-or another or contribute to a global system of west-to-east sediment transport that persists over 
time (Savage et al., 2014). Topography appears to play an important role, as it does for sand seas on

520 Earth, in that it can help confine the sands to certain regions or preclude them from others, like from the 521 rugged Xanadu region (Lorenz et al., 2006; Radebaugh et al., 2011). Decreases in dune density within

522 radar-bright and elevated regions may provide regional-scale constraints on Titan's winds for

523 atmospheric models (Lucas et al., 2014). Furthermore, topographic obstacles can cause diversion of

524 dunes and dune/topography relationships and perhaps reveal longer-term climatic changes (Ewing et al.

525 2015).

526

527

528

529

530

Consideration of the dune fields in aggregate can also allow for analyses that require a larger area or more numerous measurements to reflect larger-scale temporal or spatial trends. For example, dune fields on Mars appear very young as they lack craters, but constraints on their age had large uncertainties due to their low individual areal coverage. Adding the dune fields together allowed for a more robust estimated crater-retention age of $<10000$ years (Fenton and Hayward, 2010). These dune fields also exhibit latitude-dependent morphological trends in crestline sharpness/pattern, dune slopes, and field shapes, so considering the dunes over the hemisphere enables studies of hich reflect different degrees of influence from polar as well as aeolian processes (Fenton and Hayward, 2010). Another study of southern intracrater dune fields on Mars compared dune field centroid locations, relative to the crater center, with mesoscale atmospheric modeling to look at broad-scale atmospheric trends (over a much longer time period than that recorded in dune slipface orientations within an individual dune field) (Hayward et al., 2009).

Although only two dune fields and a few microdune fields were identified with some certainty in the whole set of Magellan radar images of Venus, a few lines of indirect evidence suggest that unresolved small-scale anisotropic topographic features are ubiquitous; such features have been interpreted as unresolved gently sloping aeolian bedforms (Kreslavsky and Vdovichenko, 1999; 
542 Bondarenko et al., 2006). A comprehensive global inventory of aeolian bedforms on Venus will require

543 global imaging data set(s) of a higher resolution than presently exists.

544 Beyond global imaging of the data-type first used to identify the dunes, proxy measurements

545 can sometimes be used to supplement limited image coverage. For example, thermal inertia can be used

546 to identify large deposits of unconsolidated, granular material. On Mars, further evidence that these

547 dark patches with high-thermal inertia were aeolian deposits were that these were found downwind of

548 topographic depressions (Christensen, 1983; Mellon et al., 2000). Thus global maps of thermal inertia

549 with resolution $\sim 100 \mathrm{~m} / \mathrm{pixel}$ have been used to map dune fields around Mars and estimate the number

550 of dune fields and their surface areal extent (Christensen et al., 2003; Hayward et al., 2007; Hayward,

551 2011).

552

553 Summary of (4)

554 Data needed: Identification of dunes around globe (from the data used in Phases 1-3, and possibly from

555 proxy data such as thermal inertia).

556 Knowledge gain: Dune field location and (possibly) morphology/type distributions; variations in location

557 and morphology related to sediment supply, climate history, and/or and other active processes (e.g.,

558 related to latitude, regional topography); identification of large-scale sediment transport pathways

559 (larger-scale than field-specific results of Phase 2 and 3; and possibly first produced earlier based on

560

low-resolution, but high-coverage datasets) based on (global/mesoscale) atmospheric models and

561

observation of sediment sources.

562 Assumptions generated: Correlations between dunes and proxy data; feasibility of extrapolation from

563 studies of individual dune fields/sand sources to a global model. 

and temporal scale is the sand being transported (i.e., what is the lifetime of a sand grain and is sand/bedforms being recycled)?

Lead to investigations of: Age estimation of dune fields (as can aggregate together land-areas to statistical significance; likely to be a relative or crater-retention age); identification/investigation of large-scale sediment sources (locations and/or processes; perhaps updated from Phase 2); global surface areal coverage of dunes/volume of sand.

\subsection{Phase 5: Analysis of superposed bedforms on the dune "details" formed due to wind interaction} with the dune

Ripples, like dunes, form spontaneously within sand beds due to wind (or fluid) flow and record

575 wind and sediment conditions through their period of formation and evolution. However, as these are 576 much smaller features, they record conditions over smaller temporal and spatial scales and thus can be 577 reflective of a different set of environmental conditions than dunes. To-date, ripple-like features have been only observed on Mars, where HiRISE images of the martian surface have resolution up toas fine as $0.25 \mathrm{~m} /$ pixel (McEwen et al., 2007). These features have wavelengths of 1-to-a-few meters, have been found within sandy regions including on the slopes of dunes, and have been individually mapped and monitored for movement (Phase 6) (Figure 9; Bridges et al., 2012; Silvestro et al., 2011). The study of ripple morphologies and dynamics on Mars yields information about the wind flow over the dunes, under the influence of the local wind patterns as well as the dune topography. This yields information information about the temporally and spatially small-scale surface wind dynamics can be compared with meso and microscale climatic models and in-situ wind measurements (e.g., Jackson et al., 2015; Silvestro 
topographic and wind flow boundary conditions imposed by the dune morphology (Kocurek and Ewing,

589 2012), studies of the ripples' form and variation provide insights to the underlying dune's evolution

590 (Ewing et al., 2010; Vaz et al., 2016submitted).

Ripple mapping and monitoring have been an important tool within recent martian studies,

592 where the crestline orientations and migration rates and directions of the large martian ripples are

593 commonly used to reconstruct the wind regime over the dunes and to estimate sand fluxes (Ayoub et

594 al., 2014; Bridges et al., 2012a; 2012b; Cardinale et al., 2016; Silvestro et al., 2010b, 2011, 2013).

595 Automatic approaches have been developed to derive ripple trend and migration rates, enabling high-

596 resolution wind regime estimations and sand flux measurements to be computed over large areas

597 (Ayoub et al., 2014; Bridges et al., 2012a; 2012b; Silvestro et al., 2011; Vaz and Silvestro, 2014).

598 However, all of these studies have assumed that that the observed "smaller" bedforms on the

599 dunes are analogous to terrestrial sand ripples, and that ripple trends and migrations are normal to the

600 last wind of sufficient strength to move sand, as is typically the case for aeolian ripples on Earth. Recent

601 work has drawn those assumptions into question:

602 - Most ripple patterns on Mars are dominated by sinuous crestlines (Vaz et al., 2016 $\underline{\text { submitted), while }}$ on Earth ripple crestlines are typically straight (Rubin, 2012) (Figure 9). In some areas, ripple

604 patterns observed on Mars show complex arrangements with two crestlines intersecting at right

605 angles (Figure 10; Silvestro et al., 2011, 2013). This suggests that some of the ripples on Mars might

606 not be in equilibrium with the last sand-moving winds or that the two sets of crestlines are

607 contemporaneous, but oblique to the formative winds (Silvestro et al., 2016).

608 - Additionally, unusual longitudinal displacement of crest-line defect terminations and oblique crest

609 migrations have been observed within orbital data in Gale and Herschel crater, suggesting that the

610 large ripples of Mars might beare different from terrestrial impact ripples (Silvestro et al., z01프

611 press5; Vaz et al., Z016submitted). This hypothesis may beis in agreement with recent in situ 
observations from the NASA MSL Curiosity rover, which shows that large ripples have sinuous and sharp crests and slip faces with evident grainfall and grainflow structures (Bridges et al., 2016; Lapotre et al., 2016a) (Figure 10) that are not common within terrestrial impact ripples. Superposing these large bedforms are smaller "terrestrial-like" impact ripples of $\sim 10 \mathrm{~cm}$ in wavelength (Bridges et al., 2016; Lapotre et al., 2016a).

These observations suggest that terrestrial aeolian impact ripples might not be good analogs for

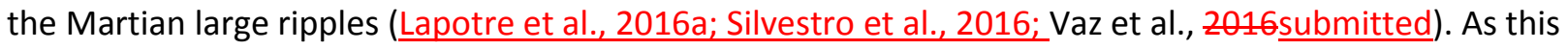
gets worked out, previous studies will need to be carefully reviewed, such as where the interpretation

620 has been that a multidirectional wind regime exists, perhaps triggered by the local dune topography or

621 by larger topographic features (e.g., Jackson et al., 2015; Silvestro et al., 2011). Also, the presence of

622 such large ripples on the dune's stoss side and their migration across the slipface (Figures 9-10) may

623 alter the wind profile above the dune and the slipface dynamics, beyond the way that these processes

624 are typically captured in dune evolution models applied to terrestrial dunes and their ripples (e.g., Ewing

625 et al., 2016). Increased coverage of high-resolution images coupled with in-situ observations by rovers

626 are necessary to progress understanding of the nature and dynamic of the martian large ripples. This is

627 fundamental for understanding how these ripples can be used to constrain local wind directions and to 628 tune sand flux estimations over the dunes.

\section{Summary of (5)}

631 Data needed: Higher-resolution images of dune field, reflecting variation over the dune, including in

632 composition or granulometrics; mapping and analysis of second-order and higher-order bedforms (e.g., 633 ripples) and how these reflect the wind pattern around the dune.

634 Knowledge gain: Measurements of ripple movement and characteristics over the dune. 
636 features.

637 Questions: What is the local sand flux and wind patterns over the dunes (as reflected in ripple

638 movement)? Are grains sorted within the ripples, and if so, why? Is ripple movement coupled

639 with/connected with current dune evolution, or e.g. does ripple movement reflect a surficial mobile

640 layer of sand over a relict dune core?

641 Lead to investigations of: Wind diversion around dune topography; observation/better understanding

642 of local source regions.

643
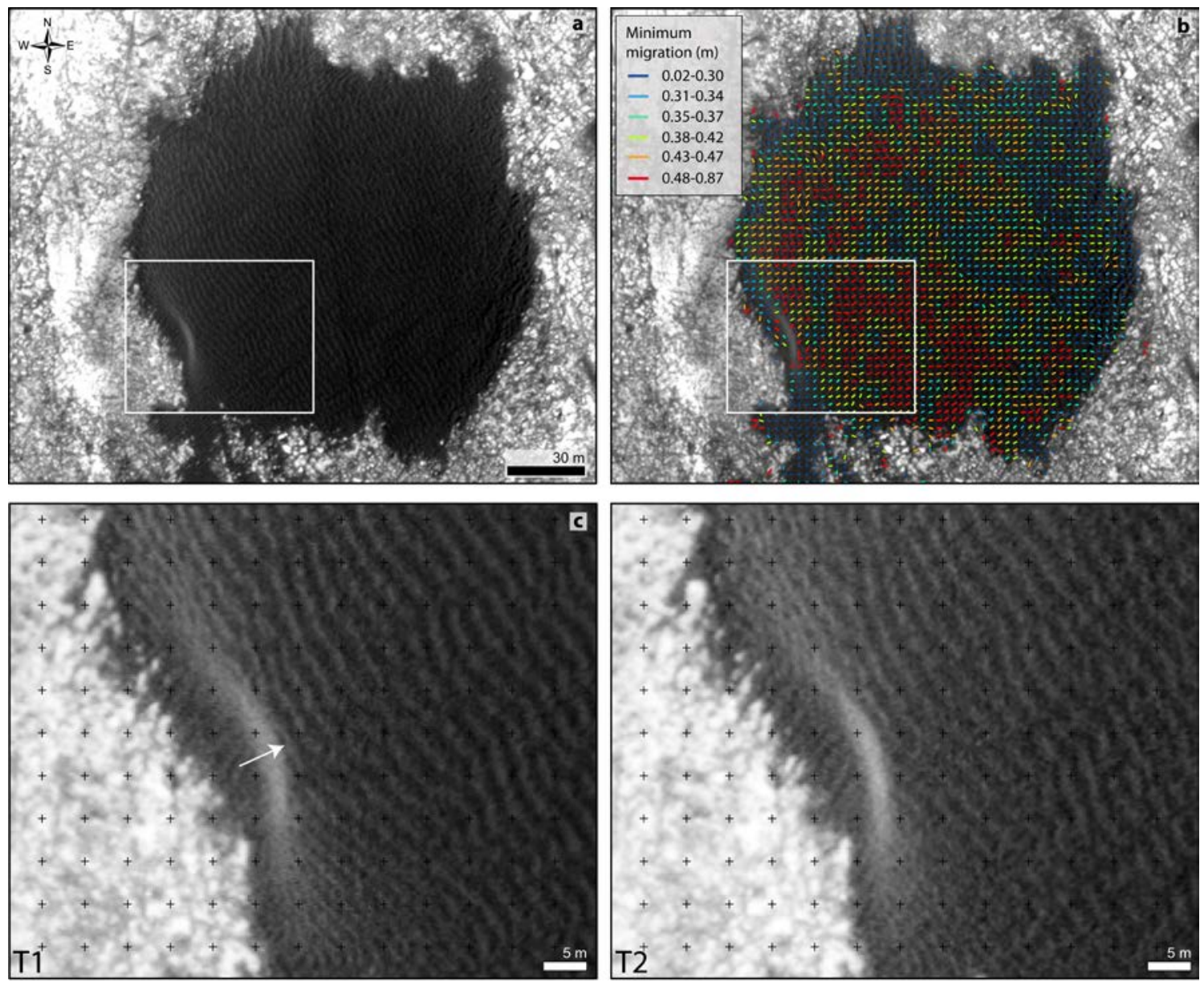

Figure 9. Observed ripple movement on Mars. Images show (a) a rippled dome dune in the Bagnold

dune field, Gale Crater, with (b) ripple migration over the dune stoss side between Mars years 28 (2006) 
and 29 (2008) (Silvestro et al., 2013). (c: T1-T2) The zoom-in shows one ripple (white arrow) moving over the dune brink, reflecting grain transport onto the slipface and suggesting that dune migration may also be occurring. HiRISE images shown: (a,c/T1) PSP_001488_1750 (taken 20 November 2006), (c/T2)

650 PSP_009650_1755 (17 August 2008) (MRO/NASA/UA).

651
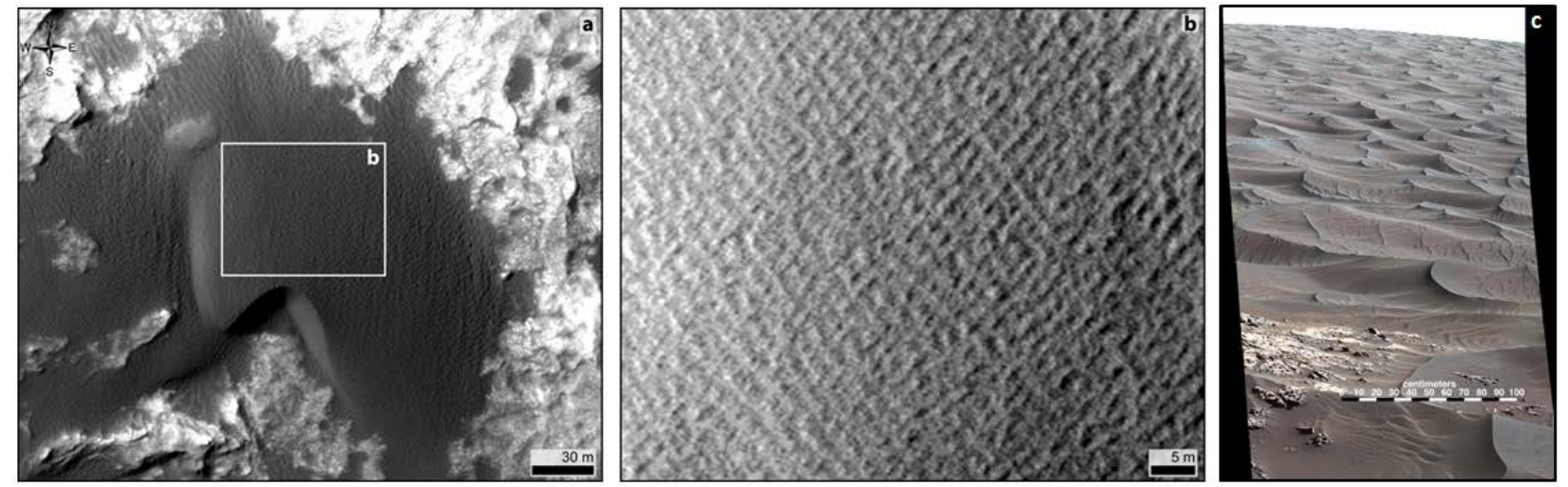

653 Figure 10. Ripple morphology on Mars. (a-b) HiRISE images of High Dune, an active dune within the

654

655

656

657

658

659

660

661

662

663

664

Bagnold dune field, Gale Crater, that has also been investigated by MSL Curiosity (Bridges et al., 2016;

Lapotre et al., 2016a). Visible in these orbital images is a complex ripple pattern on High dune's stoss

slope, with what appears to be two sets of large ripples intersecting at right angles_(Silvestro et al.,

2016). This ripple configuration is typical of the Bagnold dunes and seems to be common on Mars. HiRISE images are: (a) ESP_042682_1755, (b) PSP_009294_1750. (MRO/NASA/UA) (c) This image of the High

Dune stoss slope was taken by the Mast Camera on Curiosity, showing the complex morphology of these large ripples, which in this closer-inspection perhaps do not appear analogous to terrestrial sand ripples.

The scalebar (one meter length) is for the lower portion of this cropped image. Image is from NASA Photojournal PIA20168.

\subsection{Phase 6: Observation of dune activity (aeolian or otherwise)}


Only recently has it been observed that martian dunes and ripples are very actively migrating

666 and evolving within the present-day climate (Figure 9; Bourke et al., 2008; Bridges et al., 2012a; 2012b;

667 Chojnacki et al., 2011; 2015; Fenton, 2006; Geissler et al., 201ㅍz; Silvestro et al., 2010b; 2011; 2013).

668 Previously, an incongruence appeared in our understanding of present-day martian sand transport, as

669 the morphology of many aeolian bedforms (apparently sharp crestlines of dunes and ripples) and a

670 surface observation of saltation (Greeley et al., 2006) and ripple movement (Sullivan et al., 2008)

671 suggested that some aeolian bedforms should be active. However climate models did not produce the

672 wind velocities predicted for saltation processes to occur under present conditions and no bedform

673 motion was observed within higher-resolution images (although some dome dunes were seen to

674 disappear (Bourke et al., 2008)). This was taken to imply that martian dunes may be stabilized (e.g..,

675 Zimbelman, 2000) and possibly relict features of a past climate with a denser atmosphere (e.g., Breed et

676 al., 1979) $)_{L}$ and that surface degradation processes must be slow. However, acquisition of a sufficient

677 temporal baseline and careful comparison of overlapping high-resolution images now yield measurable

678 and consistent changes in dune margin and ripple crestline locations through several fields (e.g...

679 Endeavor Crater: Chojnacki et al., 2015), and show that sand fluxes on Mars are comparable to, and in

some casesexceeding, terrestrial sand fluxes in the Antarctic Dry Valleys (Bridges et al., 2012b). Within

681

Endeavor Crater, these martian sand fluxes are sufficient for dune turnover times to be much less than

the time since known large climatic shifts (e.g., an obliquity shift or increased atmosphere density).

implying that these dunes are not records of paleo-climate conditions (Chojnacki et al., 2015).

685 that at least some aeolian bedforms are presently active, were helpful in the advance of sediment flux

686 models and understanding how sediment flux dynamics may vary on different planetary bodies. For

687 example, an update to the model of steady state saltation (Kok and Renno, 2009) and application to

688 Earth and Mars conditions (Kok, 2010) showed that saltation can be maintained on Mars by wind speeds 
an order of magnitude less than that required to initiate it, while nearly the same wind speed is needed to both initiate and maintain saltation on Earth. This provides a viable explanation for why aeolian bedforms appear to evolve at lower-than-predicted wind velocities (as well as an explanation for the smaller-than-expected minimum dune size on Mars: Kok, 2010). Estimates of aeolian sand flux (in the present or past) are important as they feed into models of surface erosion rates (e.g., Golombek et al., 2006; 2014).

Sand dunes on Mars are also subject to other processes in the present-day. For example, $;$ in particular, small-and large-scale gullyalcove-apron and alcove-channel-apron (i.e., gully) formation activity has been observed in southern mid-latitude dune fields (Figure 8; Diniega et al., 2010b; Dundas et al., 2012; 2015) and similar alcove fan formationactivity has been observed in the north polar dune fields (Hansen et al., 2011; 2015; Horgan and Bell, 2012), moving large volumes of sand downslope and possibly contributing to the overall migration of the dunes. Some have proposed that martian gullythis activity may have aeolian drivers (Horgan and Bell, 2012; Treiman, 2003), but most studies have shown a seasonal control on the timing of gully activityfeature formation and evolution, possibly related to $\mathrm{CO}_{2}$ frost processes (Diniega et al., 2010b; Dundas et al., 2012; 2015; Hansen et al., 2011). It is also possible that both aeolian and seasonal frost processes have an influence on these types of dune modification activities (Hansen et al., 2015). Regardless of underlying process, these changes are actively modifying the dune slopes (Allen et al., 2016; Diniega et al., 2016; Hansen et al., 2011) and thus need to be investigated and explained to form a complete story for the martian dune evolution and accurate interpretation of observed dune morphology. Is also important to note that some dunes have features indicative of a lack of activity, such as fissures on north polar dunes (Portyankina et al., 2012) and pits and softened topography on southern mid-latitude dunes (Fenton and Hayward, 2010). Such evidence for stability can provide constraints on 
the current availability of mobile material and the near-surface wind environment, as well as a contrast with the conditions when the (now inactive) bedform had evolved.

\section{Summary of (6)}

Data needed: Repeat images of sufficient spatial and temporal resolution to detect (and measure) changes in surface morphology (or lack thereof).

Knowledge gain: Observation and constraints on the estimated (average/net) amount of fand possibly, measurement) of sediment transport.

Assumptions generated: Activity rates observed in the present-day can be extrapolated to past times and conditions.

Questions: What other processes are contributing to dune evolution? How much sediment is moving within the present climate? Has that amount of aeolian sediment transport changed since a previous

climate?

Lead to investigations of: How the estimated sediment transport may affect surface erosion rates

(including formation of sand) and formation of other aeolian features such as yardangs; How the climate has shifted, if changes in sediment transport are apparent.

\subsection{Phase 7: Groundtruth measurements}

To-date, we have only visited - at ground-level and up-close - dunes on one planet other than the Earth. While various Mars rovers have in situ imaged sand deposits and ripples (e.g., Greeley et al., 2006; JPL, 2012; 2014; Sullivan et al., 2005), Curiosity's visit to Bagnold Dune Field is the first in situ observation of dunes and dune sand (JPL, 2015; Bridges et al., 2016). This rover has examined dune sand on several different slopes on and around dunes slopes thought to be undergoing different levels of aeolian activity (based on orbital observations of ripple migration and the strength of spectral signatures 
of dust cover (Lapotre et al., 2016b)). Within even the first observations of dune sand (scooped from the

737 stoss slope and imaged on the lee slope; Figure 11), grain size differences have been noted that are

738 perhaps correlated with differences in grain composition (as grains of different sizes appear to

739 correspond to different materials) (Achilles et al., 2016; Cousin et al., 2016; Ehlmann et al., 2016).

740 Images of the lee slope of the more active "High dune" have yielded many grainflow features and

741 potentially evidence of some level of induration (Figure 12; Ewing et al., 2016) - none of which was-were

742 visible in the orbital images. The first results of this work are currently being put together, and we look

743 forward to learning more about the first in situ investigated extraterrestrial dunes.

744

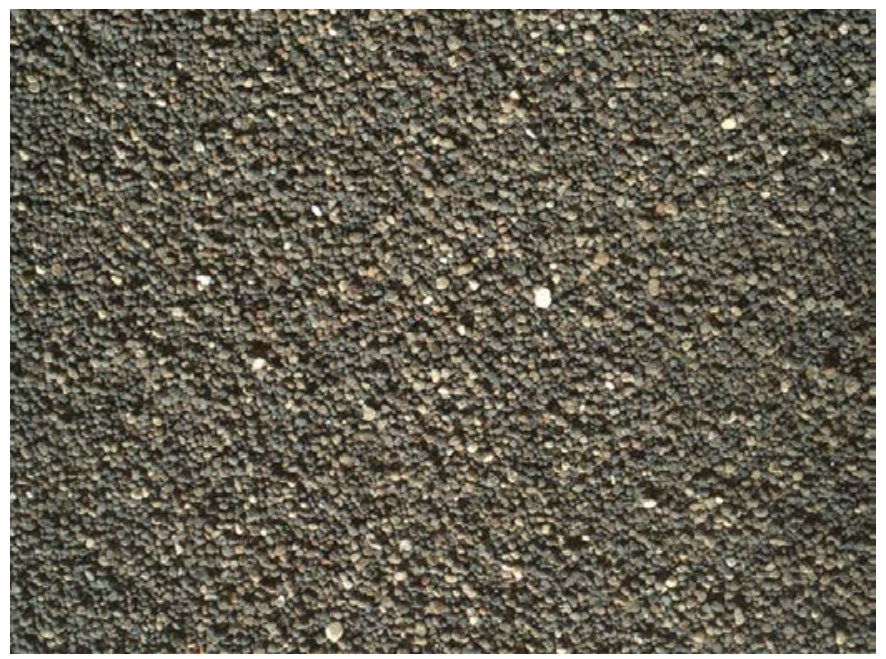

746 Figure 11. Image of the undisturbed surface within the base a Martian sand dune called "High Dune"

747 visited by NASA's Curiosity rover. The image covers an area 3.6 by 2.7 centimeters. Grain sizes show

748 some range, but a fairly consistent size - comparable to dune sand on Earth. It was taken by the Mars

749 Hand Lens Imager (MAHLI) camera on the Curiosity rover's arm on Dec. 5, 2015. Image and description

750 are from JPL (2015). 


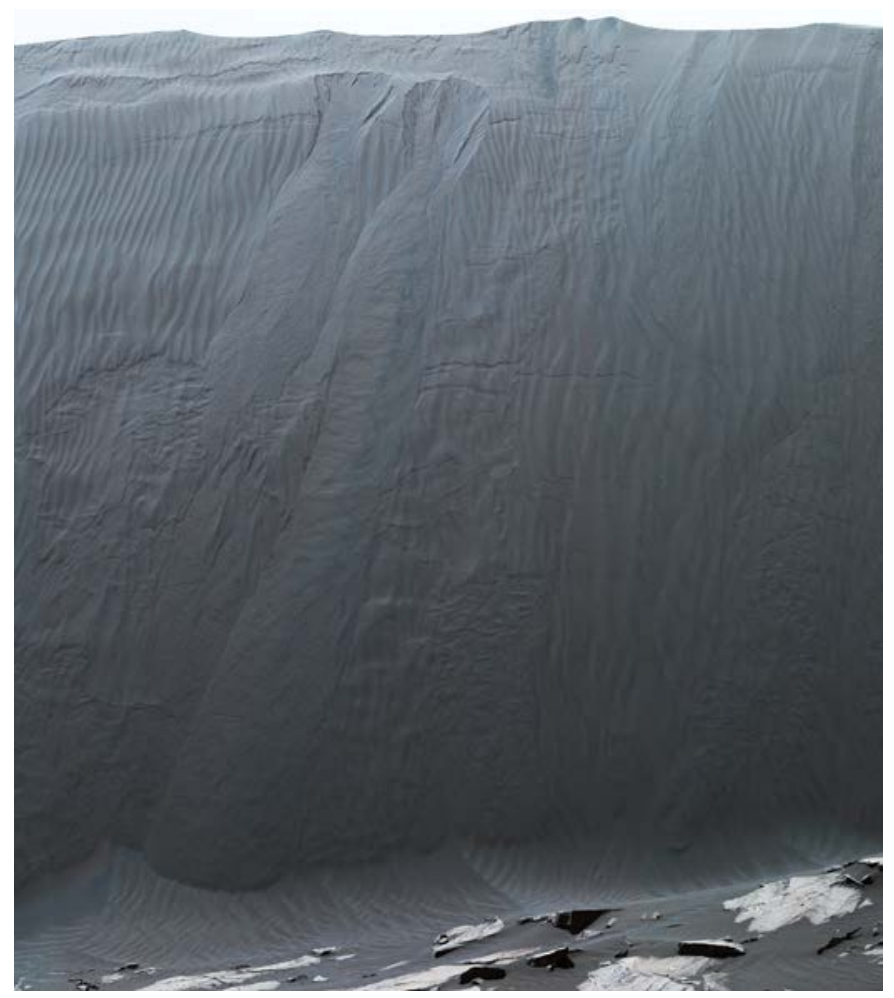

753 Figure 12: An active dune slipface on Mars, imaged by NASA's Curiosity Mars rover. Multiple grain

754 flows, slumps, and ripples are visible on the slipface of "Namib Dune," a dune within the "Bagnold

755 Dunes" field along the northwestern flank of Mount Sharp, Gale Crater. None of these fine details are

756 visible from orbital (HiRISE) images. The overall slope is $26-28^{\circ}$, and 4-5 $m$ in height. This view combines

757 multiple images from the telephoto-lens camera of the Mast Camera (Mastcam), taken on Dec. $21,2015$.

758 The scene is presented with a color adjustment that approximates white balancing, to resemble how the

759 sand would appear under daytime lighting conditions on Earth. Image and description are from NASA

760 Photojournal PIA20283.

761

762 Summary of (7)

763 Data needed: In situ observations of the dune and dune sand (possibly from different portions of the

764 dune); possibly observations of saltation on the dune or grainflow on the slipface.

765 Knowledge gain: Size, composition, and other characteristics of grains involved in saltation. 
Assumptions generated: That the observed characteristics and activity are not anomalous, in time and

767

768

769

770

771

772

773

774

775

776

777

778

779

780

781

782

783

784

785

786

787

788

space (i.e., the observation didn't catch a rare circumstance/event).

Questions: Why do the grains look as they do, and what causes the variation/distribution in grain size?

How representative is this observed dune's characteristics and activity? What causes the dune's

features? How can observations of sediment grain size and bedform morphology provide insight

regarding transport processes and the nature/frequency of mobilization events?

Lead to investigations of: Models of dune activity and evolution, and generation of the observed sand

grains (extending or perhaps redirecting previous work); Based on in situ observation of features that

may not be visible from orbit, what is implied about dune activity and characteristics and how does

information that feed back into models of dune evolution (and what assumptions and related results

should be re-evaluated).

\section{Discussion}

There are some differences between the aeolian science investigations undertaken on each planetary body - in particular as study methods of more recently studied bodies can build from lessons learned in aeolian bedform studies of a previously observed body, and as overall our understanding of aeolian processes becomes more refined as models are forced to reconcile with a wider range of environmental and planetary conditions. But, as has been described, studies of aeolian bedforms on planets (other than Earth) broadly tend to follow a similar pattern of gained knowledge, generated assumptions, and follow-up investigations (that rely on the new knowledge and assumptions). The similarities in the history of aeolian science over different planetary bodies (Figure 13) are due partially to the knowledge-advancement at each body being based on the same types of data. Such data is usually acquired in the same order, which is based on the way in which higher-resolution and increased 
coverage are acquired during extended or subsequent missions, and as concepts and investigations mature and become more specific within all areas of planetary exploration.

792 body. We then move beyond planetary aeolian studies, to look at the interplay of planetary aeolian

793 bedform studies with investigative fields that follow their own sequences of discovery and refinement: aeolian process modeling and terrestrial aeolian studies.
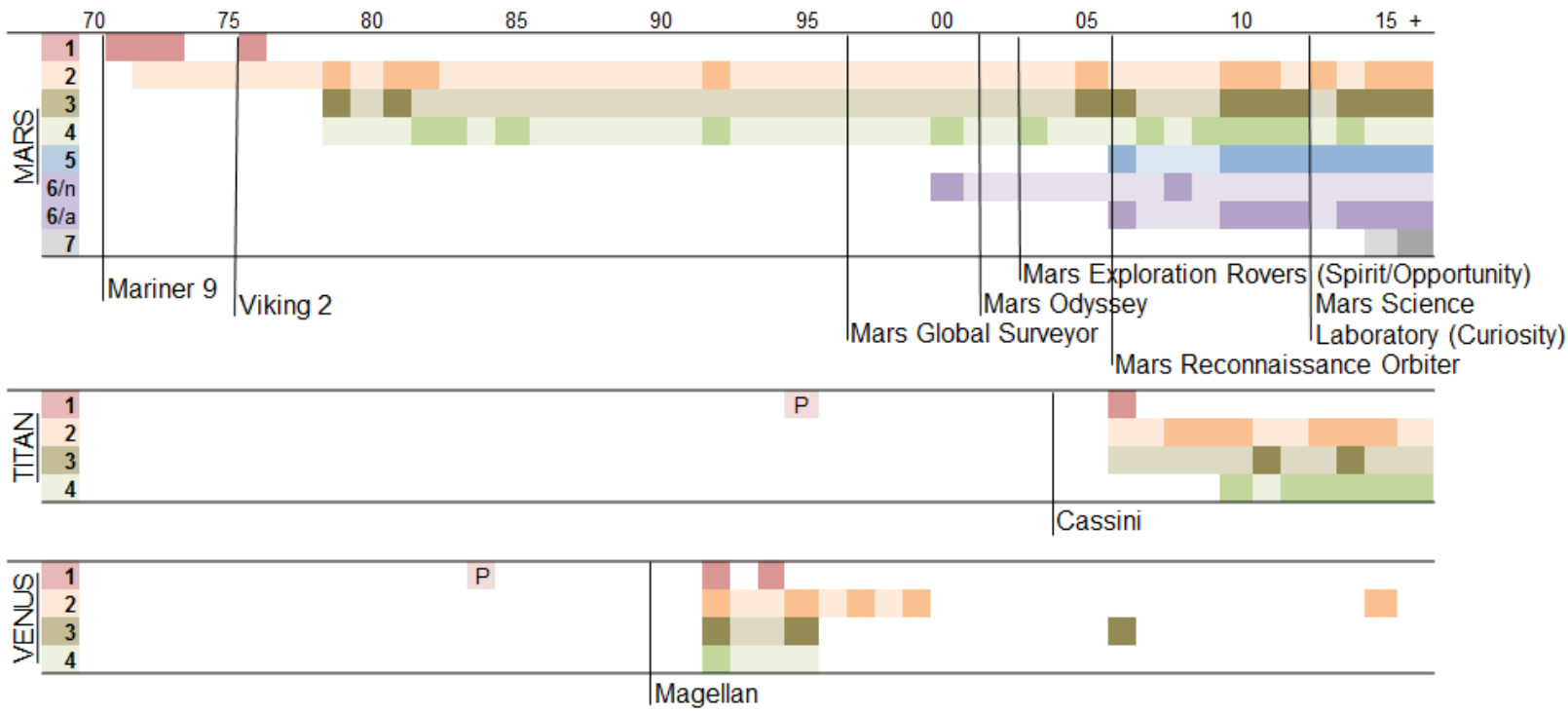

Figure 13. Timelines showing movement into and through different investigation phases, for Mars,

Titan, and Venus. Darker colors indicate publication dates for relevant studies (as referenced within this

paper), and lighter colors indicate the general period of activity (again, based The timespans for the

investigations phases are based on publication datesreferences within this paper and checked against

801

google.scholar search results with keywords e.g., "Venus dunes"). Under Mars, Phase 6 is divided into

observations of "no dune activity due to aeolian bedform processes" (6/n) and of such activity (6/a).

Within Phase 1 for Titan and Venus, publications predicting a limit on aeolian bedform formation on 

examples: conditions.

of relevant spacecraft, to the planetary body, are included_for obvious reasons, these often initiate or re-invigorate investigations begun during a previous mission.

\subsection{Gaps that can form within the planetary aeolian science sequence of investigations}

Over time and as more data is acquired, our understanding of aeolian processes and

interpretation of the aeolian landforms builds. However, as that understanding builds, it is important to

keep track of which building blocks are assumptions and not actual observations. While-lit is necessary

for assumptions to be made to keep the science investigations moving forward and to guide

development of the next set of investigations, but an assumption that is treated like an "observation"

can lead to models with unrecognized limitations, which in turn can lead to incorrect interpretations of

new observations or even a lack of attention paid to "contradictory" observations. Thus, assumptions

should be recognized as such (and not treated as data) and be re-evaluated for consistency with new

and different data, until direct measurement of the assumed variable or process is possible - doing this

can make it easier to identify and investigate intriguing new understandings about processes and

Several examples of areas where new information has supplanted previous assumptions have been mentioned within the discussion of the investigation phases (Subsections 2.1-7). Some additional

- As higher-resolution and more detailed studies are completed about specific dune fields, results of these studies (Phases 5-7) should be inserted into field (Phases 2 \& 3) and global studies (Phase 4) that previously relied on lower-resolution or less complete data and assumptions about form and process uniformity (in time and space) through the field. As was discussed under Phase 7, the martian large ripples are a new example of this -- where in situ observations are drawing into question previous work done regarding the scaling of aeolian bedform size between Earth and Mars 
and interpretations of ripple crestline complexity, that had been based on interpretation of orbital

images. In general, as more detailed studies are conducted over specific martian dune fields, it is important to regularly consider how those results fit within the results of larger-scale studies.

832 - These observations have also led into a model of a potential new mode of subaerial bedform

833 migration and evolution (Lapotre et al., 2016a). As discussed in Phase 5, on the stoss slope of Namib

834 dune, two types of ripples have been imaged: The large ripples (few m-wavelength) were previously

835 observed in orbital images, and were through to be analogous to the wind ripples that we see on

836 the slopes of terrestrial dunes (e.g., Sullivan et al. 2008). However these large ripples have very different morphology and dynamics (Silvestro et al., 2016) and in fact are superimposed by small ripples ( $10 \mathrm{~s} \mathrm{~cm}$ wavelength) that have morphology more similar to terrestrial sand-impact ripples (but were not visible within orbital images; Figure 10). The large ripples are now hypothesized to be fluid-drag ripples (Bagnold, 1951; Wilson, 1973), which on Earth form under water, but on Mars are able to develop sub-aerially because of the higher kinematic viscosity of the low density atmosphere (Lapotre et al., 2016a) a form of aeolian bedform that does not form on the Earth, due to our much thicker atmosphere. Although this model is still being worked out and debated, tThis example has

- $\underline{\text { Dune s}}$ Sand grain sizes on Mars have been estimated since dunes were first seen, based on assumptions about conditions for dune formation (Phases $1 \& 2$ ). Efforts to "measure" grain sizes 850 from proxy thermal inertia estimates have also been undertaken (mentioned within Phase 4), and compared to and debated against the assumptions about the ability of the wind to move grains of 852 different sizes. Studies based on these estimations, and their results, now should be re-evaluated as 
Curiosity has recently completed the first in situ investigation of a dune located on a planet other than Earth (Phase 7), yielding the first direct measurements of martian dune grain sizes (Figure 11). While on Titan sand grain sizes have not yet been measured in situ (and won't be in the nearcan possibly be tracked from visible imagery, climate models, and/or topography models, compositional information about the dune grains and the potential sand sources is needed to check that the model is consistent with the full environment. This may extend beyond compositional information in the local

867 or have been recycled a few times - and this history may not be apparent without a broad-swath of the martian polar regions have morphologies and features different from those in the equatorial region, making it clear that polar processes are altering the aeolian bedforms and thus must be considered in their interpretation (e.g., in the north: Hansen et al., 2011; 2015; in the south: Fenton et al., 2010).

\subsection{Connections to modeling of the physical processes}


aeolian processes without assumption of Earth-conditions. This can especially have a large impact on

878 models of the small-scale and complicated dynamics of sand-wind and sand-sand interactions. For

879 example, as discussed under Phases 2 and 6, our understanding of the way in which sand is picked up by

880 the wind, causing or continuing saltation, has now been "tested" under terrestrial, martian, and

881 venusian conditions (Kok, 2010; 2012), resulting in an updated model of how saltation and reptation are 882 initiated and interact.

On Titan, questions about how "sticky" organic sand particles would interact with the wind

884 were part of an investigation to explain how the dunes had formed, and from that to connect the

885 crestline orientation to the forming-wind direction(s). The Titan dune sand color appears consistent with

886 a composition of organics, and such long-chain molecules (of as-yet undetermined exact composition)

887 could be derived from the atmospheric photodissociation of methane, which creates small particles

888 (Carl Sagan's "tholins") that snow down from the atmosphere (and then perhaps get incorporated into

889 surface sedimentary layers or clump together into larger granules, that are eroded and transported to

890 the dune-forming regions) (Radebaugh, 2013; Barnes et al., 2015). Studies of clay-rich dunes in China

891 had revealed that "sticky" particles could form dunes, but would anchor themselves to the downwind

892 edge of a longitudinal dune and thus progress_grow and migrate the dune_in their transport direction,

along the dune crestline; this was proposed as a potential analog to the Titan dunes (Rubin and Hesp,

2009). Although the Titan dune morphologies were overall found to be generally-more consistent with

freely-moving particles (i.e., the saltation more usually observed on Earth) and thus this longitudinal

dune formation model is less favored than the model discussed in Subsection 2.2. This type of

897 questioning highlighted a different type of terrestrial dune-formation mechanism and "tested" behavior

898 of the traditional dune formation model if one does not assume a non-cohesive sand grain. This led to

further development of a dune-wind alignment model that brought these two hypotheses together as 
wind regime (Courrech du Pont et al., 2014). Within this single model, dune alignment reflects growth via either a "bed instability mode" (which approximates the longitudinal dune growth process proposed by Rubin and Hunter (1987) and Rubin and Ikeda (1990)) or a "fingering mode" (the growth process proposed by Rubin and Hesp (2009)), depending on sediment availability.

Models that examine larger-scale dynamics can also be tested through application to different planetary surfaces. For example, it was in studying martian dunes that a discrepancy was noticed between the minimum dune size expected on that planet ( 100x the minimum Earth dune size) and that observed ( 10x), thus driving new models of dune formation to explain the scaling factor. Model studies aiming to replicate the observed minimum barchan dune size on Earth and Mars addressed this question, and tested assumptions about how saltation, reptation, and wind drag interact in setting characteristic sand trajectory distances, and from this the generation of instability within a sand bed under a moving fluid (Claudin and Andreotti, 2006).

\subsection{Connections to terrestrial studies and knowledge gain}

The trajectory of terrestrial dune studies has differed markedly from the framework proposed here for planetary dune studies. In essence, the difference is one of top-down vs. bottom-up approaches as in situ observations of terrestrial landforms, conditions, and activity are significantly easier $\forall$ to carry out. However, this has not resulted in the history of terrestrial dune fields being an opposite to the sequence suggested as being characteristic of planetary dune research. The earliest published studies of terrestrial dune fields were linked with exploration by non-indigenous people, and many of the founding points of contemporary dune science can be traced to these expeditions. The exploration of the southern African and Australian interior (mid-19th century), the Sahara (around the beginning of the 20th century, mostly by the French in the west and the English in the east) and the Arabian Rub al'Khali (most notably by Wilfred Thesiger in the late 1940s) all had exploration as their primary goals. As with 
contemporary rover exploration of the martian dune fields, many dune fields were approached with

926 trepidation due to the hazards they posed. Despite science being incidental rather than implicit to most

927 of the explorations, there was, nonetheless, early recognition of the great spatial extent of many dune

928 fields, the remarkably organized nature of dunes and the fact that dunes could exist at differing activity

929 levels.

$930 \quad$ Although Bagnold's work in the 1930s and 1940s is most commonly cited as being the

931 foundation of modern understanding of aeolian processes and landforms, there were significant

932 precursors. George Perkins Marsh (1864) considered geoengineering problems associated with drifting

933 sand, and the role of vegetation in stabilizing dunes, and Russian geologist Nikolay Sokolów had

934 discussed dune sedimentology and theories of dune formation in a 300 page book devoted to the

935 subject (1894). Georges Rolland, a French mining engineer, set out a series of propositions in 1890

936 based on fieldwork in the Algerian Sahara which addressed such issues as sediment source, the

937 distribution of dune fields, varying levels of dune activity and the relationship between wind regime and

938 different dune shapes (Burt et al., 2008). At this point, the role of the wind in dune formation was still

939 contested by many, and it was widely held that dunes would prove to have rocky cores (Goudie, 2002).

940 Many other aspects of contemporary aeolian science date from surprisingly early studies. Aerial imagery

941 was used to examine dune planform morphology in the 1930s (Aufrère 1932, Madigan 1936), and the

942 recognition of dunes as a particulate waveform in a fluid medium can be traced to the work of Cornish

943 (1914). Bagnold's work, utilizing field and wind tunnel experimentation, is an early example of the

944 'quantitative revolution' widely recognized in geosciences in the middle of the 20th century. This directly

945 influenced the next half-century of research, via fieldwork and laboratory experimentation, in a phase

946 perhaps best summarized by Lancaster's (1995) state-of-the-art textbook. Coincidentally, the same year

947 saw the publication of Werner's (1995) application of cellular automata models to aeolian bedforms,

948 which accepted that dunes formed as an emergent property of a complex system, one of the first 
949 indications of the failure of reductionist approaches to fully explain aeolian landscapes (Livingstone et

950 al., 2007). The same period saw the rise of the use of luminescence dating to provide ages for dune

951 emplacement, since described as having has a transformative effect on studies of dryland science

952 (Singhvi and Porat, 2008).

953 Planetary studies of aeolian dunes therefore have the advantage of decades of terrestrial work

954 to draw upon, and this is reflected in the very rapid progress made on newly-discovered dunes (e.g.

955 Titan, Comet 67P). Terrestrial science, conversely, has had the advantage of a relatively steady

956 progression in the quality of the available data -- although the related understanding of aeolian systems

957 has not progressed as steadily. The progress made in understanding terrestrial dunes has not been

958 without challenges, and it is instructive to reflect on whether there are lessons for the planetary

959 community can be drawn from progress on terrestrial dune fields, and conversely whether the evolution

960 of extraterrestrial dune research can inform the research strategies of Earth's dune studies.

961

What can planetary science learn from the history of terrestrial dune studies?

Much of planetary dune science is already directly influenced by the methods, theory and

964 process understanding derived from terrestrial studies, manifest in the numerous analog studies.

965 However, there are some less well-discussed points that are worthy of consideration.

As was noted in section 3.1, close attention must be paid to the difference between assumed

967 and observed knowledge. Cautionary tales can be drawn from terrestrial dune studies, and this is

968 perhaps best illustrated by the roll vortex hypothesis for longitudinal (linear) dune formation. First

969 proposed by Bagnold (1953), and promoted subsequently (e.g. Hanna, 1969) this suggested that

970 thermally induced vortices in regional wind-flow would lead to the development of helical horizontal

971 flow cells that might lead to sand accumulation in linear bedforms extending downwind. The theory is

972 strikingly devoid of empirical supporting evidence, and yet still persists in the literature. Quite simply, 
973

974

975

976

977

978

979

980

981

982

983

984

985

986

987

988

989

990

991

992

993

994

995

996

vortices of sizes that might explain dune spacing have never been observed despite numerous experimental attempts, and the transverse component of roll vortices does not appear to have sufficient velocity to move sand (Lancaster 1995). Planetary studies should be careful to question existing paradigms and theories, and be willing to point out when data do not support these hypotheses.

Bagnold's great advances in aeolian science can be largely attributed to willingness and fearlessness towards innovation, in terms of methods and physical exploration. The novel application of wind tunnels to aeolian transport and sedimentation and the methods developed to enable remote desert travel directly enabled the advances in understanding that Bagnold brought. Planetary perspectives support this, with the radical advances in data brought from missions such as MSL, Cassini/Huygens, Rosetta/Philae and New Horizons. Such evidence supports the potential knowledge gains from similarly ambitious mission concepts of other planetary surface exploration missions, such as AVIATR (Barnes et al. 2012) and VISE (NRC, 2013) which have been considered for Titan and Venus exploration, respectively. The evidence from both terrestrial and planetary dune studies suggests that high-risk, innovative research has led to some of the greatest advances.

The discrepancy between the timescales of aeolian process and the timescales evident in aeolian landscapes is also very evident - possibly even more so - on some planetary bodies. Despite processes operating within dune landscape on timescales of seconds to- hours, the resultant landscape development frequently operates on timescales of $>10^{3}$ years. Dating of aeolian sediment, primarily via the suite of luminescence dating methods, has been adopted very widely on terrestrial dune studies, and has played a crucial role in linking the short-term process understanding with the long-term geomorphological record. It has enabled calculation of rates of landform evolution beyond that possible using observational records (e.g. Kocurek et al., 2007; Telfer, 2011), revealed complex spatial variability in aeolian accumulation (Telfer and Thomas, 2007) and frequently been used to infer external drivers of dune activity (e.g. climatic changes). Experimentation with luminescence readers suitable for Mars 
997 missions has been explored (e.g. McKeever et al., 2003; Jain et al. 2006), and if the substantial technical

998 challenges can be overcome (Doran et al. 2004), martian luminescence dating offers the potential to

999 extend understanding of accumulation beyond the period of direct observation. Recent progress

1000 suggests that solutions may exist to these challenges (e.g. Sohbati et al., 2012).

1001

1002

1003

1004

1005

1006

1007

1008

1009

1010

1011

1012

1013

1014

1015

1016

1017

1018

1019

1020

W Much of the focus of this paper has been on the increasing avalability, resolution, and coverage

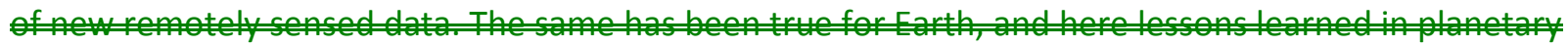

-

resolution of the imagery. This is perhaps best illustrated with the example of the highlycontestedissue

of extensive palae dune fields in the Amzon Basin, presentlycoved withextensive tropical forest

Fricart (1974), working with recently released first-generation tandsat imagery, identified widespead

s.

times (e.g. Klammer, 1982) and lead to a widespea belief in a rid phases ampanied byvegetation

loss during the late Quaternaryevolution of the region, with huge implications for understandingof

regional biogeog phy in one of the world's most biodiverse regions. Hower, whilst subsequent

-a of

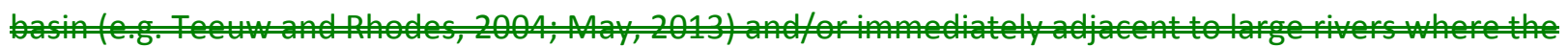

sediment supply has at times been the dominant control (e.g. Garneiro, 2002), the existence of wide

5. of

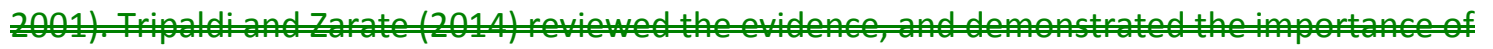

\%

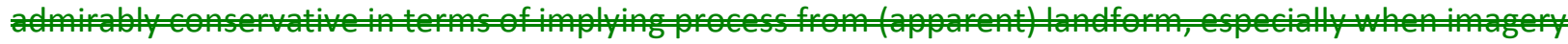

is to for of of of

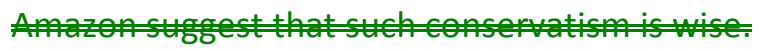




\section{What can terrestrial dune studies learn from the history of planetary science?}

Although at least parts of Phases 1-3 and 5-7 have been investigated on Earth for 70 years or more, a striking difference between planetary and terrestrial dune studies is that currently there is no global catalogue of dunes for Earth (Phase 4). The first editions of the Mars Global Digital Dune Database (Hayward et al., 2007) was published within six years of the start of THEMIS data collection (which are used to identify the thermal inertia proxy identifiers for dune fields), and global mapping of Titan's dunes within the constraints of the available data (Lorenz and Radebaugh, 2009) was published within a similar timeframe since the arrival of Cassini at Titan. Although some terrestrial regions have been mapped and duneforms catalogued (e.g., Namib; Livingstone et al., 2010), and a global database of dunes with dating constraints has recently been complied (Lancaster et al., in press), global-scale consideration of terrestrial dune fields is currently lagging behind planetary science. Efforts in this direction are currently in progress (Hesse et al., 2015) -- but it has been over 40 years since the advent of global terrestrial satellite coverage. The focus of planetary global catalogues of dunes has been on understanding global circulation patterns (e.g. Charnay et al. 2015, Ewing et al. 2015), sediment sources (e.g. Tirsch et al., 2011), identification of large-scale variations in dune form due to different evolution processes or rates (e.g., Hayward and Fenton, 2010; Savage et al., 2014), and targeting areas for detailed study (e.g., Hayward, 2011). Whilst it is not necessary to use dune morphology to understand modern circulation patterns on Earth, applications of such a database would include quantification of aeolian sediment volumes and flux, improved understanding of regions where dunes are currently stabilized, and potential for monitoring change in environmentally-sensitive, dynamic landscapes.

Livingstone et al. (2007), reviewing the state of understanding of terrestrial dune geomorphology, concluded that decades of largely inductive, and increasingly reductionist, study had not brought the completeness of understanding that had been hoped, and that integration of methodologies (field, modeling and remote sensing) offered the best prospects for knowledge. Perhaps 
1045 due to the difficulties in conducting 'field study' of extraterrestrial dunes (i.e., Phase 7), which are only

1046 very recently being overcome on Mars, such combined strategies are often exemplified by planetary

1047 aeolian studies, where studies employing a wide range of methodologies including numerical modeling,

1048 laboratory experimentation, field study (presently via analog environments), and remote sensing are

1049 commonplace (e.g., Lucas et al. 2014). Although some terrestrial studies do synthesize such diverse

1050 methodologies, the example set by many planetary studies is a good one for terrestrial dune studies.

1051 Much of the focus of this paper has been on the increasing availability, resolution, and coverage

1052 of new remotely sensed data. The same has been true for Earth, and here lessons learned in planetary

1053 studies help guide interpretation of terrestrial images at the margins of the spectral and/or spatial

1054 resolution of the imagery. This is perhaps best illustrated with the example of the highly contested issue

1055 of extensive palaeo-dune fields in the Amazon Basin, presently covered with extensive tropical forest.

1056 Tricart (1974), working with recently-released first-generation Landsat imagery, identified widespread

1057 stabilized aeolian landforms in the tropical Amazon Basin. This interpretation was repeated numerous

1058 times (e.g. Klammer, 1982) and lead to a widespread belief in arid phases accompanied by vegetation

1059 loss during the late Quaternary evolution of the region, with huge implications for understanding of

1060

regional biogeography in one of the world's most biodiverse regions. However, whilst subsequent

1061

reanalysis of high-resolution data has revealed aeolian dune fields around the margins of the Amazon

1062

basin (e.g. Teeuw and Rhodes, 2004; May, 2013) and/or immediately adjacent to large rivers where the

1063

sediment supply has at times been the dominant control (e.g. Carneiro, 2002), the existence of wide

1064

swathes of paleodunes across the Amazon basin has not withstood closer scrutiny (Colinvaux et al.,

2001). Tripaldi and Zarate (in press) reviewed the evidence, and demonstrated the importance of

1066

groundtruthing when image interpretation is challenging. Planetary geomorphologists are usually

1067

admirably conservative in terms of implying process from (apparent) landform, especially when imagery 


\section{is at the limit of its spatial or spectral resolution, and terrestrial incidents such as the question of an arid} Amazon suggest that such conservatism is wise.

\section{Conclusion/Summary}

Studies of aeolian bedforms over a wide range of planetary bodies have resulted in significant progress in our understanding of past and present climate and surface conditions, physical processes, and the interconnectivity of dynamics over a range of spatial and temporal scales. These studies contribute, in meaningful and often unique ways, towards a range of planetary science investigations. For example, as discussed, interpretation of dune morphology often provides unique, if proxy, groundtruth data about past or present wind conditions, and the proven presence of a large amount of sand grains can drive investigations about processes responsible for creating such grains. Beyond studies that involve this type of direct interpretation of the aeolian bedforms, aeolian science studies also yield information about many tangentially-related areas of investigation. In particular, aeolian-driven sand flux appears to be an important force in erosional modification of a planetary surface. Quantitative estimations of wind speeds and sand flux and identification of sediment transport pathways yield quantitative estimates of erosional process rates. This can, for example, lead to improved interpretation of observed landforms - such as yardangs (e.g., Ward 1979), or the rate of crater degradation by aeolian processes which is important for accurately estimating the age of a planetary surface (e.g., Golombek et al., 2014; Grant et al., 2006; 2008; 2016). This can also provide bounds on surface-ages of exposed rock surfaces, which is can be of importance to rover missions - such as Mars missions searching for reachable-environments near the surface that may have been habitable and that may include preserved biosignatures (e.g., Arvidson et al., 2015).

As discussed, planetary aeolian studies have also made key contributions towards improving the methodologies employed in aeolian science, and in challenging assumptions built (perhaps 
1092 inadvertently) into aeolian process models based on terrestrial observations. To-date, this has resulted

1093 in the refinement of several models of dune-field forming processes, from interactions between sand

1094 grains and the wind or with each other, up through interactions between dunes and topography and

1095 climate shifts.

1096 Given all of the ways in which our aeolian study results impact our understanding of planetary

1097 surface conditions and histories (as well as the Earth's), it is thus very important to critically look at how

1098 we progress in planetary aeolian science, and in particular to consider carefully which results (and

1099 resultant models) are based on assumptions versus observations - and then to revisit those results

1100 when new information becomes available. Here, we have proposed one framework for identifying

1101 progress within planetary aeolian studies, and have used that framework to chart the progression of

1102 data, assumptions, and generated knowledge. We hope this framework, and our identification of gaps,

1103 will help future planetary aeolian researchers strategically fill knowledge gaps or at least carefully

1104 recognize where assumptions are being used to progress a study.

1105 Additionally, this framework may help identify the types of data that would be most useful for

1106 future planetary missions. Pluto, lo, and Comet 67P were all discussed as having reached Phase 1, where

1107 at least a potential aeolian bedform has been observed. On Titan, global datasets exist and have

1108 contributed to large shifts in our understanding of the Titan climate and organic cycles. Venus also has a

1109 global topography dataset, but the low resolution and apparent lack of dune fields stalled progress in its

1110 aeolian science investigations (and thus related advancements in planetary surface studies).

1111 Unfortunately for Venus and Titan, further progression within Phases 2-4 (and movement into Phases 5

1112 and beyond) will likely need to wait for new and higher-resolution surface datasets.

1113 Mars' aeolian bedforms are the best studied within planetary aeolian science (outside of

1114 Earth's), with both widespread coverage in certain data-types and many regions with high-resolution

1115 data regarding the dunes' and dune field environment's morphology and composition, collected over 
1116 the past 43 years. However, with the progress that has been made, we cannot lose sight of the fact that

1117 much of it has been built on interpretations of remote data. (As discussed under Phase 7, in situ duene

1118 field observations have not been possible until just recently.) Furthermore, much of the work involves a

1119 meshing of coarse global data with a few more-deeply monitored and studied dune fields, and thus

1120 much extrapolation is done that assumes certain types of consistency between fields. This is an odd

1121 contrast with Earth dune field studies, where the global dataset (Phase 4) is what is missing.

1122 For all planetary bodies (including Earth), we look forward to further advancements in the

1123 interpretation of aeolian bedforms and what interpretations about those bedforms will imply about the

1124 environmental conditions and processes. If history is to be any guide, with each advance into a new

1125 phase (due to acquisition of a new type of data and/or enablement of a new type of analysis), we find

1126 exciting new understandings about that planetary body and the general understanding of aeolian

1127 processes. One area of intriguing advancement is the prediction of where dunes and/or ripples could be

found (which could be thought of as a "Phase 0" within our framework). As we explore more bodies and

learn more about the conditions under which bedforms resembling aeolian dunes are found, we can

wonder about the next place where we may expect to find potential dunes, as well as identify lessons to

aid in such predictions (e.g., when we return to Venus). In addition, Pperhaps in the near future, we will

move into a yet-undefined Phase 8 (e.g., through comparison between in situ measurements of some

1133 very different types of aeolian bedforms? Hints of that are starting with sand grain comparisons (e.g.,

1134 O'Connell-Cooper, 2016)), yielding a new type of data that can supersede assumptions made in Phases

1135 1-7, further expanding our broad understanding of aeolian processes and bedforms, and increasing the

1136 overall information gained from planetary aeolian studies.

1138 Acknowledgements

1139 [Mostly removed for review.] We thank the two reviewers for their very helpful comments, and in

1140 particular for the suggestions of additional references. 


\section{References}

Achilles, C.N., D.T. Vaniman, D.F. Blake, T.F. Bristow, E.B. Rampe, D.W. Ming, S.J. Chipera, R.V. Morris, S.M. Morrison, R.T. Downs, K.V. Fendrich, B.L. Ehlmann, A.S. Yen, P.C. Sarrazin, A.H. Treiman, P.I. Craig, M.G.A. Lapotre, K.S. Edgett, R. Gellert, J.A. Crisp, J.M. Morookian, J.P. Grotzinger, D.J. Des Marais, J.D. Farmer, 2016. Mineralogy of eolian sands at Gale crater. 47 $7^{\text {th }}$ LPSC, Ab. 2532.

Allen, A., S. Diniega, C. Hansen, 2016. Gully and aeolian activity within the "Tleilax" dune field in the Olympia Undae, Mars. 47 $7^{\text {th }}$ LPSC, Ab. 1759.

Andreotti, B., P. Claudin, O. Pouliquen, 2006. Aeolian Sand Ripples: Experimental Study of Fully Developed States. Physical Review Letters, v. 96, 028001, doi:10.1103/PhysRevLett.96.028001.

Arvidson, R. E., J.F. Bell III, J.G. Catalano, B.C. Clark, V.K. Fox, R. Gellert, J.P. Grotzinger, E. A. Guinness, K.E. Herkenhoff, A.H. Knoll, M. G. A. Lapotre, S.M. McLennan, D.W. Ming, R.V. Morris, S.L. Murchie, K.E. Powell, M.D. Smith, S.W. Squyres, M.J. Wolff, J.J. Wray, 2015. Mars Reconnaissance Orbiter and Opportunity Observations of Burns Formation and Underlying Strata: Crater-Hopping at Meridiani Planum. J. Geophys. Res. - Planets, v. 120, issue 3, 429-451, doi:10.1002/2014JE004686.

Aufrère, L., 1932. Morphologie dunaire et météorologie saharienne. Association de Géographes Français Bulletin 56, 34-47.

Ayoub, F., J-P. Avouac, C.E. Newman, M.I. Richardson, A. Lucas, S. Leprince, N.T Bridges, 2014. Threshold for sand mobility on Mars calibrated from seasonal variations of sand flux. Nature Communications 5, doi:10.1038/ncomms6096.

Bagnold, R.A., 1941. The Physics of Blown Sand and Desert Dunes (New York: Methuen).

Bagnold, R.A, 1953. The surface movement of blown sand in relation to meteorology. Research Council of Israel, Special Publication, 2, 89-93.

Barnes, J.W., R.H. Brown, L. Soderblom, C. Sotin, S. Le Mouelic, S. Rodriguez, R. Jaumann, R.A. Beyer, R. Clark, P. Nicholson, 2008. Spectroscopy, morphometry, and photoclinometry of Titan's dune fields from Cassini/VIMS. Icarus 195, 400-414.

Barnes, J.W., L. Lemke, R. Foch, C.P. McKay, R.A. Beyer, J.Radebaugh, D.H. Atkinson, R.D. Lorenz, S. Le Mouélic, S. Rodriguez, J. Gundlach, 2012. AVIATR-Aerial Vehicle for In-situ and Airborne Titan Reconnaissance. Experimental Astronomy, 33(1), pp.55-127.

Barnes, J.W., R.D. Lorenz, J. Radebaugh, A.G. Hayes, K. Arnold, C. Chandler, 2015. Production and global transport of Titan's sand particles. Planetary Science 4, 1-19.

Basilevsky, A.T., R.O. Kuzmin, O.V. Nikolaeva, A.A. Pronin, L.B. Ronca, V.S. Avduevsky, G.R. Uspensky, Z.P. Cheremukhina, V.V. Semenchenko, V.M. Ladygin, 1985. The surface of Venus as revealed by the Venera landings: Part II. Geological Society of America Bulletin, 96, 137-144.

Belcher, D., J. Veverka, C. Sagan, 1971. Mariner photography of Mars and aerial photography of Earth: Some analogies, Icarus, vol. 15, 241252.

Bondarenko, N. V., M. A. Kreslavsky, J. W. Head, 2006. North-south roughness anisotropy on Venus from the Magellan Radar Altimeter: Correlation with geology, Journal of Geophysical Research (Planets) 111, E06S12. 
Bourke, M.C., K.S. Edgett, B.A. Cantor, 2008. Recent aeolian dune change on Mars. Geomorphology, 94(1-2), 247-255, doi:10.1016/j.geomorph.2007.05.012.

Breed, C., M. J. Grolier, J.F. McCauley, 1979. Morphology and Distribution of Common 'Sand' Dunes on Mars: Comparison With the Earth, J. Geophys. Res., vol. 84, no. B14, 8183-8204.

Bridges, N.T., M.C. Bourke, P.E. Geissler, M.E. Banks, C. Colon, S. Diniega, M.P. Golombek, C.J. Hansen, S. Mattson, A.S. McEwen, M.T. Mellon, N. Stantzos, B.J. Thomson (2012a), Planet-wide sand motion on Mars. Geology 40(1), 31-34, doi:10.1130/G32373.1.

Bridges, N.T., F. Ayoub, J-P. Avouac, S. Leprince, A. Lucas, S. Mattson (2012b), Earth-like sand fluxes on Mars. Nature 485, 339-342, doi:10.1038/nature11022.

Bridges,N.T, B.L. Ehlmann, R.C. Ewing, C.E. Newman, R. Sullivan, P.G. Conrad, A. Cousin, K.S. Edgett, M.R. Fisk, A.A. Fraeman, J.R. Johnson, M. Lamb, M. Lapotre, S. Le Mouélic, G.M. Martinez, P-Y. Meslin, P. Pinet, L.M. Thompson, J. van Beek, A.R. Vasavada, R.C. Wiens, 2016. Investigation of the Bagnold Dunes by the Curiosity rover: Overview of initial results from the first study of an active dune field on another planet, 47th LPSC, Ab. 2298.

Burt et al. 2008 (eds). The history of the study of landforms, Volume 4: A history of geomorphology between the 1890s and the 1960s. London, The Geological Society.

Burr, D. M., S.A. Drummond, R. Cartwright, B.A. Black, J.T. Perron (2013). Morphology of fluvial networks on Titan: Evidence for structural control, Icarus, vol. 226(1), 742-759, doi:10.1016/j.icarus.2013.06.016.

Canada Dept. Agriculture (1976), Glossary of terms in soil science, (c) Minister of Supply and Services, Canada, ISBN 0-662-01533-9. http://sis.agr.qc.ca/cansis/publications/manuals/1976glossary/pub1459 report.pdf

Cardinale, M., G. Komatzu, S. silvestro, D. Tirsch, 2012. The influence of local topography for wind direction on Mars: two examples of dune fields in crater basins. Earth Surface Processes and Landforms, 37, 13, 1437-1443, DOI: 10.1002/esp.3289.

Cardinale, M., S. Silvestro, D.A. Vaz, T. Michaels, M.C. Bourke, G. Komatsu, L. Marinangeli, 2016. Presentday aeolian activity in Herschel Crater, Mars. Icarus 265, 139-148, doi:10.1038/ncomms6096.

Carneiro Filho, A., D. Schwartz, S.H. Tatumi, T. Rosique, 2002. Amazonian paleodunes provide evidence for drier climate phases during the Late Pleistocene-Holocene. Quaternary Research, 58(2), pp.205209.

Charnay, B., E. Barth, S. Rafkin, C. Narteau, S. Lebonnois, S. Rodriguez, S.C. Du Pont, A. Lucas, 2015. Methane storms as a driver of Titan's dune orientation. Nature Geoscience, 8(5), pp.362-366.

Cheng, A.F., C.M. Lisse, M. A'Hearn, 2013. Surface geomorphology of Jupiter Family Comets: A geologic process perspective. Icarus 222, 808-817, doi:10.1016/j.icarus.2012.10.004.

Christensen, P.R., 1983. Eolian intracrater deposits on Mars: Physical properties and global distribution. Icarus 56(3), 496-518.

Christensen, P.R., J.L. Bandfield, J.F. Bell III, N. Gorelick, V.E. Hamilton, A. Ivanov, B.M. Jakosky, H.H. Kieffer, M.D. Lane, M.C. Malin, T. McConnochie, 2003. Morphology and composition of the surface of Mars: Mars Odyssey THEMIS results. Science 300(5628), pp.2056-2061.

Chojnacki, M., D.M. Burr, J.E. Moersch, T.I. Michaels, 2011. Orbital observations of contemporary dune activity in Endeavour Crater, Meridiani Planum, Mars. J. Geophys. Res. 116, E00F19. 
Chojnacki, M., D. M. Burr, J. E. Moersch, J. J. Wray, 2014. Valles Marineris dune sediment provenance and pathways. Icarus, 232(0), 187-219, doi:10.1016/j.icarus.2014.01.011.

Chojnacki, M., J.R. Johnson, J.E. Moersch, L.K. Fenton, T.I. Michaels, J.F. Bell III, 2015. Persistent aeolian activity at Endeavour crater, Meridiani Planum, Mars; new observations from orbit and the surface. Icarus, 251(0), 275-290, doi:10.1016/j.icarus.2014.04.044.

Claudin, P., B. Andreotti, 2006. A scaling law for aeolian dunes on Mars, Venus, Earth, and for subaqueous ripples. Earth and Planetary Science Letters, vol. 252, 30-44, doi:10.1016/j.epsl.2006.09.004.

Colinvaux, P.A., G. Irion, M.E. Räsänen, M.B. Bush, J.N. De Mello, 2001. A paradigm to be discarded: geological and paleoecological data falsify the Haffer \& Prance refuge hypothesis of Amazonian speciation. Amazoniana, 16(3), pp.609-646.

Courrech du Pont, S., C. Narteau, X. Gao, 2014. Two modes for dune orientation. Geology, 42(9), doi:10.1130/G35657.1.

Cousin, A., O. Forni, P.-Y. Meslin, S. Schröder, O. Gasnault, N. Bridges, B. Elhmann, S. Maurice, R. Wiens, 2016. Chemical diversity among fine-grained soils at Gale (Mars): a chemical transition as the rover is approaching the Bagnold Dunes? 47 ${ }^{\text {th }}$ LPSC, Ab. 2044.

Cutts, J.A., R.S.U. Smith, 1973. Eolian deposit and Dunes on Mars. J. Geophys. Res. 78(20), 4139-4154.

Cutts, J.A., K.R. Blasius, G.A. Briggs, M.H. Carr, R. Greeley, H. Masursky, 1976. North Polar Region of Mars: Imaging Results from Viking 2. Science, vol. 194(4271), 1329-37.

Diniega, S., K. Glasner, S. Byrne, 2010a. Long scale evolution of aeolian sand dune fields: influences of initial conditions and dune collisions. Geomorphology (special edition: Planetary Dunes) 121, 55-68, doi:10.1016/j.geomorph.2009.02.010.

Diniega, S., S. Byrne, N.T. Bridges, C.M. Dundas, A.S. McEwen, 2010b. Seasonality of present-day Martian dune-gully activity. Geology 38, no. 11, 1047-1050, doi:10.1130/G31287.1.

Diniega, S., A. Allen, T. Perez, C.J. Hansen, 2016. Tracking gully activity within the north polar erg, Mars. $47^{\text {th }}$ LPSC, Ab. 1740.

Doran, P.T., S.M. Clifford, S.L. Forman, L. Nyquist, D.A. Papanastassiou, B.W. Stewart, N.C. Sturchio, T.D. Swindle, T. Cerling, J. Kargel, G. McDonald, 2004. Mars chronology: assessing techniques for quantifying surficial processes. Earth-Science Reviews, 67(3), pp.313-337.

Dundas C.M., S. Diniega, C.J. Hansen, S. Byrne, A.S. McEwen, 2012. HiRISE observations of seasonal activity and morphological changes in Martian gullies. Icarus 220(1), 124-143, doi:10.1016/j.icarus.2012.04.005.

Dundas, C.M., S. Diniega, A.S. McEwen, 2015. Long-Term Monitoring of Martian Gully Formation on Mars and Evolution with HiRISE. Icarus (special issue: Dynamic Mars) 251, 244-263, doi:10.1016/j.icarus.2014.05.013.

Edgett, K.S., P.R. Christensen, 1991. The particle size of Martian aeolian dunes. JGR 96(E5), 22765-22776.

Edgett, K. S., N. Lancaster (1993), Volcaniclastic aeolian dunes: terrestrial examples and application to martian sands, J. Arid Environ., 25(3), 271-297, doi:10.1006/jare.1993.1061.

Ehlmann, B.L., N. Bridges, A.A. Fraeman, M.G.A. Lapotre, K. Edgett, J.R. Johnson, A. Cousin, A. Yen, P. Conrad, L. Thompson, J. Van Beek, D. Vaniman, S. Schröder, A. Vasavada, 2016. Chemistry and mineralogy in situ at the Bagnold sand dunes: Evidence for aeolian sorting and size-dependence in sand composition. $47^{\text {th }}$ LPSC, Ab. 1536. 
Ewing, R.C., G. Kocurek, 2010. Aeolian dune-field pattern boundary conditions. Geomorphology 114, 175-187, doi:10.1016/j.geomorph.2009.06.015.

Ewing, R.C. A. Peyret, G. Kocurek and M.C. Bourke, 2010. Dune-field pattern formation and recent transporting winds in the Olympia Undae dune field, north polar region of Mars. Journal of Geophysical Research, 115, E08005.

Ewing, R.C., A.G. Hayes, A. Lucas, 2015. Sand dune patterns on Titan controlled by long-term climate cycles. Nature 10.1038/ngeo2323.

Ewing, R.C., N.T. Bridges, R. Sullivan, M.G.A. Lapotre, W.W. Fisher, M.P. Lamb, D. Rubin, K. Lewis, S. Gupta, 2016. Aeolian Sedimentary Processes at the Bagnold Dunes, Mars: Implications for Modern Dune Dynamics and Sedimentary Structures in the Aeolian Stratigraphic Record of Mars. $47^{\text {th }}$ LPSC, Ab. 2783.

Fenton, L.K., 2005. Potential sand sources for the dune fields in Noachis Terra, Mars. J. Geophys. Res., vol. 110, E11, doi:10.1029/2005JE002436.

Fenton, L. K., 2006. Dune migration and slip face advancement in the Rabe Crater dune field, Mars. Geophys. Res. Lett., 33(20), 1-5, doi:10.1029/2006GL027133.

Fenton, L., 2016. Dunes on Pluto? Blog on SETI website: http://www.seti.org/seti-institute/dunes-onpluto.

Fenton, L.K., R.K. Hayward, 2010. Southern high latitude dune fields on Mars: Morphology, aeolian inactivity, and climate change, Geomorphology 121, Issues 1-2, 98-121, doi:10.1016/j.geomorph.2009.11.006.

Fenton, L.K., A.D. Toigo, M.I. Richardson, 2005. Aeolian processes in Proctor Crater on Mars: Mesoscale modeling of dune-forming winds. J. Geophys. Res. 110, E06005, doi:10.1029/2004JE002309.

Florensky, C.P., A.T. Basilevsky, V.P. Krychkov, R.O. Kusmin, O.V. Nikolaeva, A.A. Pronin, I.M. Chernaya, Yu.S. Tyuflin, A.S. Selivanov, M.K. Naraeva, L.B. Ronca, 1983. Venera 13 and Venera 14: Sedimentary rocks on Venus? Science 221, 57-589.

Fryberger, S.G., G. Dean, 1979. Dune forms and wind regime, in, E. D. McKee, ed., A study of global sand seas. U.S. Geol. Surv. Prof. Pap. 1052, 137-169.

Gardin, E., P. Allemand, C. Quantin, S. Silvestro, C. Delacourt, 2012. Dune fields on Mars: Recorders of a climate change? Planet. Space Sci. 60, 314-321, doi:10.1016/j.pss.2011.10.004.

Garzanti, E., P. Vermeesch, S. Andò, G. Vezzoli, M. Valagussa, K. Allen, K.A. Kadi, A.I.A. Al-Juboury, 2013. Provenance and recycling of Arabian desert sand. Earth-Sci. Rev. 120, 1-19, doi:10.1016/j.earscirev.2013.01.005.

Geissler, P.E., N.W. Stantzos, N.T. Bridges, M.C. Bourke, S. Silvestro, L.K. Fenton, 201ㄹz. Shifting sands on Mars: Insights from tropical intra-crater dunes. ESP\&L, vol. 38, no. 4, 407-412, doi:10.1002/esp.3331.

Golombek, M. P., J.A. Grant, L.S. Crumpler, R. Greeley, R.E. Arvidson, J.F. Bell III, C.M. Weitz, R. Sullivan, P.R. Christensen, L.A. Soderblom, S.W. Squyres, 2006. Erosion rates at the Mars Exploration Rover landing sites and long-term climate change on Mars. J. Geophys. Res., 111, E12S10, doi:10.1029/2006JE002754.

Golombek, M.P., N.H. Warner, V. Ganti, M.P. Lamb, T.J. Parker, R.L. Fergason, R. Sullivan, 2014. Small crater modification on Meridiani Planum and implications for erosion rates and climate change on Mars. J. Geophys. Res. Planets, 119, doi:10.1002/2014JE004658. 
1305

1306

1307

1308

1309

1310

1311

1312

1313

1314

1315

1316

1317

1318

1319

1320

1321

1322

1323

1324

1325

1326

1327

1328

1329

1330

1331

1332

1333

1334

1335

1336

1337

1338

1339

1340

1341

1342

1343

1344

Goudie, A., 2002. Great warm deserts of the world: landscapes and evolution (Vol. 1). Oxford University Press on Demand.

Grant, J. A., R.E. Arvidson, L.S. Crumpler, M.P. Golombek, B. Hahn, A.F.C. Haldemann, R. Li, L.A. Soderblom, S. W. Squyres, S.P. Wright, W.A. Watters, 2006. Crater gradation in Gusev crater and Meridiani Planum, Mars. J. Geophys. Res., 111, E02S08, doi:10.1029/2005JE002465.

Grant, J. A., S. A. Wilson, B. A. Cohen, M. P. Golombek, P. E. Geissler, R. J. Sullivan, R. L. Kirk, and T. J. Parker (2008), Degradation of Victoria crater, Mars, J. Geophys. Res., 113, E11010, doi:10.1029/2008JE003155.

Grant, J. A., T. J. Parker, L. S. Crumpler, S. A. Wilson, M. P. Golombek, and D. W. Mittlefehldt, (2016), The degradational history of Endeavour crater, Mars: Icarus, doi:10.1016/j.icarus.2015.08.019, in press.

Greeley, R., R.E. Arvidson, 1990. Aeolian processes on Venus. Earth, Moon, and Planets, 50/51, 127-157.

Greeley, R., J.D. Iversen, J.B. Pollack, N. Udovich, B. White, 1974. Wind tunnel studies of martian aeolian processes. Proc. Royal Soc. London, 341, 331-360, doi: 10.1098/rspa.1974.0191.

Greeley, R., R. Leach, B. White, J. Iversen, J. Pollack, 1980. Threshold windspeeds for sand on Mars: Wind tunnel simulations. Geophysical Research Letters, vol. 7, no. 2, 121-124.

Greeley, R., J. Iversen, R. Leach, J. Marshall, B. White, S. Williams, 1984a. Windblown sand on Venus: Preliminary results of laboratory simulations. Icarus 57(1), 112-124.

Greeley, R., J.R. Marshall, R.N. Leach, 1984b. Microdunes and other aeolian bedforms on Venus: Wind tunnel experiments. Icarus 60, 152-160.

Greeley R., N. Lancaster, S. Lee, P. Thomas, 1992a. Martian aeolian processes, sediments and features, in: Kieffer, H., Jakosky, B.M., Snyder, C.W., Matthews, M.S. (Eds.), Mars. University of Arizona Press, Tucson, pp. 730-767.

Greeley, R., R.E. Arvidson, C. Elachi, M.A. Geringer, J.J. Plaut, R.S. Saunders, G. Schubert, E.R. Stofan,

E.J.P. Thouvenot, S.D. Wall, C.M Weitz, 1992 $\underline{b}$. Aeolian features on Venus: Preliminary Magellan results. J. Geophys. Res. 97(E8), 13319-13345.

Greeley, R. K. Bender, P.E. Thomas, G. Schubert, D. Limonadi, C.M. Weitz, 1995. Wind-related features and processes on Venus: Summary of Magellan results. Icarus, 115, 399-420.

Greeley, R., K.C. Bender, R.S. Saunders, G. Schubert, C. M. Weitz, 1997. Aeolian processes and features on Venus, in Venus II: Geology, Geophysics, Atmosphere, and Solar Wind Environment, edited by S. W. Bougher, D. M. Hunten, and R. J. Philips, pp. 547- 590, Univ. of Ariz. Press, Tucson.

Greeley, R., R.E. Arvidson, P.W. Barlett, D. Blaney, N.A. Cabrol, P.R. Christensen, R.L. Fergason, M.P. Golombek, G.A. Landis, M.T. Lemmon, S.M. McLennan, J.N. Maki, T. Michaels, J.E. Moersch, L.D.V. Neakrase, S.C.R. Rafkin, L. Richter, S.W. Squyres, P.A. de Souza Jr., R.J. Sullivan, S.D. Thompson, P.L. Whelley, 2006. Gusev crater: Wind-related features and processes observed by the Mars Exploration Rover Spirit. J. Geophys. Res. 111, E02S09, doi:10.1029/2005JE002491.

Hanna, S.R., 1969. The formation of longitudinal sand dunes by large helical eddies in the atmosphere. Journal of Applied Meteorology, 8(6), pp.874-883.

Hansen, C. J., M. Bourke, N.T. Bridges, S. Byrne, C. Colon, S. Diniega, C. Dundas, K. Herkenhoff, A. McEwen, M. Mellon, G. Portyankina, N. Thomas, 2011. Seasonal erosion and restoration of Mars' northern polar dunes. Science 331(6017), 575-578, doi:10.1126/science.1197636. 
1345

1346

1347

1348

1349

1350

1351

1352

1353

1354

1355

1356

1357

1358

1359

1360

1361

1362

1363

1364

1365

1366

1367

1368

1369

1370

1371

1372

1373

1374

1375

1376

1377

1378

1379

1380

1381

1382

1383

1384

Hansen, C.J., S. Diniega, N. Bridges, S. Byrne, C. Dundas, A. McEwen, G. Portyankina, 2015. Agents of change on Mars' northern dunes: CO2 ice and wind, Icarus (special issue: Dynamic Mars) 251, 264274. doi:10.1016/j.icarus.2014.11.015.

Hayward, R.K., 2011. Mars Global Digital Dune Database (MGD3): north polar region (MC-1) distribution, applications, and volume estimates. Earth Surface Processes and Landforms, doi:10.1002/esp.2219.

Hayward, R.K., K.F. Mullins, L.K. Fenton, T.M. Hare, T.N. Titus, M.C. Bourke, A. Colaprete, P.R. Christensen, 2007. Mars global digital dune database and initial science results. J. Geophys. Res. Planets 112, E11007, doi:10.1029/2007JE002943.

Hayward, R.K., T.N. Titus, T.I. Michaels, L.K. Fenton, A. Colaprete, P.R. Christensen, 2009. Aeolian dunes as ground truth for atmospheric modeling on Mars. J. Geophys. Res., 114, E11012, doi:10.1029/2009JE003428.

Hayward, R.K., L.K. Fenton, T.N. Titus, 2014. Mars Global Digital Dune Database (MGD3): Global dune distribution and wind pattern observations. Icarus, 230, 38-46, doi:10.1016/i.icarus.2013.04.011.

Hersen, P., 2004. On the crescentic shape of barchan dunes. Eur. Phys. J. B., vol. 37, 507-514, doi:10.1140/epjb/e2004-00087-y.

Hesse, P., N. Lancaster, M.W. Telfer, 2015. Digital mapping of the extent of global dune systems. Geophysical Research Abstracts, vol. 17, EGU2015-3638.

Horgan, B.H.N., J.F. Bell, 2012. Seasonally active slipface avalanches in the north polar sand sea of Mars: Evidence for a wind-related origin. Geophys. Res. Lett. 39, L09201, doi:10.1029/2012GL051329.

Hugenholtz, C.H., T.E. Barchyn, 2010. Spatial analysis of sand dunes with a new global topographic dataset: new approaches and opportunities. Earth Surf. Process. Landforms 35, 986-992, doi:10.1002/esp.2013.

Jackson, D.W.T., M.C. Bourke, T.A.G. Smyth, 2015. The dune effect on sand-transporting winds on Mars. Nature Communications, DOI: 10.1038/ncomms9796.

Jain, M., C.E. Andersen, L. Bøtter-Jensen, A.S. Murray, H. Haack, J.C. Bridges, 2006. Luminescence dating on Mars: OSL characteristics of Martian analogue materials and GCR dosimetry. Radiation Measurements, 41(7), pp.755-761.

Jerolmack, D.J., R.C. Ewing, F. Falcini, R.L. Martin, C. Masteller, C. Phillips, M.D. Reitz, I. Buynevich, 2012. Internal boundary layer model for the evolution of desert dune fields. Nature Geoscience, 5, 3, 1-4, DOI: 10.1038/ngeo1381.

JPL, Oct. 4, 2012. NASA Mars Curiosity Rover Prepares to Study Martian Soil, Press Release http://www.jpl.nasa.gov/news/news.php?feature=3540.

JPL, Feb. 3, 2014. Through the Gap: Curiosity Mars Rover Crosses Dune, Press Release http://www.jpl.nasa.gov/news/news.php?release=2014-035.

JPL, Dec. 10, 2015. NASA Mars Rover Curiosity Reaches Sand Dunes, Press Release http://www.jpl.nasa.gov/news/news.php?feature $=4787$.

Klammer, G., 1982. Die Paleoste des Pantanal von Mato Grosso und die pleistozene Klimageschichte der brasilianischen Randtropen. Zeitschrift. der Geomorphologie N.F., vol. 26, 393-416

Kieffer, S.W., R. Lopes-Gautier, A. McEwen, W. Smythe, L. Keszthelyi, R. Carlson, 2000. Prometheus: Io's wandering plume. Science 288, 1204-1208. 
1385

1386

1387

1388

1389

1390

1391

1392

1393

1394

1395

1396

1397

1398

1399

1400

1401

1402

1403

1404

1405

1406

1407

1408

1409

1410

1411

1412

1413

1414

1415

1416

1417

1418

1419

1420

1421

1422

1423

1424

1425

Kocurek, G., R.C. Ewing, 2005. Aeolian dune field self-organization - implications for the formation of simple versus complex dune-field patterns. Geomorphology 72, 94-105, doi:10.1016/j.geomorph.2005.05.005.

Kocurek, G., N. Lancaster, 1999. Aeolian system sediment state: theory and Mojave Desert Kelso dune field example. Sedimentology 46, 505 - 515.

Kocurek, G., R.C. Ewing, 2012. Source-to-sink: An Earth/Mars comparison of boundary conditions for eolian dune systems. Sedimentary Geology of Mars, SEPM Special Publication No. 102, Print ISBN 978-1-56576-312-8, CD/DVD ISBN 978-1-56576-313-5, p. 151-168.

Kocurek, G., M. Carr, R. Ewing, K.G. Havholm, Y.C. Nagar, A.K. Singhvi, 2007. White Sands Dune Field, New Mexico: age, dune dynamics and recent accumulations. Sedimentary Geology, vol. 197, no. 3, 313-331.

Kok, J. F., N.O. Renno, 2009. A comprehensive numerical model of steady state saltation (COMSALT). J. Geophys. Res., 114, D17204, doi:10.1029/2009JD011702.

Kok, J.F., 2010. Difference in the wind speeds required for initiation versus continuation of sand transport on Mars: Implications for dunes and dust Storms. Phys. Rev. Lett. 104, 074502, doi:10.1103/PhysRevLett.104.074502.

Kok J.F., E.J.R. Parteli, T.I. Michaels, D. Bou Karam, 2012. The physics of windblown sand and dust. Rep. Prog. Phys. 75, 106901, doi:10.1088/0034-4885/75/10/106901.

Kreslavsky, M.A., R.V. Vdovichenko, 1999. Anisotropy of Venus Surface Properties Inferred from Magellan Side-Looking-Radar Data. Solar System Research 33, 110.

Lancaster, N., 1995. Geomorphology of Desert Dunes (Routledge Physical Environment Series). Routledge. ISBN-13: 978-0415060943.

Lancaster, N., S. Wolfe, D. Thomas, C. Bristow, O. Bubenzer, S. Burrough, G. Duller, A. Halfen, P. Hesse, J. Roskin, A. Singhvi, H. Tsoar, A. Tripaldi, X. Yang, M. Zárate, M., in press. The INQUA Dunes Atlas chronologic database. Quaternary International, doi:10.1016/j.quaint.2015.10.044.

Lapotre, M.G.A., R.C. Ewing, M.P. Lamb, W.W. Fischer, J.P. Grotzinger, D.M. Rubin, K.W. Lewis, M. Ballard, M. Day, S. Gupta, S.G. Banham, N.T. Bridges, D.J. Des Marais, A.A. Fraeman, J.A. Grant, K.E. Herkenhoff, D.W. Ming, M.A. Mischna, M.S. Rice, D.A. Summer, A.R. Vasavada, R.A. Yingst, $2016 a$. Large wind ripples on Mars: A record of atmospheric evolution. Science, 353, 6294, 55-58, DOI: 10.1126/science.aaf3206.

tapotre, M.G.A., R.C. Ewing, M.P. Lamb, W.W. Fischer, K. Lewis, M. Ballard, M. Day, D. Rubin, J.P. Grotzinger (2016a) Orbital and in-situ observations in support of the existence of an unknown stable aeolian bedform regime on Mars, $47^{\text {th }}$ LPSC, Ab. 1510. [this has also been written up in a submitted paper]

Lapotre, M.G.A., B.L. Ehlmann, A.A. Fraeman, S.E. Minson, F. Ayoub, R.C. Ewing, R.E. Arvidson, N.T. Bridges, MSL Science Team, 2016b. A quantitative assessment of aeolian fractionation the Bagnold dunes of Gale crater, Mars, from orbit to the ground. $47^{\text {th }}$ LPSC, Ab. 1513.

Le Gall, A., A.G. Hayes, R. Ewing, M.A. Janssen, J. Radebaugh, C. Savage, P. Encrenaz, 2012. Latitudinal and altitudinal controls of Titan's dune field morphometry. Icarus, vol. 217, issue 1, 231-242.

Livingstone, I., G.F. Wiggs, C.M. Weaver, 2007. Geomorphology of desert sand dunes: a review of recent progress. Earth-Science Reviews, 80(3), 239-257. 
Livingstone, I., C. Bristow, R.G. Bryant, J. Bullard, K. White, G.F. Wiggs, A.C. Baas, M.D. Bateman, D.S. Thomas, 2010. The Namib Sand Sea digital database of aeolian dunes and key forcing variables. Aeolian Research, 2(2), 93-104.

Lorenz, R.D., 2015. Heights of Fortuna-Meshknet Dunes (Al-Uzza Undae), Venus, from Magellan Radarclinometry. Fourth Annual International Planetary Dunes Workshop, abstract \# 8004.

Lorenz, R.D., J. Radebaugh, 2009. Global pattern of Titan's dunes: Radar survey from the Cassini prime mission. Geophys. Res. Lett. 36, L03202, doi:10.1029/2008/GL036850.

Lorenz, R.D., J.I. Lunine, J.A. Grier, M.A. Fisher, 1995. Prediction of aeolian features on planets: Application to Titan paleoclimatology. JGR 100(E12), 26377-26386.

Lorenz, R.D., S. Wall, J. Radebaugh, G. Boubin, E. Reffet, M. Janssen, E. Stofan, R. Lopes, R. Kirk, C. Elachi, J. Lunine, K. Mitchell, F. Paganelli, L. Soderblom, C. Wood, L. Wye, H. Zebker, Y. Anderson, S. Ostro, M. Allison, R. Boehmer, P. Callahan, P. Encrenaz, G.G. Ori, G. Francescetti, Y. Gim, G. Hamilton, S. Hensley, W. Johnson, K. Kelleher, D. Muhleman, G. Picardi, F. Posa, L. Roth, R. Seu, S. Shaffer, B. Stiles, S. Vetrella, E. Flamini, R. West, 2006. The sand seas of Titan: Cassini RADAR observations of longitudinal dunes. Science 312, 724-727, doi: 10.1126/science.1123257.

Lorenz, R. D., R.M. Lopes, F. Paganelli, J.I. Lunine, R.L. Kirk, K.L. Mitchell, L.A. Soderblom, E.R. Stofan, G. Ori, M. Myers, H. Miyamoto, J. Radebaugh, B. Stiles, S.D. Wall, C.A. Wood and the Cassini RADAR Team, 2008. Fluvial channels on Titan: Initial Cassini RADAR observations. Planet. Space Sci. 56, 1132-1144.

Lucas, A., S. Rodriguez, C. Narteau, B. Charnay, S.C. Pont, T. Tokano, A. Garcia, M. Thiriet, A.G. Hayes, R.D. Lorenz, O. Aharonson, 2014. Growth mechanisms and dune orientation on Titan. Geophysical Research Letters, 41(17), 6093-6100.

Madigan, C.T., 1936. The Australian sand-ridge deserts. Geographical Review, 26(2), 205-227.

Malaska, M.J., R.M. Lopes, A.G. Hayes, J. Radebaugh, R.D. Lorenz and E.P. Turtle, 2016. Material transport map of Titan: The fate of dunes. Icarus, 270, 183-196, doi:10.1016/j.icarus.2015.09.029.

Marsh, G.P., 1864. Man and Nature. (Reprint, 1965) Cambridge, MA: Harvard University Press.

Marshall, J.R., R. Greeley, 1992. An experimental study of aeolian structures on Venus. J. Geophys. Res. 97(E1), 1007-1016.

May, J.H., 2013. Dunes and dune fields in the Bolivian Chaco as potential records of environmental change. Aeolian Research, vol. 10, 89-102.

McCauley, J.F., M.H. Carr, J.A. Cutts, W.K. Hartmann, H. Masursky, D.J. Milton, R.P. Sharp, D.E. Wilhelms, 1972. Preliminary Mariner 9 Report on the Geology of Mars, Icarus 17(2), 289-327, doi:10.1016/0019-1035(72)90003-6.

McEwen, A.S., M.J.S. Belton, H.H. Breneman, S.A. Fagents, P. Geissler, R. Greeley, J.W. Head, G. Hoppa, W.L. Jaeger, T.V. Johnson, L. Keszthelyi, 2000. Galileo at lo: Results from high-resolution imaging. Science, vol. 288, no. 5469, 1193-1198.

McEwen, A.S., E.M. Eliason, J.W. Bergstrom, N.T. Bridges, C.J. Hansen, W.A. Delamere, J.A. Grant, V.C. Gulick, K.E. Herkenhoff, L. Keszthelyi, R.L. Kirk, 2007. Mars Reconnaissance Orbiter's High Resolution Imaging Science Experiment (HiRISE). J. Geophys. Res., 112, issue E5, doi:10.1029/2005JE002605. 
McKeever, S.W.S., D. Banerjee, M. Blair, S.M. Clifford, M.S. Clowdsley, S.S. Kim, M. Lamothe, K. Lepper, M. Leuschen, K.J. McKeever, M. Prather, 2003. Concepts and approaches to in situ luminescence dating of martian sediments. Radiation Measurements, 37(4), pp.527-534.

Mellon, M.T., B.M. Jakovsky, H.H. Kieffer, P.R. Christensen, 2000. High-resolution thermal inertia mapping from the Mars Global Surveyor Thermal Emissino Spectrometer. Icarus, 148, 437-455, doi:10.1006/icar.2000.6503.

Milazzo, M.P., L.P. Keszthelyi, A.S. McEwen, 2001. Observations and initial modeling of lava-SO ${ }_{2}$ interactions at Prometheus, lo. J. Geophys. Res. 106, 33,121-33,127.

Moore, J.M., A.D. Howard, P.M. Schenk, W.B. McKinnon, R.T. Pappalardo, R.C. Ewing, E.B. Bierhaus, V.J. Bray, J.R. Spencer, R.P. Binzel, B. Buratti, 2015. Geology before Pluto: Pre-encounter considerations. Icarus, 246, 65-81, doi:10.1016/j.icarus.2014.04.028.

Moore, J.M., W.B. McKinnon, J.R. Spencer, A.D. Howard, P.M. Schenk, R.A. Beyer, F. Nimmo, K.N. Singer, O.M. Umurhan, O.L. White, S.A. Stern, K. Ennico, C.B. Olkin, H.A. Weaver, L.A. Young, R.P. Binzel, M.W. Buie, B.J. Buratti, A.F. Cheng, D.P. Cruikshank, W.M. Grundy, I.R. Linscott, H.J. Reitsema, D.C. Reuter, M.R. Showalter, V.J. Bray, C.L. Chavez, C.J.A. Howett, T.R. Lauer, C.M. Lisse, A.H. Parker, S.B. Porter, S.J. Robbins, K. Runyon, T. Stryk, H.B. Throop, C.C.C. Tsang, A.J. Verbiscer, A.M. Zangari, A.L. Chaikin, D.E. Wilhelms, New Horizons Science Team, 2016. The geology of Pluto and Charon through the eyes of New Horizons. Science v. 351, Is. 6279, 1284-93. doi:10.1126/science.aad7055.

Mottola, S., Arnold, G., Grothues, H.-G., Jaumann, R., Michaelis, H., Neukum, G., Bibring, J.-P., Schröder, S.E., Hamm, M., Otto, K.A., Pelivan, I., Proffe, G., Scholten, F., Tirsch, D., Kreslavsky, M., Remetean, E., Souvannavong, F., Dolives, B., 2015. The structure of the regolith on 67P/ChuryumovGerasimenko from ROLIS descent imaging. Science 349, 10.1126/science.aab0232.

Neakrase, L.D.V. (2015), Terrestrial Analogues for Venusian dunes: Sub-aqueous, seafloor dune fields. Fourth International Planetary Dunes Workshop. Ab. 8023.

New Horizons, 2015. http://www.nasa.gov/mission pages/newhorizons/images/index.html.

New Horizons, 2016. The Tartarus Dorsa Mountains Rise Up Along Pluto, http://www.nasa.gov/imagefeature/the-tartarus-dorsa-mountains-rise-up-along-pluto.

NRC, 2013. Vision and Voyages for Planetary Science in the Decade 2013-2022. Steering Group Chair: Squyres, National Academies Press, Washington, D.C., ISBN: 0-309-20955-2.

O'Connell-Cooper, C.D., L.M. Thompson, J.G. Spray, J.A. Berger, E.D. Desouza, M. Schmidt, A. Yen, N.I. Boyd, R. Gellert, G. Perrett, S.J. VanBommel, the MSL-APXS Team, 2016. Preliminary comparison of soils within Gale crater to those from Gusev Crater and Meridiani Planum. 47 ${ }^{\text {th }}$ LPSC, Ab. 2477.

Parteli, E.J.R., O. Durán, H.J. Herrmann, 2007. Minimal size of a barchan dune. Phys. Rev. E 75, 011301, doi:10.1103/PhysRevE.75.011301.

Parteli, E.J.R., O. Durán, H. Tsoar, V. Schwämmle, H.J. Herrmann, 2009. Dune formation under bimodal winds. PNAS 106(52), 22085-22089, doi:10.1073/pnas.0808646106.

Pelletier, J.D., 2009. Controls on the height and spacing of eolian ripples and transverse dunes: A numerical modeling investigation. Geomorphology, v. 105, 322-333, doi:10.1016/j.geomorph.2008.10.010.

Pelletier, J.D., 2015. Controls on the large-scale spatial variations of dune field properties in the barchanoid portion of White Sands dune field, New Mexico. J. Geophys. Res. Earth Surf., 120, 453473, doi:10.1002/2014JF003314. 
Portyankina, G., A. Pommerol, K.-M. Aye, C. J. Hansen, N. Thomas, 2012. Polygonal cracks in the seasonal semi-translucent $\mathrm{CO}_{2}$ ice layer in Martian polar areas. J. Geophys. Res., 117(E2006), doi:10.1029/2011JE003917.

Radebaugh, J., 2013. Dunes on Saturn's moon Titan at the end of the Cassini Equinox Mission. Aeolian Research 11, 23-41.

Radebaugh, J., R. Lorenz, J. Lunine, S. Wall, G. Boubin, E. Reffet, R. Kirk, R. Lopes, E. Stofan, L. Soderblom, M. Allison, M. Janssen, P. Paillou, P. Callahan and the Cassini Radar Team, 2008. Dunes on Titan observed by Cassini Radar. Icarus 194, 690-703, doi:10.1016/j.icarus.2007.10.015.

Radebaugh, J., R. Lorenz, T. Farr, P. Paillou, C. Savage, C. Spencer, 2010. Linear dunes on Titan and earth: Initial remote sensing comparisons. Geomorphology 121, 122-132, doi:10.1016/j.geomorph.2009.02.022.

Radebaugh, J., R.D. Lorenz, S.D. Wall, R.L. Kirk, C.A. Wood, J.I. Lunine, E.R. Stofan, R.M.C. Lopes, P. Valora, T.G. Farr, A.G. Hayes, B. Stiles, G. Mitri, H. Zebker, M. Janssen, L. Wye, A. Le Gall, K.L. Mitchell, F. Paganelli, R.D. West, E.L. Schaller and the Cassini RADAR Team, 2011. Regional geomorphology and history of Titan's Xanadu province. Icarus 211, 672-685.

Radebaugh, J., D. Ventra, R.D. Lorenz, T. Farr, R. Kirk, A. Hayes, M.J. Malaska, S. Birch, Z. Y-C. Liu, J. Lunine, J. Barnes, A. Le Gall, R. Lopes, E. Stofan, S. Wall, P. Paillou, 2016. Alluvial and fluvial fans on Saturn's moon Titan reveal processes, materials and regional geology, in, Ventra, D. \& Clarke, L. E. (eds) Geology and Geomorphology of Alluvial and Fluvial Fans: Terrestrial and Planetary Perspectives. Geological Society, London, Special Publications, 440, doi: 10.1144/SP440.6.

Rubin, D.M., 2012. A unifying model for planform straightness of ripples and dunes in air and water. Earth-Science Reviews, 113(3), 176-185, doi:10.1016/j.earscirev.2012.03.010.

Rubin, D.M., P.A. Hesp, 2009. Multiple origins of linear dunes on Earth and Titan. Nature Geoscience, vol. 2, 653-658, doi:10.1038/ngeo610.

Rubin, D.M., R.E. Hunter, 1987. Bedform alignment in directionally varying flows. Science, 237(4812), 276-8, doi:10.1126/science.237.4812.276.

Rubin, D. M., H. Ikeda, 1990. Flume experiments on the alignment of transverse, oblique, and longitudinal dunes in directionally varying flows. Sedimentology, 37, 673-684.

Sagan, C., J. Veverka, P. Fox, R. Dubisch, J. Lederberg, E. Levinthal, L. Quam, R. Tucker, J.B. Pollack, B.A. Smith, 1972. Variable features on Mars: Preliminary Mariner 9 television results. Icarus 17(2), 346372, doi:10.1016/0019-1035(72)90005-X.

Sauermann, G., K. Kroy, H.J. Herrmann, 2001. Continuum saltation model for sand dunes, Physical Review E, v. 64, 031305, doi:10.1103/PhysRevE.64.031305.

Savage, C.J., J. Radebaugh, E.H. Christiansen, R.D. Lorenz, 2014. Implications of dune pattern analysis for Titan's surface history. Icarus 230, 180-190.

Silvestro, S., G. Di Achille, G.G. Oria, 2010a. Dune morphology, sand transport pathways and possible source areas in east Thaumasia Region (Mars), Geomorphology, vol. 121, 84-97, doi:10.1016/j.geomorph.2009.07.019.

Silvestro, S., L.K. Fenton, D.A. Vaz, N.T. Bridges, G.G. Ori, 2010b. Ripple migration and dune activity on Mars: Evidence for dynamic processes. Geophys. Res. Lett. 37, L20203 (2010). 
1548

1549

1550

1551

1552

1553

1554

1555

1556

1557

1558

1559

1560

1561

1562

1563

1564

1565

1566

1567

1568

1569

1570

1571

1572

1573

1574

1575

1576

1577

1578

1579

1580

1581

1582

1583

1584

1585

1586

1587

1588

Silvestro, S., D.A. Vaz, L.K. Fenton and P.E. Geissler, 2011. Active Aeolian processes on Mars: a regional study in Arabia and Meridiani Terrae, Geophysical Research Letters, 38, L20201, doi:10.1029/2011GL048955.

Silvestro S., L.K. Fenton, T.I. Michaels, A. Valdez, G.G. Ori, 2012. Interpretation of the complex dune morphology on Mars: dune activity, modeling and a terrestrial analogue. Earth Surface Processes and Landforms, 37, 13, 1424-1436, DOI: 10.1002/esp.3286.

Silvestro, S., D.A. Vaz, R.C. Ewing, A.P. Rossi, L.K. Fenton, T.I. Michaels, J. Flahaut and P.E. Geissler, 2013. Pervasive aeolian activity along Curiosity's traverse in Gale Crater, Mars. Geology, 41 (4), 483-486, doi:10.1130/G34162.1.

Silvestro S., D.A. Vaz, H. Yizhaq, F. Esposito, 2016. Dune-like dynamic of martian aeolian large ripples. Geophysical Research Letters, doi:10.1002/2016GL070014.

Silvestro, S., D.A. Vaz, I.C. Popa and F. Esposito (2015), Longitudinal aeolian depositional features on Mars? Fourth International Planetary Dunes Workshop, LPI Contribution No. 1843, p.8049.

Singhvi, A.K., N. Porat, 2008. Impact of luminescence dating on geomorphological and palaeoclimate research in drylands. Boreas, 37(4), 536-558.

Soderblom, L., J. Anderson, K. Baines, J. Barnes, J. Barrett, R. Brown, B. Buratti, R. Clark, D. Cruikshank, C. Elachi, M. Janssen, R. Jaumann, R. Kirk, E. Karkoschka, S. Lemouelic, R. Lopes, R. Lorenz, J. Lunine, T. McCord, P. Nicholson, J. Radebaugh, B. Rizk, C. Sotin, E. Stofan, T. Sucharski, M. Tomasko, S. Wall, 2007. Correlations between Cassini VIMS spectra and RADAR SAR images: Implications for Titan's surface composition and the character of the Huygens Probe landing site. Planetary and Space Science, 55, 2025-2036.

Sohbati, R., A.S. Murray, J.P. Buylaert, M. Ortuño, P.P. Cunha, E. Masana, 2012. Luminescence dating of Pleistocene alluvial sediments affected by the Alhama de Murcia fault (eastern Betics, Spain)-a comparison between OSL, IRSL and post-IR IRSL ages. Boreas, 41(2), 250-262, doi:10.1111/j.15023885.2011.00230.x

Sokolów, N. A., 1894. Die Dunen; Bildung, Entwicklung, and innerer Bau (German transl. from Russian 4th ed., 1884, assisted by A. Arzruni). Berlin, Springer.

Sullivan, R., R. Arvidson, J.F. Bell III, R. Gellert, M. Golombek, R. Greeley, K. Herkenhoff, J. Johnson, S. Thompson, P. Whelley, J. Wray, 2008. Wind-driven particle mobility on Mars: Insights from Mars Exploration Rover observations at "El Dorado" and surroundings at Gusev Crater. J. Geophys. Res., 113, E06S07, doi:10.1029/2008JE003101.

Stern and the New Horizons team, 2016. New Horizons: The Exploration of the Pluto System and the Kuiper Belt beyond. 47 $7^{\text {th }}$ LPSC, Ab. 1317.

Sullivan, R., D. Banfield, J. F. Bell III, W. Calvin, D. Fike, M. Golombek, R. Greeley, J. Grotzinger, K. Herkenhoff, D. Jerolmack, M. Malin, D. Ming, L. A. Soderblom, S. W. Squyres, S. Thompson, W.A. Watters, C.M. Weitz, A. Yen, 2005. Aeolian processes at the Mars Exploration Rover Meridiani Planum landing site. Nature 436, 58-61, doi:10.1038/nature03641.

Tanaka, K.L., Rodriguezb, J.A.P., Skinner Jr., J.A., Bourke, M.C., Fortezzo, C.M., Herkenhoff, K.E., Kolb, E.J., Okubo, C.H., 2008. North polar region of Mars: Advances in stratigraphy, structure, and erosional modification. Icarus 192, 318-358, 10.1016/j.icarus.2008.01.021. 
Teeuw, R.M., E.J. Rhodes, 2004. Aeolian activity in northern Amazonia: optical dating of Late Pleistocene and Holocene palaeodunes. Journal of Quaternary Science, 19(1), pp.49-54.

Telfer, M.W., 2011. Growth by extension, and reworking, of a south-western Kalahari linear dune. Earth Surface Processes and Landforms, 36(8), pp.1125-1135.

Telfer, M.W. and Thomas, D.S.G., 2007. Late Quaternary linear dune accumulation and chronostratigraphy of the southwestern Kalahari: implications for aeolian palaeoclimatic reconstructions and predictions of future dynamics. Quaternary Science Reviews, 26(19), pp.26172630.

Tirsch, D., R. Jaumann, A. Pacifici, F. Poulet, 2011. Dark aeolian sediments in Martian craters: Composition and sources. J Geophys Res-Planet 116, doi: 10.1029/2009je003562.

Thomas, P., 1981. North-south asymmetry of eolian features in martian polar regions: Analysis based on crater-related wind markers. Icarus, 48, 76-90.

Thomas, P., 1982. Present wind activity on Mars - Relation to large latitudinally zoned sediment deposits. J. Geophys. Res., 87(B12), 9999-10,008, doi:10.1029/JB087iB12p09999.

Thomas, N., H. Sierks, C. Barbieri, P.L. Lamy, R. Rodrigo, H. Rickman, D. Koschny, H.U. Keller, J. Agarwal, M.F. A'Hearn, F. Angrilli, A.-T. Auger, M.A. Barucci, J.-L. Bertaux, I. Bertini, S. Besse, D. Bodewits, G. Cremonese, V. Da Deppo, B. Davidsson, M. De Cecco, S. Debei, S., M.R. El-Maarry, F. Ferri, S. Fornasier, M. Fulle, L. Giacomini, O. Groussin, P.J. Gutierrez, C. Güttler, S.F. Hviid, W.-H. Ip, L. Jorda, J. Knollenberg, J.-R. Kramm, E. Kührt, M. Küppers, F. La Forgia, L.M. Lara, M. Lazzarin, J.J.L. Moreno, S. Magrin, S. Marchi, F. Marzari, M. Massironi, H. Michalik, R. Moissl, S. Mottola, G. Naletto, N. Oklay, M. Pajola, A. Pommerol, F. Preusker, L. Sabau, F. Scholten, C. Snodgrass, C. Tubiana, J.-B. Vincent, K.-P. Wenzel, 2015a. The morphological diversity of comet 67P/Churyumov-Gerasimenko. Science 347, doi:10.1126/science.aaa0440.

Thomas, N., B. Davidsson, M.R. El-Maarry, S. Fornasier, L. Giacomini, A.G. Gracia-Berná, S.F. Hviid, W.-H. Ip, L. Jorda, H.U. Keller, J. Knollenberg, E. Kührt, F. La Forgia, I.L. Lai, Y. Liao, R. Marschall, M. Massironi, S. Mottola, M. Pajola, O. Poch, A. Pommerol, F. Preusker, F. Scholten, C.C. Su, J.S. Wu, J.B. Vincent, H. Sierks, C. Barbieri, P.L. Lamy, R. Rodrigo, D. Koschny, H. Rickman, M.F. A'Hearn, M.A. Barucci, J.-L. Bertaux, I. Bertini, G. Cremonese, V. Da Deppo, S. Debei, M. de Cecco, M. Fulle, O. Groussin, P.J. Gutierrez, J.-R. Kramm, M. Küppers, L.M. Lara, M. Lazzarin, J.J. Lopez Moreno, F. Marzari, H. Michalik, G. Naletto, J. Agarwal, C. Güttler, N. Oklay, C. Tubiana, 2015b. Redistribution of particles across the nucleus of comet 67P/Churyumov-Gerasimenko. Astronomy and Astrophysics, 583, A17, doi:10.1051/0004-6361/201526049.

Treiman, A.H., 2003. Geologic settings of Martian gullies: Implications for their origins. J. Geophys. Res. 108 (E4), 8031, doi:10.1029/2002JE001900.

Tricart, J., 1974. Existence de periodes seches au Quaternaire en Amazonie et dans les regions voisines. Révue de Géomorphologie Dynamique 23, 145-158

Trilling, D.E., 2016. The surface age of Sputnik Planum, Pluto, must be less than 10 million years. PLOS ONE, doi:10.1371/journal.pone.0147386.

Tripaldi, A., M.A. Zárate, in press. A review of Late Quaternary inland dune systems of South America east of the Andes. Quaternary International, available online 24 July 2014, doi:10.1016/j.quaint.2014.06.069.

Tokano, T., 2008. Dune-forming winds on Titan and the influence of topography. Icarus 194, 243-262, 
doi:10.1016/j.icarus.2007.10.007.

Tsoar, H., R. Greeley, A.R. Peterfreund, 1979. Mars: The north polar sand seas and related wind patterns. J. Geophys. Res., vol. 84, no. B14, 8167-8180.

Tsoar, H., 1983. Dynamic processes acting on a longitudinal (seif) dune. Sedimentology 30, 567-578.

Vaz, D.A., S. Silvestro, 2014. Mapping and characterization of small-scale aeolian structures on Mars: An example from the MSL landing site in Gale Crater. Icarus, vol. 230, 151-161.

Vaz, D.A., S. Silvestro, P.T.K. Sarmento, M. Cardinale, submitted. Migrating meter-scale bedforms on Martian dark dunes: are terrestrial aeolian ripples good analogs? To Aeolian Research (this issue).

Ward, A.W., 1979. Yardangs on Mars: Evidence of recent wind erosion. J. Geophys. Res 84, 8147-8165.

Ward, A.W., K.B. Doyle, P.J. Helm, M.K. Weisman, N.E. Witbeck, 1985. Global map of eolian features on Mars. J. Geophys. Res., 90(B2), 2038-2056.

Weitz, C.M., J.J. Plaut, R. Greeley, R.S. Saunders, 1994. Dunes and microdunes on Venus: Why were so few found in the Magellan data? Icarus 112, 282-295.

Werner, B.T., 1995. Eolian dunes: Computer simulations and attractor interpretation. Geology 23(12), 1107-1110.

Williams, S.H., R. Greeley, 1994. Windblown sand on Venus: The effect of high atmospheric density. Geophys. Res. Lett. 21(25), 2825-2828.

Wilson, L., J.W. Head, 1994. Mars: Review and analysis of volcanic eruption theory and relationships to observed landforms. Reviews of Geophysics, vol. 32, no. 3, 221-263.

Zimbelman, J.R., 2000. Non-active dunes in the Acheron Fossae Region of Mars between the Viking and Mars Global Surveyor eras. Geophys. Res. Lett. 27, 1069-1072, doi:10.1029/1999GL008399. 
Title: Our evolving understanding of aeolian bedforms, based on observation of dunes on different worlds

(C) 2016. All rights reserved

Authors:

Serina Diniega*,a

Mikhail Krevalevsky ${ }^{b}$,

Jani Radebaugh ${ }^{c}$,

Simone Silverstro ${ }^{\text {d,e }}$,

Matt Telfer ${ }^{\mathrm{f}}$,

Daniela Tirsch ${ }^{\mathrm{g}}$

*corresponding author: serina.diniega@jpl.nasa.gov, +1 818-393-1487

a Jet Propulsion Laboratory, California Institute of Technology, 4800 Oak Grove Dr., Pasadena, CA 91109, USA

${ }^{b}$ Earth and Planetary Sciences, University of California - Santa Cruz, 1156 High Str. Santa Cruz, CA, 95064, USA

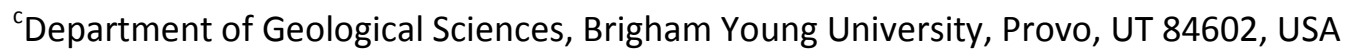

'INAF Osservatorio Astronomico di Capodimonte, Via Moiariello 16, 80131, Napoli, Italy

${ }^{\text {e}}$ Carl Sagan Center, SETI Institute 189 N Bernardo Ave, Mountain View, CA 94043, USA

'SOGEES, University of Plymouth, Drake Circus, Plymouth, Devon. PL4 8AA. UK.

${ }^{g}$ Institute of Planetary Research, German Aerospace Center (DLR), Rutherfordstrasse 2, 12489 Berlin, Germany.

\begin{abstract}
( 253 words)
Dunes, dune fields, and ripples are unique and useful records of the interaction between wind and granular materials - finding such features on a planetary surface immediately suggests certain information about climate and surface conditions (at least during the dunes' formation and evolution). Additionally, studies of dune characteristics under non-Earth conditions allow for "tests" of aeolian process models based primarily on observations of terrestrial features and dynamics, and refinement of the models to include consideration of a wider range of environmental and planetary conditions. Todate, the planetary aeolian community has found and studied dune fields on Mars, Venus, and the Saturnian moon Titan. Additionally, we have observed candidate "aeolian bedforms" on Comet 67P/Churyumov-Gerasimenko, the Jovian moon lo, and - most recently -- Pluto. In this paper, we hypothesize that the progression of investigations of aeolian bedforms and processes on a particular planetary body follows a consistent sequence - primarily set by the acquisition of data of particular types and resolutions, and by the maturation of knowledge about that planetary body. We define that sequence of generated knowledge and new questions (within seven investigation phases) and discuss examples from all of the studied bodies. The aim of such a sequence is to better define our past and current state of understanding about the aeolian bedforms of a particular body, to highlight the related assumptions that require re-analysis with data acquired during later investigations, and to use lessons learned from planetary and terrestrial aeolian studies to predict what types of investigations could be most fruitful in the future.
\end{abstract}




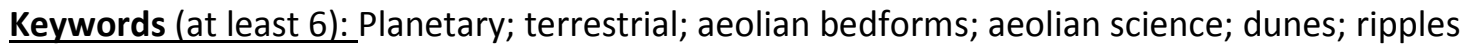

Highlights (max 85 characters, including spaces)

- Planetary dunes yield useful/unique information about climate $\&$ surface conditions.

- Aeolian bedform studies progress logically in questions/assumptions/new knowledge.

- Considering this progression exposes gaps/assumptions to be reviewed with new data.

- Comparing planetary progression with Earth aeolian studies yields lessons for each.

Acknowledgements: We thank Matt Chojnacki, Lori Fenton, and an anonymous reviewer for their very helpful comments, and in particular for the suggestions of additional references, which strengthened this manuscript. We also thank the space mission and instrument teams who collect the observations, start the analysis, and enable the described advancements in our understanding of aeolian bedform evolution and interpretation. SD's work was carried out at the Jet Propulsion Laboratory, California Institute of Technology, under a contract with the National Aeronautics and Space Administration. SS was supported by ASI through the ASI-CISAS agreement I/018/ 12/0: "DREAMS EDM Payload-ExoMars 2016." 